Portland State University

PDXScholar

\title{
Knowing Nature in the City: Comparative Analysis of Knowledge Systems Challenges Along the 'Eco- Techno' Spectrum of Green Infrastructure in Portland \& Baltimore
}

Annie Marissa Matsler Portland State University

Follow this and additional works at: https://pdxscholar.library.pdx.edu/open_access_etds

Part of the Sustainability Commons, and the Urban Studies Commons Let us know how access to this document benefits you.

\section{Recommended Citation}

Matsler, Annie Marissa, "Knowing Nature in the City: Comparative Analysis of Knowledge Systems Challenges Along the 'Eco-Techno' Spectrum of Green Infrastructure in Portland \& Baltimore" (2017). Dissertations and Theses. Paper 3767.

https://doi.org/10.15760/etd.5651

This Dissertation is brought to you for free and open access. It has been accepted for inclusion in Dissertations and Theses by an authorized administrator of PDXScholar. Please contact us if we can make this document more accessible: pdxscholar@pdx.edu. 
Knowing Nature in the City: Comparative Analysis of Knowledge Systems Challenges Along the 'Eco-Techno' Spectrum of Green Infrastructure in Portland \& Baltimore by

Annie Marissa Matsler

A dissertation submitted in partial fulfillment of the requirements for the degree of

\author{
Doctor of Philosophy \\ in \\ Urban Studies
}

Dissertation Committee:

Connie P. Ozawa, Chair

Thaddeus R. Miller, Co-Chair

Vivek Shandas

Jennifer L. Morse

Portland State University

2017 
(C) 2017 Annie Marissa Matsler 


\begin{abstract}
Green infrastructure development is desired in many municipalities because of its potential to address pressing environmental and social issues. However, despite technical optimism, institutional challenges create significant barriers to effective green infrastructure design, implementation, and maintenance. Institutional challenges stem from the disparate scales and facility types that make up the concept of green infrastructure, which span from large-scale natural areas to small engineered bioswales. Across these disparate facilities 1) different performance metrics are used, 2) different institutions have jurisdiction, and, 3) facility types are differentially classified as assets, producing epistemological and ontological variegation across the spectrum of green infrastructure that must be negotiated within and across municipal institutions. This has led to knowledge challenges that constrain and shape facility design, implementation, maintenance, and ultimately - performance on-the-ground.

Here, the eco-techno spectrum is developed to highlight the different degree to which biological entities (e.g. plants, microbes) are incorporated as infrastructural components in facilities; this inclusion presents a major knowledge challenge to green infrastructure, namely it brings biological and ecological knowledge into traditionally engineering-dominated decision-making spaces where it does not easily fit procedures for defining, measuring, or valuing existing facility component types. Therefore, municipal institutions have created and vetted new practices, protocols, and institutional structures to appropriately implement and manage green infrastructure.
\end{abstract}


The institutionalization of green infrastructure is examined in this dissertation using knowledge systems analysis in two comparative case studies conducted in Portland and Baltimore. Discourse analysis provides 'thick' description of knowledge systems dynamics within and between different municipal departments in each city; a follow-up Q-method survey is used to further examine these qualitative results and explore the subjectivities that underlie the various ways of 'knowing' green infrastructure in the city. 


\section{Acknowledgements}

I am indebted to the hard-working people in the City of Portland and the City of Baltimore who have made it their career to serve and improve the cities in which they live. This dissertation is about, and for, you. I thank you for sharing your time, your expertise, and your cities with me.

I am grateful for the guidance and constructive criticism of my dissertation committee, especially my dissertation chair, Thad Miller. The enthusiasm my entire committee showed for this research helped me get through the more challenging moments of the PhD process and their feedback and mentorship throughout my time at PSU made me the researcher I am today.

I am also forever grateful for the advice of Vivek Shandas, who in 2010 recommended that I apply for the Ecosystem Services supporting Urbanizing Regions (ESUR) IGERT program at PSU. Over the course of my PhD program, the ESUR IGERT program became more than financial support of my academic endeavors; the passionate group of scholars in this program became my intellectual family. I am grateful for the support of PI's Elise Granek, David Ervin, and Darrell Brown, and the phenomenal core faculty team leading the ESUR IGERT. They led by example, showing me interdisciplinary research like I had never seen before. And I would not have survived my dissertation without the amazing students in the IGERT program who inspired me at every turn. Many thanks to the C4SI3 crew, Restoration Club, and Sarissa for your continued intellectual comradery. I can't wait to see what we collaborate on next! 
I am grateful to Alan Yeakley for bringing me on board the Blue-Green Cities CWFA project. I learned a great deal about the research process from the exceedingly supportive Topic Group 4, led by 'social beard' Glyn Everett. I am likewise incredibly honored to have been included in the UREx SRN project as a student through the mentorship of Thad Miller. Thank you, Thad and Alan, for these opportunities; they expanded my mind and informed the path of my dissertation research.

I would like to thank Fletcher Beaudoin and the Institute for Sustainable Solutions (ISS) at PSU for their financial and project management support throughout my $\mathrm{PhD}$ process. The ISS projects I participated in moved my dissertation research forward by leaps and bounds, and helped my research remain closely connected to practice on-the-ground.

It is also customary to thank one's family for their support through this process. But it feels strange now that I am writing this; how can I say enough to thank my mom and dad on a piece of paper? They have supported me through a staggering 25 years of schooling, moves across the country and home again...and again, and counseled me through the emotional minefield that is a career spent in one's mind. I appreciate you both more than you know.

I am also exceedingly grateful that my husband went through this process before me, and therefore did not leave me at any number of the moments in the $\mathrm{PhD}$ when any reasonable person would have thrown in the towel. Thank you, KC, for your patience, your silliness, your cooking, your support, and most importantly, your unflinching love. 
Table of Contents

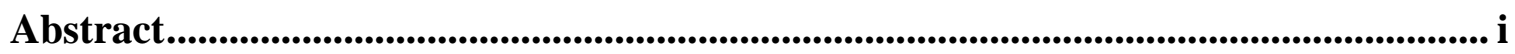

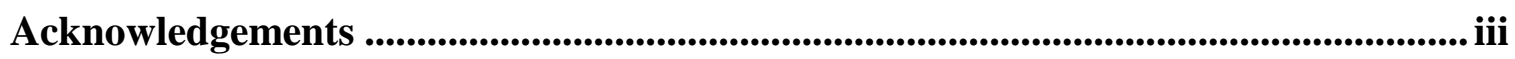

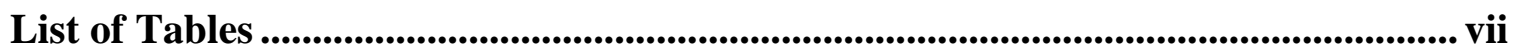

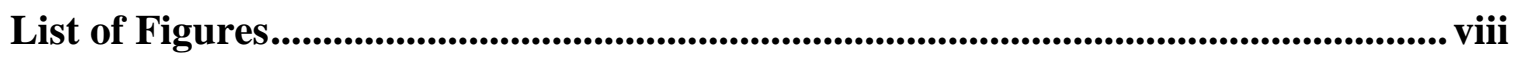

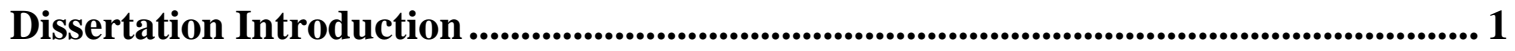

Chapter 1: Using 'eco-techno' hybridity of green infrastructure to examine the knkowledge systems' challenges of urban nature management ................................... 8

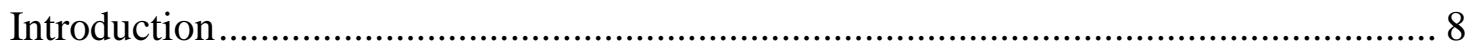

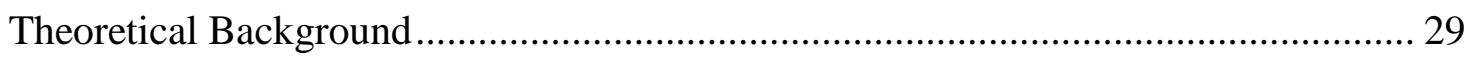

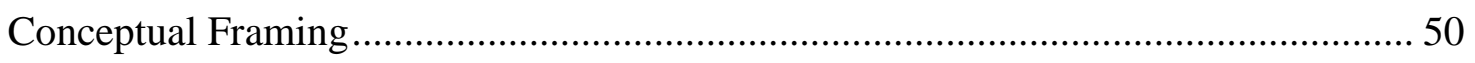

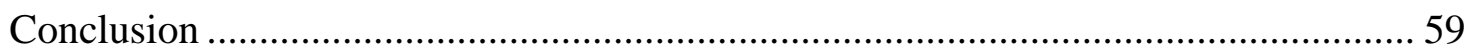

Chapter 2: Comparison of knowledge systems supporting green infrastructure in Portland and Baltimore: differentiation across the eoc-techno spectrum................. 61

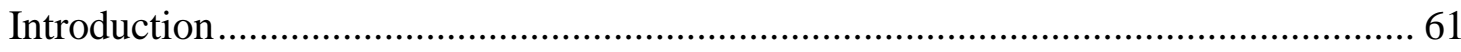

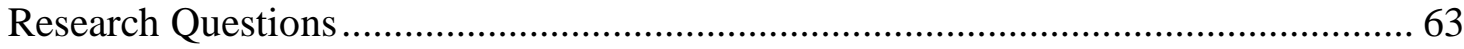

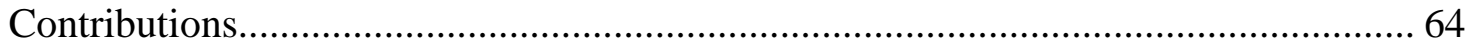

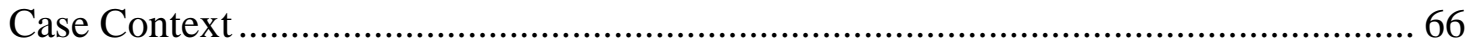

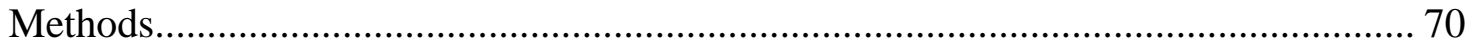

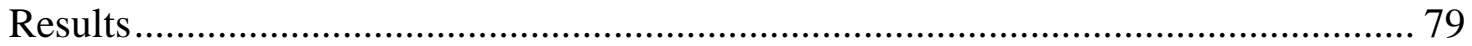

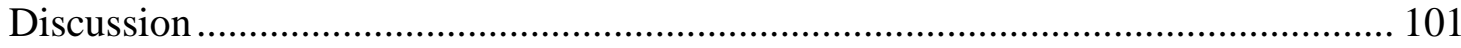

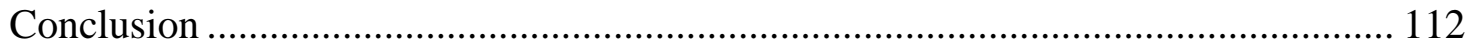

Chapter 3: Making 'green' fit in a 'grey' accounting system: valuing urban nature as a service provider ................................................................................................................. 113

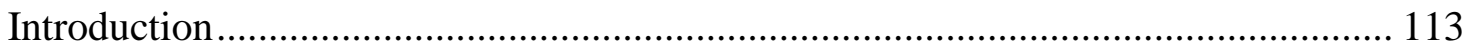

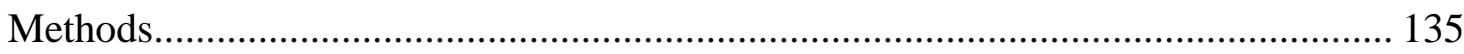

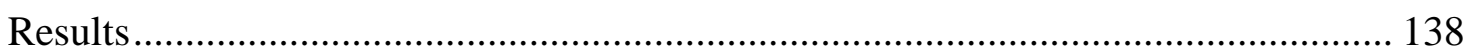

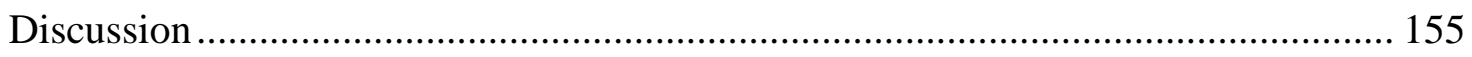


Conclusion

Chapter 4: Using Q-method to explore the epistemologies shaping green infrastructure development: an expansion of the knowledge systems toolbox

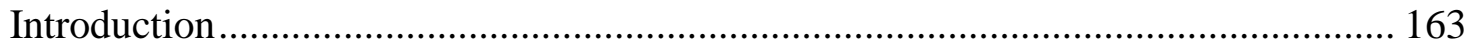

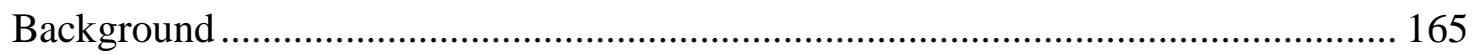

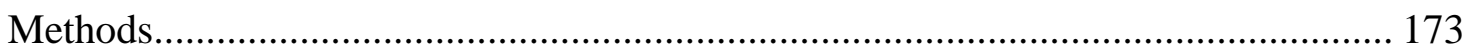

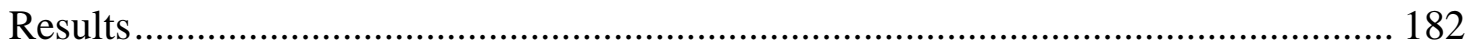

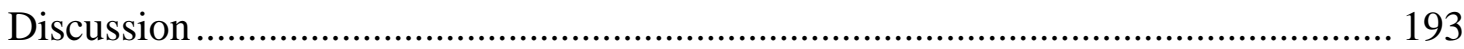

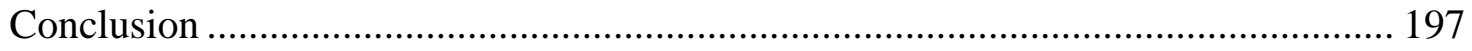

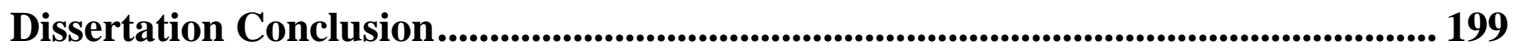

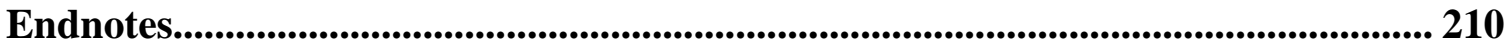

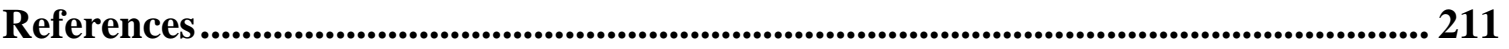

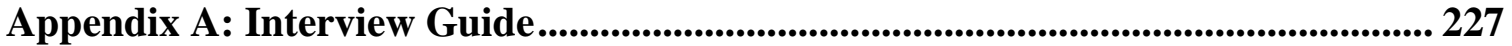

Appendix B: Qualitative Code-Book (final) ................................................................... 231

Appendix C: Participant Instructions (Q-sort Survey) .......................................... 235 


\section{List of Tables}

Table 1-1: Verbatim definitions of "green infrastructure" from a number of recent green infrastructure plans and policies from across the United States...

Table 2-1: Case city summaries, highlighting two long-term programs in different social,

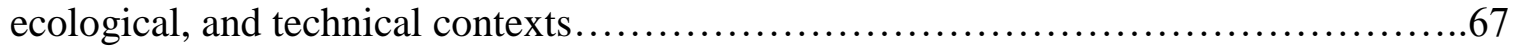

Table 2-2: Plans, policies, and reports reviewed in each case study city ................76

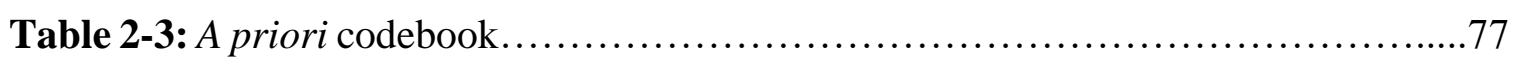

Table 2-4: Breakdown of interviewees by city and professional role...................81

Table 3-1: Asset plans, polices, and reports reviewed in Portland...................137

Table 3-2: Competing knowledge claims, norms, and protocols from ecological vs

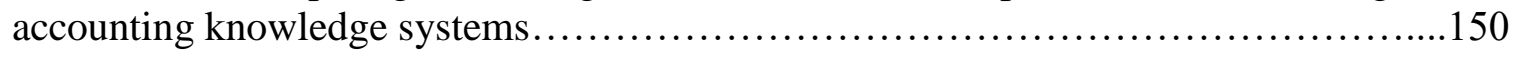

Table 4-1: Concourse statements by thematic area............................. 176

Table 4-2: Professional backgrounds of participants............................ 183

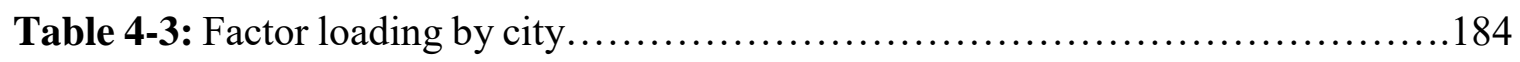

Table 4-4: The weighed composite sort representing each of the five factors.............185

Table 4-5: Factor 1 - most strongly agreed/disagreed with statements ................187

Table 4-6: Factor 2 - most strongly agreed/disagreed with statements.................189

Table 4-7: Factor 3 - most strongly agreed/disagreed with statements................190

Table 4-8: Factor 4 - most strongly agreed/disagreed with statements................191

Table 4-9: Factor 5 - most strongly agreed/disagreed with statements...............193 


\section{List of Figures}

Figure 1-1: Google search trend data for the term "green infrastructure" 2004-2017..... 15

Figure 1-2: Number of academic publications captured by the database Web of Science with the term "green infrastructure" in the title by year (1997-2016).

Figure 1-3: Number of publications with the term "green infrastructure" in the title 20002016 by Web of Science category.

Figure 1-4: The "hub" and "corridor" approach to green infrastructure from the State of Maryland's 1990 Green Infrastructure Plan.....................................21

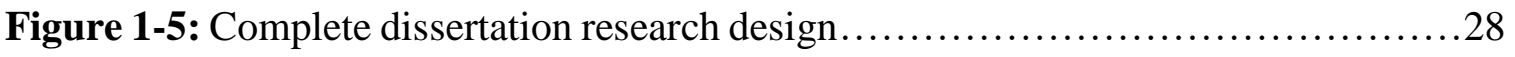

Figure 1-6: Knowledge systems act as a bridging concept between theories of SocioTechnical and Enviro-Technical Co-production.................................29

Figure 1-7: The eco-techno spectrum of green infrastructure $\ldots \ldots \ldots \ldots \ldots \ldots \ldots \ldots \ldots .54$

Figure 2-1: Overarching dissertation research design; Chapter 2 methods highlighted in

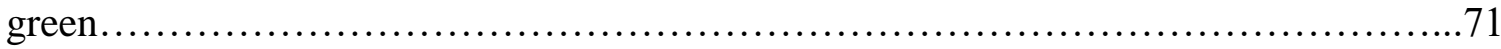

Figure 2-2: Regulations impacting green infrastructure development in both Portland and Baltimore................................................................ 84

Figure 2-3: Jurisdictional divides across the eco-techno spectrum...................90

Figure 3-1: Life cycle schedule of pavement................................. 152

Figure 3-2: Benefits and costs of a street tree through its life cycle...................152

Figure 4-1: Chapter 4 methods displayed in the context of the overarching research design of the dissertation; Chapter 4 methods highlighted in green......................... 174

Figure 4-2: Structure for statement placement, red indicating "most disagree" and green

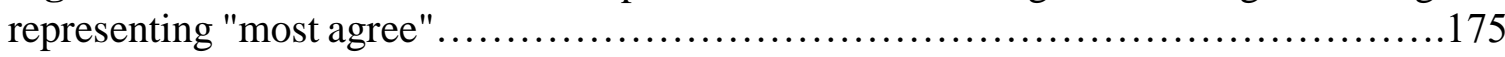

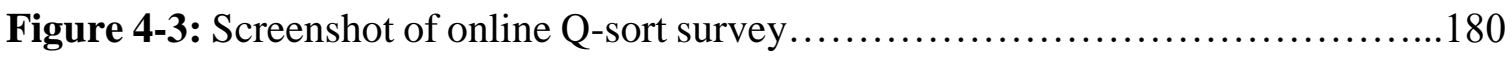

Figure 4-4: Screenshot of a partially completed online Q-sort .................... 180

Figure 4-5: Screenshot of completed online Q-sort.............................181

Figure 4-6: Screenshot of the feedback portion of the online Q-sort................181 


\section{Dissertation Introduction}

Climate change and crumbling infrastructure increasingly create expensive and dangerous conditions for urban populations that municipal governments struggle to mitigate. The intense storms of a warmer world (e.g. Hurricane Sandy in New York) result in massive damages, and put urban communities in precarious situations socially, physically, and economically. At the same time, lack of funding and political will to repair century-old infrastructures create unstable conditions for delivery of critical services, like clean water, even in business-as-usual conditions (e.g. the lead poisoning crisis in Flint, MI (Goodnough et al. 2016)). The American Society of Civil Engineers (ASCE) recently estimated that infrastructural systems in the U.S. face over a \$2 trillion funding gap in 2017; they conclude that "Congress and the states must invest an additional \$206 billion each year to prevent the economic consequences [of deteriorating infrastructure] to families, business, and the economy" (ASCE 2017).

An emerging solution to these issues nationwide is green infrastructure - the use of vegetated urban greenspaces in conjunction with a varying degree of human-made technologies to provide utility services like stormwater management (Portland 2015; Philadelphia 2011; Phoenix 2013; Baltimore 2015). Interest in green infrastructure is growing nationwide: New York City plans to build over 1,000 green street facilities within the next year; Philadelphia's $\$ 800$ million green infrastructure program was recently approved by the Environmental Protection Agency (EPA); even small towns, like Corvallis, OR, have built pilot facilities and compete for grants to help develop green 
infrastructure implementation plans. The appeal of green infrastructure lies in its potential to cost-effectively ("Banking on Green" 2012; EPA 2015; LaDuca and Kosco 2014) provide a variety of benefits (Benedict and McMahon 2006), including mitigating urban heat islands (Emmanuel and Loconsole 2015), protecting endangered species (McIntyre et al. 2015), improving energy use (Wang et al. 2014), and enhancing the visual and recreational quality of urban development (Nazir, Othman, and Nawawi 2014), among many other benefits (Tzoulas et al. 2007).

Despite technical optimism, green infrastructure faces a number of entangled social-institutional challenges in its design, implementation, and maintenance at the municipal level (Lennon 2015; Young et al. 2014; Carlet 2015). For example, Young et al. (2014) wrestle with the fact that green infrastructure is not mainstream despite 30+ years of successful implementation of projects around the world. Carlet (2015) finds that local municipal staff attitudes create a barrier to adoption/uptake of the concept; the usefulness and compatibility of green infrastructure within existing infrastructural systems is questioned at the local level.

I argue in this dissertation that many of these institutional challenges arise from conflicting and competing knowledge systems built up around managing the urban nature and infrastructure that make up green infrastructure. Here, knowledge systems are defined (following Miller et al (2010)) as the norms, protocols, and practices used to gather evidence about how the world works, give that evidence credibility, and put resulting knowledge claims to work in decision-making. Each knowledge system has embedded visions of the appropriate role of nature in the city, leading to tensions between different 
ways of knowing urban nature between knowledge systems. An analysis of these knowledge system challenges can help us better understand and acknowledge the influence of usually taken-for-granted bureaucratic processes on infrastructure outcomes; this acknowledgement opens up space for increased stakeholder inclusion and interdisciplinarity with the normative goals of making governance more effective (Healey 1997; Innes and Booher 2010; Friedmann 1993, 2011) and just (Fainstein 2010; Carmon and Fainstein 2013).

Within municipal institutions responsible for designing, implementing, and maintaining green infrastructure (such as public utilities, parks and recreation departments, and planning offices), I argue that knowledge system challenges stem, in part, from the broad range of facility types, scales, and knowledge utilization that make up the current concept of green infrastructure. From large-scale natural areas to small engineered facilities, there are different kinds of data collected to measure the social, ecological, and economic impacts and performance of facilities; different facility types are governed by different political and bureaucratic jurisdictions and studied by different disciplines; and, while all called 'green infrastructure', facility types fall differentially into either the "nature" or the "infrastructure" category depending on the orientation of the individual, discipline, or department observing the facility. I argue that this means epistemological and ontological variegation is embedded in the concept of green infrastructure which must be negotiated and reconciled within and across municipal institutions. These variations often lead to knowledge contestations between the different norms, protocols, and practices of 
municipal knowledge systems that shape facility design, implementation, maintenance, and - ultimately - performance on-the-ground.

At present, these institutional contestations are generally left un-examined as many of the decisions shaping green infrastructure are taken-for-granted as objective and/or technical. As Lennon (2015) asserts,

...literature specifically addressing GI seeks more to promote its benefits than critically appraise the reasons for its emergence, the form of its representation, or the potential consequences of its institutionalization. (p. 963)

Limited acknowledgement of contestation around institutionalization can lead to misidentifying poor facility performance as a technical failure, rather than inappropriate or myopic implementation (Perrow 1999). However, when viewed through a Science \& Technology Studies (STS) lens as socially-mediated knowledge systems' dynamics (Miller et al. 2010), the power dynamics inherent in these decision-spaces can be exposed (Jasanoff 2004). The new knowledge practices (including how to define, measure, and value urban nature) needed to manage green infrastructure are socio-politically produced and contested (Gieryn 1999) by different epistemic communities (Haas 1992) and stakeholders who must negotiate with flows of power (Flyvbjerg 1998) and credibility (Callon 1999). This process of co-production and negotiation exposes different knowledge challenges that must be addressed for new knowledge practices or work-arounds to be effective.

To examine these socio-institutional aspects of green infrastructure, this dissertation develops (in Chapter 1) the eco-techno spectrum of facility types as an organizing heuristic. This spectrum highlights the different degrees to which biological entities (i.e. plants, soils, microbes) are incorporated as infrastructural components in green 
infrastructure facilities; this inclusion presents one of the major knowledge challenges to green infrastructure implementation, namely that it brings ecological knowledge into traditionally engineering-dominated decision-making spaces where it does not easily fit procedures for defining, measuring, or valuing facilities. Therefore, municipal governments have needed to create and vet new knowledge practices to appropriately implement and manage green infrastructure (described in Chapters $2 \& 3$ ).

Understanding the embedded values and knowledge orientations of green infrastructure development is critical to understanding program outcomes; who wins and who loses from the proliferation of green infrastructure? This question becomes increasingly pertinent as programs mature. There is evidence that uneven spatial distribution of green infrastructure benefits has further disadvantaged the most vulnerable communities within cities (Kabisch and Haase 2014; Zavestoski and Agyeman 2015), and development of ecologically ineffective facilities (Van Teeffelen et al. 2015) has limited technical and economic gains. Municipalities with green infrastructure programs face continued institutional challenges stemming from lack of financial tools to systematically implement and maintain green infrastructure across the city (City of Portland in preparation), and lack of comprehensive public education surrounding the function of, and appropriate behavior around, green infrastructure facilities (Everett et al. 2015). These problems are not solved by new technical knowledge alone; but instead require negotiation between knowledges. Knowledge systems analysis can therefore be used to illuminate pathways to effective and equitable service delivery in the $21^{\text {st }}$ century city. 
This dissertation compares green infrastructure planning efforts across the ecotechno spectrum in two different municipal contexts - Portland, OR and Baltimore, MD to further understand of the role knowledge systems play in shaping urbanity, and to inform and improve future green infrastructure development. Through mixed methods, I first complete an in-depth discourse analysis through interviews and document analysis, and use Q-method as a follow-up quantitative method.

Following this initial dissertation introduction, Chapter 1 presents the conceptual framework I developed to help ground an institutional analysis of green infrastructure in ecological and technical systems. Developed through an initial exploration of green infrastructure literature and plans, the ecological-technological spectrum (or the ecotechno spectrum for short) of green infrastructure interventions is used to display the range of facility types currently used in green infrastructure plans and policies in municipalities in the US today. This spectrum serves as a platform on which to observe different social and institutional arrangements. The implications of this spectrum are described as three emergent knowledge system challenges around the definition, measurement, and valuation of urban nature as green infrastructure.

Chapter 2 presents the methods and results of comparative case studies conducted in Portland and Baltimore. Through discourse analysis employing in-depth interviews with municipal staff that design, build, and maintain green infrastructure in both Portland and Baltimore, I explore the definition and measurement knowledge challenges and workarounds (including new protocols, codes, and partnerships that address knowledge challenges) that have emerged in different departments and institutions. 
Chapter 3 focuses in on the theme of valuation and contestation regarding valuing green infrastructure facilities as assets between different municipal departments. This contestation emerged from initial interviews in the case studies presented in Chapter 2. I review current thinking and movements around ecosystem services and asset management to frame an examination of the emerging push to value nature as an essential serviceprovider in Portland, and explore new and emerging knowledge practices around green asset management.

Chapter 4 presents a further exploration and refinement of comparative case study results using Q-method as a follow-up survey. Statements derived from the case study interviews reviewed in Chapter 2 and 3, were reflected to and then ranked by all original interviewees in Portland and Baltimore, exposing individuals' subjective prioritization of a range of green infrastructure concepts and visions.

The dissertation conclusion reviews primary findings from all chapters and articulates final thoughts and recommendations regarding the current state and future trajectory of green infrastructure development in the US. 


\section{Chapter 1:}

\section{Using 'eco-techno' hybridity of green infrastructure to examine the knowledge systems' challenges of urban nature management}

Introduction

The U.S. has an infrastructure problem. The American Society of Civil Engineers (ASCE) recently gave infrastructure nationwide a grade of D+, which means, infrastructure is in fair to poor condition and mostly below standard...Condition and capacity are of serious concern with strong risk of failure (ASCE 2017).

Infrastructures are unable to withstand the new pressures placed upon them by increasing population densities in urban areas (i.e. overwhelming traffic deteriorating roads, and increased hardscape overwhelming local streams and rivers with erosion and pollution), and changing climatic conditions (i.e. increasing intensity of precipitation (Cooley and Chang 2017) overwhelming sewer systems, and intensifying storms overtopping fail-safe levees and storm walls.)

The problem of infrastructure is simultaneously technological, social, and ecological. While infrastructure design, construction, and maintenance is highly technical, involving a number of engineering experts, these processes are also fundamentally social and ecological. All municipal infrastructures must interact with people and ecosystems on the ground, connecting each residence with centralized energy, water, transportation, and waste removal systems which rely on ecosystems as final sinks for byproducts as well as background conditions in which the systems exist. Real people and other living creatures interact with technologies at the end of these systems (i.e. toilets and facets in homes and businesses), as well as intermediary points (i.e. storm drains, electric substations). 
To 'fix' the infrastructure problem in the U.S. then, we must focus not only on the technological challenges of design, construction, and maintenance, but also the social and ecological challenges of the processes. This is ultimately a knowledge systems problem: How do we gather evidence about the social, ecological, and technological problems of infrastructure? How is evidence from each of these systems perceived and prioritized within decision-making about infrastructure? Can we better design our knowledge systems to integrate these different problems? Will it lead to better outcomes on the ground?

Here, knowledge systems are defined as the norms, protocols, and procedures used to gather and vet evidence about how the world works and put it to use in municipal decision-making. Knowledge systems analysis therefore consists of examining the institutionalized and taken-for-granted procedures we use to approach the topic of infrastructure, and working to uncover the embedded visions of how the world works within them (Miller, Munoz-Erickson, and Monfreda 2010; Munoz-Erickson 2014).

Why uncover these embedded visions of technical decisions-making? The hotbutton political issues of our times are negotiated in a number of different social arenas. Debates about the value of life (human and nonhuman) and the responsibility for nurturing and supporting that life are most visible on the national political stage. It is easy to see in this heightened political climate that those who write our national policies use these policies to reach particular goals, embedding within them their worldviews, understandings of what is right and wrong, what is appropriate, and who is responsible. The way a problem is framed will favor some and disadvantage others, constraining the set of solutions we pursue as a nation moving forward. For example, one way Americans living below the 
poverty line are framed is as lazy individuals taking advantage of the system (i.e. "welfare queens"); this establishes the idea that welfare is an inappropriate system that should be reduced or removed. However, an alternate framing of these individuals as products of oppression and a financial system that does not provide living-wage jobs may lead to a solution set that includes expanding or growing welfare assistance - and potentially intervening in other connected arenas to improve wages.

While easy to see in national politics, this process is not just happening on the national stage or only in overtly political arenas. Within spaces of seemingly apolitical technical management, negotiations between worldviews are taking place, embedding certain values and epistemologies into the infrastructures that prescribe the actions of our daily lives (Lampland and Star 2009; Ben-Joseph 2005). For example, Ben-Joseph (2005) shows how municipal code dictates the way individuals interact with each other because these codes form the basic structure of the city. Many of the negotiations that end up prescribing these interactions are quite mundane, occurring in bureaucratic spaces where experts frame local problems and design potential solutions. The seemingly straightforward technical nature of these decisions belies the important co-production of technology and society. Science and technology studies (STS) is one realm of social science that interrogates the winners and losers within society via an examination of the social constructs that we create through social interactions in mundane and taken-forgranted spaces. In particular, STS examines the ways that scientific knowledge (as only one form of knowledge) and technologies (everything from cell phones to tractors 
(Rasmussen 1968)) co-produce the social structure of our world today (Winner 1986; Jasanoff and Kim 2013; Shapin, Schaffer, and Hobbes 1985).

As urban environmental issues intensify with climate change and increasing population densities in cities worldwide, our collective societal interactions with nature become ever more important to understand. This dissertation starts with the notion that the way we know nature, or our epistemic orientation towards nonhuman life, matters; that our visions of the world should not be taken for granted and examining these visions can reveal important connections between social and natural systems that may encourage or deter us from our shared goals (Dryzek 1997). As Hull et al. (2002) sum up succinctly, “...differing assumptions about nature constrain people's vision of what environmental conditions can and should exist, thereby constraining the future that can be negotiated" (Hull et al. 2002).

This chapter presents green infrastructure as a site of inquiry used in this dissertation to explore the knowledge systems influencing infrastructure decision-making in the US today. Green infrastructure employs or mimics ecological processes and functions to deliver municipal services, making it an excellent site of intersection between technological, social, and ecological systems. The eco-techno spectrum of green infrastructure interventions is developed at the end of this chapter as a conceptual heuristic for this dissertation to systematically structure an examination of green infrastructure knowledge challenges. This spectrum highlights the different degrees to which ecological entities (i.e. plants, soils, microbes) are incorporated as infrastructural components in green infrastructure facilities; this inclusion presents one of the major knowledge challenges to green infrastructure implementation, namely that it brings ecological knowledge into 
traditionally engineering-dominated decision-making spaces where it does not easily fit procedures for defining, measuring, or valuing facilities. After the eco-techno spectrum is introduced at the end of this chapter, it is used to frame an exploration of these three specific knowledge system challenges in Chapter 2, 3, and 4.

\section{Urban Nature Management}

Urban nature exists in many forms - everything from remnant woodlands, open fields, and parks, to street trees, grassy medians, and backyards. Each of these contain biological entities interacting to form elaborate food webs and ecosystems that function in the midst of and in concert with human culture. Management actions impact the structure and function of urban nature both consciously and indirectly. In some cases, jurisdictions are created specifically to manage a particular form of urban nature. For example, local departments of transportation (DOTs) are tasked with managing grassy medians and roadside ditches within guidelines set by traffic safety regulations and road engineering specifications; and planning departments craft zoning codes that dictate the management of private, commercial, and industrial landscaping features to enhance livability and neighborhood character.

Often, the goals of management differ across the various jurisdictions managing urban nature. Parks and recreation departments, for example, manage urban nature in the form of parks and street trees to provide recreational opportunities to city residents, while water utilities manage urban nature in the form of open reservoirs and restricted forested areas that provide clean water to residents. Traditional systems of city management neatly 
divide the work of managing nature across different communities of expertise, often adding these spaces onto a more central management responsibility (i.e. DOT's central responsibility is management of roads; management of roadside ditches and grassy medians is an add-on responsibility to that 'hard' infrastructural system.)

Each of these traditional ways of managing urban nature rely on particular definitions, ways of knowing, and theories of management that have grown into distinct silos through time. Increasingly, however, society recognizes the need for more integrated and holistic management of urban development (Gottlieb 2005; Worster 1990; Innes and Booher 2010; Healey 1997). Concepts such as sustainability and urban resilience advocate breaking down silos and increasing interdisciplinary approaches to understanding the city that include the voices and knowledges of citizens, in particular regarding urban nature management (Romolini et al. 2016; Grove et al. 2006; Collins et al. 2011; S. T. A. Pickett, Cadenasso, and Grove 2004; Bocchini et al. 2014; Goldstein 2012; Davoudi et al. 2012).

Green infrastructure is an emerging approach to managing urban nature that crosses bureaucratic and disciplinary silos by integrating natural elements with engineered elements in the design of facilities. For the purposes of this dissertation, the term green infrastructure refers to both naturally occurring and engineered vegetated greenspaces that are explicitly managed to provide urban services such as stormwater treatment, flood mitigation, recreation, or clean water provisioning, among other services. This definition of green infrastructure encompasses facilities that include living, biological components, rather than solely the mechanical components that are usually evoked by the term infrastructure ${ }^{i}$. The inclusion of living, ecological entities complicates the management of 
green infrastructure facilities; for example, engineering-focused jurisdictions, like a department of transportation or a sewer authority, do not traditionally have staff with ecological expertise to appropriately design and maintain the nature in green infrastructure facilities.

The concept of green infrastructure also includes a wide variety of landscape features and technologies - from large coastal wetlands and urban forests to manicured pocket parks and bioswales - any place were biological entities such as plants, soils, and microbes, are designed and managed explicitly to do the work of providing urban services. This large array of different types of green infrastructure facilities also complicates management: ownership of facility types is divvied up by department but the entire spectrum makes up a single infrastructural system. This requires coordination across departments that usually act separately, responding to their own set of institutional drivers.

In the following sections, I will present the growing popularity of green infrastructure as well as expand on the concept's technological-ecological hybridity. A subsequent review of green infrastructure plans will portray the two primary visions of green infrastructure present in the U.S. today which will be traced throughout subsequent chapters of results.

\section{Growth of green infrastructure}

Green infrastructure is increasingly popular. Today, communities of all sizes create and implement green infrastructure plans and policies: a variety of prominent cities have green infrastructure facilities on the ground, including New York City (NYC 
Environmental Protection 2010), Philadelphia (Philadelphia Water Department 2011), Seattle (City of Seattle 2015), and Chicago ("City of Chicago: Green Stormwater Infrastructure Strategy" 2014); mid-size and small communities are building new demonstration projects and assessing potential social acceptance of green infrastructure with the help of grant-funding from the EPA and other sources, including Corvallis, OR (EPA 2011), Vancouver, WA, and Coos Bay, OR; across rural and suburban settings, entire counties are implementing green infrastructure networks, including McHenry County in Illinois, Alachua County in Florida, and agricultural land throughout Indiana (WRESTORE 2017).

While it is difficult to quantify the popularity of green infrastructure comprehensively in the world today, the growth in the term's use is undeniable. An exploration of Google searches for the term "green infrastructure" show steady interest in the topic since 2004 (this is as far back as Google Trends data extends); as seen in Figure 1-1 below, Google searches peaked in popularity in 2010. While there are monthly fluctuations in searches, popularity of the search term has remained steady into the present.

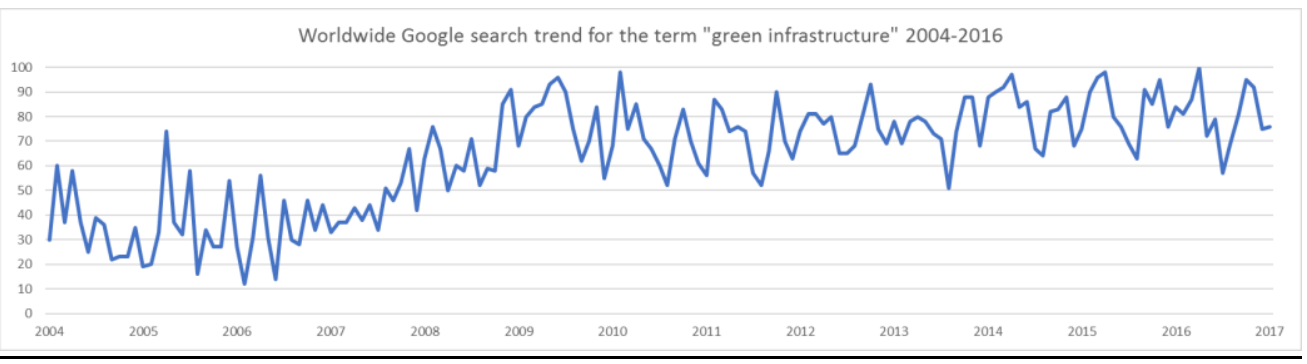

Figure 1-1: Google search trend data for the term "green infrastructure" 2004-2017; Shows the relatively popularity of the term, compared to itself through time; a score of 100 is the time stamp with the most searches for the term relative to all other time stamps 


\section{Hybridity}

Academic publication records (displayed in Figure 1-2) shed light on a different aspect of green infrastructure popularity. Since 2000, the number of academic publications with the term "green infrastructure" in the title have grown, supporting the earlier discussion of its increasing popularity. The academic database Web of Science reports that the first publication to appear with the term "green infrastructure" in the title was published in 2000. The number of publications with the term in the title remained low, only 1 or 2 each year, until 2008 when an abrupt increase in publications peaked at over 70 in 2015 , more than doubling the number of publications in 2014 (just under 30). In December of 2016, when this data was accessed, the number of publications dropped slightly to around 55 publications (see Figure 1-2).

While these increases in the use of the term "green infrastructure" as a topic of academic study generally help show the growth in popularity of the practice, a look at the disciplinary category of these publications is even more revealing, and particularly useful to the exploration of knowledge systems. As seen in Figure 1-3, the interdisciplinary categories of Environmental Studies and Urban Studies, which tend to combine social, ecological, and economic data, have the highest number of publications with "green infrastructure" in the title - more than half the 243 total publications found by Web of Science. Civil Engineering publications with "green infrastructure" in the title, on the other hand, number about 30, which is less than half the number of publications of Environmental Studies (over 70); Ecology, a more traditional disciplinary group, also has 
about half the publications of interdisciplinary categories. Economics trails the lot with only 4 publications over the 16 year period where the term shows up in publication titles.

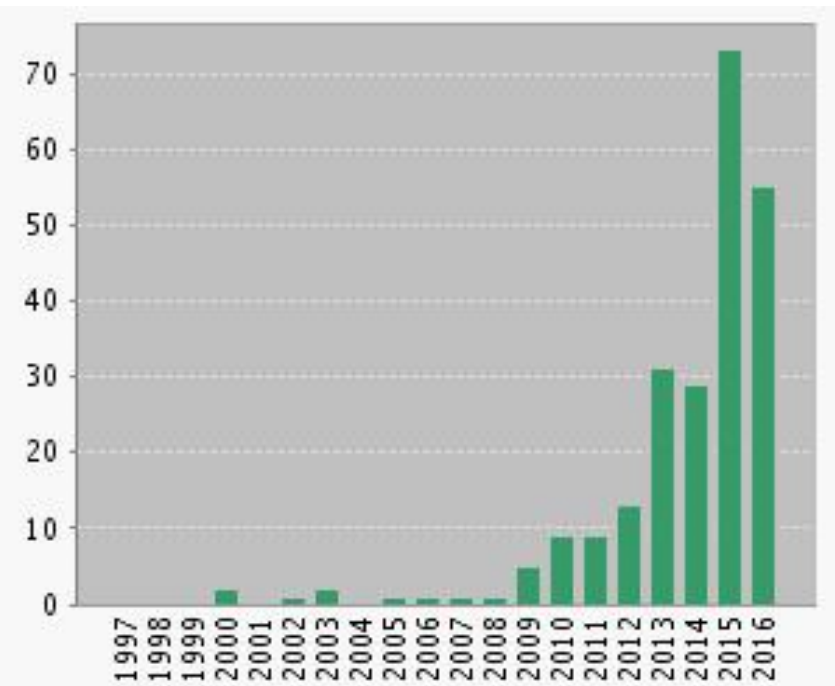

Figure 1-2: Number of academic publications captured by the database Web of Science with the term "green infrastructure" in the title by year (1997-2016)

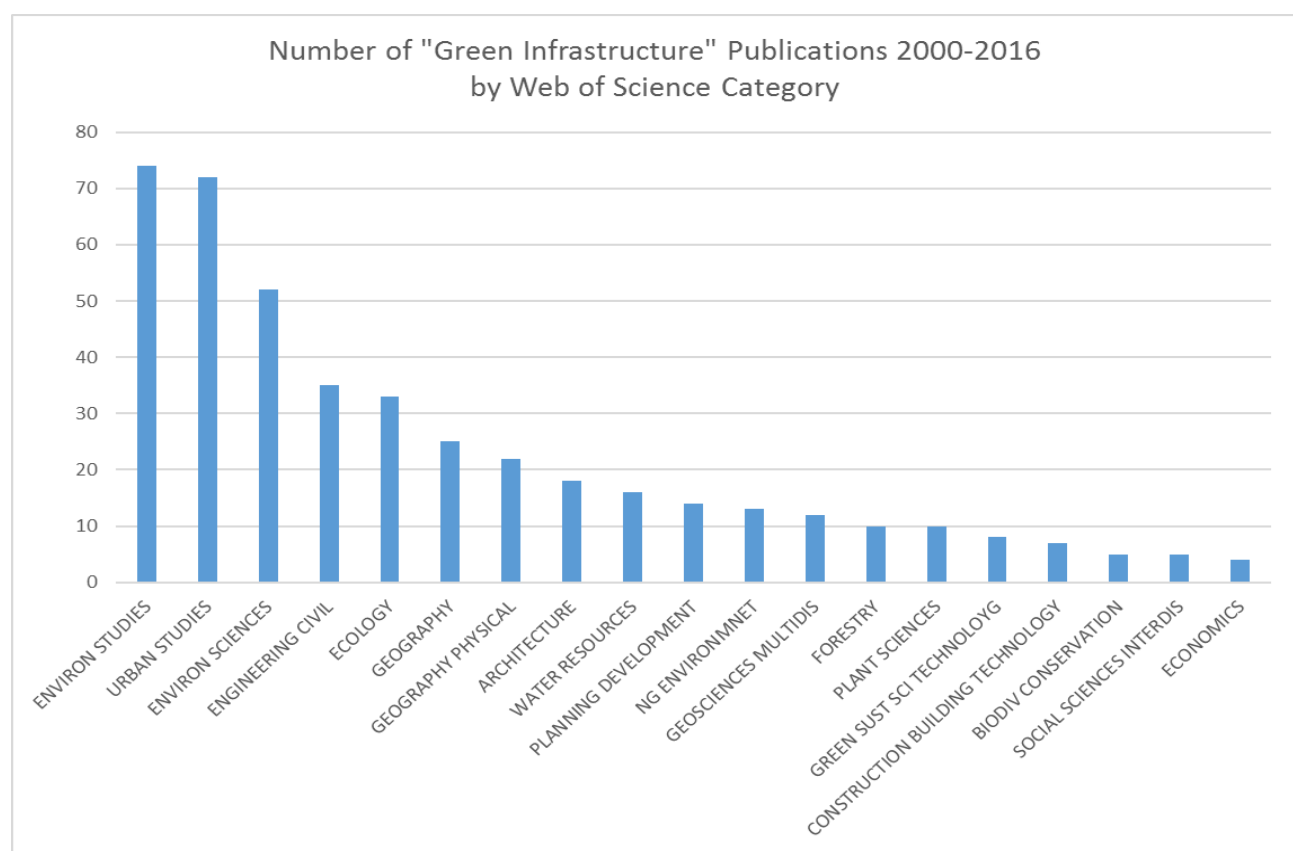

Figure 1-3: Number of publications with the term "green infrastructure" in the title 2000-2016 by Web of Science category 
This kind of publication record highlights the in-between-ness of green infrastructure. Green infrastructure is not often perceived as pure nature, therefore is not pursued as actively in Ecology as it is in interdisciplinary fields. Likewise, the living components of green infrastructure are not often viewed as real infrastructure, making facilities with living components marginal in physical-science-dominated fields like Civil Engineering. Finally, the lack of financial mechanisms to subsume green infrastructure under existing valuation techniques or theories makes it incommensurate with Economics in general (see Figure 1-3).

The ecological-technological hybridity of green infrastructure also contributes to continued lack of stable classification. Green infrastructure includes both biological, living components (e.g. plants, soils, microbes) and mechanical, physical components (e.g. pipes, concrete, pumps). Each of these component types is the epistemic territory of different professional and academic groups. For example, ecologists and conservation biologists have the "epistemic authority" (Gieryn 1999) to define the structure and function of living, non-human nature in the city. They use specific metrics to define the performance of ecological assemblages: nutrient uptake, community structure, etc. These metrics are quite different in character, scope, and type, however, from those used to define and measure the mechanical and physical components of infrastructure, which are primarily developed and circulated by engineers and physical scientists. Metrics defining infrastructure performance include acre-feet of water retained or pipe capacity and flow rate. Green infrastructure includes both living and mechanical components to do the work of service delivery in the city necessitating the negotiation of these incommensurate epistemologies. 
A review of green infrastructure plans can provide a sense of the different visions of urban nature invoked by definitions of differing epistemic authorities of green infrastructure. Recent literature establishes that the definition of green infrastructure is still unsettled internationally (Mell 2013), that the value of green infrastructure is contested (Netusil et al. 2014; Mell et al. 2016), and that social and institutional, rather than technical, uncertainties stand out as primary barriers to wider adoption of green infrastructure programs (Carlet 2015; Young et al. 2014; Thorne et al. 2015). To find a working definition for my own research, I conducted a brief, preliminary review of green infrastructure plans and policies readily available online.

Definitional confusion can be seen playing out in current green infrastructure plans, with a dichotomy of visions emerging. Table 1-1 below displays the two distinct visions of urban nature observed in green infrastructure plans from across the US. While all documents made some reference to nature and natural elements (i.e. greenspaces), some of the plans and policies defined green infrastructure as a natural area conservation strategy and others as a stormwater management technique.

Not all plans adhered completely to one vision or the other, however, there are elements of similarity across the definitions used. For example, the terms "hub and corridor" are used to describe a green infrastructure as ecological network vision (see Figure 1-4), while the idea of "mimicking natural processes" is prominent in a green infrastructure as cheap and sustainable stormwater management vision. I use the shorthand 'network' and 'stormwater' respectively to refer to these two different visions. 
While not the only visions of nature at work in the city (Dryzek 1997), these 'stormwater' and 'network' visions are the two most prominent and influential visions within the current green infrastructure discussion that I have deciphered through extensive literature review, preliminary interviews, and preliminary plan review (Table 1-1). Likewise, the differing ways of knowing nature in the city that form the foundation of these visions are an example of two directly conflicting knowledge systems that can be usefully examined through a knowledge systems analysis frame.

In particular, this dichotomy of visions raises a number of questions: How are these conceptual visions stabilized? Is one vision more influential than the other? Could vision inconsistency be a barrier to the broad uptake of green infrastructure or to any positive outcomes of green infrastructure implementation?

It is important to note that neither of these conceptual visions of green infrastructure is wrong, nor is one necessarily better than the other. I believe that both conceptions are useful to the development of resilience in our cities today; in fact in a minority of the plans, both visions are discussed (as seen in McHenry County's definition in Table 1-1). But underlying this dichotomy is a rub - a tension - between two epistemically and ontologically disconnected views of urban nature that deserves additional consideration. These two visions of urban nature are in fact incommensurate in many contexts, creating potential issues to their realization. For example, in many cases, the creation of small-scale facilities for stormwater management focuses green infrastructure development narrowly on technological solutions that reduce water quantity concerns at the expense of ecological and social co-benefits of greenspaces like access to nature, biodiversity, urban cooling, etc. 
I argue throughout this dissertation that the underlying tension between different views of the role of urban nature creates institutional barriers to the increased implementation and mainstreaming of green infrastructure throughout the US.

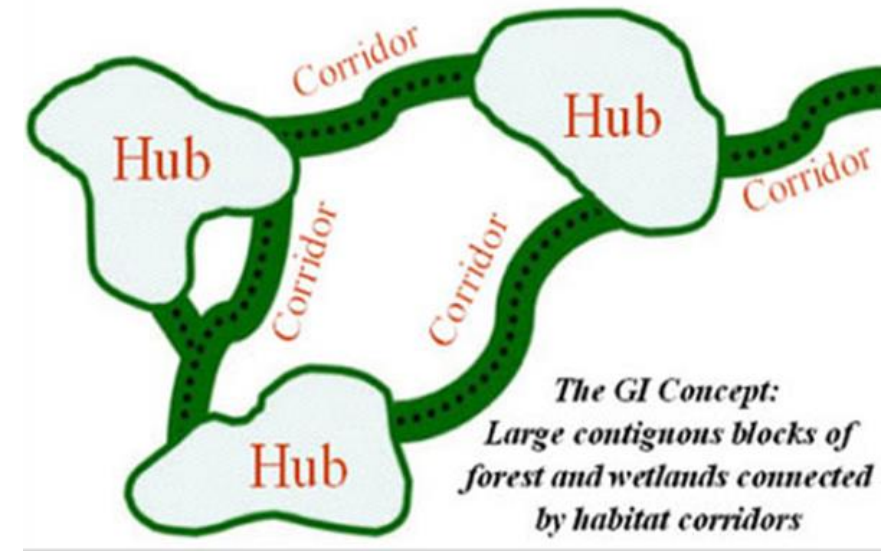

Figure 1-4: The "hub" and "corridor" approach to green infrastructure from the State of Maryland's 1990 Green Infrastructure Plan. This structure represents the principal of greenspace connectivity that is central to the 'network' vision of green infrastructure displayed in Table 1-1 and discussed throughout this dissertation. 
Table 1-1: This table displays the verbatim definitions of "green infrastructure" from a number of recent green infrastructure plans and policies from across the United States. Each of these definitions frames the problem that green infrastructure is employed to solve in each city/region, and therefore constrains the solution set (i.e. facility types considered) in each case.

\begin{tabular}{|c|c|c|}
\hline \multicolumn{3}{|c|}{ Examples of Network Vision } \\
\hline Plan/Policy & Year & Definition \\
\hline $\begin{array}{l}\text { Howard County, MD } \\
\text { "Green }\end{array}$ & 2012 & $\begin{array}{l}\text { "Green Infrastructure is a network of interconnected waterways, } \\
\text { wetlands, forests, meadows and other natural areas. Green }\end{array}$ \\
\hline Infrastructure & & Infrastructure helps support native plant and animal species, maintain \\
\hline Network Plan" & & $\begin{array}{l}\text { natural ecological processes, sustain air and water resources, and } \\
\text { contribute to the health and quality of life for communities. " (p.1) }\end{array}$ \\
\hline $\begin{array}{l}\text { Kane County, IL } \\
\text { "2040 Green } \\
\text { Infrastructure Plan" }\end{array}$ & 2013 & $\begin{array}{l}\text { "Green infrastructure is an interconnected systems of natural areas and } \\
\text { open spaces including woodlands, wetlands, trails, and parks, which } \\
\text { are protected and managed for the ecological values and functions they } \\
\text { provide to people and wildlife." (p. 6) }\end{array}$ \\
\hline $\begin{array}{l}\text { Saratoga County, NY } \\
\text { "Green }\end{array}$ & 2006 & $\begin{array}{l}\text { "Green infrastructure is a relatively new concept that recognizes the } \\
\text { importance of interconnected natural systems that provide valuable }\end{array}$ \\
\hline Infrastructure Plan” & & $\begin{array}{l}\text { services to us each and every day... Like the highways, water, sewer, } \\
\text { and electric lines and other built or "grey" infrastructure, "green" } \\
\text { infrastructure is the network of natural landscapes including forests, } \\
\text { farmlands, parks and preserves. " (p. 1) }\end{array}$ \\
\hline $\begin{array}{l}\text { City of Summerville, } \\
\text { SC “Green } \\
\text { Infrastructure Plan" }\end{array}$ & 2017 & $\begin{array}{l}\text { "Green infrastructure is identified as the natural assets of an area, } \\
\text { including intact forests, tree canopy, wetlands, parks, rivers, and } \\
\text { agricultural soils, and how these assets are connected throughout the } \\
\text { landscape. " (p. 1) }\end{array}$ \\
\hline
\end{tabular}

\section{Example of Combined Network \& Stormwater Visions

Plan/Policy Year Definition

McHenry County 2012 "The term green infrastructure has many definitions. Some focus on

"Green efforts to manage natural lands for their ecological and recreational

Infrastructure Plan" value. Others see it as networked lands that support biodiversity and habitats for plant and animal life. Yet, others view the term as a description of the technologies and engineering (e.g. green roofs, vegetated swales, and permeable pavement) that replicate natural water and environmental processes - as opposed to conventional gray infrastructure methods... different sections of this plan highlight the different ways in which GI can be defined and applied, from a regional scale all the way down to individual sites." (p. 7) 


\begin{tabular}{|c|c|c|}
\hline \multicolumn{3}{|c|}{ Examples of Stormwater Vision } \\
\hline Plan/Policy & Year & Definition \\
\hline $\begin{array}{l}\text { Illinois "Green } \\
\text { Infrastructure for } \\
\text { Clean Water Act" }\end{array}$ & 2010 & $\begin{array}{l}\text { "Green infrastructure means any storm water management } \\
\text { technique or practice employed with the primary goal of preserving, } \\
\text { restoring, or mimicking natural hydrology. Green infrastructure } \\
\text { includes, but is not limited to, methods of using soil and vegetation } \\
\text { to promote soil percolation, evapotranspiration, and filtration." }\end{array}$ \\
\hline $\begin{array}{l}\text { Milwaukee, WI } \\
\text { "Regional Green } \\
\text { Infrastructure Plan } \\
\text { (Phase 1)" }\end{array}$ & 2013 & $\begin{array}{l}\text { "...green infrastructure is one piece of the multi-tiered approach to } \\
\text { meeting the [sewerage district]'s } 2035 \text { Vision for zero basement } \\
\text { backups, zero overflows, and improved water quality." (p.5) }\end{array}$ \\
\hline $\begin{array}{l}\text { Northeastern Ohio } \\
\text { "Project Clean Lake: } \\
\text { Green Infrastructure } \\
\text { Plan" }\end{array}$ & 2012 & $\begin{array}{l}\text { "GI is defined in the Consent Decree as "a range of stormwater } \\
\text { control measures that use plant/soil systems, permeable pavement, } \\
\text { or stormwater harvest and reuse, to store, infiltrate, or } \\
\text { evapotranspirate stormwater and reduce flows to the combined } \\
\text { sewer system (CSS). Green infrastructure may include, but is not } \\
\text { limited to, bioretention and extended detention wetland areas as } \\
\text { well as green roofs and cisterns." " (p. 1-1) }\end{array}$ \\
\hline $\begin{array}{l}\text { City of Mount Rainier, } \\
\text { MD "Urban Green } \\
\text { Infrastructure Master } \\
\text { Plan" }\end{array}$ & 2013 & $\begin{array}{l}\text { "...presents a set of tools to be utilized when selecting and } \\
\text { implementing projects to improve and reduce urban stormwater } \\
\text { runoff." (p. iv) }\end{array}$ \\
\hline $\begin{array}{l}\text { City of Pittsburgh, PA } \\
\text { "Wet Weather } \\
\text { Feasibility Study" }\end{array}$ & 2013 & $\begin{array}{l}\text { "Green infrastructure refers to a variety of strategies designed to } \\
\text { mitigate the effects of development on the surrounding } \\
\text { environment, typically using smaller, distributed management } \\
\text { practices which infiltrate, evapotranspirate, and/or detain } \\
\text { stormwater runoff on-site." (p. 9-2) }\end{array}$ \\
\hline $\begin{array}{l}\text { City of Chicago, IL } \\
\text { "Green Stormwater } \\
\text { Infrastructure } \\
\text { Strategy" }\end{array}$ & 2014 & $\begin{array}{l}\text { "a term used to refer to strategies for handling storm precipitation } \\
\text { where it falls rather than after it has run off into a sewer system." } \\
\text { (p. 17) }\end{array}$ \\
\hline $\begin{array}{l}\text { City of Tucson, AZ } \\
\text { "Green Streets Policy" }\end{array}$ & 2013 & $\begin{array}{l}\text { "Landscape and engineering features that utilize soils and } \\
\text { vegetation to manage stormwater for multiple environmental and } \\
\text { community benefits. These features...include but are not limited } \\
\text { to, curb scuppers, curb depressions, core drills, water harvesting } \\
\text { basins, swales, bio-retention basins, berms, check dams, } \\
\text { infiltration trenches, and active water harvesting/storage systems." } \\
\text { (p. 1)" }\end{array}$ \\
\hline $\begin{array}{l}\text { Washington, D.C. } \\
\text { "Clean Rivers Project: } \\
\text { Green Infrastructure } \\
\text { Program Plan" }\end{array}$ & 2016 & $\begin{array}{l}\text { "GI uses plants, trees and other measures to mimic natural } \\
\text { processes to control stormwater, resulting in cleaned, cooled and } \\
\text { slowed stormwater runoff." (p. ES-1) }\end{array}$ \\
\hline
\end{tabular}




\section{Research Motivations}

This research is motivated by an intense interest in the different visions of the role of nature in the city, and the influence of these visions on management actions and outcomes on the ground. The long-standing dichotomy between "country" and "city" / "society" and "nature" that permeates the way we know and understand the world around us is challenged by the very notion that there is non-human nature living and thriving by its own rules in our city centers. Many of the historical ideas and frameworks that define "nature" as the opposite of "city" have been dismantled (Wachsmuth 2012; Light 2009; Collins et al. 2011). However, a new understanding of the relationship between nature and society in cities that effectively answers persistent social and ecological problems has been difficult to forge; much of the urban sustainability and urban resilience literature continues to ask: what is the structure and function of cities as socio-nature hybrid spaces (Felson and Pickett 2005; Kaye et al. 2006; Alberti et al. 2003; Collins et al. 2011)? and what are the appropriate ways for humans and urban nature to interact (Goldstein 2012; Davoudi et al. 2012; Gottlieb 2005)?

Infrastructure is an excellent site of inquiry to begin to answer these questions. This is because all infrastructural systems use/require nature in some shape or form and therefore influence the relationship of urban humans to ecosystems. As Edwards (2003) thoroughly describes, infrastructures provide stability in an otherwise dynamic natural systems and change our responses to nature:

Infrastructures constitute an artificial environment, channeling and/or reproducing those properties of the natural environment that we find most useful and comfortable; providing others that the natural environment cannot; and eliminating features we find dangerous, uncomfortable, or merely inconvenient. 
In doing so, they simultaneously constitute our experience of the natural environment, as commodity, object of romantic or pastoralist emotions and aesthetic sensibilities, or occasional impediment. They also structure nature as resource, fuel, or "raw material", which must be shaped and processed by technological means to satisfy human ends (Edwards 2003).

While all infrastructural systems must cross epistemic and physical boundaries in their organization and management (Pinch 2010; Star 1999), green infrastructure represents a new assemblage of previously disparate groupings and component types which have not been traditionally viewed as 'infrastructure' (i.e. plants are not typically understood as water storage and filtration tanks) and therefore do not fit into established silos. The ways in which this new infrastructure is understood, and the job it is conceived to do, are still under negotiation between the various organizations in charge of designing, implementing, and maintaining green infrastructure. This differs from most urban infrastructures that have faded into the background of daily life as "certain, cold, unproblematic, black box[es]" (Latour 1987). For example, society is now familiar with the concept of wastewater treatment plants - we know that when we flush the toilet or wash the dishes the water travels through a managed sewer system that then 'takes care' of the waste. The messy political and social decisions of the late 1800s that moved us towards building wastewater treatment plants throughout the US in the late 1940s and 1950s are mostly closed - we don't question the usefulness of microbes in the cleaning of our wastewater as was once openly contested among chemical and physical science experts (Schneider 2011).

This research, then, takes advantage of green infrastructure as an interdisciplinary site of "infrastructure in the making" (Bowker et al. 2009). I follow Latour's lead when he 
writes, "the impossible task of opening the black box is made feasible (if not easy) by moving in time and space until one finds the controversial topic on which scientists and engineers are busy at work" (Latour 1987). Through my own experience in the field of urban sustainable design and stormwater management, I have seen that the definition, measurement, and valuation of urban nature are places where scientists and engineers are in uncertain territory and are actively making decisions about open controversies of ecological fact. Green infrastructure represents a site where I can observe and analyze the production and use of ecological knowledge by different epistemic communities, providing insight into deeply held ontologies of municipal actors that are usually hidden during business-as-usual infrastructure design and implementation processes.

As discussed above, green infrastructure is a locus of activity where the role of nature in cities is currently being reimagined; I therefore use this emerging concept as a research site to explore the relationship between conceptual framings of how the world works and urban nature management. I use the analytical concept of knowledge systems to examine the varied visions of urban nature at work in municipal bureaucratic structures of two similarly-sized metropolitan areas that have long-term engagement with the concept of low impact development (LID) and green infrastructure: Baltimore, MD and Portland, OR. The project carries out comparative case studies of two ongoing green infrastructure planning and implementation processes within these cities. The important contextual differences between the two cities, including their socio-economic make-up, racial identity, regulatory environment, and sewer system technology, make them ripe for comparison of contexts. 


\section{Research Design}

The following research questions flow from the motivations of this study. While there are a number of ways to approach the current problems of infrastructure, I use knowledge systems analysis to better understand the institutional challenges of combining social, ecological, and technological aspects of infrastructure design, construction, and maintenance. I use green infrastructure as a site of inquiry, asking the following questions:

How do different institutions generate knowledge claims about the definition, performance, and value of green infrastructure, including both built and natural components? How are these knowledge claims contested? What new knowledge practices are created?

How do the knowledge systems shaping green infrastructure design, implementation, and maintenance in Portland and Baltimore compare?

How is nature (re)made into infrastructure by the epistemic and ontological orientations of the green infrastructure knowledge systems in each city?

How are green infrastructure knowledge systems challenges changing institutions and ecosystems on-the-ground?

To answer these questions, I used a mixed-methods research design (which is summarized in Figure 1-5) that employed both in-depth interviews and follow-up surveys of municipal and nonprofit staff. I spent a cumulative 8 weeks in Baltimore over summer, fall, and winter 2016 conducting interviews and site visits. I interviewed staff at the City of Portland in January and February of 2017, but spent substantial time when living in Portland from 2012-2015 visiting sites and working on other green infrastructure related projects throughout Portland. In Chapter $2 \& 3$, I present the Core Data Collection methods and results outlined in Figure 1-5 in more detail and in Chapter 4, I present the methods and results of the Follow-up Data Collection methods (also outlined in Figure 1-5). 

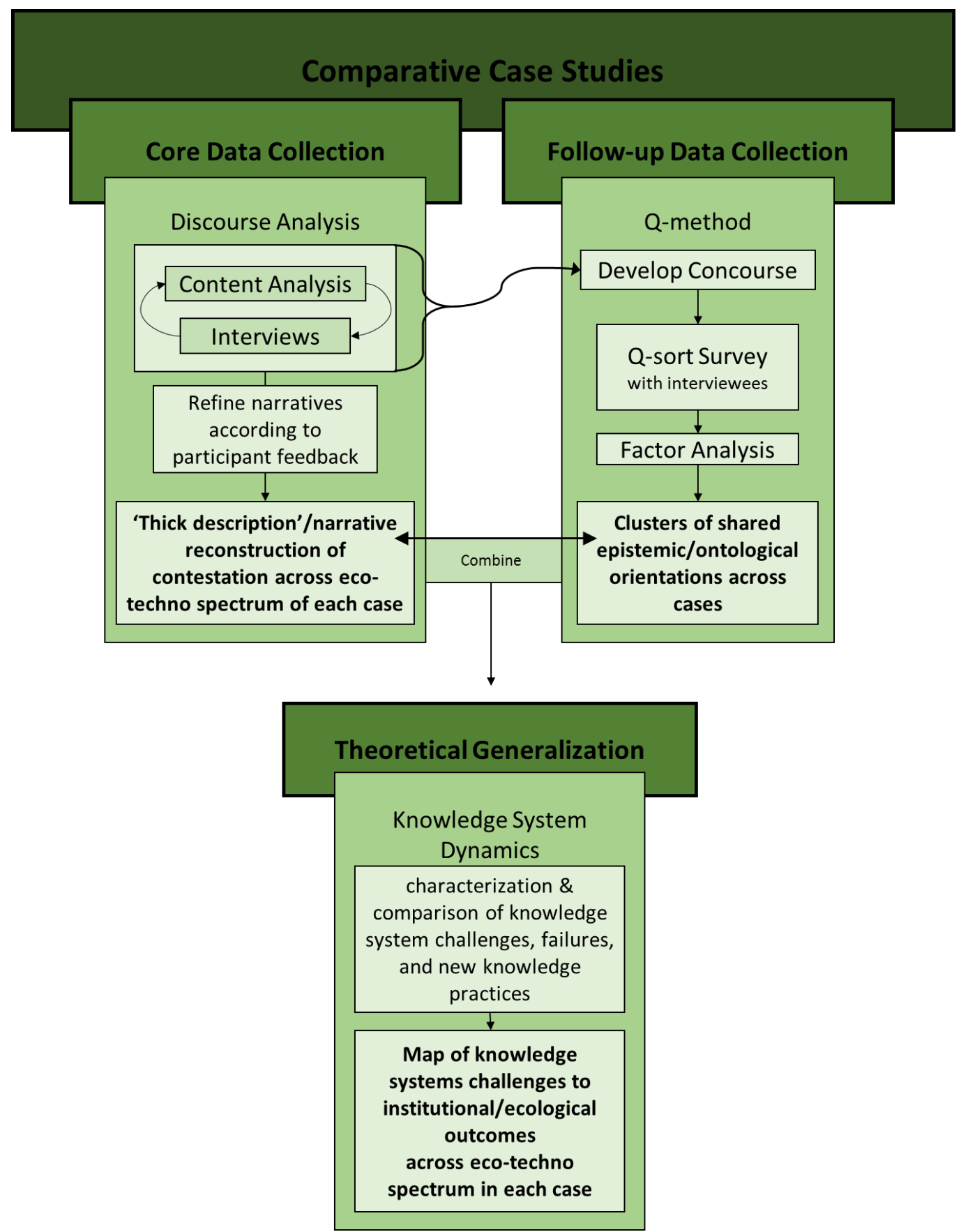

Figure 1-5: Complete dissertation research design 


\section{Theoretical Background}

This dissertation engages with the intellectual history of work on the social construction of nature and critical infrastructure studies to understand green infrastructure planning, implementation, and management in the U.S. today. The concept of knowledge systems is utilized to operationalize and bridge a study of these two theoretical approaches to co-production, as shown in Figure 1-6.

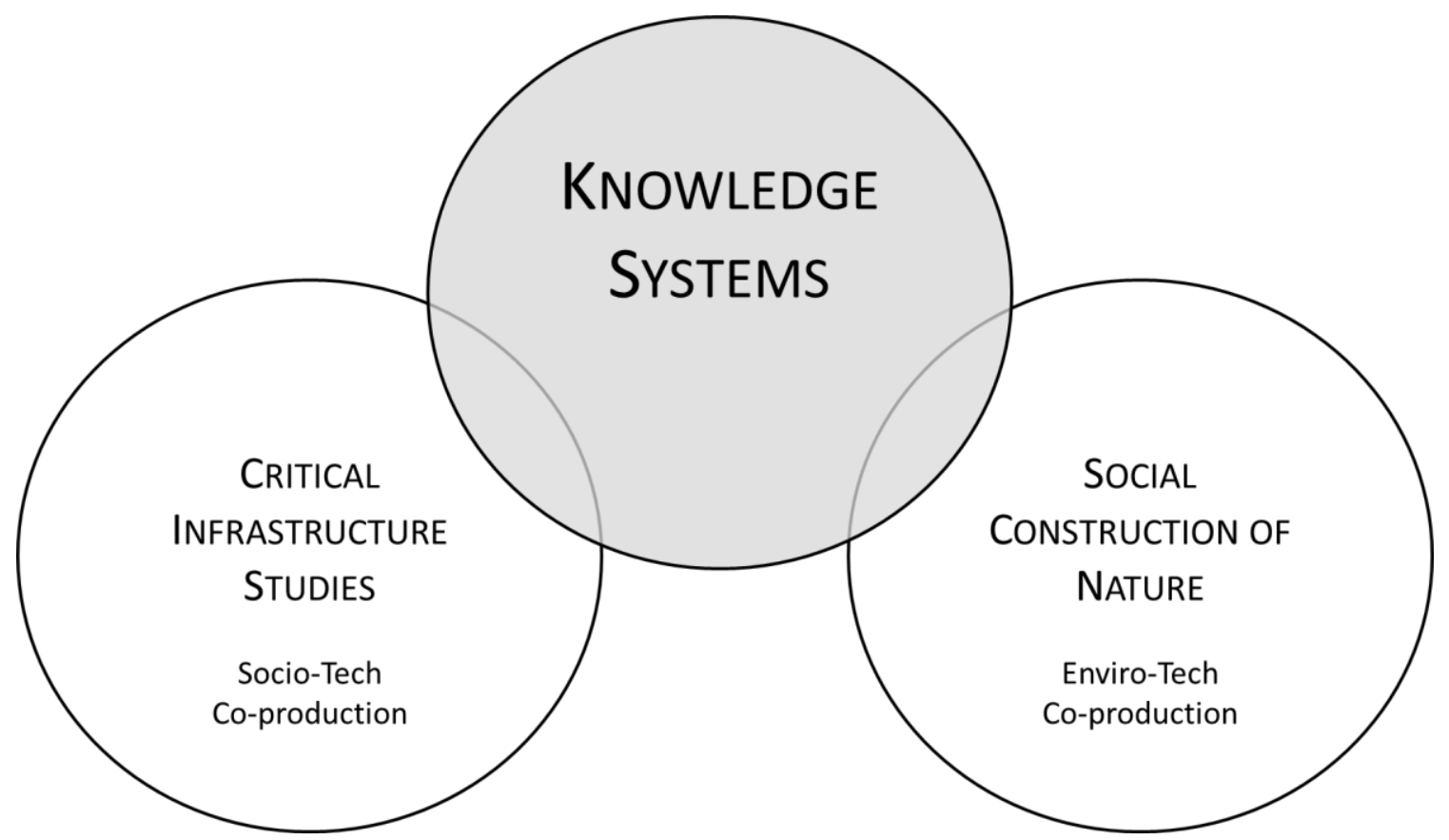

Figure 1-6: Knowledge systems acts as an operationalized bridging concept between theories of SocioTechnical and Enviro-Technical Co-production

A theoretical grounding in knowledge systems begins by recognizing a recent revisioning of the city as an ecological space, in addition to its traditional understanding as a social space. This shift has changed the ways in which researchers gather data about and explain the processes we see in urban areas (Lave et al. 2014; S. T. Pickett et al. 2001). This, in turn, has changed the knowledge available to urban decision-makers, influencing 
the ways that cities are built and governed in general (Lachmund 2013; Light 2009). In particular, the design, implementation, and maintenance of urban infrastructure is influenced by this 'ecological turn'; as ecological thinking has increasingly permeated popular thought (Worster 1990), a push to "work with nature" by designing 'soft' infrastructural systems has grown, while prior paradigms of "command-and-control" of nature with 'hard' infrastructure has become unfavorable and viewed as flawed by many (Greenberg 2012; Kimmelman 2012).

The knowledge systems literature can be usefully applied to understand the ways the city is conceptualized by different social groups, and also begin to untangle the influences that different theoretical frameworks (both scientific and otherwise) have on practice and decision-making in the city. Tools from the knowledge systems literature, therefore, can illuminate the knowledge used and produced around the shift from "command-and-control" of nature to a "work with nature" paradigm within cities, and when viewed in tandem with the critical infrastructure studies literature can also explore the consequences of such a shift on the design, implementation, and maintenance of urban infrastructures; for example, the knowledge systems literature illuminates current and past understandings of the feedback loops between humans and nature in the city, and how urban infrastructures mediate this relationship.

A focus on knowledge is timely. As Knorr-Cetina (1999) asserts, "There is widespread consensus that contemporary Western societies are in one sense or another ruled by knowledge and expertise" (p. 5); therefore, understanding the production, negotiation, and utilization of knowledge claims allows researchers to track power 
relationships (Lave 2011; Miller, Munoz-Erickson, and Monfreda 2010) and relate knowledge claims to their negotiated material outcomes (Callon 1999; Lave et al. 2014) in general in the city. A better understanding of these relationships allows us to consciously design our knowledge systems to be more effective and inclusive.

I have also chosen this focus because of the increasing use of knowledge from the natural sciences, and specifically ecology, in designing and governing the city in recent decades (Davoudi 2012; Healey 1997). One aspect of this increase is the growing popularity of describing cities as socio-ecological systems (SES) in both urban ecology (Felson and Pickett 2005; S. T. A. Pickett, Cadenasso, and Grove 2004) and the social sciences (Anderies, Janssen, and Ostrom 2004; McGinnis and Ostrom 2011). To understand the wider impacts of emerging SES knowledge claims, the knowledge production process and its social and material consequences needs to be traced.

Ecological knowledge about the city has only recently begun to be produced; initially the field of ecology focused on ecosystems far from humans. Only areas beyond human influence were considered natural and the appropriate subject matter for ecological inquiry (Kingsland 2005; Light 2009; S. Pickett, Cadenasso, and Meiners 2009). Over time, ecological knowledge of the city has grown in legitimacy. In particular, the application of ecological knowledge about the city to the engineering-dominated field of infrastructure design and implementation has become popular in cities hoping to improve their sustainability.

To examine epistemological knowledge system concerns in infrastructure, it is useful to explore the STS literature around socio-technical systems; STS scholars have 
worked to outline a number of different system parameters that exist in the feedback loops between technical-material actors and socio-political actors (Winner 1986). While initially focused on the dialectical relationship between technology and society, STS scholars have increasingly focused on the influence of nature as an actor on these mutually articulating factors (Gandy 2002; S. B. Pritchard 2012). This opens a connection between infrastructure studies, environmental history, and urban ecology within the new analytical framework of socio-ecological-technical systems or SETS (Redman and Miller 2015; McPhearson et al. 2016). Because, as asserted in the introduction, the infrastructure problems faced in the U.S. are simultaneously social, ecological, and technological, SETS is an excellent conceptual tool to illuminate the social and material consequences of the emergence of green infrastructure development in particular.

In the remainder of this section, I review both the knowledge systems literature and the infrastructure studies literature in an effort to better contextualize this dissertation research and point to its theoretical positioning. The literature reviewed here is operationalized in the following conceptual framing section.

\section{Knowledge Systems}

The knowledge systems literature explores the production, validation, circulation, consumption (Miller, Munoz-Erickson, and Monfreda 2010), negotiation, translation (Callon 1999), and utilization of knowledge in society. None of these is a discrete step or process; in practice, knowledge systems processes are not linear and often happen simultaneously (Miller, Munoz-Erickson, and Monfreda 2010). Therefore, each will be 
touched on in the following review of STS scholarship. While the knowledge system concept has varied meanings in the work of different scholars, most agree that "new knowledge claims do not merely appear, fully formulated. Rather they are the product of sometimes long and involved work" (Miller, Munoz-Erickson, and Monfreda 2010).

Expert-driven decision-making processes have become the norm in a variety of social settings in today's world (Knorr-Cetina 1999). This is especially true of engineeringbased infrastructural design, implementation, and maintenance decisions. While a privileging of one type of knowledge (i.e. quantitative, expert, engineering knowledge (Friedmann 1993)) initially brought cities enormous health benefits (e.g. sewer pipes and piped drinking water systems eliminating cholera epidemics in early industrial cities (Tarr 1996)), the use of an abundance of one kind of knowledge, from a select and elite group of people, has not necessarily led to better societal (or material for that matter) outcomes (Scott 1998). Often diverse, experiential, or tacit knowledge claims, can provide the needed contextual information to solve a problem that generalized expert knowledge alone cannot complete (Mukerji 2009).

Before moving forward, a working definition of 'knowledge' itself should be put forward. I borrow the succinct but broad definition put forth by Miller et al. (2010) for use in this paper:

Knowledge...refers to claims made by actors (who can be individuals or institutions) that either purport to tell us something of a factual character about the world (of potentially varying degrees of certainty) or are taken by actors to tell us something factual about the world (p. 1).

This definition is helpful to my work regarding green infrastructure development because of its explicit focus on decision-making: 
Knowledge refers to an idea or belief that someone, whether an individual or a community, takes to be true, or at least relatively more true than other kinds of statements, and therefore of sufficient character to guide his, her, or their reasoning or, especially...action (p. 1, emphasis added).

I would also like to quickly note the primacy of uncertainty in science and knowledge systems before moving forward with this review. Because each piece of new knowledge expands known unknowns (i.e. each single piece of knowledge illuminates multiple new questions), in a 'knowledge society', where expert knowledge is produced around the clock, there will be more ignorance (unknowns) and therefore more surprises. "If this is the case, handling ignorance and surprise becomes one of the distinctive features of decision-making in contemporary society" (Gross 2010, p.1). In infrastructure design and implementation, the emerging production and application of ecological knowledge in the city means a variety of facilities are now built with ecological components whose response to social, political, and other ecological actors in the city is unknown. As Gross (2010) states "new knowledge...allows for new options without delivering secure criteria for how these new options need to be handled" (p. 1). Uncertainty in infrastructure outcomes is important to infrastructure decision-making and it permeates all the concepts discussed below.

\section{Production of Knowledge}

Western societies are increasingly described as 'knowledge societies'; consistent with the concept of a 'post-industrial society' this term acknowledges an emerging economic relationship in which knowledge is "a productive force replacing capital, labor, and natural resources as the central value- and wealth-creating factor...fundamentally 
changing the nature of production systems" (Knorr-Cetina 1999). This makes knowledge an increasingly important phenomenon to trace within modern societies, as it has increasingly more impact on decision-making processes and material systems of our world (Miller, Munoz-Erickson, and Monfreda 2010; Ozawa 1991).

In particular, scientific knowledge $\mathrm{i}^{\mathrm{ii}}$ dominates the ways in which we collectively understand and interpret the world around us (Ozawa 1991). This necessitates the work of a variety of experts to collect, integrate, and interpret scientific data for us (Bocking 2004). As Knorr-Cetina (1999) describes, knowledge societies "run on expert processes and expert systems... are epitomized by science" (p.1). I follow the lead of scholars who have worked to improve the social, political, and ecological relationships of our world by demystifying and examining epistemological orientations that become "structured into all areas of social life" (Knorr-Cetina, 1999, p. 1) from expert knowledge production.

While popularly considered objective - happening somewhere 'out there' away from politics - science is in fact entangled deeply within social and political processes and concerns (Jasanoff 2004). As Gieryn (1999) notes, science actually has a wide "reservoir of meanings" (p. 21) and people selectively use what meanings they want to when it is useful to them. Knorr-Cetina recognizes this overlap between politics, expertise, science, and society and asserts that

in a knowledge society, exclusive definitions of expert settings and social settings - and their respective cultures - are theoretically no longer adequate; this is why the study of knowledge settings becomes a goal in the attempt to understand not only science and expertise but also the type of society that runs on knowledge and expertise (p.8). 
Urban infrastructure is often considered to be made up a number of "certain, cold, unproblematic, black box[es]" (Latour, 1987, p.4); but by utilizing the tools of STS scholars and focusing on the 'epistemic machineries' (Knorr-Cetina) of emerging green infrastructure development, I can observe knowledge systems negotiations in real time, providing insight into deeply held knowledge claims that are hidden during business-asusual infrastructure design and implementation.

\section{Co-production of Knowledge}

Rather than forwarding a compartmentalized view of urban nature, a relational perspective recognizes the indelible connectedness of urban residents with their material surroundings. Such a perspective is helpful to understand how the contemporary conditions of cities came into being and how they can be reworked into more desirable configurations. (Karvonen 2011, p. ix)

The concept of co-production is central to the exploration of knowledge systems. Jasanoff (2004) describes co-production as "shorthand for the proposition that the ways in which we know and represent the world (both nature and society) are inseparable from the ways in which we choose to live in it" (p.2). From this standpoint, knowledge creation is entangled both materially and ideologically, one inseparable from the other, and constantly evolving. Knowledge is not something pure that is waiting out there for humans to find it (like Plato's Forms); but it is instead constantly produced and re-formed through human social and political processes, as well as through ecological and physical processes.

The idea of co-production is therefore a direct challenge to common conceptions of scientific knowledge as "...a transcendent mirror of reality" (Jasonoff 2004, p.3). From a positivist viewpoint, the scientist strives to distill information about the world into a few 
underlying fundamental and unchanging laws (Cartwright 1999). An important assertion of this viewpoint is that the scientist, via scientific methods, can produce an objective image/description of the world. The quantitative nature of much scientific expression solidifies the notion that scientific knowledge is objective (T. Porter 1994; T. M. Porter 1996); we hear this culturally reinforced in our daily lives through colloquial expressions like 'numbers don't lie.' However, the very act of making decisions about what to measure and how to measure it in scientific research studies entangles the quantitative scientific knowledge creation process with ideology, politics, and culture (Jasanoff 2004; T. Porter 1994; Scott 1998).

In particular, co-production is implicated in the practices of state-making and governance: “...co-production offers new ways of thinking about power, highlighting the often invisible role of knowledges, expertise, technical practices and material objects in shaping, sustaining, subverting or transforming relations of authority" (Jasanoff, 2004, p. 4). By examining which pieces of knowledge are used and which are thrown out of a decision-making process, or observing how and which specific topics are considered by scientists, can shed light on who is influencing knowledge creation. Flyvbjerg (1998) posits that Francis Bacon's famous idiom "knowledge is power" is not uni-directional; power is also knowledge, due to the control that the powerful have over what knowledge is counted as relevant and pertinent in the world: "Power procures the knowledge which supports its purposes, while it ignores or suppresses that knowledge which does not serve it" (p. 319). Therefore, tracking the knowledge production and utilization process allows a researcher to study power relations within state-making at the same time; "the findings [of knowledge 
co-production research can] help to clarify how power originates, where it gets lodged, who wields it, and by what means, and with what effect within the complex networks of contemporary societies" (Jasanoff 2004).

In the end, co-production is a crucial analytical tool for understanding the feedback loops between knowledge production and use. As Jasanoff (2004) says, "our methods of understanding and manipulating the world curve back and reorder our collective experience along unforeseen pathways..." (p.13). In other words, the way that we understand the world, the definitions and conceptual frameworks we use, influence our day-to-day social and material experience in the world; therefore, if we change the ways that we conceive of the world around us, we can change our socio-material experience of reality.

\section{Infrastructure}

\section{What is infrastructure?}

Analytically, infrastructure appears only as a relational property, not as a thing stripped of use. (Star \& Ruhleder 1996, p. 113)

A standard dictionary definition points to the most common understanding of an infrastructural system: "the basic equipment and structures (such as roads and bridges) that are needed for a country, region, or organization to function properly" (Merriam-Webster 2014). What is left out of this predominant, dictionary definition which emphasizes infrastructure as a physical network of pipes, cables, asphalt, etc., is that infrastructures also consist of overlapping socio-political networks; embedded within an infrastructure's physical components are a vast array of values and knowledge types (Star 1999; Winner 
1986). The STS literature therefore employs an extended definition of infrastructures for the purposes of understanding the complex interactions between social and technical factors.

There are two popular ways that the socio-technical relationship within infrastructures, and technologies in general, is viewed. One is technological instrumentalism and the other is technological determinism (Rowland and Passoth 2014; Winner 1986). First the technological instrumentalist view: "...technologies carry no intrinsic meanings. Their meanings are always to be found amongst social groups who interact with the technology and share a meaning of the technology" (Pinch 2010, p. 79). In this way, politics work through technology (Rowland and Passoth 2014), but the technology itself is not an actor; consequences are wholly reducible to characteristics of social actors. Next, the technological determinist view: Winner (1986) asserts, "if the experience of modern society shows us anything...it is that technologies are not merely aids to human activity, but also powerful forces acting to reshape that activity and its meaning." (Winner 1986). In this view, politics are in technology itself (Rowland and Passoth 2014); technology has a 'life of its own' and becomes a nonhuman actor separate from human and social actions. Both views essentialize and reduce the complexity of sociotechnical relationships to either a social or a technical phenomenon; therefore, STS scholars actively work to blend these two perspectives of the world, showing how technologies are neither completely reducible to social or technological determinants but are instead coproducing:

...social and technical causes and effects are bound up together in ways that are more complex than either the instrumentalist or determinist views can encompass. 
As a consequence, the emergence of new forms of technology cannot be attributed to a single, simple cause, whether the pure human will or some inherent technological imperative" (Kirkman, 2008, p. 237).

I will use Pinch (2010) to provide an example of the balance between socially and technologically reductionist views of infrastructure in STS research. Pinch's (2010) case study involves the building of an eruv around his hometown. An eruv is an invisible wall that can built around a house, neighborhood, or town using wires and poles that has great significance for Orthodox Jews (i.e. it designates an area as temple-like allowing people to behave differently on the Sabbath within its boundary); but an eruv would just look like a series of telephone poles to anyone else. Pinch notes that, even in its invisibility, the eruv does require material elements - namely the phone poles constructed in a specific way as to satisfy the doctrine (the wire must be perfectly aligned over the tops of the poles, etc). Even though the eruv is mostly symbolic, holding very special meaning for a specific social group, it is has real consequences in the material world; namely it costs a money and time.

The example of the eruv displays that the "deep insight of recent social studies of technology is to show that signification and materiality always form an interaction process" (Pinch 2010). This is exquisitely powerful to the examination of infrastructure; it allows the researcher to describe both the impact of physical structures on social life as well as outline the impacts of social and political actions on the physical structure of our world. STS scholars show that technologies are an actor in the meaning-making process involved in the development knowledge systems. As Pinch (2010) says, "...technologies and their meanings do not exist detached from the rest of society, its institutions, culture and the vast assemblages of technologies and humans we have already built" (p.80). He illustrates this 
point through a case study of a proposal to build an eruv around a neighborhood in Ithaca. The proposal sparked open public debate regarding the separation between church and state, economic responsibility, and even what legally constituted a "sign." National laws, economics, local social stratification all came into play in these public debates about what was essentially an invisible wall.

Beyond the general balance between technological determinist and technological instrumentalist views, infrastructures require additional layers of analysis because of their position as connections between technologies and social groups. Larkin (2013) goes as far as saying that infrastructure is distinct from technology generally because it is inherently a system: "What distinguishes infrastructures from technologies is that they are objects that create the grounds on which other objects operate, and when they do so they operate as systems" (Larkin 2013). The large networks that these systems represent make defining the actual object under study in infrastructure research difficult.

Given the ever-proliferating networks that can be mobilized to understand infrastructure, we are reminded that discussing an infrastructure is a categorical act. It is a moment of tearing into those heterogeneous networks to define which aspect of which network is to be discussed and which parts will be ignored (Larkin 2013).

\section{Adding Nature to the mix}

STS as a whole has been primarily concerned with science and technology while issues related to nature and the environmental assumed a secondary position. Nature is consequently - and quite ironically - naturalized. A necessary correction would be to, rather than reject it as a hollow concept, add it again to the arsenal of machineries that are studied by STS: that is what enviro-technical analysis is aiming at. (Pritchard 2011; Rowland and Passoth 2014) 
While the STS recognition of the hybridity of society and technology is very useful, it often neglects another critical actor: nature. Recognizing nature as an actor moves the discussion from Kirkman's "sociotechnical ensembles" to socio-ecological-technical systems (SETS). The emergent concept of infrastructures as SETS complicates the picture of infrastructures as shaping, and being shaped by, society with the addition of ecological actors. Plants, animals, fungi, and microbes all play a role in infrastructural service delivery, either by design (for example, bacteria in a wastewater treatment plant) or unintentionally (for example, scum growing on the inside of pipes). This means that all urban infrastructural systems interact with ecology - the degree to which city managers and engineers explicitly define this relationship varies spatially and temporally. This suggests that differential definitions, or the use of different kinds (Hacking), influences the functionality of these systems in addressing social and ecological parameters.

While the use of living ecological components (i.e. microbes, trees, vegetation, etc.) in infrastructural design has been present throughout the history of urban development, the specific configuration of the human-ecology interaction has changed throughout this time. The relationship is constantly reimagined as human needs and ecological/geological systems evolve. As the concept of the Sustainable City continues to emerge in the $21^{\text {st }}$ century, it is increasingly important to define the enrollment of nature in the creation of infrastructure. Recognizing the past definitions of the human-nature relationship materialized in infrastructure facilities becomes critical data in the quest to reveal the political, social, and ecological consequences of these changing relationships (Schneider 2011). 
STS scholars have explored the hybridity of nature and technology though a number of different frameworks. Pritchard's $(2011 ; 2012)$ approach focuses on the social construction of nature. While acknowledging that, “...nonhuman nature may be profoundly mediated and constructed, both literally and metaphorically", she admits that "it is not wholly reducible to culture" (Pritchard 2011); Pritchard argues that what is important to track is how nature can be evoked within strategic political arguments by specific groups of humans for particular ends.

Pritchard (2012) uses the term 'envirotechnical system' - defined as "the historically and culturally specific configurations of intertwined 'ecological' and 'technological' systems, which may be composed of artifacts, practices, people, and ecologies" (p.19) - to define a set of technological and natural systems used by politicians within a specific governance context referred to as an "envirotechnical regime." Regimes in this case are prescriptive, made up of "the institutions, people, ideologies, technologies, and landscapes that together define, justify, build, and maintain a particular envirotechnical system as normative" (p.23). In Pritchard's work,

...various groups and ambiguous agencies did what STS scholars claim we are doing all the time: we are not just building technologies into an otherwise pure and unaltered nature, but are engaged in enviro-technical modifications; we are not holding nature and technology apart, but are continuously binding and stitching them together (Rowland and Passoth 2014).

When considering green infrastructure knowledge systems, this 'stitching together' begins to interact with various standards. Policy-makers begin to ask, can we count a tree as a technological asset? Is an engineered green street facility natural, meaning that it can be included in an ecosystem services management plan? While we continually intertwine 
human-made and ecological components of the city, these two categories increasingly 'rub up' against incompatible preexisting standards (Bowker and Star 1999); a new kind must be 'made and modeled' (Hacking 1999) for green infrastructure to allow for the creation of new categories with new standards (Lampland and Star 2009).

The description of power relations in Pritchard's work is also closely tied to the concept of co-production of knowledge and state power (Jasanoff 2004). The concept of linked technical and environmental spheres articulated under the control of political power is important to the study of urban infrastructure, and highlights the importance of contextualization. Examination of the emergence of new norms, protocols, and practices within infrastructure design at the local level is predicated on the concept that context matters, and that local implementation of generic knowledge creates unique and emergent knowledge systems that can change the efficacy of best management practice (BMP) facilities socially, ecologically, and technologically.

Because infrastructures are, by definition, built to provide on-going services or processes rather than end-point products, they are ideal artifacts to use to describe SETS as systems in particular. As Star mentions, infrastructure does not exist outside of the concept of use, it "appears only as a relational property, not as a thing stripped of use." For example, bioswales push the limits of the traditional viewpoint of nature as raw material; they are built to explicitly take advantage of process in nature: water filtration and storage in soil. Therefore, it is easy to see this infrastructural facility as more than just an end point, or a technology that we feed raw materials from nature. It is a visual and explicit hybrid of the natural and the technological. With this starting point, a study of infrastructure can 
focus on process without having to black-box one side or the other.

Another framing of this topic dismisses a discussion of hybridity all together and analyzes the direct acknowledgement of nature as infrastructure itself: "Nature is...in some sense the ultimate infrastructure" (Edwards 2003, p.196). This recognition of nature as infrastructure is somewhat new. In the past, "infrastructure implies artifice, nature typically signifies its absence" (Carse 2012). Carse (2012) describes an example of how this idea is changing explaining how the natural landscape around the Panama Canal has increasingly become viewed as a water-provisioning infrastructural system. Without the water stored in the soils of the surrounding landscape, the Panama Canal would not have enough water to fill the locks that transport tankers and boats, making nature a key water management infrastructure system.

Also, because of the ambiguity of what infrastructure actually is, it can be stretched to encompass nature as well as technology. "The concept of infrastructure does not delimit a priori which - or even what kind of - components are needed to achieve a desired objective" (Carse 2012). Therefore, nature becomes much like a technology in STS research: "As nature becomes infrastructure through work, human politics and values are inscribed on the landscape, much as they are embedded in arrangement of steel and concrete" (Carse 2012).

Lastly, one of the most important aspects of the STS lens is that technical and ecological system components are viewed as actors, rather than static background conditions. In this framework, infrastructures can be revealed as important mediators of the human relationship with nature: 
Infrastructures constitute an artificial environment, channeling and/or reproducing those properties of the natural environment that we find most useful and comfortable; providing others that the natural environment cannot; and eliminating features we find dangerous, uncomfortable, or merely inconvenient. In doing so, they simultaneously constitute our experience of the natural environment, as commodity, object of romantic or pastoralist emotions and aesthetics sensibilities, or occasional impediment. They also structure nature as resource, fuel, or "raw material," which must be shaped and processed by technological means to satisfy human ends. Thus to construct infrastructures is simultaneously to construct a particular kind of nature, a Nature as Other to society and technology (Edwards 2003, p. 189).

All of these STS interpretations lead to a greater understanding of the emergence green infrastructure design and implementation; however, it is important to keep in mind that "studies of infrastructure tend to privilege the technological even if they qualify it by defining urban spaces as hybrid systems of humans and machines bundled together through infrastructural networks" (Larkin 2013, p. 339).

\section{$\underline{\text { Invisibility }}$}

Basic etymology highlights the overwhelming background-ness of infrastructure. Through employing the Latin prefix 'infra-', meaning below or underneath, 'infrastructure' is an antonym of 'superstructure' (Merriam-Webster 2014). While superstructures are overt, visible, and often seen as powerful, infrastructure is primarily hidden, taken-forgranted, and seen as mundane; it is "something that other things 'run on', things that are substrate to events and movements" but that aren't events or movements themselves (Lampland and Star 2009). This is because most people interact directly with the output end of infrastructures; they notice the goods and services provided by infrastructural systems because that is what they need and want (Edwards 2003). The ways in which infrastructure provide those goods and services are for the most part invisible to the user. 
Take for example, an electric outlet. In my house, I use outlets everyday to run a variety of appliances: my coffee maker, the bedside lamp, my dishwasher, my cell phone charger. Electric outlets allow me to go about the activities of my day, but I rarely think about the outlets or the electricity they provide to run the appliances in my life; instead, I think about that first sip of coffee that wakes me up in the morning, the ability to see my book when I read in bed, my clean dishes to make dinner, and calling my mom in the middle of the day. This is closely related to the concept that infrastructures only appear relationally: "Analytically, infrastructure appears only as a relational property, not as a thing stripped of use" (Star \& Ruhleder 1996, p. 113).

The daily invisibility of infrastructure is an oft repeated insight of the STS literature (Larkin 2013). However, it is important to be nuanced in the discussion of invisibility. As Star (1999) mentions, “one person's infrastructure is another's topic, or difficulty” (p.380). A tangible example of this is the stairs leading to the front door of a building; for most people it is simply taken-for-granted transportation infrastructure, but for a person in a wheelchair it represents a real barrier to use. Depending on a variety of demographic factors, infrastructures can be either background systems or front and center problems (Larkin 2013).

This nuanced description of invisibility also illuminates the relationship between invisibility and pluralism. Bowker and Star (1999) argue that for information to be perceived, it "must reside in more than one context" (p. 290). This is because "we know what something is by contrast with what it is not" (Bowker and Star 1999). To communicate knowledge, therefore, there must be multiple interpretations at work: 
A radical statement of this would be that information is only information when there are multiple interpretations. One person's noise may be another's signal or two people may agree to attend to something, but it is the tension between contexts that actually creates representation....This multiplicity is primary, not accidental nor incidental" (Bowker and Star 1999, p. 291).

In other words, you never need to create a representation of something that everyone else already understands and views in the same way. However, in the pluralistic world in which we live, there are multiple viewpoints of the same objects and processes that need to be translated, shared, and communicated in order for understanding and action to take place.

A corollary theme to the invisibility of man-made infrastructures, is the deeper invisibility of earth systems from daily life. Primarily, the purpose of infrastructure systems is to deliver life-support services in a more steady fashion than ecosystems would if left unaltered (Edwards 2003). In our day-to-day lives, as discussed above, we primarily interact with the human-crafted technical hardware and software of infrastructural systems - facets, roads, electrical sockets, grocery carts. But in the background of these systems are ecological systems - water filtering through the soil and plants, microbes fixing nitrogen in farm fields, plants and animals dying and slowly becoming formations of coal and gas (Millennium Ecosystem Assessment 2005). Most people rarely, if ever, engage with this part of infrastructure directly. These processes are messy, seasonal, too slow or too fast, contrasting ordered urban infrastructural systems (Edwards 2003).

Infrastructure therefore alters the city-dwellers' vision of the life-support network provided by ecosystems; one of the problematic pieces of this vision is the distributed and distant feedback loops that do not allow individuals to directly see their interactions with 
nature. Instead of messiness and evolving ecosystems, they see a consistent service delivery (Edwards 2003). This influences the production of knowledge about infrastructure through time, therefore changing the kinds of knowledge available for application in the city. For example, as users continue to expect reliable clean water in their pipes, ever-morecomplicated mechanical water treatment has been added to the system (Melosi 2008; Tarr 1996). As Edwards (2003) asserts, “[infrastructures'] capacities permit us...to approach nature as a consumable good, something to be experienced (or not) as and when we wish" (p. 189).

The messy work done by natural actors, or ecosystem components of infrastructure, has been minimized or re-branded as part of mechanical systems throughout the industrial era (microbes in wastewater treatment are an excellent example of this as described by (Schneider 2011)). This has meant that the role of nature in the city has been underplayed and made less visible through time (notable exceptions have been in park design where social and moral improvements have been attributed to natural systems (Gandy 2002; Lachmund 2013)). As the perceived role of nature in water infrastructure design and maintenance decreased, the attention to ecological elements of the system likewise waned. In this way, we have come to measure and categorize water infrastructure as a human-made technology, rather than as a natural ecosystem (Schneider 2011); this categorization, or kind-making (Hacking), has influenced the development of scientific and tacit knowledge about water in the city, determining the ways that we measure and therefore value water infrastructure (Edwards, Gandy). 
Both the network and stormwater visions of green infrastructure work to change this invisibility of ecology in infrastructure and the city in general. The ecosystem services framework has been developed as a way to categorize the benefits humans receive from nature (Millennium Ecosystem Assessment 2005). There are wide-ranging benefits included in the framework, from provision of clean air and clean water (via natural cycles of filtration through biotic and abiotic ecological components) to spiritual rejuvenation and sense of place (inspired by interactions with intact forests, wetlands, lakes, etc.) (Millennium Ecosystem Assessment 2005). These new categories valorize the contributions of natural systems while silencing the work of man-made systems which is opposite to the way that the categories are currently perceived (popularly and in municipal government). These new service categories are on track to become new standards for urban nature and green infrastructure in the city. As reviewed thus far, research into these changing categories can shed light on the power of knowledge systems in the city (Jasanoff 2004).

\section{Conceptual Framing}

\section{The 'Eco-Techno’ Spectrum of Green Infrastructure Interventions}

The idea of green infrastructure today comes with a significant amount of conceptual baggage from the differing worldviews that invoke the term to accomplish different goals. As described in detail in earlier sections of this chapter, different stakeholders hold different ideas about both what green infrastructure is and what it should do. These differing visions are contested in cities attempting to build low-cost and 
sustainable infrastructures. For example, green infrastructure options were originally dismissed by engineers in Pittsburgh when completing a new stormwater management plan; the knowledge claims regarding green infrastructure's effectiveness, which are mostly regarding ecological benefits, were not relevant or salient to their knowledge system which focused on the engineering problem of reducing water quantity in the sewer system. Non-profit and community groups in marginalized areas of the city however, envisioned the many benefits green infrastructure could provide, from social cohesion to reduction of urban heat island effects, contesting the all-grey-infrastructure CSO plan in the city and demanding revisions that included green infrastructure (Finewood 2016).

To better understand green infrastructure, and its potential outcomes, we must better understand the ways that differing definitions and visions of green infrastructure are being evoked and negotiated in cities today. How are the different conceptualizations of green infrastructure combining or competing, and what socio-natures do they produce on the ground? To do this, a connection between disparate facilities and the siloed institutions that manage them must be made. Therefore, I developed the eco-techno spectrum (displayed in Figure 1-7) to connect the large variety of green infrastructure interventions currently in use in the United States in a single framework. This framework exposes three important knowledge system challenges (described in more detail in the following section) that are examined through comparative case studies in the following chapters.

The eco-techno spectrum highlights the different degrees to which a green infrastructure facility includes biological entities, or living 'stuff' (including plants, microbes, etc) as a designed component of the facility. This living stuff is the 'eco' part of 
'eco-techo' shorthand. There is more ecology on the left-hand side of the spectrum and more physical-mechanical technology on right-hand, or 'techno', side of the spectrum.

As discussed in the introduction, a wide variety of facility types are included in municipal green infrastructure programs and plans (Mell 2013), spanning from small-scale, highly engineered facilities like bioswales and green roofs (as seen in New York City's plan (NYC Environmental Protection 2010)) to larger-scale parks, natural areas, urban wetlands and floodplains (as seen in Philadelphia's Green City, Clean Waters Plan (Philadelphia Water Department 2011)). And in between these two extremes are urban agriculture facilities, smaller and more developed parks, and greenbelts, as well as street tree networks and urban tree canopies (as seen in Portland's Watershed Management Plan and Baltimore's Green Pattern Book). The primary distinguishing characteristic of green infrastructure across this variety is the explicit use (or mimicry) of ecological processes to provide utility services; biological elements are integrated to differing degrees with grey technological components to provide these services, making green infrastructure facilities ecological-technological hybrids.

Others scholars have presented similar spectrums to examine aspects of green infrastructure, including Mell's (2013) use of Davies' "grey-green continuum” which highlights the distinctions between facilities that are 'visually green' (i.e. parks, grass) and those that are considered green because they are 'sustainable' (i.e. bike paths, LEED buildings); and the Royal Society's (2014) rejection of an infrastructure binary (i.e. as either 'grey' or 'green') through recognizing a "hybrid" category of resilient infrastructure 
options that exists between "ecosystem-based" and "engineering" options (see also Grimm et al. (2016)).

The eco-techno spectrum, therefore, follows the lead of Mell (2013), the Royal Society (2014), and other scholars (Grimm et al. 2016) that display the usefulness of continuums in exposing the nuances of green infrastructure programs. However, the ecotechno spectrum differs from these other research projects by specifically highlighting facilities that use living organisms in their design and service delivery, therefore directly engaging with both non-human nature and technology (Redman and Miller 2015). Because of this cross-epistemological framing, the eco-techno spectrum is well suited to explore the connections (and disconnects) between various knowledge systems.

While a relatively simple ordering of green infrastructure facility types, the ecotechno spectrum is a powerful tool because it captures the diversity of technologies, jurisdictions, scales, and ecosystems that make up green infrastructure in current municipal programs. Heterogeneity of components, scales, and jurisdictions is not unique to green infrastructure, as nearly all infrastructural systems must cross epistemic and physical boundaries in their organization and management (Pinch 2010; Star 1999). However, green infrastructure represents a new assemblage of previously disparate groupings and component types which have not been traditionally viewed as 'infrastructure' (i.e. plants are not typically viewed as water storage and filtration 'tanks'). The well-established kinds (Hacking 1999), categories (Bowker and Star 1999), and standards (Lampland and Star 2009) that have developed over time in municipal management to deal with cross-boundary issues of grey infrastructure are not germane to managing the ecological processes and 
biological entities of green infrastructure. In fact, in most instances biological components and their ecological properties are invisible to the epistemic communities designing, constructing, and maintaining them.

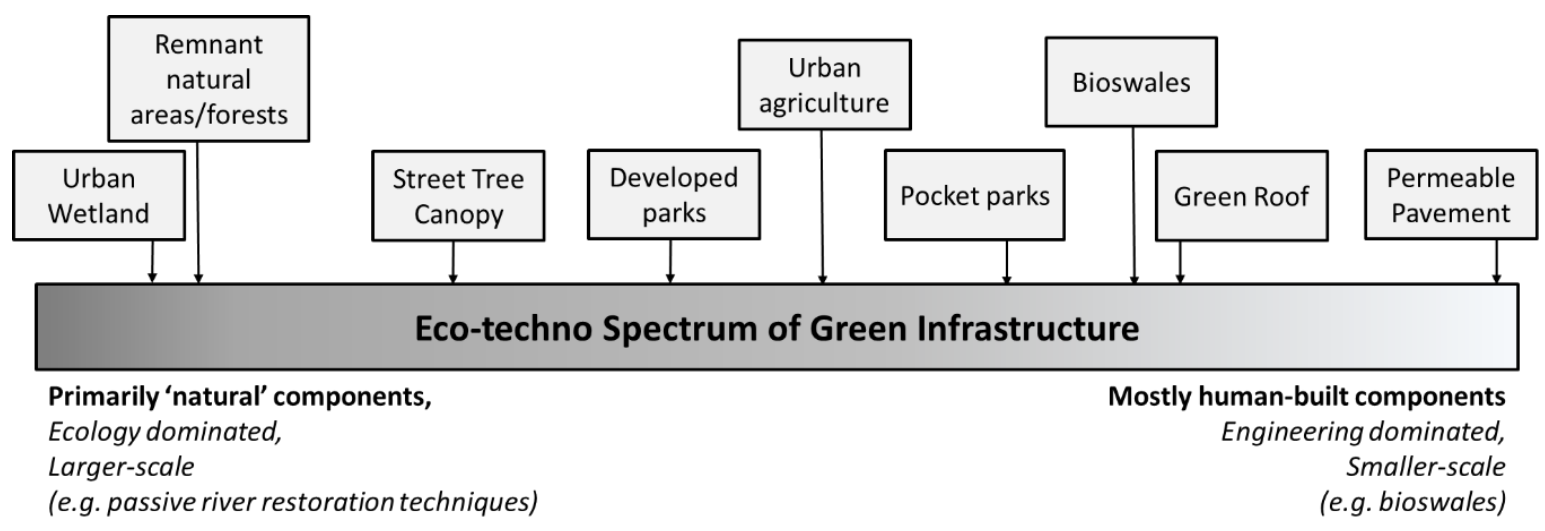

Figure 1-7: The eco-techno spectrum displays the varying ecological-technological hybridity of green infrastructure facilities. On the left-hand side of the spectrum ecological and biological components make up more of the facility, whereas on the right-hand side technological, mechanical components make up more of the facility. This spectrum is used as heuristic to organize insights regarding current green infrastructure knowledge challenges across a practice-oriented spectrum of facilities.

I use the eco-techno spectrum throughout the remaining chapters of this dissertation to link insights regarding knowledge systems' negotiations and changes back to the different facility types that different knowledge competitions and combinations encourage and discourage.

Below I describe three important knowledge system challenges that are exposed by the eco-techno spectrum. Comparative case studies explored throughout Chapters 2, 3, and 4 look for evidence of these challenges and explore how each is negotiated in both Portland and Baltimore. 


\section{Emergent Knowledge System Challenges}

\section{Definitional Challenges}

The hybrid biological/mechanical make-up of green infrastructure facilities do not fit neatly into the jurisdiction of any one municipal department or agency. The divergent goals and missions of these managing authorities has led to differing definitions of green infrastructure facilities and components across, and even within, cities. Therefore, the development of cohesive city-wide green infrastructure strategies (including development of facility design, implementation, and maintenance standards that work with existing landuse plans) is not straightforward; it requires the negotiation and reconciliation of multiple nascent knowledge practices and work-arounds found across cities and across city bureaus and departments.

Definitional challenges stem from ontological tensions within green infrastructure development; in particular the categorization of what is natural and what is human. This observation builds off a robust literature that explores the social construction of 'nature' and 'ecology' as something separate from humans (Katz 1997; Cronon 1992; Worster 1990): "What is considered natural and what constitutes nature changes historically and culturally...[O]ur view of nature has more to do with the society we live in than with an objective 'nature'; in other words, nature is a social construct." (Hartmann 1998)

Few contemporary urban concepts expose this ontological tension between the natural and the human better than green infrastructure. While the specific definition of green infrastructure varies from place to place (Mell 2013), green infrastructure is generally understood as networked green spaces that provide ecosystem services (Millennium 
Ecosystem Assessment 2005) to human populations and provide contiguous habitat for non-human nature. Depending on the institution, however, the services and facilities included in the definition of "green infrastructure" can be quite different. For example, Benedict and McMahon's (2006) highly cited definition of green infrastructure stresses the importance of conservation of natural areas:

...green infrastructure is...an interconnected network of green space that conserves natural ecosystem values and functions and provides associated benefits to human populations. (Benedict and McMahon 2006, p. 5)

These authors and those that cite them (primarily environmental non-profits and ecologists) claim that the primary service provided by green infrastructure is natural ecosystem function and protection, while the benefits to human populations are secondary. From this perspective, green infrastructure is described as a win-win land-use solution that helps both humans and the environment, but with an explicit focus on environmental gains. To these groups, green infrastructure represents preserved/conserved/restored nature.

Regulatory institutions like the U.S. EPA, instead, focus on the stormwater management benefits of green infrastructure systems and are often agnostic to the natural character of facilities, allowing engineering solutions to be a major component of the concept:

Green infrastructure is a cost-effective, resilient approach to managing wet weather impacts that provides many community benefits... At the neighborhood or site scale, stormwater management systems that mimic nature soak up and store water. (EPA 2015)

Cost-effectiveness and resilience in addressing regulatory compliance issues are upfront in definitions from institutions like these, with habitat benefits a happy secondary outcome. 
Facilities within this framing mimic the functions natural systems offer with engineering/grey solutions, rather than creating facilities through restoration or conservation of ecosystems. This win-win land-use solution emphasizes technology over the environment. To these groups, green infrastructure is human.

\section{Measurement Challenges}

Green infrastructure facilities rely on multi-faceted ecological functions that result from the combination of biological actors, instead of narrowly-defined and precisely measured physical functions that result from well-understood mechanical combinations of grey infrastructure components. In many cases, the combination of ecological entities in facilities is novel (Hobbs, Higgs, and Harris 2009; Kaye et al. 2006), meaning current ecological theory may not apply to the size and composition of the community assembled in a green infrastructure facility. This reliance on new and unpredictable ecological structure and function makes it difficult to measure or predict the performance of green infrastructure facilities, complicating estimates of total service delivery.

This challenge stems primarily from an epistemological tension within green infrastructure development. Different epistemic communities measure services in different, sometimes conflicting, ways (Haas 1992). Essentially, "an epistemic community is a network of professionals with recognized expertise and competence in a particular domain and an authoritative claim to policy-relevant knowledge within that domain or issue-area" (Haas 1992). For example, engineers represent an epistemic community which has strong 
"authoritative claim" over the knowledge relevant to infrastructure performance, and the services that a particular infrastructure is meant to provide.

Knowledge systems analysis is particularly important to apply to the discretionary utilization of ecological knowledge claims within green infrastructure technologies because of the hybrid epistemologies (Wilson 2009; Burnham, Ma, and Zhang 2016) that must be formed to design, build, and manage these facilities. Hybrid knowledge practices allow the particularities of the green knowledge systems (i.e. their engagement with ecological structure and function) to 'fit' in a traditional grey knowledge system. These new practices present challenges to existing institutional structures and their knowledge systems, and create new barriers to specific ecosystem services (i.e. the focus on water quantity management puts the emphasis on amplifying this function at the expense of other important benefits like nutrient cycling, recreation, and air filtration, among many others.) As Bowker and Star (1999) put it, "each standard and each category" - a knowledge practice or epistemology in the case of this dissertation - "valorizes some point of view and silences another. This in not inherently a bad thing - indeed it is inescapable. But it is an ethical choice, and as such is dangerous - not bad, but dangerous" (p. 5-6). We need to be explicit about what and who is being silenced by current green infrastructure knowledge systems to better understand and predict facility performance on-the-ground.

\section{Valuation Challenges}

Current infrastructure valuation and asset management in cities is based on the cost and maintenance of mechanical components of traditional grey infrastructure, including 
pipes, pumps, wells, and mechanical filtration systems. Biological entities are not easily valued with existing techniques, making green infrastructure facilities difficult to integrate into business-as-usual asset management and financialization at the municipal, state, and federal level.

Valuation is as a specific case of both the challenges described above: financial entities do not categorize biological components as infrastructure, and have limited ways to measure biological components even if they want to categorize them as infrastructure. I draw out valuation as a separate challenge because valuation emerged as a major decisionmaking point within green infrastructure planning throughout case study work. The City of Portland is openly struggling with valuation of green infrastructure; and many other cities are asking Portland how they include green infrastructure in asset management, indicating that they struggle with similar issues. This makes valuation (monetary and otherwise) an excellent exposed decision-making process that can be used to explore the other two challenges (explored in detail in Chapter 3).

\section{$\underline{\text { Conclusion }}$}

While most urban infrastructures have faded into the background of daily life as "certain, cold, unproblematic, black box[es]" (Latour 1987), the three knowledge systems challenges described here expose green infrastructure as a knowledge system 'in the making'; unlike now well-established ecological-technological hybrid infrastructures, like wastewater treatment plants (Schneider 2011), the messy political decisions of definition and measurement are openly contested. By studying green infrastructure, then, I follow 
Latour's lead: "The impossible task of opening the black box is made feasible (if not easy) by moving in time and space until one finds the controversial topic on which scientists and engineers are busy at work" (Latour 1987). Measurement, definition, and valuation of urban nature is where scientists and engineers are in uncertain territory and are actively making decisions about open controversies of ecological fact. It is where I can observe and analyze the production and use of ecological knowledge by different epistemic communities, providing insight into deeply held ontologies of municipal actors that are usually hidden during business-as-usual infrastructure design and implementation processes.

In summary, all three of these green infrastructure challenges display the usefulness of knowledge systems analysis as an analytical tool for understanding the feedback loops between social and material reality. As Jasanoff (2004) says, "our methods of understanding and manipulating the world curve back and reorder our collective experience along unforeseen pathways..." (p.13). Knowledge systems analysis begins to expose and characterize these pathways so they can be designed more openly and more sustainably. 


\section{Chapter 2}

\section{Comparison of knowledge systems supporting green infrastructure in Portland and Baltimore: differentiation across the eco-techno spectrum}

\section{$\underline{\text { Introduction }}$}

Urbanity is dynamic; the city is constantly changing as old buildings are retrofit or demolished and streets accommodate new modes of transportation over the course of decades; businesses thrive and dwindle year-to-year; and daily washing, sweeping, and shopping circulates provisions and wastes in and out of homes and bodies (human and nonhuman alike). Different conceptualizations of these giant, many-faceted systems we call cities focus popular and expert attention on different system components and scales framing new social, ecological, and technological problems and pointing towards different solution sets.

One way to analyze these conceptions of the city is as knowledge systems, or the norms, protocols, and practices where knowledge claims about how the city works are produced, vetted, and put to use in decision-making. While this processing of knowledge claims happens in all arenas of social life, this dissertation focuses specifically on this process within municipal institutions and expert-dominated spaces. It is important to better understand the knowledge systems underpinning municipal decision-making because these practices influence the solutions that are deemed appropriate to solve pressing urban problems. Potentially useful knowledge claims from alternative knowledge systems may be inadvertently dismissed from the decision-making process because the established knowledge system is unable to produce or vet them. As Munoz-Erickson (2014) explains, 
...even when new knowledge is created that can support novel solutions, this knowledge may not proceed to be used in the political process because there are other already established and powerful knowledge systems informing the policy process as well (e.g. use of economic indicators in state planning agencies). Moreover, assumptions about what knowledge is more credible in decisionmaking can ultimately affect how well we understand the dynamics of the system under study (e.g. ecosystems). (Munoz-Erickson 2014, p. )

In the case of green infrastructure, knowledge claims about the definition, measurement, and value of urban nature are often different and sometimes incommensurate across the institutions with emergent responsibility for managing green infrastructure facilities. This leads to contestation over the design, implementation, and maintenance of green infrastructure. These contestations shape the system and its outcomes on-the-ground. For example, consider the difference between two municipal departments and their metrics of interest: The water storage capabilities of soils in natural areas is important to sewer utilities trying to keep stormwater runoff out of pipes and people's basements. However, the soil nutrient content of natural areas is important to Parks and Recreation departments trying to keep native plants thriving to meet biodiversity goals. Designing, measuring, and valuing natural areas for specific soil infiltration rates and water retention potentials overlooks soil nutrient content needs. In some cases, focus on infiltration rate alone can lead to negative nutrient effects (i.e. leaching of nutrients leading to limited plant growth and eutrophication issues further downstream). But focus on a single function or parameter is what typically happens in management.

In this chapter, I introduce the knowledge systems uncovered in both Portland and Baltimore that are supporting green infrastructure design, implementation, and maintenance. I explore the challenges that these knowledge systems face and the 
institutional changes (structural and otherwise) that have emerged to deal with these challenges. I look at two broad categories of knowledge system challenges - namely, definitional and measurement challenges - that I anticipated a priori from initial examinations of green infrastructure literature and practice (see Chapter 1 for more detail on each knowledge challenge). Within each of these categories, infrastructure maintenance and regulatory concerns emerged as powerful themes.

Each category of challenges is entangled in ontological and epistemological conflicts of meaning and identity between different disciplines and institutions involved in green infrastructure development (as the example above of soil characteristics displays). Using examples in both Portland and Baltimore, I will show how the wide variety of facility types encompassed by the eco-techno spectrum (developed in Chapter 1) exacerbates these conflicts, but also how opportunities for more holistic infrastructure planning and implementation might be possible by embracing the entire eco-techno spectrum.

First, I review the research questions engaged in this chapter and then describe the comparative case study methods undertaken to answer them. Next, I present the comparative results of this investigation and conclude with an exploration of the knowledge systems and eco-techno spectrum connections across and between these results.

\section{$\underline{\text { Research Questions }}$}

This chapter seeks to examine green infrastructure knowledge systems. As little is known about the emerging epistemologies of green infrastructure, my research questions begin by working to identify and understand what knowledge systems are supporting and 
interacting with green infrastructure development. First, I ask: How do different institutions 'know' green infrastructure? This entails examining what knowledge claims are being used to define, measure, and value green infrastructure within different institutions; and how these knowledge claims are generated, vetted, and/or contested within and between institutions. I then ask, what new knowledge practices are created to address knowledge contestations and challenges? These new knowledge practices (e.g. protocols, norms, subinstitutions, communication strategies, etc.) shape investments in, and therefore outcomes of, facilities on the ground. Finally, I use comparative work to answer the question: How do green infrastructure knowledge systems in Portland and Baltimore compare?

\section{$\underline{\text { Contributions }}$}

Within the urban planning literature, there is a call to improve decision-making spaces. Through a more rigorous understanding of the knowledge systems challenges, blind-spots, and path dependencies inherent in policy-making arenas, there is an opportunity to learn and design processes that take into account more varied ways of knowing the world, increasing inclusion (Booher and Innes 2010) and ultimately resilience of governance (Goldstein 2012).

In particular, the knowledge systems' literature calls for the design of knowledge systems to support desirable framing concepts like 'sustainability' and 'resilience.' Cash et al. (2003) call for an analysis of the structure of knowledge systems for sustainability: "How...knowledge systems for sustainability can best be structured remains a question for scholarly research, practical experimentation, and comparative learning" (p. 8090). 
Scholars have answered this call to action in different ways (Munoz-Erickson 2014), but there remains a lack of 'comparative learning' within such research spaces.

Increased comparative learning regarding different structures for knowledge systems that support sustainability is the gap in the literature that this chapter begins to fill. I focus on the structure of a particular (potentially) sustainable knowledge system - the green infrastructure knowledge system - and through comparative case studies look for useful institutional structures, protocols, and other knowledge claim generating, legitimating, and employing practices that provide effective design, implementation, and maintenance strategies for green infrastructure networks. Surprisingly, each of these different infrastructure processes (i.e. design, implementation, and maintenance) are often disconnected and the knowledge systems supporting one process may not be called upon in another. This means that effective green infrastructure is not always realized in cities even though parts of the system may be functioning quite well.

Through this work, I also seek to contribute to the urban planning literature, albeit indirectly, that seeks to improve inclusion at the decision-making table. Communicative planning concepts and practices (Healey 1997; Friedmann 1993) can be viewed as knowledge systems working to overcome the knowledge challenges of effectively bringing together the multiple ways of knowing the city. Ultimately, the study of municipal knowledge systems has something to say about the role of planners as mediators (Susskind and Ozawa 1984), illuminating the ways "they are organizers (or disorganizers) of public attention" (Forester 1982). 
In the next section I contextualize the development of green infrastructure in both Portland and Baltimore using social, ecological, and technological similarities and differences of each, before describing the research design and methods employed in this chapter in subsequent sections.

\section{$\underline{\text { Case Context }}$}

To increase comparative learning about knowledge systems supporting green infrastructure, I conducted in-depth comparative analysis of two cities in the U.S: Portland and Baltimore. Municipal institutions in both cities have been involved with green infrastructure ideas for 20+ years: Baltimore has been a part of robust Low Impact Development (LID) programs at the state level since the late 1990s initiated primarily by Chesapeake Bay pollution concerns, while Portland began implementing a number of different green infrastructure techniques city-wide in 1991 in response to combined sewer overflow (CSO) violations.

These two cities are appropriate for comparison because, while they have both been working with green infrastructure ideas for a long time, they represent two very different social-ecological-technical (SET) contexts (Redman and Miller 2015; Ramaswami et al. 2012; McPhearson et al. 2016), allowing me to examine these contextual influences on green infrastructure knowledge systems development. For example, socially, while Portland has been growing consistently and gentrifying its inner city areas, Baltimore has experienced 'white flight' and declining populations, with more than 16,000 abandoned houses and 14,000 vacant lots in 2013; ecologically, while Portland and Baltimore receive 
similar amounts of total rainfall, Baltimore receives rain in much more intense storms, whereas Portland has a more consistent, low-volume rainfall throughout the winter months (however, this is changing, see Cooley and Chang (2017)). Table 2-1 below shows a sideby-side comparison of different social, ecological, and technological aspects of each city. A more detailed description of each city follows in the next two sections.

Table 2-1: Case city summaries, highlighting two long-term programs in different social, ecological, and technical contexts

\begin{tabular}{|c|c|c|}
\hline CONTEXT & Baltimore & Portland \\
\hline \multicolumn{3}{|l|}{ SOCIAL } \\
\hline Population & 622,793 & 619,360 \\
\hline African American & $63 \%$ & $6 \%$ \\
\hline White & $31 \%$ & $76 \%$ \\
\hline Median Income & $\$ 41,385$ & $\$ 52,657$ \\
\hline \multirow[t]{2}{*}{ Growth } & $\begin{array}{l}\text { Shrinking city with large amt of } \\
\text { vacant and abandoned lots }\end{array}$ & $\begin{array}{l}\text { Growing city with increasing housing } \\
\text { market pricing out many residents }\end{array}$ \\
\hline & $\begin{array}{l}\text { High poverty rates and racial } \\
\text { segregation }\end{array}$ & $\begin{array}{l}\text { Large and growing homeless } \\
\text { population }\end{array}$ \\
\hline \multicolumn{3}{|l|}{ TECHNOLOGY } \\
\hline Sewer system & $\begin{array}{l}\text { Separated storm and sanitary } \\
\text { sewer }\end{array}$ & $\begin{array}{l}\text { Combined storm and sanitary sewer } \\
\text { (some areas separated sewer) }\end{array}$ \\
\hline \multicolumn{3}{|l|}{ REGULATIONS } \\
\hline $\begin{array}{l}\text { National pollutant } \\
\text { discharge } \\
\text { elimination } \\
\text { system (NPDES) }\end{array}$ & $\begin{array}{l}\text { MS4 } \\
\text { SSO program }\end{array}$ & $\begin{array}{l}\text { MS4 } \\
\text { CSO program }\end{array}$ \\
\hline $\begin{array}{l}\text { EPA Consent } \\
\text { Decree }\end{array}$ & 2002 & 1991 \\
\hline TMDLS & $\begin{array}{l}\text { Trash, Nitrogen, Total } \\
\text { Suspended Solids (TSS) }\end{array}$ & $\begin{array}{l}\text { Phosphorus, Total Suspended Solids } \\
\text { (TSS) }\end{array}$ \\
\hline \multicolumn{3}{|l|}{ ECOLOGICAL } \\
\hline Avg precipitation & 41.9 " in 116 days & $43.5 "$ in 164 days \\
\hline Rainfall patterns & $\begin{array}{l}\text { Short, intense } \\
\text { rainstorms/thunderstorms }\end{array}$ & Continuous, low intensity rainfall \\
\hline Biome & Temperate Forest & Boreal Forest \\
\hline
\end{tabular}




\section{Portland}

The City of Portland has a reputation for 'being green'. Other case studies highlight Portland's 'political will' to work for sustainability as a driving factor of green infrastructure development (WERF 2009). Strong leadership and policy champions within city bureaus and citizen groups allowed green infrastructure options to be on the proverbial decision-making table when the city's CSO Program was developed even though green infrastructure was not popular nationally, nor endorsed by the EPA at that time (Nelson 2011; WERF 2009). Also, as a growing city, Portland's stormwater management manual has triggered an extensive amount of green infrastructure to be built on private property by requiring new development to deal with up to $50 \%$ of stormwater run-off onsite (SWMM 2015). However, much of the private development has been unevenly distributed across the city (Zavestoski and Agyeman 2015). In east Portland, where most streets lack sidewalks, bioswales in particular stick out as strange and ugly facilities that residents do not understand, or worse, actively oppose (Everett et al. 2015).

Portland has been altering its approach to stormwater infrastructure for over 25 years, beginning in earnest in 1991 with the initiation of a 20-year combined sewer overflow (CSO) program; staff refer to the advent of green infrastructure in the city as a "sea change" in thinking about sewer and water systems in the city (Nelson 2011; Portland's CSO Program 1991-2011 2011). The City of Portland has built over 2,000 bioswales throughout the city (facilities that fall on the 'techno' side of the eco-techno spectrum introduced in Chapter 1) and established a willing-seller program to restore connectivity to large portions of urbanized floodplain (a facility that falls on the 'eco' side 
of the green infrastructure spectrum). The CSO program has focused most of Portland's green infrastructure facilities on providing stormwater management services over any other potential ecosystem services.

\section{Baltimore}

Baltimore is located on the Chesapeake Bay, a region that has struggled with water quality issues from urban and agricultural run-off. The concept of Low Impact Development (LID), a development-friendly approach to green infrastructure design, emerged out this region in response to these water quality issues (Weinstein 2008). In 1998, the Low Impact Development Center was created in Maryland as a non-profit resource for developers needing to address run-off more effectively. At the state level, Maryland was involved in mapping green space for comprehensive planning purposes (Weber and Wolf 2000; Weber, Sloan, and Wolf 2006), which meant that City of Baltimore had access to state-of-the-art maps of greenery in their city even in the early 2000's. More sophisticated mapping would come along later, which the Chesapeake Bay Conservancy recently used to estimate Baltimore's urban forest canopy cover at $28.3 \%$ with $50 \%$ of the city being green space over all (“Green Infrastructure Report: Baltimore City” 2015).

Unlike Portland, Baltimore is a shrinking city; vacant and abandoned property is a substantial issue (Schilling and Logan 2008). As the 2015 Green Pattern Book states, there were over 16,000 abandoned houses and 14,000 vacant lots in the City of Baltimore in 2013 (Baltimore Department of Planning, Office of Sustainability 2015). Much of the green infrastructure planning efforts in the city have therefore been focused on these areas 
of blight, rather than stormwater management which has been the focus in Portland and other cities. (Baltimore's anomalous completely separated sewer system also means that green infrastructure for mitigating CSOs is not a driver in the city.) The Vacant Lot Opportunities Analyst was recently created with high-resolution maps of Baltimore to "provide information and inspiration for individuals and groups looking to redevelop vacant lots in their community" (“Green Infrastructure Report: Baltimore City” 2015). Many of the redevelop options provided by this tool expand the green infrastructure network (these facilities tend to fall on the 'techno' side of the green infrastructure spectrum).

Non-profit and federal government organizations in Baltimore have recently partnered with the city to address a number of environmental issues. In 2013, restoration of Masonville Cove was designated as the first Urban Wildlife Refuge by US Fish and Wildlife (representing a facility on the 'eco' side of the eco-techno spectrum), allowing a number of conservation programs to come into effect. In 2014, the City's Growing Green Initiative was launched, and in 2015 the Greater Baltimore Wilderness Coalition was formed. Each of these programs encourages green infrastructure development at all points along the eco-techno Spectrum to be built in Baltimore.

\section{$\underline{\text { Methods }}$}

I answered my research questions regarding green infrastructure knowledge systems in Portland and Baltimore using a mixed methods research design. I began with qualitative discourse analysis of green infrastructure plans and policies in both cities, 
followed by in-depth interviews with municipal staff and staff at NGO organizations that closely partner with the city. Figure 2-1 below shows the methods employed in this chapter in the context of the overarching research design of this entire dissertation; the methods employed in this chapter are highlighted in green.

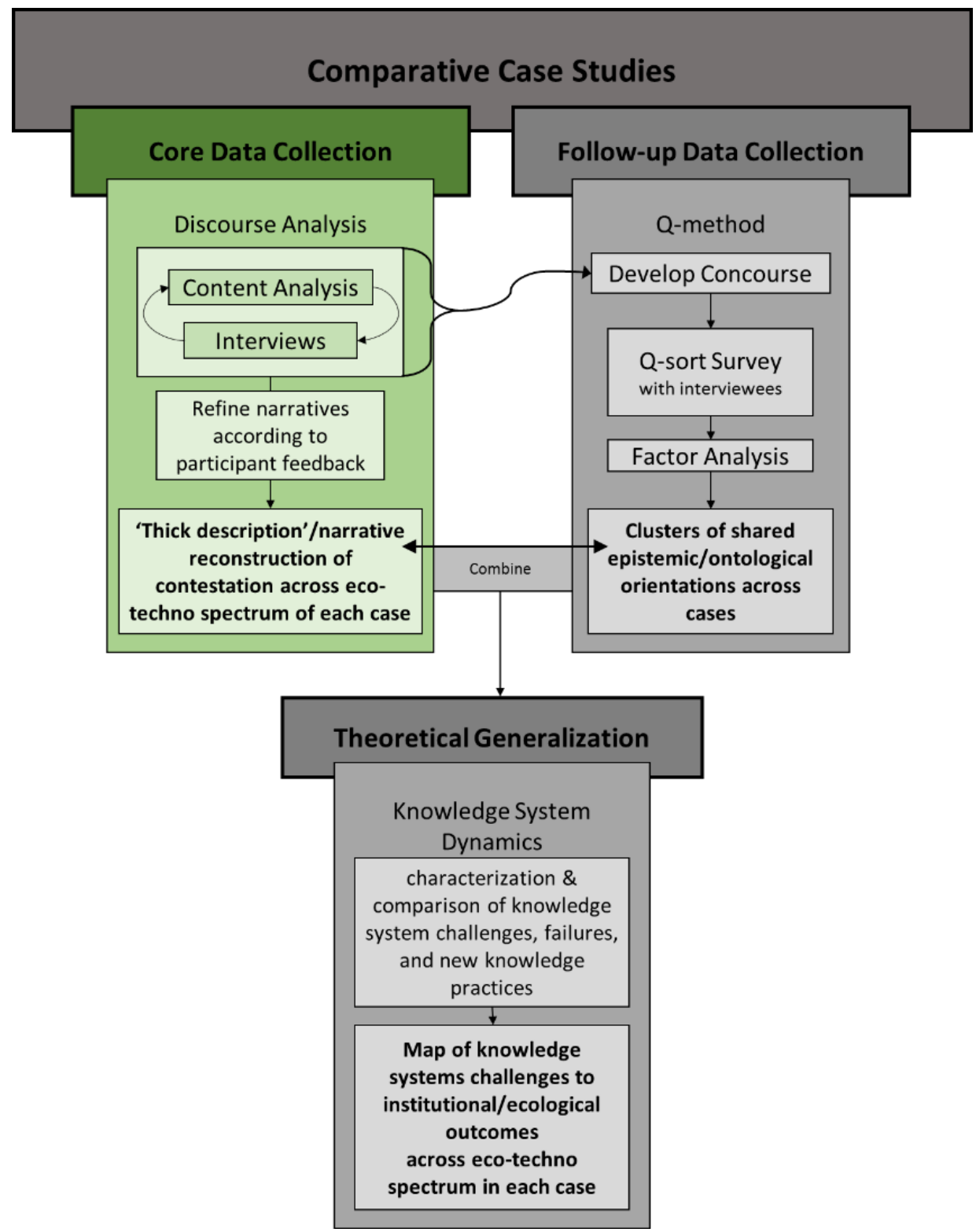

Figure 2-1: Overarching dissertation research design; Chapter 2 (this chapter) methods highlighted in green 


\section{Comparative Case Studies}

Case studies are useful in research situations in which "(1) the main research questions are "how" or "why" questions; (2) a researcher has little or no control over behavioral events; and (3) the focus of study is a contemporary (as opposed to entirely historical) phenomenon" (Yin 2014). In this dissertation (1) I ask how knowledge claims about nature were used in municipal-level infrastructure development; (2) I am unable to control for a vast majority of the events occurring in green infrastructure development at present; and (3) green infrastructure is a currently emerging phenomenon across the US, making it contemporary.

Additionally, case study research is well suited to examining "operational links needing to be traced over time" in regard to an ambiguous phenomenon, which differs from research which seeks to find the frequency or incidence of a well-defined phenomenon (Yin 2014). As an emerging planning practice, with contested and shifting meaning (Lennon 2015; Mell 2013; Wright 2011)(also see chapter 1), green infrastructure is an excellent topic for case study research of this kind; I looked for "operational links" between knowledge systems and infrastructure design, implementation, and maintenance in each case.

Finally, context is extremely important in case study research; phenomena are observed within their "real-world context" (Yin 2014), rather than in controlled environments where there is an attempt to remove all contextual influences, as is done in some empirical scientific research. This makes case study research particularly useful when the "boundaries between phenomenon and context may not be clearly evident" (Yin 2014). 
The tight coupling of context and the phenomenon of green infrastructure development then also makes this dissertation topic well-suited to case study methods.

A robust case study design requires a clearly defined unit of analysis and a careful bounding of the case (Yin 2014). In this dissertation, the cases examined are institutions, specifically municipal level departments and local nonprofit organizations that design, implement, and/or maintain green infrastructure facilities. This dissertation examines the production and use of knowledge claims about urban nature within these institutions in both Portland, OR and Baltimore, MD with each city's constellation of institutions acting as a case within a multiple-case study design. The cases are therefore bounded geographically (by their location in cities in different parts of the country) and sociopolitically (by specifying municipal-level departments and non-profit organizations involved in green infrastructure management).

Multiple-case study design helps this research distinguish between context and phenomenon. Examining what holds across contexts and what is variable across contexts can expose potential general use of new knowledge practices by institutions from casespecific use. It is important to note the meaning of "general findings" in this dissertation, especially because this dissertation is addressed to an interdisciplinary audience. Yin (2014) states, "in doing case study research, your goal will be to expand and generalize theories (analytic generalizations) and not to extrapolate probabilities (statistical generalizations)" (p. 21). Therefore, this dissertation compares across cases to see what theoretical constructs of knowledge systems dynamics hold, and where they differ, rather 
than generalizing findings to "extrapolate probabilities" of green infrastructure particulars across cities.

\section{Discourse Analysis}

The primary analytical tool used within comparative case studies in this dissertation is discourse analysis, which incorporates the specific methods of content analysis, in-depth interviews (Chapter $2 \& 3$ ), and Q-sort surveys (Chapter 4). Discourse is defined in this dissertation as "an ensemble of ideas, concepts and categories through which meaning is given to social and physical phenomena, and which is produced and reproduced through an identifiable set of practices" (Hajer and Versteeg 2005, p. 175). This type of analysis is particularly useful in understanding environmental decision-making. As (Hajer and Versteeg 2005) explain,

...it is not an environmental phenomenon in itself that is important, but the way in which society makes sense of this phenomenon. Dying forests do not contain in themselves the reason for the public attention and concern they receive. The fact that they do receive this attention at a specific place and time cannot be deduced from a natural-scientific analysis of its urgency, but from the symbols and experiences that govern the way people think and act (p. 176).

The institutional framing of urban nature is then treated here as the important "symbols and experiences that govern the way people think and act" regarding green infrastructure. Discourse analysis can illuminate the "multiplicity of forms of knowledge" present in the green infrastructure design and implementation process, and reveal the impact of “competing expert knowledges" (Brand \& Karvonen 2007, p. 23) regarding urban nature embedded within green infrastructure decision-making. This is key to understanding the epistemic and ontological tensions between different knowledge types working at the 
municipal level. As Knorr-Cetina points out, "to discover practices, it is 'necessary to gain a working familiarity with the frames of meaning' within which people enact their lives, and symbolic doings such as rituals or 'writings' are as much practices as any others" (p. 364). Green infrastructure knowledge systems are therefore explored through discourse analysis of green infrastructure plans and policies as well as interviews and site visits.

Additionally, there is an increasing number of empirical engagements with discourse analysis:

It is...crucial to show how the concepts and methods of discourse analysis can be 'operationalized' in meaningful ways, that is, it is important for discourse analysts to apply their abstract theories and concepts to empirical research questions so as to produce novel interpretations, and show the 'added value' of their studies in understanding and explaining the social world (Howarth 2000, p. 2).

My dissertation adds to this body of literature, by operationalizing discourse analysis in the critical examination of green infrastructure development, an active policy arena in cities today.

Finally, discourse analysis is useful because of its potential to be transformative. Howarth (2000) describes one of the goals of discourse analysis as "locat[ing]...investigated practices and logics in larger historical and social contexts, so that they may acquire a different significance and provide the basis for a possible critique and transformation of existing practices and social meanings" (p. 129). Through an analysis of the discourse surrounding green infrastructure development in Portland and Baltimore, I illuminate currently implicit unsustainable knowledge practices and provide potential alternative pathways towards more sustainable green infrastructure programs in the future. 


\section{Content Analysis}

I reviewed the publicly available green infrastructure planning, design, implementation, and maintenance documents in both Portland and Baltimore listed in the Table 2-2. I initially sought out documents that 'self-identified' their association with green infrastructure though online searches for the "green infrastructure." Additional documents were recommended by interviewees or were cited in original documents reviewed.

Table 2-2: Plans, policies, and reports reviewed in each case study city

\section{Documents reviewed}

City of Portland

Stormwater Management Manual (SWMM)

Watershed Management Plan

Grey to Green Initiative Benefits Report - Portland's Green Infrastructure:

Quantifying the Health, Energy, and Community Livability Benefits

Stormwater Stars (handouts)

2015 Citywide Asset Report

\section{City of Baltimore}

City of Baltimore and USFS, Green Pattern Book

State of Maryland Stormwater Design Manual Volumes I \& II

Green Network Plan (website and handouts)

MS4 and TMDL Watershed Implementation Plan (WIP)

Blue Water Baltimore 2014 Annual Report

I identified three themes a priori that I used to begin the content analysis; as

described in Chapter 1, each is useful in the characterization of the knowledge systems dynamics at work in each case. The three themes are: definitions, metrics, and values. Specifically, I looked for the elements listed in Table 2-3.

All content analysis followed the procedures described in Chenail (2012) regarding the unit of analysis when performing a qualitative review of text, whether an interview 
transcript or a report. Chenail (2012) argues that content analysis should not be concerned with each line of text as “...a line of text might not constitute a suitable, undivided entity or whole to analyze qualitatively" (Chenail 2012). Instead a researcher should focus their attention on extracting codes from concepts and thoughts that may appear in single paragraphs or groups of paragraphs.

Table 2-3: A priori codebook for document content review

\section{Definitions of green infrastructure}

Facility types described as green infrastructure

Services assumed to be provided by green infrastructure facilities

Green Infrastructure Performance Metrics

Types of services measured by the metrics

Regulations dictating specific metrics/methods

Disciplines responsible for collecting data

\section{Valuation of green infrastructure}

Economic valuation methods used to justify green vs grey

Explicit values referenced

Facility financing mechanisms

Ecosystems services assessments (explicit and implicit)

Interviews

I conducted interviews with municipal staff, as well as with local non-profit and private firm staff, who self-identified as being involved in green infrastructure in some way in each of the case study cities. In Portland, I connected with a number of staff through participation in previous green infrastructure research projects, and I conducted preliminary focus groups and interviews in the city prior to undertaking dissertation research; some snow-ball sampling proceeded from this initial group of interviewees. In Baltimore, I relied on academic colleagues within the UREx SRN and Baltimore 
Ecosystem Study to connect me with relevant municipal staff and snow-ball sampled from this original set of seeded interviewees.

Interviews were semi-structured, with some over-arching questions developed from content analysis of municipal plans and other document review; these questions were asked of all participants. Additional questions were tailored to each staff members' position and job title to better understand their specific role in green infrastructure management. Introduction and wrap-up questions were open-ended to allow interviewees to describe green infrastructure definitions, metrics, and values in their own words. (See Appendix A for the interview guide used.)

All interview audio was transcribed by a $3^{\text {rd }}$ party transcription service. I reviewed each transcription for accuracy by listening to interview audio during my first read-through of each transcription. This also allowed me to hear specific intonation and other verbal cues that could be misinterpreted when reading the text only.

Interviews were analyzed within ATLAS.ti, a proprietary qualitative analysis software, using the content analysis methods listed above. The same a priori themes developed for document review (listed in Table 2-3) were used to seed the initial content analysis of interviews. Additionally, qualitative coding methods developed by Friese (2014) for use in ATLAS.ti were employed to structure the coding process. Over 500 additional, emergent codes were generated and then consolidated through the coding process, revealing important themes not originally hypothesized. See Appendix B for a complete, final codebook. 


\section{$\underline{\text { Results }}$}

I will discuss the results of the discourse analysis portion (or the core qualitative portion displayed in Figure 2-1) of my mixed methods research design in this chapter (and also in Chapter 3). These results are derived from qualitative analysis of in-depth interviews, with some supporting evidence from document analysis of policies, plans, and reports in both case study cities (listed in Table 2-2).

First, I report the characteristics of study participants in both Portland and Baltimore. Next, I describe the regulatory context that I found in each city; interactions with state and federal level water pollution standards differentiated the two cases in many ways and influenced green infrastructure definitions and metrics. I will then report the findings of each theme - Definition and Measurement - separately. (Findings regarding Valuation are presented in Chapter 3). I organize each thematic area by presenting 1) the variety of responses I received across both cases using the eco-techno spectrum as a platform to organize the institutional structures and protocols discussed; 2) the knowledge system challenges brought up in each theme; and 3) any changes or work-arounds that interviewees mentioned regarding each thematic area. Maintenance concerns were brought up in regard to all thematic areas and will be a discussed in each as a cross-cutting challenge. I report the primary descriptive findings in this section of the chapter, and expand on knowledge systems analysis with these findings in the subsequent discussion section. 


\section{Participants}

I conducted 42 interviews total: 23 interviews in Portland and 20 in Baltimore. Because the primary focus in this dissertation is on the knowledge systems of municipal government institutions, the majority of my interviews were with city staff. As shown in Table 2-4, all of my interviews in Portland were conducted with city staff at the various bureaus involved with green infrastructure management. While I also interacted with 2 private consultants and 3 non-profit staff in Portland, I did not complete formal interviews. Most design, implementation, and maintenance of green infrastructure facilities, and the knowledge production supporting those actions, is done in-house in Portland (discussed in more detail in the next section) and private firms and NGOs were not mentioned by city staff in Portland during interviews when discussing green infrastructure programs. Therefore, I felt confident confining my interviews to city staff.

In contrast, as shown in Table 2-4, I interviewed 8 local NGO staff in addition to 10 municipal staff involved in green infrastructure in Baltimore. It was necessary to expand interviews outside of city staff in Baltimore because most of the green infrastructure design, implementation, and maintenance is conducted by NGOs. These non-profit groups increasingly work in collaboration with the city. In every interview I conducted with municipal staff in Baltimore, at least one non-profit (and usually upwards of three) was mentioned as an instigator, an implementer, or a partner in green infrastructure development; therefore I was confident in including multiple NGOs in my Baltimore case study. Two additional interviews were also conducted with private consultants who were recommended by NGO staff who work closely with private firms to design facilities. 
Table 2-4: Breakdown of interviewees by city and professional role

\section{Participants Role Baltimore Portland}

\begin{tabular}{|c|c|c|}
\hline City institutions & & \\
\hline $\begin{array}{l}\text { Portland Bureau of Environmental } \\
\text { Services (BES) / Baltimore } \\
\text { Department of Public Works } \\
\text { (DPW) }\end{array}$ & 4 & 11 \\
\hline $\begin{array}{l}\text { Portland Parks \& Recreation / } \\
\text { Baltimore Recreation \& Parks }\end{array}$ & 3 & 4 \\
\hline $\begin{array}{l}\text { Portland Bureau of Planning and } \\
\text { Sustainability (BPS) / Baltimore } \\
\text { Dept of Planning, Office of } \\
\text { Sustainability }\end{array}$ & 3 & 2 \\
\hline Portland Water Bureau & 0 & 1 \\
\hline $\begin{array}{l}\text { Portland Office of Management } \\
\text { and Finance (OMF) }\end{array}$ & 0 & 5 \\
\hline NGOs & 8 & 0 \\
\hline Private companies & 2 & 0 \\
\hline Total \# of Participants & 20 & 23 \\
\hline
\end{tabular}

Regulatory Context

Regulations were discussed at length by participants in both cities as important drivers and constraints of green infrastructure development. While federal level regulations stemming from the Clean Water Act (CWA), primarily CSO/SSO programs and TMDLs, are discussed in much of the literature around green infrastructure (Montalto et al. 2007; Finewood 2016), important differences in state-level guidance and leadership were found between these comparative cases. First, I will outline the federal level push observed, which echoes established green infrastructure literature, and then I present the unique statelevel findings of this research. 


\section{Federal level}

First, federal regulatory pressures are quite different between Portland and Baltimore; this is due primarily to the simple difference in sewer system technology in the two cities. Portland has primarily a combined sewer system, meaning that sanitary and stormwater sewer pipes are one in the same, all leading to the wastewater treatment plant. When heavy rain events occur, this combined system can become overwhelmed and combined sewer overflows (CSO) occur; raw sewage and untreated stormwtaer overflows directly into surface water bodies like the Willamette River, creating conditions that violate Portland's National Pollutant Discharge Elimination System (NPDES) permit, putting the city in violation of the CWA.

In contrast, Baltimore has a completely separated sewer system. After a massive fire in 1907, the city had to rebuild most of its infrastructure and opted for a separated sewer system. This means that the stormwater flows, untreated, directly into surface water bodies like the Chesapeake Bay, while sanitary sewer flows separately to the wastewater treatment plant. A separated sanitary sewer also experiences overflows, SSOs, when it becomes clogged with fats, oils, and grease (FOG) or when rainwater leaks into old, cracked pipes, overwhelming the system.

Both separated and combined systems have their pros and cons. Combined sewers have the advantage of treating stormwater at wastewater treatment plants before it is released into surface waters. But combined systems are often overwhelmed by rainstorms as populations and hardscape expand and climate change intensifies storm events. Separated systems have the advantage that they are less prone to overflows but stormwater 
usually flows untreated into surface waters, exacerbating the non-point source pollution problem in cities.

In the current and recent regulatory climate, a combined system is a huge liability. The EPA has been enforcing permit violations across the country. In 1991, Portland was issued a Stipulation and Final Order (SFO) by the Oregon DEQ to reduce CSOs by over 90\%. This began the 20-year CSO Program which was completed in 2011.

The CSO Program was the initial driving force of Portland's green infrastructure program, giving it a huge regulatory push of funding and staff hours. Baltimore on the other hand, did not have such a push. Instead, SSO violations were addressed by the EPA in 2002 with a consent decree. Because different services were needed to prevent CSOs than SSOs, green infrastructure was not as useful to Baltimore's program. Wastewater treatment plant upgrades were paramount instead.

The SFO legally bound Portland to fix the CSO violations it was experiencing frequently. This allowed resources within pertinent bureaus to be allocated to stormwater management which had not existed previously. Participants in Baltimore were also keenly aware of the influence that federal CWA violations had on green infrastructure development and that they lacked any such regulatory push:

I think where Portland and Baltimore are different than a lot of locations is that this whole gray versus green infrastructure tends to be more around whether they're combined systems. (City of Baltimore DPW staff)

It's also completely different in combined sewer systems versus separate sewer systems, because combined sewer systems' green infrastructure has the added benefit of runoff reduction. That's how cities like...Portland, Philadelphia, Seattle, can justify large expenditures for green infrastructure, because of...preventing the water from getting into CSO. For the rest of us that have 
separate systems, it's a harder sell to implement green infrastructure. (City of Baltimore DPW staff)

[We have] a regulatory obligation to meet TMDL. As I mentioned, green infrastructure is not that cost effective for doing. The communities set up to really put green infrastructure in the ground in a big way were communities with CSOs. (City of Baltimore DPW staff)

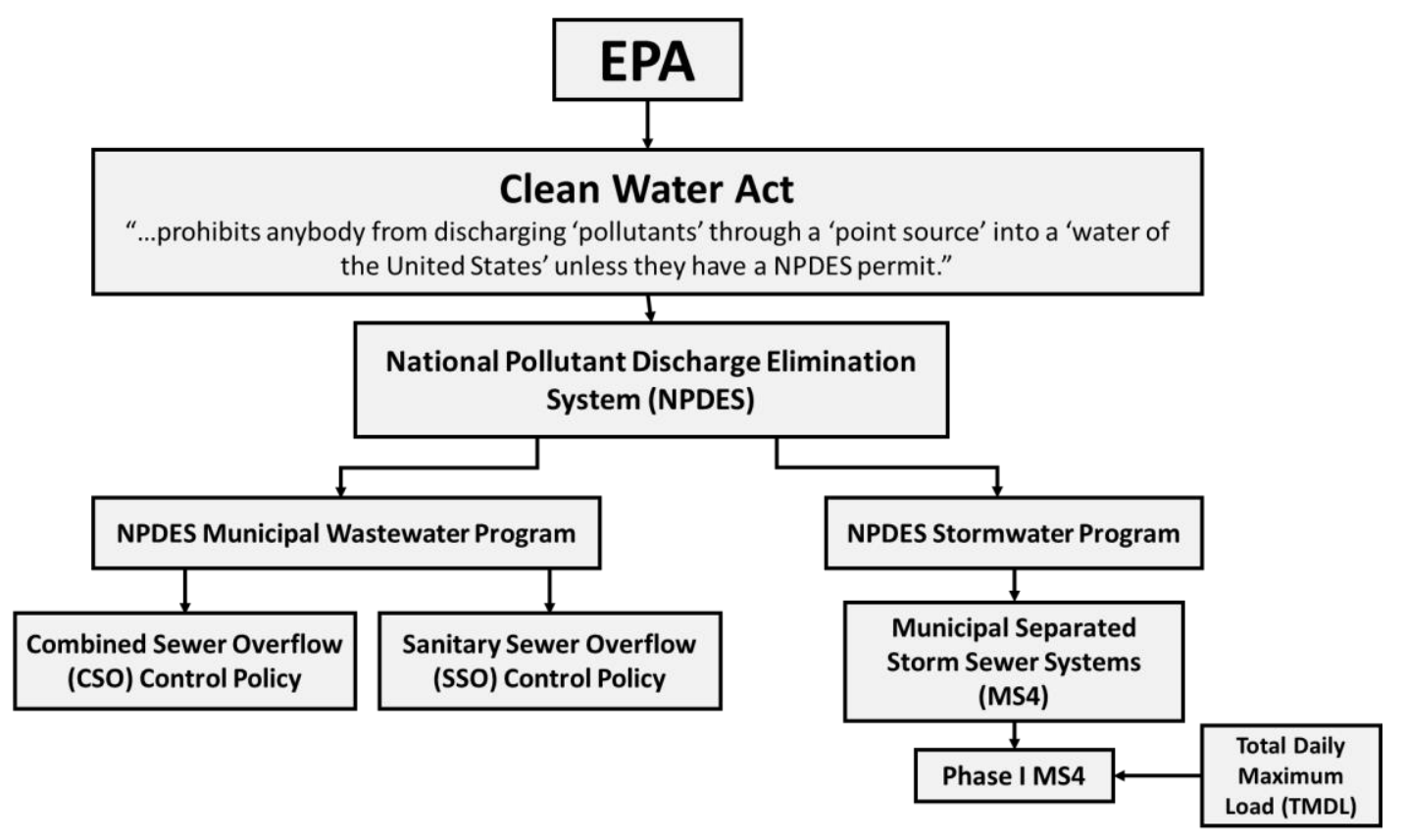

Figure 2-2: Regulations impacting green infrastructure development in both Portland and Baltimore

\section{$\underline{\text { State level }}$ \\ While discussion of CWA violations and combined vs separated sewer} technologies are often discussed in green infrastructure literature (Montalto et al. 2013; Montalto et al. 2007; Finewood 2016) this research also uncovered an influential impact of state-level leadership around pollution and environmental protection at play, differentiating the cases. 
First, in Baltimore, state level regulations regarding stormwater management were mentioned again and again in interviews in discussion of what green infrastructure is and the services it provides. In some cases, green infrastructure was equated with the state's Environmental Site Design (ESD) standards, and used synonymously with green infrastructure:

[We] implement ESD, which is the same at LID or green infrastructure (City of Baltimore DPW staff);

or ESD facilities were explained as a subset of green infrastructure:

Green infrastructure is just much more broad a term. When you say ESD it's referring to this very specific methodology. (City of Baltimore private firm staff)

They've taken this idea of GI and then said here are 10 or 12 practices that you can use and they have to be designed a certain way. (City of Baltimore private firm staff)

State-level stormwater management regulations are also credited with the increasing the number of green infrastructure facilities in Baltimore:

Our older facilities, things that were built before about 2010, are mostly large what we call structural practices. Those are your ponds, your sand filters, your underground detention, that sort of thing. In 2010, Maryland changed the regulations actually requiring that all projects try to implement ESD...prior to looking at any other way of managing stormwater...So as a result, we see more and more of it in the Baltimore city area. (City of Baltimore DPW staff)

The city of Baltimore has essentially adopted state guidelines for city stormwater management. ESD guidelines and standards are in place for any green roofs, bioswales, rain gardens, etc. that are permitted in within the city.

In sharp contrast, Portland interviewees rarely mentioned state-level agency involvement in green infrastructure development. Or if it was mentioned, staff did not feel 
supported by this level of government; they felt they were left on their own to figure out green infrastructure standards and guidelines. As one staffer at BES explained,

I feel like we're a little more on an island than elsewhere. The Department of Ecology, up in Washington [state] is very active; our Department of Environmental Quality, not so much. They've had staffing problems, and a number of issues, they just haven't been particularly proactive. (City of Portland BES staff)

Another staffer explained how this lack of DEQ engagement influenced city permitting of bioswales that infiltrate stormwater into groundwater:

The DEQ for a few years now has been pretty lax on their enforcement of rules and so the city's been put in this weird position where we're the ones kind of being the regulator almost, where some action is proposed that would likely... knowingly contaminate groundwater. Depending on which program you're talking to at $D E Q$, they're fine with it, but the city is not. (City of Portland BES staff)

This sentiment towards the Oregon DEQ is not isolated. The agency has struggled with chronic under-staffing and a dwindling budget as outlined in a 2008 Oregonian article entitled "Cutbacks, low morale cast haze over DEQ" (Sherman 2008). The situation has not improved over the past decade; in March of this year (2017), local nonprofit groups filed a lawsuit against the DEQ to bring light to their 20-year backlog of water quality permits, the second worst in the nation. These environmental groups hope to force change in the agency. As OPB reports,

Oregon's DEQ has struggled with backlog of old permits for more than a decade. In 2015, the state Legislature directed the agency to hire an outside consultant to review its water quality permitting program. The consultant report concluded DEQ lacked appropriate staffing to write permits, often failed to coordinate properly the scientific and regulatory efforts needed to issue a new permit. (Schick 2017)

The strong state involvement in Baltimore and weak state involvement in Portland influenced the ways that interviewees responded to questions about green infrastructure 
development. This regulatory context shows up in the presentation and discussion of definitions, measurement, (this chapter) and valuation (Chapter 3) of green infrastructure that follows.

\section{Definition}

One of the initial interview question asked of all participants in this study was: "What is your personal working definition of green infrastructure?" This question elicited a number of nuanced responses. However, there were two generally agreed upon aspects across all participants: 1) facilities include living, biological components (not just sustainable components), and 2) green infrastructure is multifunctional and provides a number of co-benefits.

First, a strong sense that green infrastructure did in fact include nature and biological entities was expressed in both cities:

Staff from Portland:

I think anything that's just planted with vegetation, whether it's native or nonnative vegetation, and something that's a dynamic system that is managed as such. (City of Portland BES staff)

Personally, I was interested in using soil and plants to slow down the runoff, to filter the runoff, and to try to infiltrate and remove as much of the runoff, as close to its source as possible. I think that's pretty close to our official definition. (City of Portland BES staff)

Staff from Baltimore:

Streams, trees, green roofs. I think about everything about dealing with surface water. (City of Baltimore DPW staff)

To me, green infrastructure is natural. It's...trees, vegetation; especially when that's replacing impervious concrete and grey infrastructure...It's green because it's a natural feature, like a native plant. It is based on a living organism and a 
local ecosystem. I guess that would be my definition." (City of Baltimore nonprofit staff)

But it was also clear that the urban nature that makes up green infrastructure is not just any nature. Green infrastructure refers to nature that provides services; this type of nature was what made it green infrastructure:

It is natural systems that are being used to support services that we provide. (City of Portland OMF staff)

Anything that you could provide traditionally in a built way that you're instead providing in a green type of way. (City of Baltimore Office of Sustainability staff)

Only two people, one from Baltimore and one from Portland (neither from departments that own or manage green infrastructure directly) said that green infrastructure facilities included sustainable infrastructure facilities without vegetation or biological components of any kind. Electric cars are an example of something that these respondents included in their definition of green infrastructure. But the general, overwhelming definition of participants was that nature was integral to the concept of green infrastructure. This finding counters Mell's finding in the UK where a number of sustainable practices/facilities, like bike lanes and LED street lights, are included in the definition of green infrastructure among urban planners (Mell 2013).

Second, green infrastructure was overwhelming defined as multifunctional, providing a tremendous amount of co-benefits. Interviewees gave me laundry lists when asked what services were provided by green infrastructure: urban heat island mitigation, storwmater management, air purification, water treatment, biodiversity, traffic calming, habitat...etc. This was summed up in a quote from Baltimore DPW staffer who began "oh everything" when asked about the services provided by green infrastructure. 
Beyond these nodes of agreement, there was differentiation regarding the definition of green infrastructure. Differences between Portland and Baltimore definitionally stemmed in part from regulatory context. In Baltimore, state-level or EPA definitions were referenced most often, whereas in Portland, local documents were referenced outlining Portland-specific definitions of green infrastructure. But, otherwise, definitions were more strongly differentiated across departments/institutions. For example, both Rec and Parks, and Parks and Rec focused on an expanded network view of green infrastructure which included forest patches and natural areas as facility types (facilities found on the 'eco' side of the eco-techno spectrum); utility departments like BES and DPW focused instead on modular stormwater-focused projects and other facilities found on the 'techno' side of the eco-techno spectrum. This was unsurprising due to the types of facilities each different type of institution owns and the different methods of measuring and valuation employed by each institution to fulfill their mission statement and public obligation.

The division of facility types was similar between Portland and Baltimore. For example, Baltimore's sewer utility, Department of Public Works (DPW), was responsible for permitting and inspecting bioswales, permeable pavement, and green roofs, as was Portland's sewer utility, Bureau of Environmental Services (BES). All of these facility types fall on the 'techno' end of the eco-techno spectrum as shown in Figure 2-3. As described above, Parks departments in both cities were responsible for facilities towards the 'eco' side of the spectrum, also shown in Figure 2-3. 


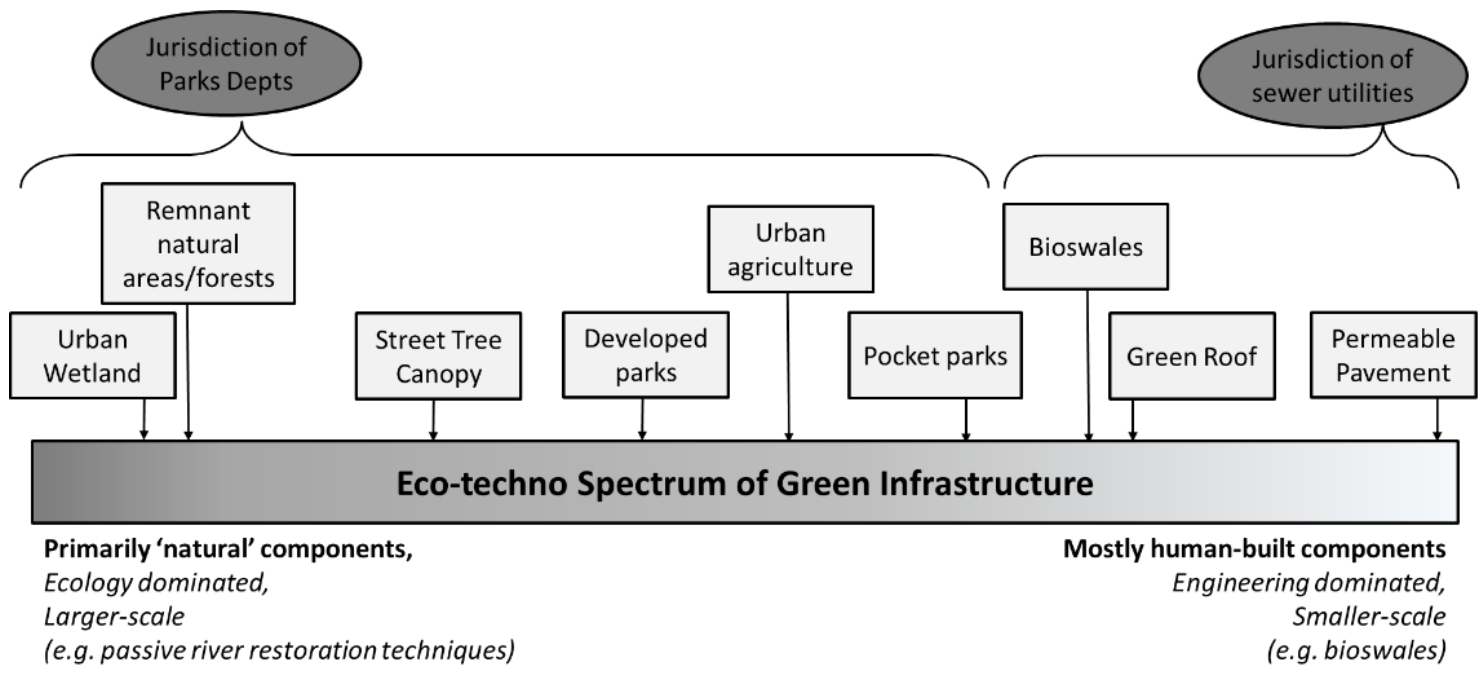

Figure 2-3: Jurisdictional divides across the eco-techno spectrum

One unexpected difference in jurisdiction that was differentiated by city, rather than department/institution, was maintenance responsibility. In Baltimore, the city does not own many of the facilities currently built (this will be changing as the city's planning moves into implementation). Non-profit groups, private companies, and residents instead own the majority of facilities. This means that maintenance is the responsibility of homeowners, developers, or non-profits. In the case of green roofs, developers often continue to provide maintenance of facilities over a number of years. In the case of bioswales, non-profit groups usually sign MOUs with local residents to care for the facility indefinitely. In Portland, on the other hand, many bioswale facilities are built in the public right of way. These facilities are owned and maintained by the City of Portland.

This difference in maintenance responsibility, however, was only observed on the 'techno' end of the spectrum; when it came to parks, natural areas, and wetlands, Parks \& Rec and Rec \& Parks maintained all facilities. 
Maintenance has important implications for the function of facilities into the future. Understanding the breakdown of facilities managed privately vs publicly in cities can help better understand maintenance outcomes. As discussed in the next chapter, envisioning nature a service-provider has implications for the privatization of green infrastructure in the future. Findings here point to maintenance responsibility as an important metric to trace in future research.

\section{Challenges}

Participants in both cities brought up the broadness and ambiguity of the term 'green infrastructure'. A staffer at Rec \& Parks in the City of Baltimore sums up the overarching sentiment: “It's such a broad term, I mean, I don't think I've ever heard a textbook definition that everyone has agreed upon." The definitions that were given by various interviewees reflected this broadness; for example one interviewee responded: "We consider anything that has some sort of green space or green benefit, at least in my mind, I consider to be green infrastructure" (City of Baltimore Office of Sustainability). This entails a number of different facility types and a broad range of urban nature configurations that spans the eco-techno spectrum.

While it was widely agreed in the participant group that the definition of green infrastructure was quite broad (reflecting the findings of others, particularly Young et al. (2014) and Mell (2013)), this broadness was described alternately as a positive and negative feature by different participants. The difference in this viewpoint was not delineated by city. Some characterized the definition as "too broad" which led to misunderstandings and miscommunications about green infrastructure: 
I think it's one of those terms that is just so broad that people do shy away a little bit because they don't fully understand it. Even people who are experts in related fields, I don't think everybody really has the same understanding of it. (City of Baltimore non-profit staff)

Broadness was also considered a problem because it allowed certain types of infrastructure that did not include nature or vegetation to be considered green infrastructure:

It's too broad in the environmental field...If there is a house with solar panels, is that green infrastructure? I think it's too broad maybe. (City of Baltimore nonprofit staff)

Another problem that stemmed from the definition of green infrastructure being too broad was that green infrastructure could be misunderstood as a panacea, implemented without assessing disservices:

It's so general... [and] because it's general, there's been a lot of confusion among people. A lot of people just don't understand what it is, and they make some blanket statements that aren't necessarily true. It's like the panacea for what ails us." (City of Baltimore DPW staff)

Overall, the sentiment towards definitional broadness differed by department and organization. For example, the idea that the broadness of the definition of green infrastructure could allow it to include just about any greenspace was described as a problem for utility departments. Staff at DPW in the City of Baltimore expressed concern over the implications of this broadness for the stormwater management budget:

We focus on [stormwater] because when it becomes too broad green infrastructure suddenly becomes greening. Suddenly it becomes let's spend DPW stormwater fee utility money...to do community gardens...[or] any number of things that really have little to no benefit for stormwater. So we have to be very careful using the terminology and managing our funds... There are people within city government and outside city government that feel like oh, we have now this pot of money that we can use for any type of greening and...we can't because our goal is to meet the MS4 permit.

Likewise in Portland: 
There's definitely, still, different words. I think it has, certainly, more teeth than it did in the past. Philadelphia and Seattle use green stormwater infrastructure, to be very specific about the type of infrastructure that it is, we use that occasionally, sometimes, ourselves. (City of Portland BES)

However, others saw the broadness of the term in a positive light. Staff in coordinating departments and agencies, like planning, are encouraged by the possibilities and the 'wiggle room' available from ambiguity; it allowed them to connect more stakeholders to projects. This difference in want for specificity represents, therefore, a knowledge system challenge. One bureau 'knows' infrastructure as working in tight physical and economic tolerances and categories that must be met for appropriate function; it has knowledge practices, for example protocols for quantifying stormwater run-off, that fit a single-service infrastructure vision. Other bureaus 'know' infrastructure as something that needs to be functional for multiple different groups and therefore must accommodate a wider range of categories in planning; they have knowledge practices, for example norms of inclusivity and protocols for gathering multiple qualitative points of view at public meetings and outreach events, that fit a wider multiple benefit infrastructure vision. This is a common push-pull within cities (Friedmann 1993; Scott 1998; Fainstein 2010) that I am framing in this dissertation as a knowledge systems challenge.

An additional challenge was the lack of understanding or definition of facilities as 'infrastructure' by residents and property owners. In Baltimore, it was challenging for facility inspectors to keep up with new property owners who didn't know that the garden area on their new property was actually a piece of stormwater infrastructure:

People don't even know what they have. With green infrastructure in particular, they look at it and all they see is, "I've got a garden. If I let the weeds grow in the garden, so what?" They don't know what they're supposed to do... We find a lot of 
times our inspections are re-informing the property owners of what they're supposed to do. (City of Baltimore DPW staff)

In Portland, BES faced a lawsuit in 2014 from ratepayers arguing that green infrastructure was part of "mission creep" within he bureau and spending on green streets was a "misappropriation of sewer funds" spent on "luxury greening projects" rather than real sewer projects (more detail on this challenge in Chapter 3).

The motivations of each department to think the way they do is displayed in the quotes and discussion above: the ambiguity around green infrastructure had legal budgeting challenges for some departments, but an expanded green infrastructure definition that included all urban nature generally providing multiple benefits was a boon to planning departments in both cities.

\section{Changes}

The institutional work-arounds observed in both cities to address definitional challenges of green infrastructure development were primarily focused between departments. Of note was the development of new collaborative quarterly meetings across departments in Baltimore; this was primarily to aid in communication between groups. Because different departments, including DPW, Rec \& Parks, and DOT, as well as a number of different non-profits, were all removing impervious surface and planting trees on each other's property, it became important to coordinate the installation of these facilities. For example, Rec \& Parks may identify an area where new street trees are needed. But shortly after trees are planted, DOT may dig up the entire project for planned street 
repairs or DPW pipe replacements, leading to the death and scrapping of the newly planted trees. Without communication across departments, this was a common occurrence.

New quarterly meetings were brought about by the recognition that each of the departments and agencies was a player in coordinated green infrastructure development. The facility construction and repair that each had planned should be shared across all departments to aid in more efficient and cost-effective development. While the meetings have not yet produced an integrated understanding of green infrastructure across departments in the City of Baltimore, the open lines of communication are now established to begin to move towards more comprehensive planning.

Another, more specific, emerging change in the City of Baltimore is the creation of new educational workshops for developers and property owners to teach them what green infrastructure is and that it needs special maintenance:

We're looking at doing some informational sessions, specifically with the large property owners, the large developers in the neighborhood. Basically, explaining to them, "This is what stormwater management is. This is why you're doing it. This is what it means to you. It's not just put it in the ground and walk away. You're going to have to do something about this in the future." Then we throw them the carrot that if you do this [training], and you submit your application, you can get a reduction in your stormwater management fee. (City of Baltimore DPW staff)

This kind of training would have an influence on the definition of urban nature in the City of Baltimore; residents may begin to see urban nature as more than just greening, perhaps viewing facilities as service-providers. This would be a small change, but if residents must think about gardens as infrastructure on their own property, it could have an influence over time on their view of urban nature generally. 


\section{Measurement}

Performance metrics are an important piece of infrastructure management. As discussed in more detail in Chapter 3, maintenance of facilities depends on accurate measurement of performance. However, it was apparent from interviews that performance metrics were heavily influenced by definitions of green infrastructure and the goals and mission of the institution implementing the facility.

In this study, attention was given to measurement of biological entities in particular in green infrastructure facilities since traditional infrastructure metrics do not include living components. In the literature, the plants used within facilities are sometimes described as having little or no influence on the functionality of a facility, but rather are planted to make the facility more appealing to residents. I questioned my interviewees about this concept. All replied that they believed plants to have an important role in facility function to varying degrees; but some said that, while they knew the plants were important, they did not have metrics that were regularly employed to assess that functionality. As one engineer described it, it depended on what service was being measured:

You could easily support that idea [that the plants are only window-dressing] by picking one of those analytes out. Like if you said, hey, let's focus on the metals or the solids or something, maybe the plants aren't that critical because it's really the media, or it's that filter, that's stopping that material from going and reaching that under drain or overflow pipe that's essentially gonna go to the creek or to the street, storm sewer. However, they reduce the heat island effect, they help temperature, they help uptake of certain other things like nitrates...Oils and greases tend to get trapped in vegetation at a certain rate, volume, and all that stuff. So, it depends on what you're talking about. (City of Portland BES staff)

In Baltimore and in Portland, the focus on water quantity and quality was highlighted in the discussion of measurement generally. Nearly all regulatory requirements 
of the system revolved around these metrics, making them the most discussed and most well developed across all departments to measure green infrastructure:

It's all rooted in hydrology. So, it's looking at here's what a site would look like hydrologically if it was all wooded and forested. And then your objective is to build buildings on it but mimic that natural hydrograph. So as long as you can do it, you can fit as many buildings on there as you want, as many roads, but if you can capture and treat the run off and mimic that natural hydrograph, then the state would give you a check mark, you have done your job. " (City of Baltimore private firm staff)

\section{Challenges}

The current conception of green infrastructure as a stormwater management tool has produced a number of measurement challenges to engineering departments in both cities. The focus on stormwater management (as discussed above and throughout this dissertation) has meant that performance metrices of facilities are primarily based on water quantity and water quality measurement:

[Water] quantity is a real important aspect and benefit of green infrastructure. Going beyond, and that's what the manual is designed. There's other benefits to green infrastructure that's recognized, but that's not the driver for us as far as requiring green infrastructure. (City of Portland BES staff)

In Portland, the primary focus has been on measuring water quantity, while in Baltimore the focus is on water quality, but both are a response to regulatory concerns (CSO in Portland and MS4 in Baltimore).

The focus on water quantity and quality has meant that less attention has been given to other services (like urban heat island attenuation, social cohesion, air quality improvements, etc). These other services were discussed by interviewees, but actual mechanisms to integrate these services into level of service or performance metrics was 
not observed in either city. Delivery of such services is mostly assumed based on academic literature indicating the potential for green infrastructure to do more.

One specific challenge of measurement faced in Baltimore was the ability to count green infrastructure facilities towards their MS4 permit. In order for a green infrastructure facility to be counted within the permit, it needed to be assessed by an engineer as it was being built. A document is created by that engineer to show how closely the designs for the facility matched what was actually built on the ground. This document is referred to as an "as-built." Without an as-built, no green infrastructure facility in the city could be counted towards Baltimore's MS4 permit. This measurement challenge, and its emerging solution, is discussed in more detail in the following section.

\section{Changes}

To work around measurement challenges, interviewees described some institutional changes and adjustments that were primarily focused within department/bureau. Performance metrics are tied closely to the mission and public obligation of each department (i.e. CSO reductions by BES, or recreation obligations of Rec \& Parks) and must reflect the progress that the institution is making towards its level of service goals. This contrasts with the definitional challenges and changes discussed above which are mostly in regards to communication across bureaus and differing missions and goals.

First, both cities mentioned the extended use of asset management software to track green infrastructure facility performance through time. Initially, green infrastructure facilities were not included in BES or DPW's databases. At BES, as the number of green 
streets grew over time, they were added to the database, but the biological aspects of the facilities were not included. Staff now say that more detailed information regarding the condition of these biological entities is being tracked via their asset management software and that this tracking has become more granular through time:

It used to be that, if they went up to do maintenance, and that was a project that had...twenty green streets, they would all be lumped into one entry. They would just say, "We went out, we did this and that," and it would be a single entry for all 20 facilities. Now they're able to actually pinpoint, "Well, 18 of those 20 facilities were easy, and these 2 here were the hard ones, that had a lot of sediment, or had problems with plant coverage," or what have you. It allows us to look a little more closely at patterns and maintenance activity, and that's certainly kind of a new focus. (City of Portland BES staff)

Increased tracking of maintenance activities and facility condition will ultimately feedback into the design and implementation of green infrastructure in Portland, making the selection of what to measure an important decision point in this knowledge system:

Back in the beginning, it really was trying to get the function down, trying to understand the different design conditions that we were building facilities in a way that focused on the design and construction end of things, and that's still something that we do. (City of Portland BES staff)

A second important work-around to a measurement challenge was observed in Baltimore. This change stemmed from the tension between DPW and non-profit groups. When non-profit groups began building green infrastructure facilities with state grants, the city did not yet have its green infrastructure plan, nor any local guidelines or standards, in place. Green-streets-like bioretention in the public right-of-way built by non-profits followed the ESD standards developed by the state. These were built with extensive interactions with community groups and granting organizations, but the city lacked the capacity or knowledge system practices to actively engage with the new construction. The 
city was instead dealing with its MS4 permit which requires a minimum amount of hydrologic restoration. The green infrastructure facilities built by non-profits could provide credits towards that goal. However, as described above, as-builts were needed for each facility to be counted.

Because as-builts are quite expensive, and were not a required metric from funders, non-profits generally did not complete this process when building new green infrastructure facilities. This was frustrating to DPW that wanted to engage with non-profits around the comprehensive planning and design of grant-funded facilities, but had no incentive (or mandate) to do so if the facilities did not count towards their MS4 permit requirements.

A collaborative process has begun to attempt to address this measurement challenge. Non-profits have worked directly with funders to earmark construction funds for the completion of as-builts. The city has also contributed some funds to the endeavor to retroactively commission as-builts on as many existing facilities as possible. In this way, DPW can count these facilities as credits towards meeting their MS4 permit:

The As-Built is a document that says, here's what actually was built. DNR was not providing funding for a group like Parks \& People to do an As-Built, so we all got together and said, "There's this disconnect." Right? You're providing funding to these groups. However, your funding is not allowing them to take that last step to then help me, the city's MS4, which is what you're also wanting to try to meet. How do we do that? I think they then became more flexible. I think they said like, "Okay, you can use X number of dollars within your funding towards the AsBuilts. (City of Baltimore DPW staff)

"If you want to meet the intent of the money you need to include funding for asbuilts so they can be transferred to the city as credits. So facilities that have already been put in...now we are developing an MOU with the city, for projects that you can go back and say yes, this is the project that happened...For some of our projects that are just impervious removal, it is easy to go back and say this is an areal photo... We can show that we took [out] this amount of impervious 
surface... But for facilities that have specific layers at specific depths, ... [as-builts] can only be done during construction. (City of Baltimore non-profit staff)

Both non-profits and the City of Baltimore are happy to see this process moving forward. The tension between the institutions is gradually easing as they find ways to mutually support one another in green infrastructure development:

We are in the process of going through ...[and] transferring credit to the city. It makes you feel good that you are making change. (City of Baltimore non-profit staff)

\section{$\underline{\text { Discussion }}$}

The definitional and measurement knowledge practices, norms, and protocols revealed in the results section above can be examined as stemming from distinct knowledge system processes. As reviewed in more detail in Chapter 1, knowledge systems include knowledge production, vetting, and circulation. Each of these processes is important to understand more fully because each influences outcomes. While I do not wish to overstate each mundane detail of institutional process, I do hope to shed light on usually taken-forgranted decision-points that could be used as leverage points in the explicit design of a more effective knowledge system in the future.

I see both knowledge production and knowledge circulation as moments of interest and points of leverage and discuss them both below. Additionally, these processes act differently from one side of the eco-techno spectrum to the other. Therefore, I examine the interaction of these ideas with the eco-techno spectrum in both cities, and the knowledge system integration tactics in use to reconcile facilities from one end to the other. 


\section{Network vs Stormwater Visions}

When examining the definitions of green infrastructure across both cities, I found both Benedict and McMahon's (2006) network vision in use as well as a more stormwaterfocused vision (EPA 2017) that defines and measures only water quality and water quantity (these lined up well with the 'network' and 'stormwater' visions described in Chapter 1). There is not a unified vision of the appropriate role of urban nature or green infrastructure in either city; but it does appear that these two visions integrate and compete in different ways in the two different contexts.

Primarily, I observed knowledge practices that were dictated by regulations, and knowledge norms that were inherent in economic status, influencing the interplay of these two concepts in the two different cities. Each viewpoint has found different knowledge challenge work-arounds within the prevailing regulatory and economic structure they find themselves in, to varying levels of success. For example, the CSO Program was the initial driver of green infrastructure development in Portland. Because the needs of this program were to manage water quantity, primarily aimed at keeping stormwater out of the combined sewer system, a stormwater-focused way of knowing green infrastructure emerged most strongly in Portland.

Without a CSO regulatory push, Baltimore has been more influenced by the network vision, or way of knowing, green infrastructure. Actions taken to integrate with Chesapeake Bay-wide efforts to address water quality issues are better served by this Benedict and McMahon (2006) definition. Also, Baltimore's MS4 permit and TMDL violations have manifest as forest patch enhancement and restoration acres, in which 
hardscape is removed "restoring" natural hydrologic regimes on a site. The facility types encouraged by this type of regulation are more easily integrated in a larger, regional green network vision of green infrastructure. However, facilities from across the eco-techno spectrum are built in both cities, showing that the negotiation of various definitional and measurement contestations regarding green infrastructure do not result in uniform adoption of one vision or the other.

This provides two interesting points to explore further in efforts to more deliberately design knowledge systems in the future. The first, is the finding that overarching regulatory standards seem to primarily influence green infrastructure investments and definitions differentiation via technological differences; in this case, the separated or combined sewer dictated the type and severity of the regulatory violation of each city, driving the adoption of different types of green solutions. But, a second finding of the study shows, at the local level, municipal knowledge systems show differentiation within, or in spite of, this overarching regulatory framework. The tensions between the knowledge systems of engineering, ecology, utility departments, and planning offices were much stronger than technological differences to the framing of the usefulness of green infrastructure. This allowed both 'network' and 'stormwater' visions to be at play in both cities even though sewer technology differed substantially.

\section{Knowledge production}

Where does legitimate information come from? Who is producing this information and what does that tell us about the knowledge systems involved here? I observed a 
difference in the way interviewees discussed knowledge production between the two cities.

In Portland, I observed much of the definition and measurement information on facilities being produced in-house. For example, BES referred me to the bureau's own green infrastructure definition, written by city staff, rather than an outside authority's definition, like the EPA. Also, in the 1990s, Portland collected their own data on the holding capacity of a number of facility types to address their CSO violations:

We were acting as a kind of in-house consultant for the city...And at the time, that's when the green infrastructure and stormwater facilities really started to grow and the city of Portland created the Stormwater Management Manual in the late '90s for development requirements and to build private green infrastructure as well as green streets and city infrastructure as well, green infrastructure. So, we were doing a lot of monitoring projects with swales, planters, treatment ponds, things like that, and it was really a great experience at the time. And I didn't know it, but it was really cradle to grave, it was building some of these facilities for the city and then setting up monitoring programs and stations and equipment and looking at them over seasons and reporting back on efficiencies and contaminant removal, efficiencies, and stuff. (City of Portland BES staff)

They continue this in-house knowledge production regarding the performance of facilities; currently BES staff are beginning testing of their green streets soil mix to dial in an appropriate compost content that balances maximum plant health with minimum nutrient leaching from the soils.

In Baltimore, on the other hand, most interviewees referred to state-level definitions or the EPA definition of green infrastructure when asked. Facility specifications were described as being created by outside agencies, then adopted or used wholesale to Baltimore. These guidelines were used in permitting and inspection of facilities:

So, we use the Maryland Department of the Environment, their stormwater manual, chapter 5, environment site design. It's been the standard that everyone 
has been using in the absence of more local, specific guidance. But, that's in terms of the real nuts and bolts, the real engineering of it. In terms of aesthetics and community functionality, we'll look around the country for models of what's probably been adopted an accepted. (City of Baltimore non-profit staff)

One noted difference in this trend (Portland producing information about green infrastructure in-house and Baltimore adopting information from outside sources) is Baltimore DPW's recent involvement in the creation of a new green infrastructure maintenance certification program. While not done completely in-house, staff from Baltimore participated in teams that developed the curriculum for the course organized by WEF. This was a direct involvement of the city with knowledge production practices at the national level, which are now put to use in Baltimore.

These findings show knowledge production as an important point to intervene in the design of knowledge system elements. Designing a knowledge system to integrate both in-house perspectives and data collection with outside knowledge claims can allow a more robust decision-making process.

Interactions across the Eco-Techno Spectrum

Interviewees in both cities indicated that facility types considered green infrastructure span the entire eco-techno spectrum. While not every department, bureau, non-profit, or company recognizes the entire spectrum, all points along it are recognized by at least one institution I spoke with in both cities. 
Protocols stemming from regulatory structure and norms inherent in economic status were observed in differentiating whether or not an institution opted to build more ‘techno' or more ‘eco' leaning facilities. For example, Baltimore faces huge budget short falls; large rates of property abandonment means greatly reduced property tax revenue. Facilities on the techno-side of the eco-techno spectrum, while cheaper than most grey systems, are still quite expensive. Without the CSO regulatory push demanding money be spent on this problem, the knowledge claims indicating the multiple benefits of most ‘techno' green infrastructure solutions do not sway a cost-benefit analysis to justify their implementation. In fact, Portland is now dealing with this issue in separated sewer areas of town, and are looking to other options to address stormwater than green streets in these areas as they don't make much sense in the separated context:

Now that we've done the first phase of our combined sewer work, and are in more of a maintenance phase for that, we've started to put more attention into the separated parts for our system, the MS4 system, and then truly just get up drainage parts of our system, too. The questions become a little more difficult, it's not quite as easy to do an apples to apples comparison of gray and green anymore. If you're dealing with water quality issues, how much did you spend to remove a pound of TSS out of the system? Those questions aren't quite so clear-cut. (City of Portland, BES staff)

Institutional norms in Portland have moved towards an integration of facilities across the eco-techno spectrum, with a focus on more comprehensive planning integrating both a stormwater and a network vision:

I call what we do, little $G$, little I, green infrastructure, and then there's capital $G$, capital I, Green Infrastructure, which would include all of the interconnected, larger ecosystem type things that come in, so really our forests, and then natural areas and stream corridors that we still have that need to be protected, and interconnect those things. (City of Portland BES staff) 
We have natural areas which are areas that are wetlands and upland areas, and we have a lot of facilities such as stormwater management facilities that are also wetland systems and ponds, and larger areas that capture stormwater runoff that gets treated before it goes out to a water body, and then we have green streets. Those are kind of the three components of our green infrastructure program that we have and manage. (City of Portland BES staff)

Portland's movement towards integration across the spectrum, and comprehensive planning, is most likely spurred by the existing history of working on the 'techno' side of green infrastructure during their CSO Program and their new attention to dealing with separated sewer areas that tend to lend themselves to more 'eco' side solutions.

A potentially integrative knowledge system change that was discussed in both cities was the creation of a new sub-agency that would oversee the maintenance of all green infrastructure facilities within a city:

We've met with other agencies. You know, does it make sense to have one maintenance responsibility? Whether it's Recreation and Parks or a school, that there's one entity that maintains it and that different agencies might put some of their budget into it. One example of that in the city are fleet services. One entity is responsible for fleet, all of our cars and vehicles, and then agencies support that because they use those. (City of Baltimore DPW staff)

The creation of a such an agency would mitigate many of the definitional and measurement knowledge challenges currently involved in siloed maintenance of facilities. A city-wide maintenance agency would be able to consolidate performance metrics and begin the integration of definitions:

Interviewee: the way the city works is that each agency is responsible for their own property that they own. Housing, department of general services, DPW, DOT, they all have their own facilities.

Interviewer: Do you have a sense that each group is doing different kinds of maintenance or different departments have different ...

Interviewee: Different levels of maintenance I think is a better way of describing it. One of the things we're currently working on is seeing if we can form a group 
that is in charge of all city facilities' maintenance [to address those different levels]. (City of Baltimore DPW staff)

\section{Green infrastructure as state simplification}

One way to interpret and analyze the institutional processes discussed above is through an STS lens as processes of state simplification (Scott 1998), in which the state attempts to make the messy reality of its territory "legible" in order to tax, manage, and govern. Scott (1998) asserts that state simplifications "are observations of only those aspects of social life that are of official interest"; they consist of "interested," "documentary," "static," "aggregate," and "standardized" facts (p.80). They are often called into play to organize the state around managing scarcity; as Scott explains,

As long as common property was abundant and had essentially no fiscal value, the illegibility of its tenure was not problem. But the moment it became scarce (when "nature" became "natural resources"), it became subject to property rights law, whether of the state or of the citizens. The history of property in this sense has meant the inexorable incorporation of what were once thought of as free gifts of nature: forests, game, wasteland, prairie, subsurface minerals, water and watercourses, air rights (rights to the air above buildings or surface area), breathable air, and even genetic sequences, into a property regime. (Scott 1998, p. 39)

Green infrastructure can be seen as an extension of this history of property where ecosystem services (once considered common property or "free gifts of nature") are being reimagined as municipal services with very real (in some cases still potential) fiscal value.

What the concept of state simplification helps highlight in this case is the necessary reduction of complexity of knowledge for legibility, which is quite useful for efficient management; through simplification generally, certain aspects of a system are highlighted 
while others are ignored. It is important to note that only specific components of the system are considered relevant to the task at hand by those managing the system, and that decisions regarding what is relevant are political decisions (although usually implicitly so), often leading to the erasure or inattention to local, tacit knowledge of place. For example, state simplifications, such as maps, "are designed to summarize precisely those aspects of a complex world that are of immediate interest to the map-maker and to ignore the rest..." (Scott 1998, p.87); one cannot place every detail of the landscape on a map without rendering it no more useful than looking at the landscape directly. A map's purpose is therefore to "abstract and summarize." This is quite useful in design of infrastructure; focus on a single function allows for its optimization.

As seen in the results presented in the previous section of this chapter, the discussion of definitional ambiguity among practitioners can be seen as representing two competing systems of legibility. Engineers require a definition of green infrastructure that makes facilities legible in their knowledge system. In planning, tolerances are wider. There is also movement in this field to avoid erasing local voices and tacit knowledges (as state simplification does) and maintain inclusive processes of decision-making.

Why should we pay attention to state simplifications? What Scott (1998) finds is that, for all their usefulness, state simplifications often run afoul. This is primarily because such simplifications have the power "to transform as well as merely to summarize the facts that they portray." Scott uses the unintended negative consequences of scientific forestry as an example of a state simplification gone awry; this concept, which focuses management only on timber in forests, transformed forests in Europe into monocultures of neat rows of 
economically-pertinent tree species. While initially successful, these monocultures soon began to slow their production. Nutrients that had built up in the soils from past forests were used up and not replenished; pests became more pronounced, able to wipe out large areas of monoculture without predators or competition from the other plant and animal species that had been removed for efficiency's sake. In the end, the simplification of the forest, which eliminated local and tacit knowledge from the system of understanding, ended up ignoring some essential complexities of nature (i.e. nutrient cycling, competition, food webs, etc).

The driver behind the notion of scientific forestry was a scarcity of timber and wood in Europe. Existing forests appeared to be terribly inefficient in growing trees at a rate needed to keep the state running. From this, rose the idea to optimize the forest by growing trees, and only trees. Land was cleared and trees were planted in neat and tidy rows. All other plants were referred to as weeds and were kept at bay between each row of trees.

A very similar process is currently underway with green infrastructure. Nature in the city is seen as useful in providing certain services. Municipal departments are therefore attempting to optimize urban nature to provide these services and only these services. These utilitarian visions of urban nature fit well within the mission of departments required to provide services with increased efficiency and at low cost. However, the novel ecosystems that make up green infrastructure are not well known ecologically or socially. A mis-understanding of their functionality may occur in much the same way as scientific forestry if they are optimized to provide just one service. 
While similar in many aspects, green infrastructure also differs from scientific forestry in a number of ways. One important difference is the focus of green infrastructure on process and function of ecosystems rather than on products received from nature. This is, as Carse (2012) has found, a consequence of the concept of infrastructure more generally. As he asserts, "the concept of infrastructure does not delimit a priori which - or even what kind of - components are needed to achieve a desired objective" (p. 540); this has made a conceptual opening for nature to be considered as infrastructure if it is able to achieve the same objectives as a built system. Additionally,

In the case of natural infrastructure...emphasis is placed on the functions, benefits, or services that a subordinate system delivers, rather than the type or character of its individual components. (p. 542, emphasis added) (Carse 2012)

I found that this holds true for green infrastructure in the cities I examined as it did in Carse's case in Panama. Carse examined the 'infrastructure-ification' of the watershed surrounding the Panama Canal. This landscape provides the important service of water storage for the canal to use in low water seasons, but originally was not managed as such. Instead, farmers managed the land for soil formation and nutrient cycling. When new management practices were instigated to optimize water storage, it created conflict with the farmers' management. It seemed only one or the other service could be optimized for in this case.

A consequence of this shift in Panama has been a movement of state power exerted through the physical control of water itself (in reservoirs, etc.) to power exerted through legal control of watershed practices: 
Whereas canal administrators had previously emphasized the control of water in tis liquid state, watershed management emerged as an attempt to manipulate water flows through the legal restriction of agriculture and protection of watershed forests. (Carse 2012, p. 542)

Building off of this insight, this dissertation finds the shift to nature as a service- provider in the city similarly clashes with existing functions, as displayed by the definitional conflict between departments discussed throughout this section.

\section{$\underline{\text { Conclusion }}$}

Through comparative knowledge system analysis, tracking knowledge challenges and various institutional work-arounds, I observed the interplay of various definitions, metrics, and values of green infrastructure. In the end, it was difficult to separate the knowledge systems influences of each of these different ontological and epistemic categories of challenges from one another. Definition of facility often directly influenced the performance metrics used, which then drove the selection of valuation techniques and maintenance strategies. This close connection of challenges makes it difficult to study or re-design the knowledge systems at work within a municipality. The categorization of results here, then, represent merely a starting point to deepen the understanding of a knowledge systems analysis generally. 


\section{Chapter 3}

\section{Making 'green' fit in a 'grey' accounting system: valuing urban nature as a service-provider}

\section{$\underline{\text { Introduction }}$}

Over the past 20 years, green infrastructure development has increased in US cities that are working to cheaply and sustainably address stormwater infrastructure overcapacity and inefficacy (WERF 2009; EPA 2015). As a form of infrastructure that explicitly includes ecological, living components (primarily plants and soils) in its design, green infrastructure blends practices and knowledge claims from both ecological and engineering knowledge systems (as described in detail in Chapter 1). This blending of relatively distinct and often incommensurate knowledge systems presents challenges that are being negotiated between and within municipal departments responsible for designing, implementing, and maintaining the growing green infrastructure networks in cities across the US. In particular, ecological knowledge does not 'fit' well-established, engineeringdominated ways of defining and measuring infrastructure and urban nature (as discussed in detail in Chapter 2).

As negotiation between knowledge systems moves forward, new knowledge practices are being developed to help make this "square peg fit in a round hole." Notably in Portland, staff are working to develop new urban nature valuation practices, norms, and protocols. The changes precipitated by these new knowledge practices have the potential to shape future urban nature and infrastructure by changing long-term city investments in both by imbuing nature with the connotations of infrastructure. 
One important connotation of infrastructure is its necessity to city life. Without infrastructure like sewers and wastewater treatment plants, urban population densities would be extremely risky, with high disease/mortality rates and low quality of life, as was common in cities during the industrial revolution before water treatment practices were implemented (Melosi 2008). In contrast to this understanding of human-built infrastructure, nature has been thought of as a luxury or a beautification tactic in cities through time. Even in the era of progressive reformers, culminating in enduring features like Olmsted's Central Park in New York City, nature was thought of as charity or philanthropy to improve the social cohesion and morality of the lower class, but was never on the same footing as built infrastructure or other development (Rawson 2004). One of the knowledge system changes then that the concept of green infrastructure brings about is the treatment of nature as a critical service provider.

To recognize urban nature as a critical service-provider, like other infrastructural systems, a number of institutional changes must occur. In this chapter, I specifically look at the new valuation techniques undertaken to integrate nature (as green infrastructure) into city-wide asset management, and the knowledge system challenges these new practices create.

Some municipal staff in Portland are in favor of including various urban nature configurations as "green assets" in city-wide asset management; the move follows a successful transition within municipal infrastructure management generally towards more comprehensive and standardized asset management procedures. These procedures are 
borrowed from the private sector where they have been shown to better anticipate and prioritize risk of asset failure and improve the efficiency of service delivery.

Municipal infrastructure in the US - including bridges, sewer mains, and roads face huge deferred maintenance deficits. The most recent ASCE Infrastructure Report Card gives the nation's infrastructure systems a cumulative grade of D+, which means, infrastructure is in fair to poor condition and mostly below standard, with many elements approaching the end of their service life. A large portion of the system exhibits significant deterioration. Condition and capacity are of serious concern with strong risk of failure (ASCE 2017).

Deteriorating infrastructure is especially a problem at the local municipal level, where engineers are responsible for repairing and maintaining infrastructure systems with an ever smaller budget: “...because of inadequate funding or inappropriate support technologies, certain components of infrastructure have been neglected and have received only remedial treatments" (Vanier 2000, p. 40). Development and investment trends exacerbated this problem through the 1970s, 80s, and 90s:

To make matters worse, ...too much emphasis has been placed on new construction for the past three decades, all to the detriment of maintaining the existing facilities. As a result, organizations may have more facilities than they can afford to maintain...Added to these escalating problems, some municipalities are experiencing reductions in revenues caused by urban sprawl and relocation of industries to suburbs... (Vanier and Danylo 1998, p. 26).

While seemingly mundane and bureaucratic, city-wide asset management processes are increasingly important "leverage points" (Meadows 1999) for municipal engineers to bring attention to deferred maintenance issues, and to legitimate claims that increased investment in maintenance activities is both needed and efficient. For example, a recent survey done in the municipal water utility sector in the US found that, of the 451 water utilities surveyed, "the ability to explain and defend budgets and investments is the 
benefit experienced by the largest percentage of those doing four or more asset management practices" (McGraw-Hill Construction 2013, p. 2). In particular, this study also found that "concerns about the condition of...physical assets are the most important factors driving adoption of asset management by water utilities" and "for $75 \%$ of the utilities surveyed, addressing their aging infrastructure is an important factor leading them to adopt an asset management approach" (McGraw-Hill Construction 2013, p. 1).

In short, by bringing attention to, quantifying, and prioritizing the different risks of infrastructure failure city-wide, asset management techniques play an important role in guiding long-term investments in municipal infrastructure in the US. A move to explicitly fold green infrastructure into this system, by categorizing and measuring facilities as 'green assets', would be expected to likewise change infrastructure investment patterns in green, sustainable solutions. However, as discussed in Chapters $1 \& 2$, knowledge systems surrounding urban nature do not fit neatly within existing engineering knowledge systems upon which current infrastructure asset management is built.

In this chapter, I examine the emergence of the specific knowledge system challenge of fitting green infrastructure into existing asset management practices. First, I discuss the knowledge systems negotiation between financial-economic and ecological knowledge systems generally at the national and international level through the development of the ecosystem services concept and the Sustainable Accounting Standards Board (SASB), which both attempt to value nature as a critical service provider rather than a luxury. I then contextualize this national process with the results of semi-structured interviews with staff at the City of Portland. 


\section{$\underline{\text { The Value of Nature }}$}

WE ALL NEED NATURE.

Nature is crucial to our survival - without food, clean air and water, a buffer against floods and fires, we lose our way of life.

Nature is the backbone of the economy, but when is the last time you noticed it on a balance sheet? Far too often, nature is left out of the equation in accounting.

("Earth Economics: About Us" 2017)

What is the value of urban nature? City staffers mandated to provide and maintain greenspaces in the city increasingly ask this question in an era of climate change and crumbling infrastructure. Municipal budgets are notoriously tight, especially in shrinking cities like St. Louis, Syracuse, and Baltimore, whose tax base is not large enough to support infrastructures built up to serve a much larger population. Even in growing cities like New York, Portland, and San Francisco, departments responsible for greenspaces in the city are funded more sparsely and often unreliably through general funds (in contrast to utility departments which are funded by ratepayers). In an attempt to procure much-needed funding for the operations and maintenance $(\mathrm{O} \& \mathrm{M})$ of greenspaces, many practitioners argue that the value of nature in and around cities must be more deliberately and specifically calculated and communicated to both city decision-makers and the public. In other words, as the Earth Economics quote above advocates, the value of nature must be recognized officially by putting it on the accounting balance sheet.

To accomplish the task of accurately "booking" nature within financial and accounting practices today, the current understanding of the role of urban nature must change. Urban nature must not be seen only as a nicety or a beautification technique but as a service provider with functions and benefits valued at the same level as other urban 
infrastructural systems (i.e. the electric power grid). Traditionally, this has not occurred, even when parks were advocated for by powerful visionaries like Fredrick Law Olmsted. Park spaces, for example, are now argued to increase the competitiveness of a city because they beautify urban areas and increase livability. But outside of this, by and large, parks are not considered essential to urban life.

However, that understanding of parks and other urban nature is changing in some circles. For example, the National Recreation and Parks Association (NRPA) - a national non-profit organization of parks \& rec professionals and advocates - works to provide support to local level park projects. One of the primary knowledge claims asserted in their work is that parks and recreation "are essential public services" (NRPA 2010). In a succinct 2010 brief, they summarized academic research done at that time, quantifying the economic, health \& environmental, and social benefits of parks and greenspaces. This kind of reporting suggests that, as an institution, NRPA 'knows' urban nature as a service provider. Following the definition of a knowledge system used in this dissertation, this means that NRPA works to gain evidence about how nature works by better understanding the interactions between people and parks; they make that evidence credible through quantification of these interactions, some in economic and monetized terms like "trees in cities save $\$ 400$ billion in storm water retention facility costs" (p. 1), and others as functional outcomes like park redevelopment initiated "a 25 percent increase of residents who exercise at least three times per week" (p. 2); and, they circulate this information to others via professional webinars and meetings with local level professionals (NRPA 2017) to influence local decision-making. 
By recognizing and validating urban nature as a service provider (à la NPRA), greenspaces are made explicitly into infrastructure. This has important consequences for the management of urban nature, most notably changing levels of investment in its design, implementation, and maintenance. In this chapter, I examine the different knowledge system challenges that emerge when organizations attempt to recognize urban nature as a service providers and some of the work-arounds that have been employed in Portland to address these challenges.

But first, I provide wider context for the discussion of Portland with a review of different national and international movements to re-imagine the institutionalized ways we value nature today.

\section{Valuing ecosystems for their services}

At the global level, a particularly influential concept in the arena of increasing the visibility of nature as a service provider is the concept of ecosystem services. Ecosystem services are simply defined as the benefits humans receive from nature. The concept was developed primarily as a means to better communicate the value of nature to the everyday quality-of-life of all people (Millennium Ecosystem Assessment 2005), in particular highlighting the life-support and public health benefits provided by intact ecosystems. Some scientists, politicians, and bureaucrats hope that the ecosystem services framework will aid in increasing land conservation, preservation, and restoration efforts by quantifying the benefits that humans receive from nature for use in policy-making (National Ecosystem Services Partnership 2014); others hope that a systematic classification of ecosystem 
service benefits will allow previously unmeasured services provided by ecosystems to be monetized and otherwise integrated into our current economic system, ultimately giving nature equal footing in political debates around ecologically degrading practices (Costanza et al. 1997) or opening up previously untapped economic markets for exploitation ("Willamette Partnership" 2014). In other words, the ecosystem services framework attempts to translate nature into knowledge claims that are credible and actionable within the existing financial and economic knowledge systems dominating development in the world today.

Despite continued use of, and optimism around, the ecosystem services concept, actual on-the-ground valuation of ecosystem services has proved to be difficult (M. M. Robertson 2004; M. Robertson et al. 2014; Norgaard 2010; Chan, Satterfield, and Goldstein 2012) and fraught with ethical conundrums (Vucetich, Bruskotter, and Nelson 2015; Luck et al. 2012). For example, Robertson et al. (2014) find that the new practice of "stacking" ecosystem services - meaning multiple different environmental credits can be sold from a single restoration site - has the unintended consequence of allowing multiple sites to be developed per one restored site, leading to net loss in ecosystem services from an ecological knowledge systems view, even though the accounting knowledge system is satisfied.

One of the big challenges, that I focus on in this chapter, is the translation of ecological knowledge claims regarding ecosystem structure and function into financial and bureaucratic knowledge claims about benefits and services. Essentially, the components and generation of ecosystem services must be 'known' as valuable outside of the ecological 
knowledge system and within the dominant financial knowledge system. In order to do this, new knowledge practices that integrate ecological and financial knowledge systems must be developed; two such attempts are reviewed here: 1) ecological knowledge claims are being morphed to fit into existing financial knowledge systems (TEEB 2014), and 2) the financial knowledge system is being adjusted to accept ecological knowledge claims as they are (SASB 2012). Both of these movements remain on the fringes of the existing and powerful knowledge systems of mainstream institutions; but, as I will discuss in the following sections, both create spaces for knowledge system changes and innovation at the local municipal level.

Integrating Ecological and Financial Knowledge Systems

Two movements to integrate financial and ecological knowledge systems are at work in the world today, both attempting to improve the accuracy and precision of the valuation of nature, reinforcing the vision of nature as infrastructure and as serviceprovider generally. The first movement entails tailoring ecological knowledge claims to fit existing financial knowledge systems. Environmental non-profits and consulting groups work to compile and collect ecological data (e.g. nitrogen reduction potential of soils (nutrient cycling), species richness (biodiversity), etc.) and employ economists to elicit non-market values for these various ecological structures and functions using willingnessto-pay surveys, choice experiments, and other contingent valuation methods (Costanza 2011; De Groot, Wilson, and Boumans 2002; "Earth Economics: About Us" 2017) (e.g. how much are people willing to pay to keep a species from going extinct, or to have a 
fishable, but not a swimmable, river near their homes, etc.). These non-profits and corporations use these values, or their proxies, to create new market values of nature. This type of knowledge system negotiation, in which ecological knowledge claims are translated into monetized values through standard economic practices, has seen some success wetland banking for example is a prosperous, if small, business (Robertson 2004); and pollution credit trading has expanded in the US opening opportunities for greenspace to generate revenue outside of traditional development practice ("Willamette Partnership" 2014).

The Economics of Ecosystems and Biodiversity initiative - known as TEEB - is an international example of this knowledge system negotiation in action. A global research initiative launched in 2007, TEEB works on "making nature's values visible" (TEEB 2014). The initiative has a 3-tiered process to translate ecosystem structure and function into ecosystem services; the process consists of "recognizing value in ecosystems", "demonstrating value in economic terms", and finally "capturing value...in [financial] mechanisms". I argue that this process can be analyzed through the lens of knowledge systems: this movement represents a reconfiguration of ecological knowledge claims so that they are fungible in economic and financial knowledge systems. Through monetization methods, these values of nature can be used in business-as-usual financial spaces because market values count as credible knowledge claims in existing development decisionmaking spaces (i.e. the way this movement gathers and makes evidence credible about how nature works and puts it to use in decision-making is through quantification and then 
monetization of ecosystem services through traditional economic techniques, which is credible to investors and financiers).

Despite some success in the ecosystem services movement (most notably at the local level via trading of ecosystem service credits, see ("Willamette Partnership" 2014)), there is push-back against the concept of monetizing nature. This push-back can also be understood through the lens of knowledge systems. For example, biological conservation and ecological preservation institutions with their own established knowledge systems, 'know' the role of nature differently. Many ecologists argue that nature is greatly undervaluated by traditional economic methods (Chan, Satterfield, and Goldstein 2012; Luck et al. 2012). They stress that nature is invaluable because humans must have nature to survive. In particular, it doesn't matter what the public is willing to pay for nature - we will all die without it. And therefore they challenge economic knowledge claims that willingness-topay (WTP) survey work is a credible valuation technique among others.

The different ways that these two established knowledge systems - the ecological and the financial knowledge system - understand how nature works highlights the incommensurability of many knowledge claims about the value of nature.

A second knowledge systems integration movement, which is seen at the national level in the US, approaches this issue from the opposite direction; its advocates attempt to widen the financial knowledge system to accept ecological knowledge claims more directly. The Sustainable Accounting Standards Board, or SASB, was created in 2011. The organization grew out of research done at Harvard regarding voluntary corporate 
sustainability reporting programs and the need for standardization of Key Performance Indicators (KPI) of sustainability for businesses. These researchers state that their goal is ...to encourage the uptake of sustainability reporting in the United States... Focusing on key sustainability issues for each sector can facilitate the emergence of a reporting framework in which sustainability and financial reporting converge (Lydenberg, Rogers, and Wood 2010).

Discussion of convergence in this quote is telling: it highlights the usual distance between knowledge claims in ecological (i.e. sustainability) and financial knowledge systems by pointing out the need for these two sets of knowledge claims need to converge.

The founders of SASB overtly seek to confront an important disconnect between ecological and financial knowledge systems through their work; this disconnect emerges from the usual accounting standards view of nature. A brief history of these standards highlights the disconnect. Accounting standards were put in place nationally to protect investors and corporations. These standards dictate what can and can't be "booked" as an asset (i.e. what property/buildings/supplies a company owns that can be recorded as an asset) among other financial reporting needs. Accounting standards allow for a more comparable playing field between businesses with the intention of removing the ability of any one company to falsely inflate their worth.

Accounting standards have been built up around the need to quantify and know built property and human-made items. The knowledge system that supports these standards, therefore, knows nature as raw materials, building blocks, or background conditions, rather than a complete asset in and of itself. The institution that oversees these standards at the national level is the Federal Accounting Standards Board, or FASB. 
The way that FASB knows nature is not compatible with emerging ecological knowledge claims that assert nature as a critical service provider. Because of the powerful and slow-changing structure of FASB, and its focus on human-built capital, a new entity needed to form to address the concept of nature as an asset class. SASB was formed to create these missing standards for private companies to book their sustainability practices so that they can be more competitive to investors who increasingly care about green stuff (Cowan 2017). SASB represents the faction of the financial sector, then, that is actively working to adjust its knowledge system to incorporate ecological knowledge claims.

This second movement to legitimate nature as a service provider also faces challenges. SASB remains marginal in the world of finance, with only $\mathrm{X}$ companies reporting with their standards. It also faces competition from other emerging sustainability reporting processes and has been accused of green washing.

Regardless of push-back, the sustainability movement has permeated development activities in many ways. This has necessitated the integration of ecological and financial knowledge systems to translate and legitimate knowledge claims for use in institutional decision-making. Both of the movements reviewed here, that are attempting to translate knowledge claims and create new knowledge system practices, have an influence on local level governance of infrastructure. Connections to infrastructure will be presented in the next section and analyzed in Portland specifically through a case study at the end of this chapter. 


\section{$\underline{\text { Valuing infrastructure with Asset Management }}$}

How we select, design, and manage infrastructure systems today will play a key role in how such systems affect society and the environment now and for years to come. This in turn will have consequences for the exposure of infrastructure assets themselves to environmental, social, and governance (ESG) risks.

(Weber, Alfen, and Staub-Bisang 2016)

The management of risk is at the heart of asset management. As the quote from Weber et al. above suggests, the ways we value infrastructure (i.e. select, design, maintain) will shape the risks that infrastructural systems face into the future. Will we maintain them appropriately to keep them functioning? Or will we ignore the oil light and drive until the car starts making funny noises and spewing smoke?

In cities in the US, the post-war period represented a time of growth and investment in large scale infrastructural systems. Progress was measured through building bigger and bigger systems and conquering nature with infrastructure. This technological advancement and massive growth in the economy allowed continued building and expansion to become normal. However, focus on maintenance has not be a priority municipalities or companies that continually look to build new assets; the rapid pace of technology seems to show that there is no use in maintaining assets that will become obsolete before they deteriorate. Municipal infrastructure systems, some now a century old, were lost in the mix. And now, with the stalling of growth and the Great Recession in the U.S., are suffering even more.

A "tight budget" is one of the most commonly cited reasons for lack of maintenance of infrastructure, and green infrastructure in particular, in US cities (Carlet 2015). The primacy of budget as the barrier to green infrastructure maintenance is usually taken for granted. This is because we know inherently that there is not enough money to go around 
or do all proposed projects within a city and, therefore, trade-offs must be made. The thought process concludes that cost-benefit analyses must have been done and there are just more pressing issues to deal with than maintaining infrastructure. From a critical STS perspective, however, this stated reason, or knowledge claim, is not to be overlooked. Instead of "no room in the budget" forming the conclusion of why infrastructure is underfunded, statements regarding budget open new questions: why have other projects been prioritized in the budget over infrastructure maintenance and management?

In general, maintenance is, as it has always been, a politically unsexy topic. Politicians rarely seeks to address it because elections are won on new projects, bigger and better than the other guy, keeping the city attractive and interesting to investors. Additionally, it is difficult to secure funds for ongoing operations and management (O\&M) activities because they are allocated from the general fund (existing money from the tax base of a city) rather than from investor-backed bonds (which are paid back through time).

In this case, budget trade-offs around infrastructure bring up two important questions: Which services are considered critical in cities today and which are considered amenities or luxuries? How does this influence the funding structure of urban service provision? The answers to these questions ultimately tell us about how services are, and can be, distributed and to whom across a city, as they have been shown to do in the past (Melosi 2008). Many of the negotiations regarding funding and framing of service delivery happen within bureaucratic processes at the municipal level. Examining these expert spaces as places where power is lodged in seemingly objective technical decision-making can therefore inform the way maintenance work and the value of greenspace is known in the 
city; and how this knowledge might be changing practices, norms, and standards through time, potentially prioritizing different services in the process.

Urban planning historians and theorists have traced path dependencies over time that seem to dictate which services are priorities and which are discretionary (Melosi 2008; Tarr 1996; Lachmund 2013, 2004). I briefly present this history of service delivery in cities in the US through an urban planning lens to show the influence of knowledge systems' norms on these path dependencies and their ultimate material outcomes in the following sections, before narrowing in on asset management and financial knowledge systems' development in particular.

History of Service Delivery and Urban Planning

One of the primary mandates of a municipality is to organize and regulate the delivery of services to its citizenry (Fitzgerald and Durant 1980; Melosi 2008). The definition of what services (e.g. wastewater treatment, recreational space, the internet) and how these services should be provided (e.g. single-service optimization, centralized or decentralized infrastructural systems), as well as who is provided these services (e.g. wealthy elites funding the system or all residents of regardless of payment), has changed through time as dominant, popular ideas about society and ecology have transformed urban governance and planning practice (Booher and Innes 2010; Gottlieb 2005; Healey 1997; Ortolano 1984; Rawson 2004).

The idea of urban nature as a service provider is important to this transformation over time. This is because while nearly all municipal services require the utilization of 
nature - either through direct contact with ecological structures within city limits or indirectly through the utilization of natural resources from outside of city limits (Melosi 2008; Edwards 2003) - the role of nature in urban service provisioning is not often acknowledged. For example, the ecological purification of wastewater was a long underrecognized service in urban areas. The original idea of sewer systems was to remove bad smelling wastes from city streets, where they were originally disposed of; but actual designed mechanical, chemical, or biological wastewater treatment was not developed or implemented for more than a century after the innovation of an underground sewer.

The provision of clean water vs the collection and treatment of wastewater also provides an example of the influence of economic growth benefits on early municipal infrastructure and service decisions. The power of economic elite and the market at the local level assisted in the quick development of clean piped water to urban households (Melosi 2008). Because the wealthy demanded, and could pay for, clean water provision to their homes, private industry grew around this service. However, the development of sewerage was glacially-slow: "In the case of waste disposal, there was little or no linkage at this time between the search for a pure and plentiful water supply and methods of eliminating an array of rejectamenta and effluvia. Waste disposal had yet to rise much above the level of nuisance in the eyes of the public or city officials" (Melosi 2008). The model of the human-nature relationship in this case did not flag wastewater as a problem linked to environmental degradation. It was a nuisance, yes, but primarily for the lower classes; wastewater was only something that presented health and wellbeing risk to the lower classes, while the wealthy were able to avoid it spatially. Because it did not affect 
the wealthy, or their pursuit of profit, it was not part of planners' mandate. This also meant that it would not be a very profitable business; poor people would be the primary consumers of such a centralized service (the wealthy had their own, decentralized wastewater treatment methods outside of city limits) and could not afford to pay fees for its provision. Therefore, it took quite a while before any sewerage or wastewater treatment was built in cities in the United States.

As these this brief example suggests, natural systems have been conceptualized in different ways through different urban social movements (Gottlieb 2005), leading to the utilization of different knowledge systems in urban planning activities. Differences in the norms, credibility tests, and protocols of these knowledge systems have shaped, and have been shaped by, a variety of urban infrastructures that have become embedded in urban form through time (Lachmund 2013). The waste disposal example above provides an illustration of this. In the dominate way of knowing nature in the early industrial city, ecosystems were a static background condition that would collect wastes but was not harmed or altered by this collection. In other words, the environment was conceptualized as a sink, a final outfall; engineering system models did not extend past this point. Instead, any health or environmental degradation problems that arose from waste collection in the streets was considered a symptom of social or moral corruption of the individuals (Taylor 2009), rather than being discussed as an ecological response of the natural environment.

This way of knowing, held by the dominant municipal knowledge system of the time, helped shape the types of solutions that were considered by social institutions to address poverty and disease (Melosi 2008). Combined with an expert-driven, top-down 
model of planning practice in the early industrial city (Friedmann 1993, 2011), planners attempted to optimize the physical layout of the city in ways that would improve morality. At the same time, dominate social paradigms did not hold planners responsible for many of the social ills of the industrial city; if people were in poverty, it was an indication that they were a bad person, and wealth indicated a better sort of person. It was an individual's responsibility to change their character if they wanted a better quality of life (Rawson 2004).

This example shows the influence of epistemologies - ways of knowing - on the development of cities. The assumptions that early planners held about the way nature and society worked provided the foundation for the institutional norms, practices, and protocols of municipal government.

The knowledge claims used to know nature and infrastructure in the early industrial city informed the current funding situation of service delivery in many cities in the US: wastewater collection and treatment are direct fee-for-service departments, while parks and recreation departments and transportation departments are reliant on monies from the general fund. The general fund is determined by the tax base and fluctuates with property values (in most US cities) and is divvied up between a number of different city amenities, including after-school programs and pensions for fire and emergency responders. When times are good, and there are many people and businesses in an area, those departments that use general funds do fairly well and increase their service levels. When times are rough, they are the first to lose funding. 
The dynamics discussed throughout this section laid the groundwork for the development of asset management across city departments; the siloed historical development of urban service delivery was no longer able to keep up with demands without concerted efforts to allocate maintenance dollars across infrastructures.

\section{Current Financial Knowledge System}

Financial accounting guidelines at the national level currently do not consider greenspaces, including street trees, parks, wetlands, etc. as financial assets. Financial assets are often referred to as "kickable" - they are tangible, physical goods that can be sold on the market; for example, the sewer piping system in a city is an asset which could be sold/privatized. The benefit of classifying a facility/system as an asset is that it can become collateral in borrowing situations. For example, a city can count pipes as assets when borrowing money; investors are comfortable with the loan because they know that they can take the assets the city owns if the city defaults on its loan and still make their money back.

Other important expenditures in a city include operations and management (O\&M) of assets; this includes regular maintenance activities and condition assessments. Most greenspace design, construction, and management come out of this type of budget. There is an incentive to make this budget as small as possible and improve the overall city's credit rating by maintaining more investment in capital assets than O\&M.

There are strong and powerful boundaries within this accounting knowledge system. These are the standards set at the national level which dictate what can and can't count as assets by companies (i.e. what can and can't be "booked"). As described in an 
earlier section, this has long been dictated for businesses and corporations to ensure appropriate and standardized assessment of company worth to assist investors in understanding investment risk and potential return on investment. FASB is the entity that dictates these standards.

In the early 1980s, a discussion regarding the utility of FASB standards for municipal government came to a head: municipalities have fundamentally different goals from businesses (i.e. they needed to stay solvent but they are supposed to provide services to citizens rather than make profit.) This made the standards set by FASB not quite right for cities; there was a different burden of evidence placed on cities than businesses. Therefore, the Governmental Accounting Standards Board, or GASB, was born - an entity that was to take on the unique knowledge needs of a city government in determining asset classes, depreciation rates, etc.

Because of its close ties with FASB and other corporate banking systems, GASB remains an imperfect tool for dealing with public goods. It has been criticized by those in the field for remaining too connected to corporate standards. However, it remains in place for the time being as the gold standard for municipal accounting.

\section{Asset Management in US Cities}

The emergence of standardized asset management practices in municipalities around the U.S. began in earnest in the 1980s (Leighton et al. 2016). Infrastructure across the country was in disrepair, deteriorating from a lack of consistent maintenance; as mentioned in the introduction, the focus on new development in cities exacerbated infrastructure problems (Vanier and Danylo 1998). Managers recognized the need for a 
more systematic approach to addressing deteriorating infrastructure. Asset management is used by municipal departments to highlight and systematically prioritize the maintenance of vast infrastructural networks that are continually marginalized by financial systems that favored new capital projects.

The basic definition of municipal asset management is: "a set of practices and methods for delivering desired services to residents and businesses, at the lowest life cycle cost (including environmental and social costs), while managing risk to an acceptable level" (McGraw-Hill Construction 2013). There are four common steps to asset management: 1) inventory assets, 2) assess the condition of inventoried assets, 3) assess the value of inventoried assets, 4) calculate the funding gap between budgeted funds and funds needed to maintain assets at current levels or at defined levels of service (Leighton et al. 2016).

While each of these asset management steps sound rather straightforward, each step has embedded within it a number of unspoken but powerful choices about what matters and what doesn't in the realm of infrastructure. For example, step 1: taking an inventory of all assets. As discussed in the previous sections, deciding what counts as an asset is based on a very specific worldview which originated in the context of for-profit business management and optimization. This has had real consequences due to the lack of inclusion of urban nature as assets. Assessing the condition of assets is likewise complicated by differing epistemological frames; the condition of an infrastructural system could differ depending on what services you have optimized the system to provide. In green infrastructure management, the inventory and condition assessment of nature as an asset 
differs substantially between departments and institutions. Established financial knowledge systems are well-calibrated to human-built technologies, leading facilities on the techno end of the eco-techno spectrum to be more comfortably fit in existing asset management procedures than those on the eco side of the spectrum.

The knowledge system challenges and dynamics involved with valuing green infrastructure as green assets will be explored in detail through case study results in Portland in the remainder of this chapter.

$\underline{\text { Methods }}$

This chapter presents one facet of the larger case study work undertaken in Portland; it digs into a particular theme that emerged from case study interviews and document review regarding the development of city-wide green asset reporting methods in parallel to traditional asset management processes.

A brief review of methods is presented here, highlighting only the methodological pieces of the research design of this dissertation that pertain to understanding the theme of asset management in Portland. A complete methods description of the Core Qualitative (Figure 2-1) portion of this dissertation is presented in Chapter 2.

\section{Discourse Analysis}

I used discourse analysis to illuminate this case study of asset management in Portland. Discourse analysis here incorporates the specific methods of content analysis and in-depth interviews. I define discourse as "an ensemble of ideas, concepts and categories 
through which meaning is given to social and physical phenomena, and which is produced and reproduced through an identifiable set of practices" (Hajer and Versteeg 2005).

As Knorr-Cetina points out, "to discover practices, it is 'necessary to gain a working familiarity with the frames of meaning' within which people enact their lives, and symbolic doings such as rituals or 'writings' are as much practices as any others" (p. 364). To gain familiarity with green infrastructure knowledge systems and settings, and the uncovering of the emerging attempt to integrate ecological knowledge practices within financial accounting knowledge systems, therefore, required extensive review of documents and plans, as well as asking interviewees to describe the process of valuation and financial reporting within their department or institution.

Discourse analysis is ultimately useful because of its potential to be transformative. Howarth (2000) describes one of the goals of discourse analysis as "locat[ing]...investigated practices and logics in larger historical and social contexts, so that they may acquire a different significance and provide the basis for a possible critique and transformation of existing practices and social meanings" (p. 129). Through this analysis of the discourse surrounding green assets nationally and in Portland, I call attention to usually implicit unsustainable knowledge practices and provide potential alternative pathways towards more sustainable green infrastructure programs in the future.

\section{Content Analysis}

A variety of City of Portland asset management reports and documents were collected (see Table 3-1); most were suggested by interviewees as important or influential 
to the ongoing process. All interview transcripts and suggested reports were coded using ATLAS.ti. An a priori codebook was used initially to address the larger research questions of this dissertation (as described in Chapter 2). Additional open-ended coding was conducted on the green asset subset of documents and transcripts specifically to flesh out this facet of green infrastructure knowledge systems creation in Portland. A priori codes focused on in this chapter include valuation methods, financing mechanisms, and explicit reference to values and ecosystem services assessments.

Table 3-1: Asset plans, polices, and reports reviewed in Portland

\section{Documents reviewed}

City of Portland

Australian report - 2014 Adding value through Green Infrastructure: working effectively with Local Government

DC Water: Green Infrastructure Fact Sheet

AWWA 2015 Establishing the Level of Progress in Utility Asset Management Survey Results

Smart Cities Financing Guide: Expert analysis of 28 municipal finance tools for city leaders investing in the future

2007, 2012, 2015, and the draft 2017 Citywide Asset Report

Citywide Green Asset Report (draft)

\section{Interviews}

I conducted interviews with municipal staff who work in bureaus that self-identified as being involved in green infrastructure management in some way. My initial interviewees were contacts I made through other green infrastructure projects in Portland. From this initial group, I used snowball sampling to contact other staff engaged in green infrastructure asset management. 
Interviews were semi-structured, with some over-arching questions developed from content analysis of municipal plans and other document review; these were asked of all participants. Additional questions were tailored to each staff members' position and job title to better understand their specific role in green infrastructure management. Introduction and wrap-up questions were open-ended to allow interviewees to describe green infrastructure definitions, metrics, and values in their own words.

All interview audio was transcribed by a $3^{\text {rd }}$ party transcription service. I reviewed each transcription for accuracy by listening to interview audio during my first read-through of each transcription. This also allowed me to hear specific intonation and other verbal cues that could be misinterpreted when reading the text only.

All reviewed transcriptions were then coded using the qualitative analysis software ATLAS.ti. A number of a priori codes (described in the content analysis section above) were used to code the transcriptions. Over 500 additional, emergent codes were generated and consolidated through the coding process (using Friese's (2014) coding methods), revealing important themes not originally hypothesized. Various facets of asset management emerged as primary themes from this process when coding interviews in Portland.

\section{$\underline{\text { Results }}$}

Green asset management is an institutional knowledge system change around green infrastructure development and maintenance that was observed in Portland. Multiple interviewees discussed new city-wide (rather than existing siloed department-by- 
department) management of green infrastructure as assets as integral to future green infrastructure development and maintenance. While each city bureau manages some green infrastructure facilities as assets, procedures are not standardized or recognized city-wide or across the eco-techno spectrum, leaving out facilities primarily on the 'eco' side of the spectrum. A move to standardized recognition, assessment, and prioritization of urban nature across the eco-techno spectrum as 'green assets' was described by interviewees as following the lead of the traditional infrastructure asset management practices in the city; currently, efforts are focused on exploring the possibility of creating a city-wide green asset management report as a companion document to the existing annual report.

Through interviews with city staff, a number of important drivers as well as challenges of the emerging green asset management process were outlined, helping illuminate the various knowledge systems shaping valuation of green infrastructure in Portland. Here, I first present the history of asset management in Portland that was uncovered through interviews with members of the existing City-wide Asset Management Group (CAMG). Then I outline the drivers of the emerging green asset management process, including knowledge claims within each department regarding what green assets are and how they can potentially change management of urban nature in the city. Last, I describe different knowledge systems challenges, primarily challenges around valuing urban nature, that staff described encountering as they develop the green asset report. 


\section{History of Asset Management in Portland}

The general city-wide asset management process in Portland began over 20 years ago. Deteriorating infrastructure was an initial driver of the process. As a way to allocate funds more efficiently and effectively to maintain city assets in Portland, instead of repairing systems only after costly and potentially dangerous failures occurred, a robust city-wide asset management report was issued in 2002:

The city council identified priority issues; one was to address our deteriorating infrastructure, so that's how it got started. It was a city council directive in 2002 and this was the first one. (City of Portland Water Bureau staff)

The then-new asset management group combined and standardized inventories of all facilities that fit in the category of 'infrastructural assets' in the city and rated the condition of each asset. In this way, they were able to identify the most pressing and highest risk repairs and issues. Annually, the city-wide asset management group (CAMG) generates an asset report which updates council and bureau directors on the condition of the inventory and makes recommendations for the prioritization of maintenance and repair projects for the coming year. The original goals of this group were described by one CAMG member as follows:

How much are our assets worth and are we managing them adequately? Do we have enough money? That's really what this was about. What condition is it in? Is it in bad condition? Which is implied by the title [of the first report]: "Deteriorating Infrastructure." It went from being a strategic issue for city council to turning into this asset management group that would be responsible for looking at this year after year. (City of Portland Water Bureau staff)

While city-wide asset management of infrastructure has continued to improve over the last 15+ years in Portland, green infrastructure facilities have been largely left out of the city-wide process, and instead continue to be managed in silos by multiple 
different bureaus, some of which are now dealing with large maintenance deficits, especially on facilities on the 'eco' end of the eco-techno spectrum. Each of these bureaus has its own way of defining, measuring, and valuing green infrastructure - or in other words, its own way of 'knowing' and categorizing nature and infrastructure .

Prioritization of maintenance and repair projects is also done bureau-by-bureau; but the changing make-up of facilities (i.e. more nature-filled facilities that do not register as assets in some bureaus) has not yet influenced those prioritization processes. For example, the growing number of green streets in Portland has created new maintenance tasks without a comprehensive reallocation of the budget:

It's like, 'Whoa. Our inventory is going up. Our maintenance budget hasn't gone up. How are we going to maintain these things?' which fits right into this because the condition will continue to deteriorate. (City of Portland Water Bureau staff)

If the existing asset management process in Portland is an indicator of a path forward for green infrastructure, a standardized city-wide inventory would help the city systematically make investments in maintaining and managing green infrastructure facilities, reallocating funds to infrastructure in need repair or routine maintenance. Therefore, some staff and managers would like to follow in the footsteps of CAMG from 20 years ago and begin compiling a standardized inventory and condition assessment of green infrastructure facilities (across the entire eco-techno spectrum, from Forest Park to bioswales) as 'green assets'. There are a number of drivers of this process which differ slightly by bureau; I describe these drivers in the following section. 


\section{Drivers of Green Asset Management}

Three primary drivers of the emerging green asset management process in Portland were described by interviewees. The first driver is the growing number of green infrastructure facilities in Portland without an increase in maintenance budget (which follows general national corporate and municipal trends of maintenance funding discussed in the introduction of this chapter (Vanier and Danylo 1998; Vanier 2000)). A second, related driver is the regulatory vacuum left after the push of the CSO Program dissipated when it was completed in 2011. The third driver is a need for increased legitimacy of urban nature as a service provider and increased precision in its measurement. I describe each of these drivers in turn below.

\section{Increasing maintenance burden}

The number of green infrastructure facilities in Portland is increasing. For example,

Parks and Recreation has begun a new initiative to identify areas of developed parks throughout the city where green infrastructure facilities can be built, increasing the ecological value of underutilized areas:

[We are] actually looking at bringing habitat patches and more green infrastructure into our developed parks system...Separate from BES, our bureau is also looking at how to increase [green infrastructure] in our developed parks...[in] underutilized, passive, open space. So, it's not like we're going to take some sports field or an area that's used for Frisbee and picnicking and all of that, and convert it, but we have a lot of underutilized steep hills, wet areas, corners, things like that in our park system that...doesn't meet the best use. So we're working on identifying those areas and how we can actually increase their ecological value for the city and for our park system. (City of Portland Parks and Recreation staff)

Also, green streets facilities built in the public right-of-way have increased dramatically over the last 10 years. And the SWMM incentivizes developers to build more 
of these bioswales as well. These facilities are cared for by the developers for the first two years after they are constructed (the establishment period so to speak) and then they become the city's maintenance responsibility. This system of decentralized facilities has been increasingly difficult to maintain within limited budgets:

How do we balance the maintenance cost, our budget, our level of service with aesthetics and what the perception is from the public? Because, like I said, we started with three [green streets] in 2003 and now we have 1,800 and growing. That's when we really ramped up to look at what we were doing and how we were delivering this program and the maintenance. (City of Portland BES staff)

In general, it is difficult for municipalities to consistently invest in maintenance activities. As one staffer explains it, "There isn't necessarily something driving it that makes it rise to the top of the priority list" (City of Portland BES). This is similar to national and international trends of deferred infrastructure maintenance. As mentioned in the introduction, many of the infrastructural systems in the U.S. today are suffering from millions of dollars of deferred maintenance. For example, ASCE reports "the U.S. has been underfunding its highway system for years, resulting in a $\$ 836$ billion backlog of highway and bridge capital needs" (ASCE 2017). This is just one of the many infrastructure systems - including water and wastewater treatment, energy, public transit, rail, inland waterways, and solid and hazardous waste treatment - that face million and billion dollar funding gaps that need to be addressed to provide safe and consistent service (ASCE 2017).

\section{$\underline{\text { Regulatory vacuum }}$}

Another, related driver of interest in green asset management in Portland comes not from the usual regulatory hammer (like a CSO consent decree which has driven green infrastructure development in cities like Philadelphia) but rather from the "vacuum" 
created after a regulatory push disappears. Portland's CSO Program ended in 2011; this meant that resources and staff capacity was turned away from CSO and towards other pressing regulatory "fires" that needed dousing. Therefore, much of the previous active engagement with green infrastructure development for CSO mitigation has slowed, and another pressing concern for continued green infrastructure development has not replaced it with the same power as the Stipulation and Final Order (SFO) that instigated the original program. However, the city continues to build green streets and development codes that are now on the books continue to trigger construction of green infrastructure facilities. Some facilities in the network are now 15+ years old. All of this has led to a large maintenance burden and continued management need without a regulatory push to provide funding or staff hours.

In this relative vacuum, the staff of Portland's Bureau of Environmental Services (BES) and the Parks and Recreation Bureau (Parks \& Rec) have been struggling to meet the maintenance demands of a (growing) distributed system of facilities with limited and shrinking budgets. In the asset management teams in each separate green infrastructure bureau, staff have been attuned to the successes of CAMG, namely prioritization and management of other infrastructural systems; interest in using green asset management to provide a structure for continued investment in green infrastructure maintenance therefore has grown. Staff hope that this will fill the void. As one BES staffer put it:

They always say, 'follow the money', and that's where the interest comes from. I mean if it really wasn't the need for...more money for their projects and that was a good way to find it, they wouldn't probably been interested in that, if money was no object. (City of Portland BES staff) 


\section{Legitimacy of using nature as infrastructure}

There is also a recognition within the bureaus that build and manage green infrastructure facilities that urban nature lacks legitimacy as a service provider in many circles. Facilities on the 'eco' side of the eco-techno spectrum in particular - protected or conserved natural areas, or manicured developed parks of urban nature, that make up many of the green infrastructure facilities in Portland - are not considered infrastructure or assets outside of the bureau that manages them.

One important reason for recognizing green infrastructure as assets is the increased opportunity for public outreach and education. As assets, green infrastructure facilities are valued differently by the city through official accounting practices, producing more legitimacy and credibility for the facilities as part of the infrastructural system of the city. As one staffer at BES explains it, this encourages sustained maintenance of the facilities:

This is an asset that provides a service to you. You value it. You want to keep it for a longer time, so you pay attention to it. The other part was that ... Well, you can say, 'Oh, well, we have that...It's just a jungle. It's just a park.' You know? Unless you kind of shed light on what this park will do for the health of the citizens, for their entertainment purposes, for recreation, all those kind of things, then you are at the point of, 'Oh, okay. Well, I need to take care of it because not only I want to use it, I want my children to use it, too.' (City of Portland staff, BES)

Additionally, BES was confronted with a lawsuit in 2014 from ratepayers that challenged green infrastructure investments as a misappropriation of utility funds. In particular, the lawsuit and subsequent ballot measure proposing the creation of a new Water Board to manage water resources in the city challenged spending water utility funds on the Grey to Green program (among other allegations). As a news article at the time sums it up,

A lawsuit by large industrial customers has branded the city's Gray to Green and other green infrastructure programs as "unauthorized expenditure" and 
demanded a full accounting of where the money is being spent. Those same companies are bankrolling an initiative on the May 20 ballot to strip the water and sewer bureaus from City Council control, in a bid to reduce utility rates. (Law 2014)

This invigorated a legal discussion around the legitimacy of using nature as infrastructure; surprisingly, debate was around facilities that fell on the usually more amenable 'techno' end of the eco-techno spectrum like bioswales:

In a citywide debate on the proper role of the city water and sewer utilities, it's a good time to ask: Are these bioswales and related Green Streets projects a good investment for the city's utility ratepayers? Or are they a nonessential frill pushed by green do-gooders? (Law 2014)

This debate was related directly to the mission of the managing bureau (BES) and hit home the view of the ratepayers supporting the lawsuit - in essence, green infrastructure facilities are outside of a sewer utility's mission:

"DiLorenzo says there's been "mission creep" at the city Bureau of Environmental Services, supported by green activists. "They believe this isn't a sewer agency at all any more," he says..." (Law 2014).

This can be seen as a rejection of the idea that urban nature is an essential service provider and an assertion that traditional pipes and pumps are the purview of stormwater management.

The lawsuit was a "wake-up call" as one staffer described it; better communication regarding urban nature as a service-provider (in this case, providing the service of stormwater management) was needed, as well as increased transparency in funding and budgeting for green infrastructure facilities:

In a lot of ways, the lawsuit and the referendum happened because we hadn't communicated clearly about what we were doing. (City of Portland BES staff) 
Between the regulatory vacuum and lawsuit, bureaus managing green infrastructure both lack funding to adequately manage and maintain the growing green infrastructure network in Portland, and are discouraged from spending even the amount that they do due to the lack of credibility around the notion of urban nature as a service-provider.

Because many staff at BES and Parks \& Rec in Portland recognize urban nature as a legitimate part of the infrastructure of Portland, they have sought ways to legitimate and validate green infrastructure throughout the city in order to normalize it and reduce the risk of further attacks on spending. In an effort to establish green infrastructure facilities as actual infrastructure projects, rather than allowing facilities to retain their image as green 'luxury' projects, an inventory and quantification of value of all green infrastructure, citywide, as 'green assets' would assist with this legitimation. As the BES staffer from above continues:

I think asset management teaches you to compartmentalize things and be really clear about what you're working on, and so that's what we want to do. (City of Portland BES staff)

All three of the drivers discussed in this section have made green asset management appealing to a number of departments in Portland. However, efforts to operationalize an inventory, condition assessment, and prioritization process for green assets has encountered a number of knowledge system challenges primarily around the valuation of urban nature. These are discussed in the following section. 


\section{Knowledge System Challenges}

There are differing knowledge systems at work in different bureaus that manage green infrastructure (as explored in Chapter 2). And each of these knowledge systems differs from the financial knowledge systems that prescribe asset management procedures. This creates tension between differing definitions, metrics, and valuation techniques of nature and infrastructure throughout the city. Many different knowledge system challenges were highlighted in interviews with City of Portland staff; as one staffer at BES sums it up:

Once we got into it, it become more and more complicated. (City of Portland BES staff)

The greatest challenge with creation of green assets was described as stemming from the inclusion of biological elements (i.e. nature) in green infrastructure facilities; different values ascribed to nature by different bureaus created tension. This was echoed in interviews time and time again, typified by the following:

You also recognize that the characteristics are not the same [for the green as for the grey], so you can't follow the same formula as you're...putting value on it. You just maybe need to put that in a different bucket. (City of Portland BES staff)

It's fairly straightforward to do it for our sanitary and combined system, with the pump stations that you plan, and assigning a value to those things, but assigning those values to the green infrastructure is something that is still in a bit of a state of flux for us. (City of Portland BES staff)

That's when I say that things are much more complex is because there's all different characteristics of this new category of assets that it brings that kind of things to the idea. (City of Portland)

Therefore, in this section, I present the knowledge system challenges that emerge around green asset management as conflicts between "ecological" and "accounting" knowledge systems. These terms are used as shorthand to represent two different ways of 
understanding nature. While there are many existing ways of knowing nature in the city, these two understandings were most prominent in this analysis. The "ecological" here represents a way of understanding urban nature as a self-reinforcing system - or ecosystem. This knowledge comes from the academic fields of ecology and biology but also the practice of agriculture and gardening. This knowledge system generally incorporates humans as another species in the food web, another animal, and examines human impacts on the environment at large and on specific ecosystems at the local/regional scale.

The "accounting" shorthand here represents the way that current municipal accounting systems view nature as natural resources and economic goods or investments. This knowledge system is heavily influenced by engineering in the realm of infrastructure accounting. In most bureaus at the city, for example, those in charge of asset management of infrastructure are senior engineers, able to track and assess inventoried grey assets (like pipes, pumping stations, etc.).

I argue that these two knowledge systems form the base conditions (the norms, protocols, and practices that inform decision-making) from which a number of challenges arise. These are listed in Table 3-2, which displays knowledge claims from one knowledge system next to its contradictory or conflicting knowledge claim from the other knowledge system. Each of these challenges will be discussed in turn in the following sub-sections; implications of these challenges across the eco-techno spectrum are then presented in the discussion. 
Table 3-2: Competing knowledge claims, norms, and protocols from ecological vs accounting knowledge systems

\begin{tabular}{|l|l|}
\hline \multicolumn{1}{|c|}{ Ecological Knowledge System } & \multicolumn{1}{|c|}{ Accounting Knowledge System } \\
\hline \multicolumn{2}{|c|}{ Definition of 'asset' } \\
\hline $\begin{array}{l}\text { SERVICE VALUE: The value of nature lies in the } \\
\text { services it provides (to both humans and } \\
\text { nonhumans). }\end{array}$ & $\begin{array}{l}\text { REPLACEMENT COST: The value of an asset is } \\
\text { its replacement cost }\end{array}$ \\
\hline $\begin{array}{l}\text { Assets are just things with a dollar value attached } \\
\text { to them. }\end{array}$ & $\begin{array}{l}\text { An asset is something that has a value in the } \\
\text { market/could be sold. }\end{array}$ \\
\hline \multicolumn{2}{|c|}{ Measuent } \\
\hline $\begin{array}{l}\text { Limited/unsatisfying metrics to measure the value } \\
\text { of nature in dollars to put on a ledger. }\end{array}$ & $\begin{array}{l}\text { No standards allow nature to count as an asset on } \\
\text { the books. }\end{array}$ \\
\hline $\begin{array}{l}\text { Ecosystem components (vegetation for example) } \\
\text { provide more services through time as they mature. }\end{array}$ & $\begin{array}{l}\text { An asset depreciates through time according to a } \\
\text { specific definable schedule. }\end{array}$ \\
\hline \multicolumn{2}{|c|}{ Valuation } \\
\hline $\begin{array}{l}\text { Trees are essential service providers and therefore } \\
\text { should be considered assets. }\end{array}$ & $\begin{array}{l}\text { Trees are amenities and therefore should be } \\
\text { included in decision-making in other ways (not as } \\
\text { an asset). }\end{array}$ \\
\hline $\begin{array}{l}\text { To get capital funding for a restoration project, } \\
\text { must include with a capital grey infra project. }\end{array}$ & $\begin{array}{l}\text { Anything nature related (landscaping, bioswales, } \\
\text { etc.) is included into the cost of construction of a } \\
\text { larger capital project. }\end{array}$ \\
\hline
\end{tabular}

\section{$\underline{\text { GASB Standards }}$}

The most significant challenge observed between accounting and ecological knowledge systems stems from the current incompatibility of urban nature with accounting standards. Financial accounting standards for municipalities are dictated by the Governmental Accounting Standards Board, or GASB (as described in more detail in the introduction of this chapter). As one staffer at OMF explains, as far as GASB is concerned, nature has "zero asset value":

What's the value of Forest Park? What's the value of the trees in our parks?... Those are the kind of things that, from an accounting point of view, don't get reflected on the books and records of the city. So, they have zero asset value. (City of Portland OMF staff) 
To legitimate nature as infrastructure and integrate facilities into asset management processes city-wide, they must first be valued in terms that can be "booked" (i.e. written on the accounting ledger).

Many practitioners in BES, Parks \& Rec, and the Water Bureau - bureaus that own green assets directly - talked about the importance of changing these standards to allow for nature to be "booked" to improve green infrastructure maintenance and management:

International accounting rules are still different between gray and the green assets, so there's a concerted effort from a number of cities across the country to get the GASB accounting rules changed so that we can book green infrastructure more readily. (City of Portland BES Staff)

Operations and maintenance dollars, those are a huge deal for us...Directing those appropriately is very important. And right now we're just kind of looking at, from a financial perspective, how do we really get some order and structure to that process? (City of Portland Parks \& Rec Staff)

A number of knowledge claim tensions were identified within the process of integrating green assets into accounting standards as problematic. One is a tension around the notion of depreciation. Traditionally, assets are depreciated throughout their anticipated useful life cycle. They perform at their best just after they are built and calibrated; they then deteriorate through time in a fashion similar to the life cycle schedule picture in Figure 3-1.

Green infrastructure on the other hand improves in functionality as vegetation matures, perhaps appreciating value for decades before deteriorating.

Part of the nuance that the US accounting system is based on the concept of depreciation and green assets are often appreciating. So you can plant a sapling but ten years from now its value is higher than it was when you planted it, where as when you build a building, you start depreciating it because in theory in 50 years its life cycle is...well, you don't have any value in that building anymore. (City of Portland Parks \& Rec staff) 
As Figure 3-2 shows, maintenance is also different throughout the life cycle of a green vs a grey asset. These differences must be quantified and adapted into GASB standards to be "booked" appropriately.

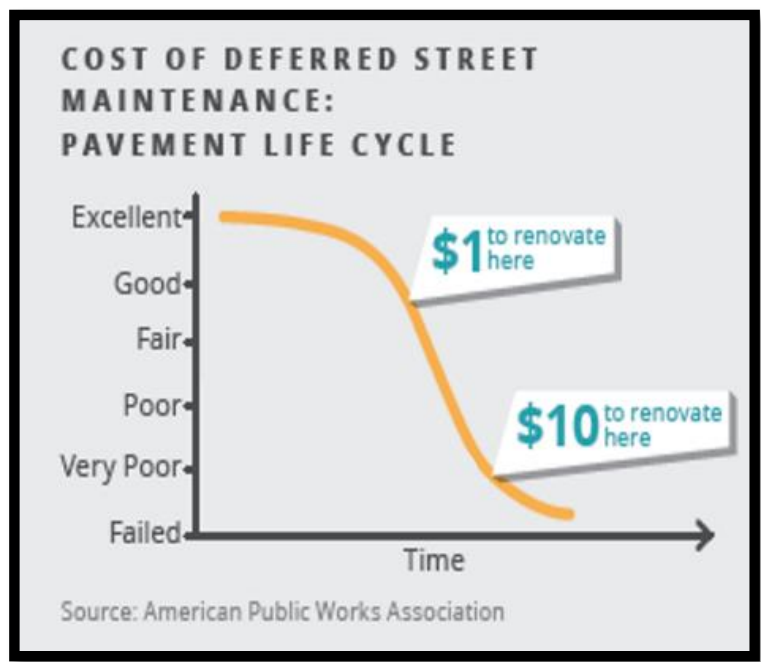

Figure 3-1: Life cycle schedule of pavement from the 2017 CAMG annual report draft.

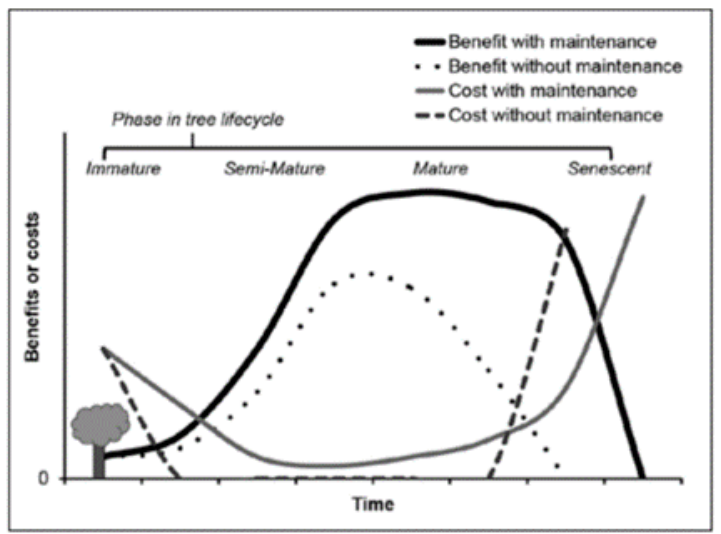

Figure 3-2: Benefits and costs of a street tree through its life cycle (from Vogt et al 2015) 


\section{Bureau knowledge system mismatch}

Another important set of knowledge systems challenges the green asset

management process faces is a mismatch in understanding between bureaus regarding the need or drive for such a change. In other words, the legitimacy of including new knowledge claims in the accounting systems is in question. For example, while staff in financial positions in BES, Parks \& Rec, and the Water Bureau advocated for green infrastructure to be considered assets (and indeed some green infrastructure facilities are currently considered as such at the bureau level), at city-wide financial offices and bureaus (i.e. Bureau of Revenue and Financial Services (BRFS), City Budget Office) staff did not see movement, nor a need, within their own disciplines to include biologically-based facilities in their operations:

I haven't heard a lot about green infrastructure particularly being a hot topic right now. (City of Portland BRFS staff)

It's clear that the accounting thinking has a different orientation and I'm not aware that people have really sat down and go, 'You know, we don't see this as correctly valuing these things' and therefore, putting that value on our financial statement. I'd say it's very, vey early in thinking and I'm not aware that there's any disciplined effort to do much about it. (City of Portland BRFS staff)

There is evidence in Portland that this lack of recognition or movement is driven by the lack of 'knowing' urban nature as a service-provider by those outside the ecological knowledge system. As one accountant described it:

I don't see any real work on the finance front [to include green infrastructure like trees in financial statements]. Now, promotional opportunities? Sure. You could say oh, this many ounces of clean air or whatever the measurement is. You could use promotional opportunities to show the benefits. (City of Portland BRFS staff)

Here trees are important as a nicety or perhaps an amenity, but not as essential by any means. As another staffer describes it, "part of the asset mix is some of these things that 
have value that we don't get to value." As promotional amenities, rather than service providers, green infrastructure facilities are still important, but are not appropriate to include as assets in official financial documents like the Comprehensive Annual Financial Report, or CAFR, which is complied city-wide each year. The sentiments of these quotes highlight the contrast between the accounting knowledge system and the ecological knowledge system and the credibility of knowledge claims regarding nature in each.

As mentioned in the introduction of this dissertation, ...even when new knowledge is created that can support novel solutions, this knowledge may not proceed to be used in the political process because there are other already established and powerful knowledge systems informing the policy process as well (e.g. use of economic indicators in state planning agencies). Moreover, assumptions about what knowledge is more credible in decisionmaking can ultimately affect how well we understand the dynamics of the system under study (e.g. ecosystems). (Munoz-Erickson 2014)

The mismatch between ecology and accounting knowledge systems described in this section represents an example of the problem Munoz-Erickson elaborates. An acknowledgement of this issue as institutional, rather than technical, begins a more productive dialogue between departments, and offers a point of intervention to design a more effective knowledge system in Portland.

Overall, the tensions observed here show the hurdles that BES, Parks \& Rec, and other departments managing green infrastructure, face to make green infrastructure 'count' as a legitimate service-provider city-wide. The reward is potentially great, helping better maintain natural assets throughout the city. Therefore, staff continue to pursue the idea; a green asset report will be released by the end of 2017 which will serve as an initial inventory and condition assessment city-wide. This report will be presented as a companion 
document to the official CAMG report. Green assets may never be incorporated directly into the official accounting processes of the city, due to the incommensurability of the facilities, but the collaborative effort helps different silos and factions in the city come together around green infrastructure and better quantify and recognize nature as a service provider. As Parks and Rec staff explain,

I think we have a long way to go. I think we're heading in the right direction, but we're just barely starting the trip.

\section{$\underline{\text { Discussion }}$}

One of the primary conceptual shifts brought about green infrastructure, found and elaborated in the results presented in this chapter, is the shift to officially 'knowing' nature as a service-provider rather than a luxury in the city. A primary tension around this shift (uncovered in interviews in Portland) is the ontological and epistemological mismatch between ecology and accounting knowledge systems. This tension is explored in the following sections using the STS literature regarding standards and standardization in conjunction with the eco-techno spectrum.

\section{Standardization}

Standardization of nature through green infrastructure is an important force in nature's depoliticization. What do I mean by this? Throughout this chapter I have outlined the drive of staff to 'know' nature as a collection of green assets. One reason is that as a luxury or nicety, urban nature is subject to political whims and philanthropic sentiments,

much like it was during the progressive reform era (Rawson 2004; Melosi 2008; Eisenman 
2013). If standardized as an essential service provider, urban nature would become a technology of sorts, further black-boxed into the mundane technical details of the city and buffered from changing political winds. It would have legitimacy as important in the engineering and financial accounting knowledge systems which dominate decision-making in the city; and become a standard that drove development patterns, much like the size of a fire truck dictates the underlying structure of the street grid and therefore development in general (Ben-Joseph 2005).

How does the act of standardization accomplish the artifice of depoliticization? The STS literature tells us that standards are formalized, bureaucratic, and often wide-spread classifications and categorizations (Bowker and Star 1999). One of the primary ways that knowledge influences our day-to-day lives is through these standards. We expect the world to look and behave a certain way in the city, largely because of the standards that have been put in place, requiring specific social and physical orientations and movements (Lampland and Star 2009).

Action is an important aspect of the definition of standards. While standards often feel static in and of themselves, they only exist in relation to the actions that they both encourage and prohibit. In other words, standards are "forms of compression and representation of action" (Lampland and Star 2009). They dictate the actions that an authority has deemed the best moving forward. For example, in urban planning, "standards are the source of how communities are designed and built. They define how places can and can't be developed, and how controls shape the physical space where we live and work" (Ben-Joseph 2005, p. xxi). 
Standards have the benefit of blending into the background and are implemented often without reflection down the line (Bowker and Star 1999). Standards are based on decisions and viewpoints of the past. Because so much is built into them, and the understanding is that they will be used without substantial local reflection (again because this is what must be done to get anything done in life), standards are not easy to change. The process is fraught with messy politics and power and decisions about the appropriate way forward (Hacking 1999). Ultimately, I argue here that the creation of standards is a knowledge system integration process, where different visions of, or ways of knowing, the world must be negotiated and then stabilized into the standards themselves.

A push-pull relationship was observed in the case study cities in this dissertation between increased standardization of green infrastructure and the ability to keep the concept broad and inclusive. As discussed in Chapter 2, the differentiation between these two viewpoints was split by department or bureau rather than by city. Within the norms and practices of engineering, very specific definitions and standards are needed for green infrastructure and its components. In contrast, coordinating agencies like the office of sustainability and planning are interested in keeping the concept more open-ended to allow for a number of stakeholders to engage with the process.

If we consider the standardization of nature in green infrastructure as a kind of state simplification process (introduced in Chapter 2), then we must be wary of the potential issues that it will create down the line by ignoring local context and knowledge. Essentially, we must decide what kind of services we expect from green infrastructure and who is responsible for service delivery. What level of service do we design them to perform? This 
is an important decision-point; there are different ways that this could go. We could continue to talk about green infrastructure as if it was a nice thing to have around, which lends itself to individuals taking care of it. Volunteers and community groups would be in responsible for maintenance and upkeep, rather than the municipality. If instead nature is infrastructure providing utility services, a way of knowing that was found in the results of this chapter, then it should be the maintenance responsibility of the municipality. As Carse (2012) found, making nature infrastructure changed the relationship of farmers with their land, and allowed the government to come in and assert more power.

We must acknowledge that there are important politics embedded in the seemingly mundane technical decisions to standardize green infrastructure facilities. Increased standardization of urban nature via green infrastructure means that urban nature will be further optimized to provide specific services over others. The decision about which services those are must be open for wide discussion and negotiation within the planning process to avoid the pitfalls of state simplifications of the past (Friedmann 1993; Scott 1998).

\section{Across the eco-techno spectrum}

This dissertation has highlighted the variety of facility types included in the concept of green infrastructure by developing the eco-techno spectrum (Chapter 1). This spectrum is useful again here in pointing out the differences between an entire watershed (i.e. the 'eco' end of the spectrum) and modular, mostly human-built bioswales (i.e. the 'techno' end of the spectrum), and illuminating the variable success municipalities have had in 
making these different types of urban nature an asset class via state simplification processes.

On the 'techno' side of the spectrum, bioswales and green roofs are treated more like traditional infrastructural facilities than facilities found on the 'eco' side of the spectrum, e.g. remnant forests, urban wetlands, etc. Because 'techno' facilities are discrete units, and contain mostly human-built components, they more easily fit into business-asusual financial accounting practices. For example, the concrete, the soil mix, and even the plants purchased from a nursery that make up a bioswale all have a well-defined replacement cost. However, these facilities still face challenges when they are brought into the accounting knowledge systems; as discussed throughout this chapter, the biological components of facilities, even on the 'techno' side of the spectrum, still don't have asset value in the current system.

Large remnant forests however, a facility on the 'eco' side of the spectrum, have an even harden time integrating into the accounting knowledge system. Usually, forested land owned by the city is either purchased cheaply or gifted because it is unfit for development. Land is valued at what was paid for it - in the case of gifted land, that value is zero. There are limited ways to value the components of this facility type; therefore, the services are instead emphasized (this finding corroborates Carse's (2012) findings in Panama).

However, measurement of services (as discussed in Chapter 1 and 2) is still lacking or contested at present. Until the services of facilities at the 'eco' end of the spectrum are better quantified, they will continue to resist state simplification. This is because without 
service metrics, municipalities still lack interested, documentary, static, aggregate, or standardized facts about this type of urban nature. Therefore, I argue that these 'eco'leaning green infrastructure facilities are not yet legible, while 'techno' facilities like bioswales, rain gardens, etc. have emerging legibility and are increasingly quantified into the asset management databases of cities building them. There is the possibility that these networks of modular nature will become like the scientific forests of the past (Scott 1998) as the municipality attempts to optimize them for a few services of interest (most likely water storage).

The legibility of 'techno' side green infrastructure facilities is also an important factor in the popularity of these types of facilities thus far in municipal planning activities. Because they are more easily understood as infrastructure (again because of all the humanbuilt pieces of the technology that accompany them) they are also easier to depoliticize.

Some of the important political work of making nature a service-provider is that this vision moves the imperative of having nature in the city away from a mythical or a moral/ethical appeal. It attempts to make nature techno-mechanical in order to standardize and routinize it into the background of our lives. While STS scholars argue that all technology is political (Winner 1986; Pinch 2010), the appeal to 'nature as infrastructure' attempts to place nature out of the political spot-light and into the everyday black-boxes of technological sophistication. Then squishy, fluffy, contingent values and understandings of nature can be left to other debates and urban nature is left as just another tool in the infrastructure toolbox, as commonplace as an electric pole, a city road, a stop-light. As 
Pritchard (2011) described it, it is the "depoliticization of technology" that makes it so appealing to place nature in that category.

This chapter provides an example of this process which was uncovered by this dissertation research. Portlanders hoped to legitimate and make credible their use of nature as infrastructure by integrating it into standardized asset management techniques. Because of the legal challenge BES faced in 2014 from ratepayers, who asserted that green infrastructure was outside of the mission of the sewer utility, they knew they must be more transparent about spending stormwater funds. But importantly, they must also show that what they were spending money on was legitimate and credible as infrastructure.

\section{$\underline{\text { Conclusion }}$}

In this chapter, I have examined the emergence of a particular knowledge system challenge between ecological and financial knowledge systems influencing the development and continued maintenance of green infrastructure in cities today. Advocates of ecosystem services and the Sustainable Accounting Standards Board (SASB) work to translate knowledge claims about the value of nature between ecological and financial conceptual frameworks. While they remain fringe in both established financial and ecological communities, the concept of nature as a service provider has gained traction at the municipal level in some places, as shown in this chapter through a review of Portland's asset management.

Current asset management standards have consequences for the path of green infrastructure moving forward. For one, asset management and GASB standards encourage 
the construction of facilities on the techno side of the eco-techno spectrum with mostly human-built components. More generally, the primary knowledge system change highlighted in this chapter is the transition of urban nature from being known as a luxury or amenity to being known as an essential service-providers. This is part of a larger trend globally to improve environmental conditions by drawing cleaner links between healthy ecosystems and human health/happiness/prosperity.

I do not mean to overstate the power of accounting standards in this work. There are a number of forces outside of accounting which shape infrastructure investments in cities (many of which are discussed in Chapter 2). Likewise, accountants are beholden to the national standards that they are given to use; they have interpretative power at the local level, but are not able to change the basic categorization scheme decided by GASB.

However, I do intend to shine light on the role that standards of accounting play in valuing nature as infrastructure throughout this chapter. I do this by highlighting the experience of staff managing greenspaces in Portland that have had to negotiate with these standards. There are many places to intervene in a system; this is merely one space where, I argue, knowledge systems can be re-designed to improve urban sustainability and resilience. 


\section{Chapter 4}

\section{Using Q-method to explore the epistemologies shaping green infrastructure development: an expansion of the knowledge systems toolbox}

Introduction

Knowledge systems, as they are developed in this dissertation, consist of the institutional norms, practices, and protocols that are used to gather evidence about how some aspect of the world works, how that evidence is made credible, and then how the resulting knowledge claims are used in decision-making. I have focused on the knowledge systems that support understandings of, and decisions about, urban nature. A critical aspect of knowledge systems is the underlying frameworks and epistemologies that support evidence collection and legitimacy. I have employed discourse analysis to describe and analyze the knowledge systems at play in an emerging form of urban nature management - green infrastructure - and now turn to Q-method to better assess the epistemic frameworks at work in these various knowledge systems and better understand hybridity of discourses and visions drawn from narratives.

To my knowledge (ha!), Q-method has not yet been used in the exploration of knowledge systems research. Knowledge systems is increasingly applied as an analytical frame to explore issues of urban development and sustainability (Munoz-Erickson 2014; Cash et al. 2003; Miller, Munoz-Erickson, and Monfreda 2010), in particular as a way to assess and strengthen the relationship between academic research and practice on the ground. For example, the National Science Foundation (NSF) recently funded a large multi-city project that draws heavily on the idea of innovating knowledge systems to better 
incorporate dynamic climate and vulnerability data into urban planning ("UREx Sustainability Research Network" 2015). Scholars argue that increased acknowledgment and understanding of knowledge systems will allow for more intentional design of such systems towards pertinent societal goals. Therefore, the broadening of analytical tools that can better describe and assess knowledge systems is a useful addition to a growing literature, and potentially to growing effective practice for urban sustainability.

In this chapter, therefore, I introduce Q-method as a new methodological tool in the knowledge system's toolbox. As a mixed method approach to the examination of subjectivity - a specific analytical conception of an individual's point of view - Q-method provides data on the shared mental frameworks that urban practitioners and/or academics are using within existing knowledge systems and/or using to create new knowledge systems. Q-method is particularly useful to explore emerging or contested concepts in the world (Brown 1993; Barry and Proops 1999), rather than determining the prevalence of well-known or well-defined ideas, which conventional survey methods are adept at doing; for example, political scientists have used Q-method to better understand views on abortion, patriotism, or gay rights (Brown 1980; McKeown and Thomas 2013). In this way, it is well-suited for understanding the subjective positions that inform emerging knowledge systems' norms and protocols, with the potential to identify innovative or hybrid frameworks not previously described in the literature (Robbins and Krueger 2000; Neff 2011).

Within the context of this dissertation, Q-method is employed to further explore the relationship between the two visions of green infrastructure introduced in Chapter 1. I ask, 
what ideas are mobilized in tandem with the stormwater or network view of green infrastructure? how are practitioners mixing and matching the concepts of both visions to produce the green infrastructure we see on the ground today? Because Q-method allows participants to group ideas in any way they see fit, hybrid epistemologies that rely on the unique self-referential frame of each individual, can emerge; this hybridity allows a different look at results to find mixed categories that did not stand out in narrative results. Additionally, I explore potential for reflexive praxis and validation using Q-method. By employing Q-method as a follow-up method, I compare findings from in-depth comparative case studies to the self-referential groupings of ideas found using Q-method. These new groupings also interrogate my preconceptions as a researcher and highlight how well my perception of different participants' views (explored in chapter 2 and 3) lines up with the Q-sorts they provide for me.

This chapter therefore serves as a reflection on multiple different levels: reflection of the wide range of concepts across cities and departments to participants; reflection of preconceptions to the researcher; and reflection of survey findings on interview findings. All of these reflections interrogate my narrative findings, exposing areas of alignment and areas of disagreement within this research.

\section{Background}

Usefulness of Q-method in case study research

Case study research comes in many forms. As explored in earlier chapters, case studies are primarily qualitative, in-depth explorations of a particular context in which a 
phenomenon of interest has emerged. As Yin (2014) outlines, case study research is a powerful way to examine phenomena in their 'real-world context' where the 'boundaries between phenomenon and context may not be clearly evident" (Yin 2014). Through comparative case studies, this boundary can be explored by examining what exists in both contexts and what is unique to just one.

In Chapter 2, I outlined the many themes that emerged describing knowledge systems challenges in two different contexts: the City of Portland and the City of Baltimore. Some challenges appeared to be similar across these contexts, while others were distinct to the particular arrangement of artifacts, regulations, and social structures in just one. Within the process of comparing knowledge systems' challenges across two different contexts, I collected a variety of conflicting ideas that represented different orientations towards the role of urban nature in green infrastructure development. Because of the limited scope of each individual interview, my interviewees usually only described their engagement with one or two of these ideas; additionally, a number of these ideas and concepts initially appear to be ideologically incommensurate. However, most of these ideas are present and must be reconciled in the day-to-day work they each conduct. Q-method gave participants an opportunity to respond to the range of ideas as a whole. It also allowed me to see how distinct, and sometimes disciplinary-specific, ideas and concepts are used in concert with one another to create hybridized viewpoints.

Within Q-method, participants rank a series of statements that represent a range of ideas within a topic area under study - in this case green infrastructure. They are forced to make trade-offs between ideas within this ranking, operationalizing their subjectivity and 
reflecting their point of view (McKeown and Thomas 2013). While I, as the researcher, limited the ideas that participants interacted with to a statement set of my choosing, participants were open to group the ideas in any way they saw fit, revealing clusters of concepts that were not visible in narrative interviews.

In this way, Q-method takes advantage of what Watts \& Stenner (2005) quote as “ 'one of psychology's most basic and well established principles', namely, our desire to structure and to ascribe meaning to 'impinging stimuli and events'." They go on to explain that,

Indeed, it is these very desires which ensure the robustness of Q methodology, as a group of participants will ultimately make vigorous attempts to impose their viewpoints onto any set of statements they are given. In other words, even a 'less than ideal ... [Q set], because it invites active configuration by participants ('effort after meaning'), may still produce useful results'. If a $\mathrm{Q}$ set is at least 'broadly representative' of its subject matter, therefore, the engagement of the participant group with that $\mathrm{Q}$ set (and the resultant configurations) will afford a general overview of relevant viewpoints 'on the subject' (which is all that is required for the purposes of Q methodology). (Watts and Stenner 2005) (p.76)

This is an important tenant of Q-method; that the work participants due to rank the statements helps reveal the structure of their thoughts on the subject whether or not the statements themselves are "less than ideal." Barry and Proops (1999) also comment on this phenomenon by stressing that the ranking scale is "relative, not absolute...It may be the case that a participant agrees with all of the statements; even so, a ranking it still possible" (p. 341). In practice, there are a variety of constraints placed on individuals. Q-method helps reveal the way specific concepts interact with their internal frame of reference, giving a researcher some indication of how their viewpoint leads them to act a certain way in the world. 


\section{Why Q-method?}

I have integrated Q-method into my study of knowledge systems for three reasons: 1) its usefulness in exploring emerging, contentious, and relatively unknown conceptions/viewpoints (Barry and Proops 1999), 2) its ability to elicit description of shared mental frameworks across contestation (Asah et al. 2012), and 3) its potential to describe unique groupings of concepts and ideas within mental frameworks (Neff and Larson 2014).

Q-method is adept at accomplishing these three tasks due to its unique structure. Qmethod was developed by physicist/psychologist Stephenson in the 1930's as a way to systematically study subjectivity. Stephenson defined subjectivity as "the internal frame of reference one calls upon to make sense of the world around oneself. Hence, in Q method, subjectivity is defined as a person's own point of view (or self-referent perspective) about a real or perceived specific situation (e.g., a "fair" facility siting process, "useful" tree species, or a sense of a "good" place)" (Robbins and Krueger 2000, p. 637).

The concept of subjectivity relates very closely to the concept of knowledge systems; subjectivity describes an individual's point of view, which I argue is integral to the development and use of the different norms, protocols, and practices that make up a knowledge system. For example, individual points of view can constrain the practices and norms of governance deemed credible and legitimate within a decision-making process. This can lead to changes in a knowledge system to better adhere to subjectivities, or rejection of alternate knowledge systems altogether if they are not deemed salient or relevant to the decision at hand. 
To approach subjectivity as it is elaborated by Stephenson and those who have refined his ideas - Stephen Brown being the most influential (Brown 1980, 1993) - Qmethod does two things: 1) it enables different questions to be asked than traditional survey methods and 2) it shifts the goal of the research design from uncovering prevalence of viewpoints to articulation of viewpoints. Both of these results help me learn more about knowledge systems.

First, Q-method asks different questions about the world than traditional survey methods. This difference is well articulated by Robbins and Krueger (2000). As they describe, the usual questions asked by survey research are "What proportion of a population believes $\mathrm{X}$, what proportion believes $\mathrm{Y}$, where $\mathrm{X}$ and $\mathrm{Y}$ are predefined claims or concepts?" whereas the questions enabled by Q-method are "How are X and Y related in the opinion and subjectivity of an individual, where $\mathrm{X}$ and $\mathrm{Y}$ are claims drawn from the language and ideas of the individual?" (p. 640). This is quite useful in the realm of green infrastructure where two robust and distinct disciplines (i.e. engineering and ecology) must be combined to produce services. Not to mention they are combined in a social, political, and economic context. Q-method helps see how these various realms are combined in participants' point of view; these views ultimately shape the infrastructure decisions they make professionally day-to-day.

Second, the goal of Q-method's research design is focused on better articulation of a variety of points of view operating in the world, rather than obtaining a better handle on the prevalence of particular points of view. This is useful to my research because it allows me to interrogate the visions revealed in my narrative results and better understand the 
points of view that underpin the decision-making processes around green infrastructure development today.

Overall, Q-method has become increasingly popular in the realm of environmental policy and management (Asah et al. 2012; Mazur and Asah 2013; Neff 2011; Neff and Larson 2014; Ghoochani et al. 2015; Rastogi et al. 2013; Iribarnegaray et al. 2014; Cotton 2015). For example, Asah et al. (2012) have employed Q-sorts in the study of natural resource conflicts, using Q to reframe debates: Q-sorts were used to display various overlaps and shared mental frameworks across stakeholders that had previously found no common ground within a negotiation process. Others similarly seek to inform ongoing debates within their geographic and cultural context, including shale gas fracking in the UK (Cotton 2015), endangered species conservation in India (Rastogi et al. 2013), and water conservation in Argentina (Iribarnegaray et al. 2014). I add to this literature an analysis of the green infrastructure development challenges in the US.

\section{Mixed Methods}

The use of Q-method in this dissertation follows the mixed methods work of David Morgan (David L. Morgan 2014; D. L. Morgan 1998). Morgan’s methodological research emphasizes the pragmatic aspects of mixed methods studies in grappling with the messy world before us, a world which does not conform completely to either qualitative or quantitative processes of meaning-making. Using a combination of quantitative and qualitative methods, Morgan argues, allows us to more 'comprehensively approximate' the phenomena around us. 
Morgan argues that all research combines both 'little q' quantitative and 'little q' qualitative methods. For example, when designing a quantitative survey, many researchers will test their survey questions eliciting qualitative responses from testers to improve survey methods. In a different disciplinary setting, natural scientists spend time observing phenomena in the field, taking qualitative and descriptive notes of an ecosystem of interest - often at near ethnographic proportions. This observational phase, the first step of the scientific method taught to elementary schoolers, often goes undiscussed and unreported in scientific papers. This qualitative step appears to be dismissed primarily because it is not 'real science' (Porter 1996; Porter 1994). However, mixed methodologists argue that reporting on, and intentionally designing, this key qualitative stage of quantitative research is critical to improving the practice of research.

My dissertation primarily utilizes qualitative analysis, which is well-suited to my research focus on emergent phenomena, rather than already well-defined perceptions or concepts. Qualitative methods allow researchers to reveal and characterize previously undefined perceptions and conceptions, instead of testing for the prevalence of wellunderstood phenomena (Neff 2011). More specific to my dissertation, qualitative methods are also well suited for considering "meaning, complexity, and institutional fragmentation in urban policy" (Maginn et al 2008); my focus on the contestation and complexity surrounding institutionalization of new green infrastructure knowledge practices is therefore well served by qualitative analysis.

My dissertation also makes use of quantitative methods (i.e. content analysis and factor analysis) as complementary analysis. Quantitative methods are used in this 
dissertation to extend, as well as bolster, qualitative results. Complementarity of methods within a mixed methods research design such as this is important; strong design allows a researcher to be more confident in their findings after deploying multiple methods. Mixed methods research has been found to be most successful when a core research method is designated, and additional methods are carefully chosen to support and serve the core method, rather than compete with its goals (Morgan 2014). My dissertation is therefore modeled on a sequential mixed methods framework in which "a smaller quantitative study helps evaluate and interpret results from a principally qualitative study" (Morgan 1998). Q-method, in this case, provides the quantitative follow-up to a core qualitative research project.

\section{'So meta'}

There is a colloquialism, popular among millennials, that has come to my mind often throughout my exploration of pragmatic mixed methodologies: "this is so meta." This selfreferential statement highlights the all-encompassing idea of knowledge systems to me. For example, a primary argument for mixed methods research is the concept of integrating as many interdisciplinary 'ways of knowing' as possible to create a more complete understanding of the phenomena being studied. As Greene et al (2001) state,

The social phenomena that we study 'on the ground' in the real world are unarguably complex, dynamic, and contextually diverse... We therefore need to use all of our methodological expertise and skills in this endeavor for contemporary understanding of social issues. We need to marshal all of our multiple ways of knowing, and their associated multiple ways of valuing, in the service of credible and useful understanding. 
This means that the very same theoretical lens I hold up to green infrastructure practice is held up to the methods I employ. Any study of knowledge systems is self-referential, caught in a never-ending loop of reflexive praxis. This makes it both invigorating and confusingly paralyzing at times: how can I as a researcher critique the myopic influence of standards and protocols when I myself am bound and blinded by my own discipline's categorization and explanation of the theory and method at play?

Realizing that one must move forward in some way to study the world, however potentially narrow, I have designed my study to take advantage of mixed methods and the robustness it provides by hopping between quantitatively and qualitatively founded knowledge systems. As Bazeley (2008) states, mixed method studies need to be “...designed to have complementary strengths and non-overlapping weaknesses” (Bazeley 2008). Qualitative methods provide 'thick descriptions' of context and phenomena; but results are difficult to compare. Quantitative methods allow for comparisons across many different contexts; but results are vast reductions of context that often have limited meaning on-the-ground. I use a sequential mixed methods research design to take advantage of the useful aspects of both quant and qual methods, working to minimize the problematic pieces of each.

\section{$\underline{\text { Methods }}$}

Within the overall research design of this dissertation, Q-method is integrated as a quantitative follow-up technique (highlighted in green in Figure 4-1) that was designed to accomplish two tasks: 1) provide validation of narrative findings of case studies and 2) 
extend the qualitative findings of the case studies with an instrument that can be used in other cities and departments.

I will describe the mechanics of the method more completely in the following sections, including the online tool I used to administer surveys. I will then present the results of the Q-sorts done by my original group of interviewees, and discuss the insights that this method provided to the comparative results presented in Chapters 2 and 3.

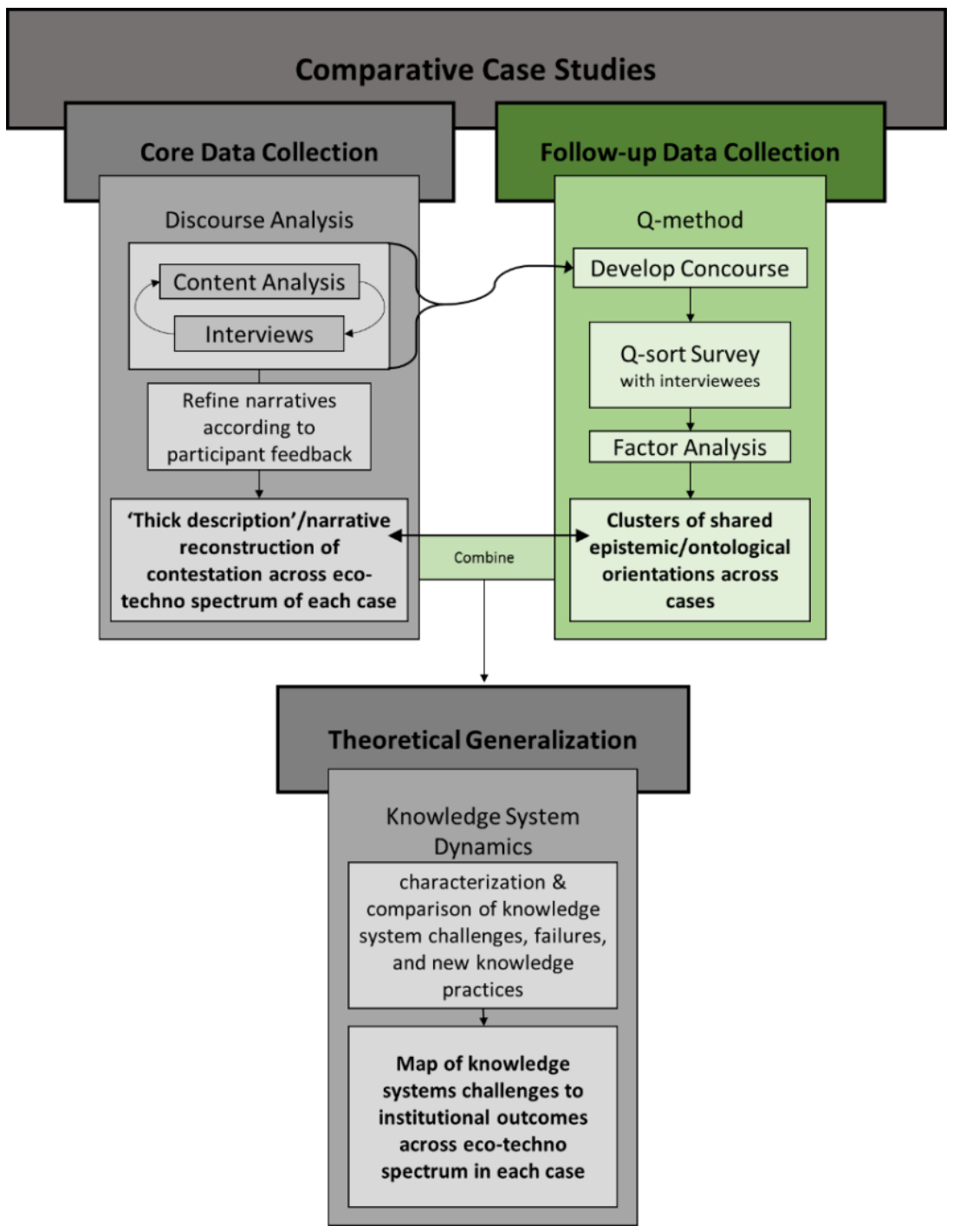

Figure 4-1: Methods of this chapter displayed in the context of the overarching research design of the dissertation; methods of this chapter highlighted in green 


\section{Q-method mechanics}

As describe in the introduction, in this dissertation I use Q-method as a follow-up method with interview participants from each of my case study sites. Q-method is accomplished by asking participants to rank-order a series of statements, or a Q-set, which is distilled from the large 'concourse' of ideas collected about a topic. The concourse is derived through a detailed discourse analysis of the topic under study. Statements, in this study, are paraphrased quotes from in-depth interviews (statements could also be derived from content analysis of plans, newspaper articles, or peer-reviewed papers depending on where the topic at hand is discussed). See Table 4-1 below for a breakdown of Q-set statements by thematic area used in this dissertation.

In this study, participants ranked these statements from "most like how I think" to "least like how I think", placing non-salient statements in the middle of the continuum. The resultant rankings are referred to as Q-sorts. Figure 4-2 below displays the structure of the Q-sort.

Least like how I think

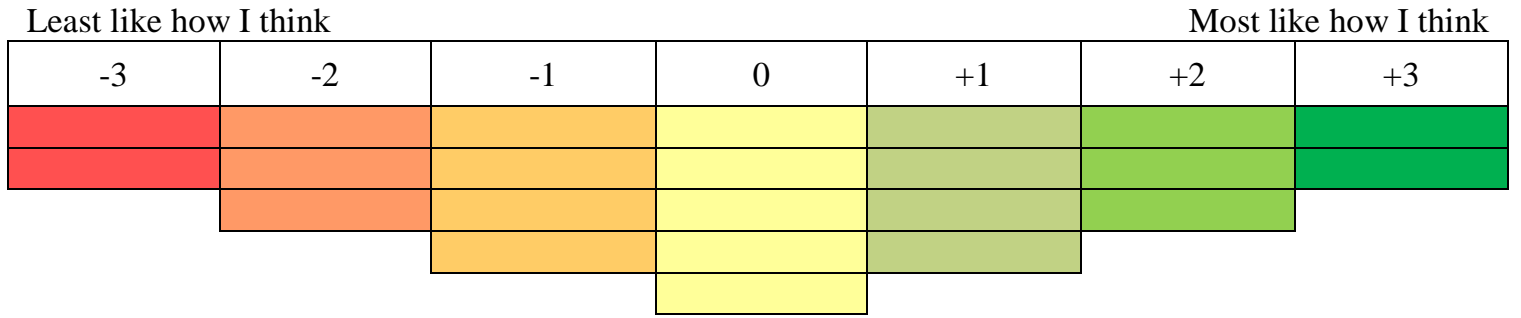

Figure 4-2: Structure for statement placement, red indicating "most disagree" and green representing "most agree"

The larger concourse of statements is chosen by the researcher to reflect a large range of opinions in the field of study; ideally, the statements elicit strong responses from all participants (McKeown \& Thomas 1988). While the researcher controls the statement 
selection, and therefore the bounds within which the participants must respond, the participant controls the prioritization of the statements without a preconceived framework from the researcher (Neff 2011).

Table 4-1: Concourse statements by thematic area

\section{General}

Communication across institutional silos is necessary for successful green infrastructure development.

Maintenance of green infrastructure facilities should not be the responsibility of community volunteers.

'Green gentrification' must be mitigated in all green infrastructure planning processes.

Green infrastructure maintenance schedules are not currently well-developed.

\section{Definition}

Every vegetated space in the city is part of green infrastructure.

Current use of the term 'green infrastructure' is too broad to be useful.

The term 'green infrastructure' helps the public understand that greenspace is important and valuable, like other urban infrastructures (e.g. roads, sewer, etc).

Natural areas are an integral part of the green infrastructure concept.

Green infrastructure includes much more than stormwater management facilities.

The public does not understand the term 'green infrastructure.'

Urban agriculture can be a part of a green infrastructure plan.

\section{Measurement}

Stormwater management is the primary service of green infrastructure.

The plants in green infrastructure facilities don't have a significant impact on the functionality of the facility.

Natural areas can mostly take care of themselves; very little maintenance is needed for them to provide services.

Curbside green infrastructure is like a series of potted plants that need constant maintenance.

New metrics must be developed to evaluate the performance of green infrastructure facilities.

We cannot measure all the benefits provided by green infrastructure.

Green infrastructure provides the same functions in every city.

\section{Valuation}

Monetization of benefits provided by green infrastructure is critical to its accurate and comprehensive management.

Green infrastructure is under-valued by current asset management techniques.

Green infrastructure does not have the appropriate characteristics or traits to be treated as a

traditional financial asset.

Including green infrastructure in current asset management processes will improve maintenance schedules.

Green infrastructure should not be a separate asset class; it should be included as part of existing capital assets.

It is problematic to monetize the benefits of green infrastructure. 
After completion of the ranking, the participant is asked to describe their ranking logic (i.e. "why did you place that statement in that column? Were there any statements that you wished you could place differently?"). In this way, the researcher does not need to intuit the reasoning framework of the participant as is often the case in standard survey research (Neff 2011). This also removes some measure of researcher bias from the methodology.

Factor analysis of all participants' Q-sorts is then conducted to identify a number of similar statement rankings (Neff 2011), in this case using PQMethod software ${ }^{\mathrm{iii}}$. As Barry and Proops (1999) describe it, this statistical analysis "allows individual responses to be collated and correlated, so as to extract 'idealized' forms of discourse latent within the data provided by the individuals involved in the study" (p.338). Extracted factors therefore represent these 'idealized' forms or a few 'typical' Q-sorts. Even though no two people have identical opinions, this quantitative analysis uncovers a number of similarly ranked and clustered concepts across the Q-sorts completed (Brown 1980; McKeown and Thomas 2013); in this case, similar rankings can tell us about how shared perceptions of green infrastructure are clustered within and between cases. It also allows participants to identify with more than one researcher-predicted framework. Discovering these previously undefined hybrid ideas is important to this work.

Development of a concourse from in-depth comparative case studies can also be used to extend the comparison of epistemic orientations to green infrastructure to a variety of other cities with minimal effort. For example, the Q-sort survey given to participants in Baltimore and Portland can also be used to survey municipal staff in New York, Miami, 
Phoenix and other cities with budding green infrastructure programs. Comparison of results can begin to expose more widely held orientations towards green infrastructure, guiding future research directions.

\section{Online Q-sort Interface}

Due to the logistics of conducting case studies in different time zones, it was not possible to schedule and travel to a second face-to-face meetings with each of my 43 participants. Instead an online version of the Q-sort process was used to follow-up with each participant. The online interface - "Q-TIP: Q-method Testing and Inquiry Platform" - was developed by Dr. Morgan Robertson at the University of Wisconsin-Madison and is available free for use securely at the following website: http://qsort.geography.wisc.edu/. The advantage of using the online version was that participants could work on the Q-sort at their convenience, starting the survey and saving their progress to work on it another time if need be. Fortunately, no one complained of technical difficulties.

The series of screenshots below give a sense of the online interface that participants interacted with. A virtual stack of cards is seen at the top of the screen. Arrows on either side of the deck allow the participant to virtually flip through each of the cards to read them all before placing them in the guide below. Figure 4-3 below shows the set-up before any cards have been sorted.

Each card is placed by drag-and-drop with a mouse into the structure provided. Participants can move cards around after they have been placed. Figure 4-4 shows the 
screen in mid-sort. A participant could close the program at this point and their placement will be saved to finish later.

Figure 4-5 displays the new command that appears just under the stack of cards after all cards have been sorted. The "All Done" button takes participants to the screen shown in Figure 4-6. This simulates the mini-interview that usually occurs at the end of a q-sort process. In this online version, participants are able to select and comment on six statements of their choosing that they had strong reactions to, either positive or negative, or that they wanted to place in a different spot but were unable to due to the structure.

One unexpected outcome of this online version of Q-method was the ability to collect succinct thoughts from participants that are useful in future Q-sort studies of green infrastructure. In the original method, the short interview process completed directly after a participant completes their Q-sort can sometimes produce rambling and unfocused responses. Occasionally, these interviews are quite long. This is useful when an interview has not been done prior to the sort. But, since robust narrative data had already been collected from participants completing the Q-sort, this kind of data would not have been as useful. Instead, the online form, seen in Figure 4-6, elicited one to two sentence responses regarding participant sorting logic. These brief responses were to the point and rich with content, most likely guided by the small response box provided. These dense comments are quite valuable to future Q-sorts and are succinct enough to serve as potential Q-sort statements in future iterations of this work. 


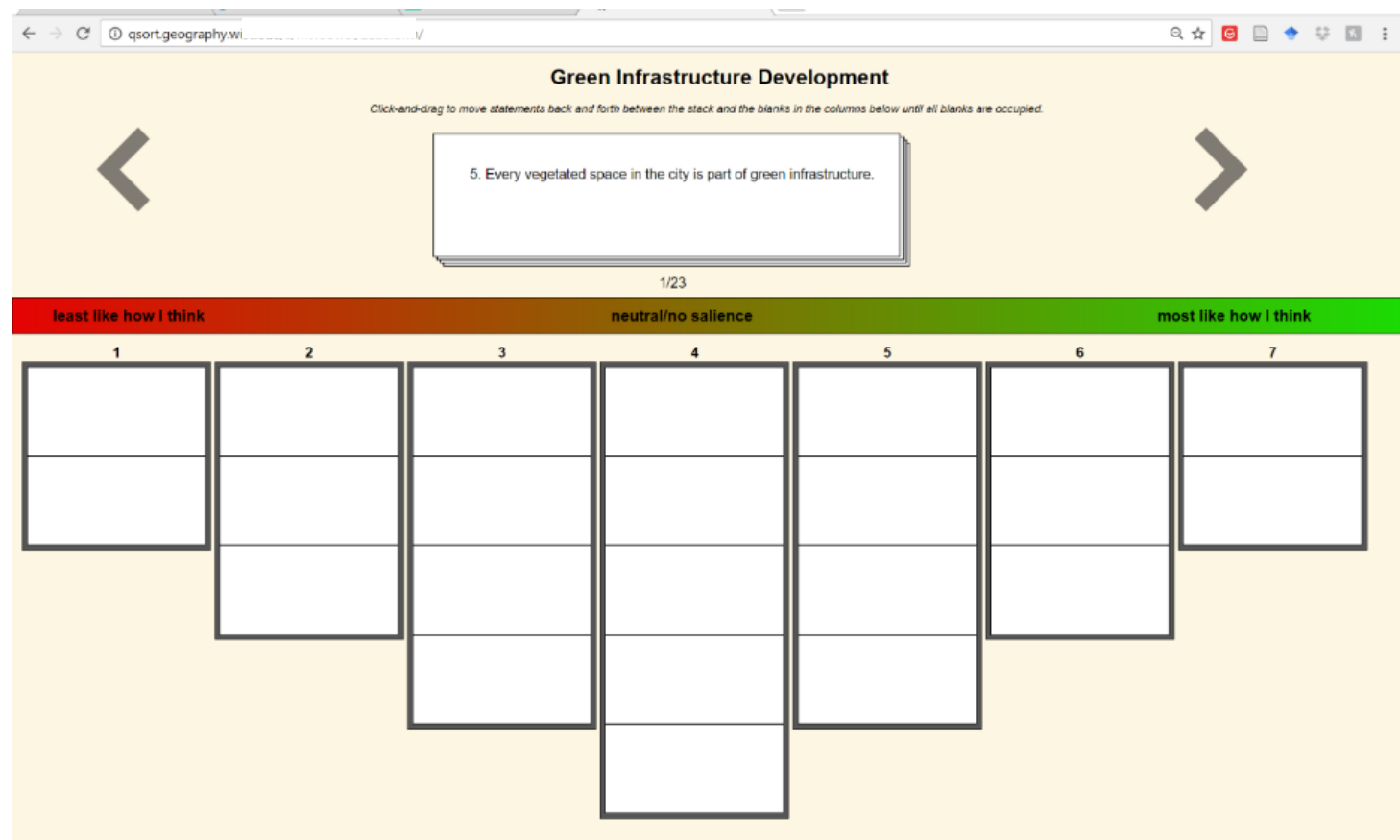

Figure 4-3: Screenshot of online Q-sort survey. A virtual pile of cards is at the top of the screen. The arrows on either side of the pile allow a participant to flip through the cards to read each one.

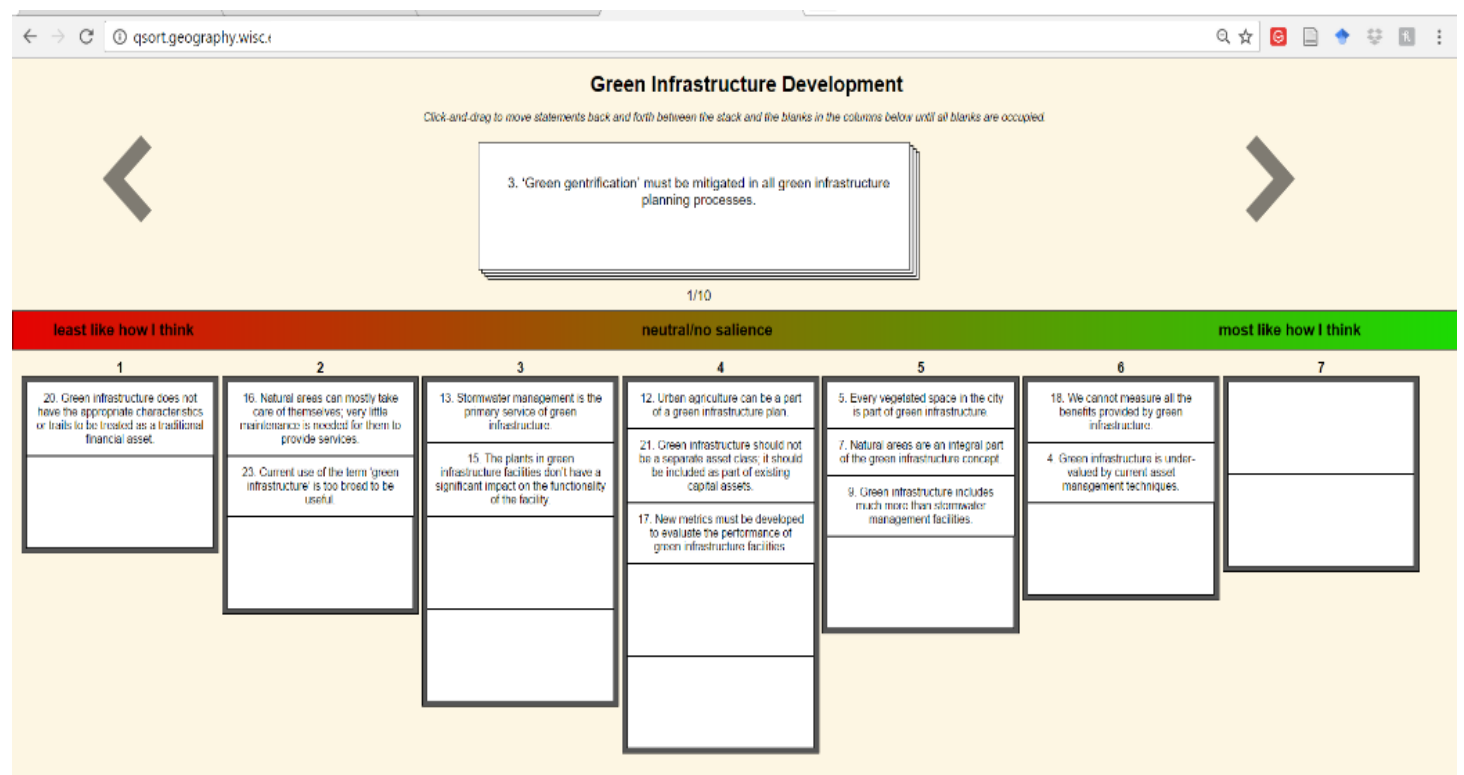

Figure 4-4: Screenshot of a partially completed Q-sort. Statements can be dragged-and-dropped directly from any column to another, or from the stack of cards at the top of the page. At this point, the participant may step away from the sorting process and come back later to complete it. All progress will be saved via the participant's unique survey link. 


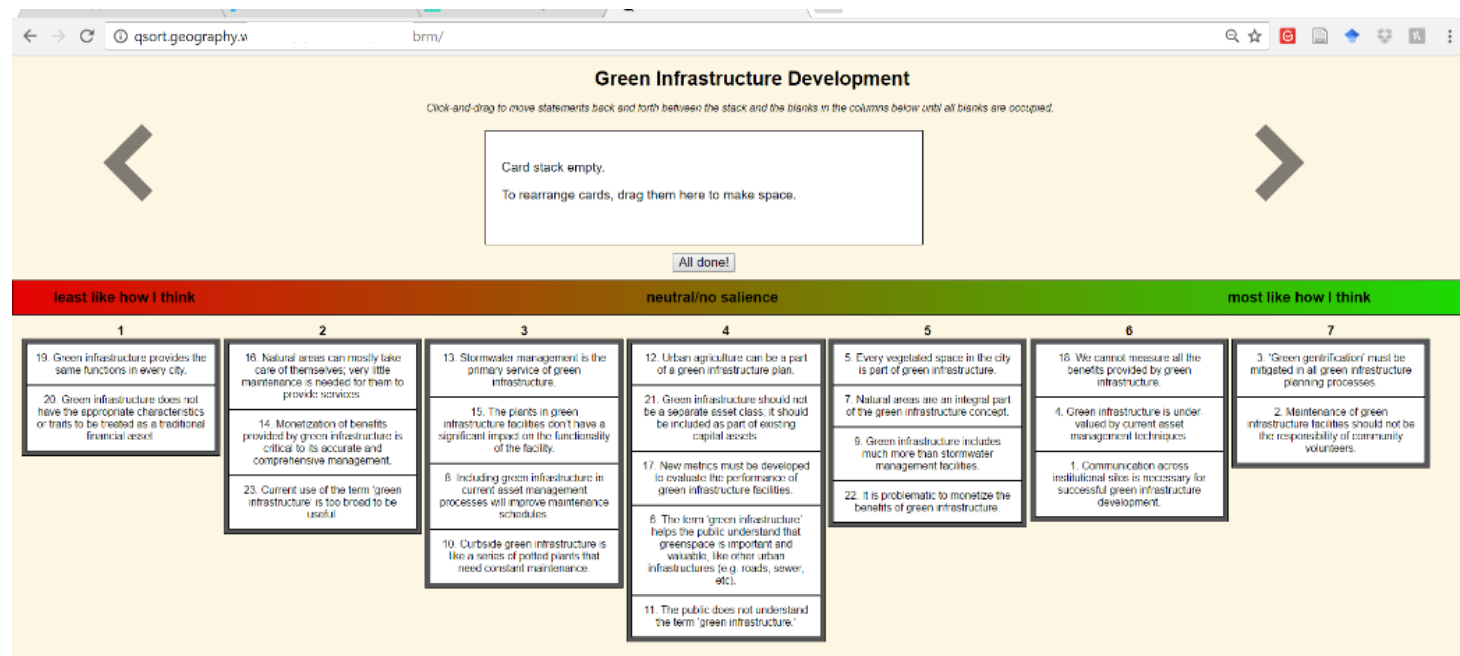

Figure 4-5: Once all of the cards have been placed, as can be seen in this screenshot, a new command appears just under the empty card stack. Clicking the "All done!" command takes the participant to the next stage of the survey.

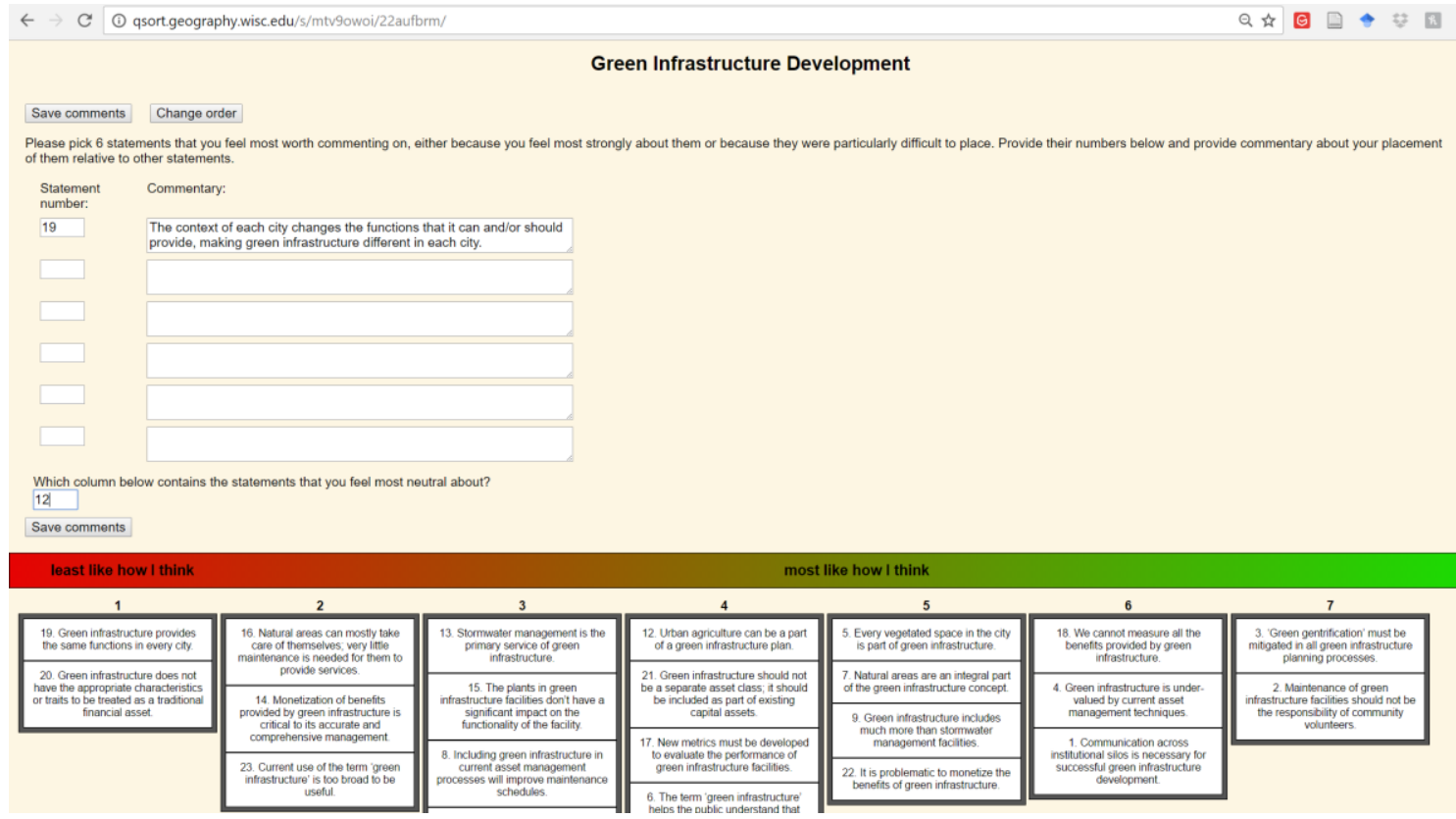

Figure 4-6: This figure displays a screenshot of the feedback portion of the method. This is where participants comment on statements that were particularly difficult to place or that they had strong reactions to. Clicking "save comments" completes the survey process and saves the results as Excel spreadsheets. 


\section{$\underline{\text { Results }}$}

The factor analysis performed on Q-sorts in this study rendered 5 relevant factors, or green infrastructure frames, that are presented below, following a brief summary of the population surveyed. Reflections of the factors on narrative results from Chapters 2 and 3 follow in the discussion, along with interactions across the eco-techno spectrum.

\section{Participants}

32 (or approx. 76\%) of my original research participants completed a Q-sort; 18 of the Q-sort participants work in Portland and 14 work in Baltimore. The backgrounds of the participants varied as seen in Table 4-2 below. Approximately even numbers of interviewees from each city participated in the Q-sort. Likewise, a similar number of different professional backgrounds participated in the Q-sort, with the exception of a large number of participants with financial (accounting, business, etc.) backgrounds participating in Portland. While this may appear to skew results towards this group, it is important to note that the majority of these participants now work in interdisciplinary roles in a variety of bureaus, departments, NGOs, and companies where they must integrate information and data from alternate disciplines from their training. Background is only one characteristic influencing their problem frame to examine. 
Table 4-2: The number of participants from each city with each different professional background. Most of the backgrounds have similar numbers between the cities; however, quite a few more participants with financial backgrounds participated from Portland than Baltimore.

\begin{tabular}{|l|c|c|c|}
\hline Background & Baltimore & Portland & Total \\
\hline environmental science & 5 & 5 & 10 \\
\hline Engineering & 3 & 4 & 7 \\
\hline landscape architecture & 3 & 1 & 4 \\
\hline Planning & 1 & 1 & 2 \\
\hline Financial & 1 & 7 & 8 \\
\hline Other & 1 & 0 & 1 \\
\hline Total \# of Participants & $\mathbf{1 4}$ & $\mathbf{1 8}$ & $\mathbf{3 2}$ \\
\hline
\end{tabular}

\section{Factors}

Five relevant factors, or clusters of similar points of view, were extracted from the Q-sorts via factor analysis. Each of these factors represents a particular green infrastructure frame or point of view based on different ways statements were grouped by participants. A composite or 'typical' Q-sort for each factor is generated to display the cluster of ideas of each frame (displayed in Table 4-4). It is important to note here that no participants' point of view adheres completely to any one factor; as Barry and Proops (1999) describe, "each individual usually has several 'typical' Q sorts contained in their particular Q sort" (p. 339). These factors instead highlight areas of overlap and shared concept frames rather than any one person in particular. Some participants "load" more heavily on one factor or another, meaning their complete Q-sort is more similar to the factor's composite, 'typical' Q-sort than others; the comments and interviews of the participants who created these "defining sorts", as they are called, are used to help interpret the factor itself.

One of the more surprising results of this factor analysis was the break-down of people loading on each factor by city. While there were important differences between the 
cities regarding technology and regulations, the results of the narrative analysis presented in Chapter 2 did not see significant differences between the ideas presented in each city. Instead, different bureaus or departments seemed to show similarities across the cities. Through the Q-sort process however, we see that the individuals who loaded heavily on Factors 1, 2, and 3 were working in Portland, and those that loaded on Factors $4 \& 5$ were working in Baltimore (see Table 4-3). This is explored in more detail in the discussion section.

Table 4-3: The number of participants from each city that loaded highly on each factor. Surprisingly, factors appeared to split along city lines.

\begin{tabular}{|l|c|c|c|c|c|c|}
\cline { 2 - 7 } \multicolumn{1}{c|}{} & F1 & F2 & F3 & F4 & F5 & Totals \\
\hline Baltimore & 2 & 2 & 1 & 5 & 4 & 14 \\
\hline Portland & 6 & 5 & 4 & 1 & 2 & 18 \\
\hline
\end{tabular}

First, I present an overview of Table 4-4 and findings across all factors. Then I present the characteristics of each factors in its own section.

All factor groups agreed with statement \#1: “Communication across institutional silos was necessary for successful GI development." Factors 3, 4, and 5 placed it in their most agree category $(+3)$ while Factors 1 and 2 strongly and somewhat agreed $(+2$ and +1 respectively). This provides evidence of the interdisciplinary nature of green infrastructure development. There was also general disagreement with the statement "GI provides the same functions in every city." Factor 1, 2, and 5 ranked it most disagree (-3), with Factor $3 \& 4$ ranking it similarly at -2 . This provides evidence that, across the board, practitioners in my study agree that green infrastructure is dynamic and must relate to its context. 
Table 4-4: The weighed composite sort representing each of the five factors. No participant ranked the statements in exactly the ways shown in this table, but participants loading highly on each factor ranked their statements similarly to these composite sorts. (Refer to Figure 4-2 for ranking placement.)

\begin{tabular}{|c|c|c|c|c|c|c|}
\hline \multicolumn{2}{|c|}{ Statement } & \multicolumn{5}{|c|}{ Factor Arrays } \\
\hline & & F1 & F2 & F3 & F4 & F5 \\
\hline 1 & $\begin{array}{l}\text { Communication across institutional silos is necessary for successful } \\
\text { green infrastructure development. }\end{array}$ & 2 & 1 & 3 & 3 & 3 \\
\hline 2 & $\begin{array}{l}\text { Maintenance of green infrastructure facilities should not be the } \\
\text { responsibility of community volunteers. }\end{array}$ & 0 & -1 & 3 & 2 & -2 \\
\hline 3 & $\begin{array}{l}\text { 'Green gentrification' must be mitigated in all green infrastructure } \\
\text { planning processes. }\end{array}$ & 1 & -1 & -3 & 1 & -1 \\
\hline 4 & $\begin{array}{l}\text { Green infrastructure is under-valued by current asset management } \\
\text { techniques. }\end{array}$ & 1 & 1 & 2 & 1 & 2 \\
\hline 5 & Every vegetated space in the city is part of green infrastructure. & 2 & 1 & -3 & 0 & -3 \\
\hline 6 & $\begin{array}{l}\text { The term 'green infrastructure' helps the public understand that } \\
\text { greenspace is important and valuable, like other urban } \\
\text { infrastructures (e.g. roads, sewer, etc). }\end{array}$ & 1 & 1 & 1 & -3 & 0 \\
\hline 7 & $\begin{array}{l}\text { Natural areas are an integral part of the green infrastructure } \\
\text { concept. }\end{array}$ & 3 & 3 & 2 & 2 & 0 \\
\hline 8 & $\begin{array}{l}\text { Including green infrastructure in current asset management } \\
\text { processes will improve maintenance schedules. }\end{array}$ & 1 & 2 & 2 & -1 & 3 \\
\hline 9 & $\begin{array}{l}\text { Green infrastructure includes much more than stormwater } \\
\text { management facilities. }\end{array}$ & 3 & 2 & 1 & 3 & 1 \\
\hline 10 & $\begin{array}{l}\text { Curbside green infrastructure is like a series of potted plants that } \\
\text { need constant maintenance. }\end{array}$ & -2 & 0 & 0 & 0 & -2 \\
\hline 11 & The public does not understand the term 'green infrastructure.' & -2 & 0 & 0 & 2 & 1 \\
\hline 12 & Urban agriculture can be a part of a green infrastructure plan. & 0 & 0 & -2 & 1 & 0 \\
\hline 13 & $\begin{array}{l}\text { Stormwater management is the primary service of green } \\
\text { infrastructure. }\end{array}$ & 0 & -3 & 0 & -1 & 1 \\
\hline 14 & $\begin{array}{l}\text { Monetization of benefits provided by green infrastructure is critical } \\
\text { to its accurate and comprehensive management. }\end{array}$ & -1 & 3 & 1 & 0 & 2 \\
\hline 15 & $\begin{array}{l}\text { The plants in green infrastructure facilities don't have a significant } \\
\text { impact on the functionality of the facility. }\end{array}$ & -2 & -1 & -1 & -2 & -2 \\
\hline 16 & $\begin{array}{l}\text { Natural areas can mostly take care of themselves; very little } \\
\text { maintenance is needed for them to provide services. }\end{array}$ & -1 & -2 & -2 & -2 & -1 \\
\hline 17 & $\begin{array}{l}\text { New metrics must be developed to evaluate the performance of } \\
\text { green infrastructure facilities. }\end{array}$ & 0 & 2 & 1 & 0 & 2 \\
\hline
\end{tabular}




\begin{tabular}{|c|c|c|c|c|c|c|}
\hline 18 & $\begin{array}{l}\text { We cannot measure all the benefits provided by green } \\
\text { infrastructure. }\end{array}$ & -1 & -1 & -1 & 1 & 1 \\
\hline 19 & Green infrastructure provides the same functions in every city. & -3 & -3 & -2 & -2 & -3 \\
\hline 20 & $\begin{array}{l}\text { Green infrastructure does not have the appropriate characteristics or } \\
\text { traits to be treated as a traditional financial asset. }\end{array}$ & -3 & -2 & 0 & -1 & -1 \\
\hline 21 & $\begin{array}{l}\text { Green infrastructure should not be a separate asset class; it should } \\
\text { be included as part of existing capital assets. }\end{array}$ & 2 & 0 & 0 & -1 & 0 \\
\hline 22 & It is problematic to monetize the benefits of green infrastructure. & 0 & -2 & -1 & 0 & -1 \\
\hline 23 & $\begin{array}{l}\text { Current use of the term 'green infrastructure' is too broad to be } \\
\text { useful. }\end{array}$ & -1 & 0 & -1 & -3 & 0 \\
\hline
\end{tabular}

Beyond overall agreement with these two positions, each factor group composite ranking differed. Below I go through each factor in turn describing the composite Q-sort. It is important to note here again that no individual adheres exactly to any one of the factors bellow. As Neff (2011) found, "all participants expressed - to differing degrees - ideas associated with several factors...; we must therefore be cautious when trying to classify a person as being a 'type" " (p. 465). Instead, these factors help illuminate "characteristics of different logical or value structure present in the...community..." (p. 466) helping us see how subjectivity shapes green infrastructure knowledge systems and how concepts might bring about or be mobilized to reconcile the different challenges those knowledge systems face.

Factor 1: Nature focus; integrate across the eco-techno spectrum for problem solving As displayed in Table 4-5, according to this factor group, living/biological components are important to the definition of green infrastructure (strong agreement with \#5 and \#7, disagreement with \#15). This group frames green infrastructure with a network 
definition, rather than a narrow stormwater-focused understanding of the concept (strong agreement with statement \#9 and \#5). This factor group thinks of green infrastructure facilities as assets (\#21 and \#20); however, statements about the challenges that arise from making green infrastructure an asset were placed in less salient and more neutral categories. Additionally, Factor 1 agreed (+2) with statement \#5, "Every vegetated space in the city if part of green infrastructure", which differed from both Factor 3 and 5 which strongly disagreed with the statement (-3). Factor 1's broader, network vision of green infrastructure is tempered with reflection on the need for asset management and treating nature as infrastructure. A comment on statement \#21 by one participant helps display the attitude of this group:

[Green infrastructure] will require different categories as it has different characteristics that need to be tracked. However, it should be strongly linked with asset management for traditional grey infrastructure. They're often parts of the same connected network, and should be as integrated as possible.

Table 4-5: Factor 1 - most strongly agreed with and strongly disagreed with statements

\begin{tabular}{|c|c|c|c|}
\hline Most disagree (-3) & $(-2)$ & $(+2)$ & Most agree $(+3)$ \\
\hline $\begin{array}{l}\# 19 . \text { Green } \\
\text { infrastructure provides } \\
\text { the same functions in } \\
\text { every city. }\end{array}$ & $\begin{array}{l}\text { \#15. The plants in } \\
\text { green infrastructure } \\
\text { facilities don't have a } \\
\text { significant impact on } \\
\text { the functionality of the } \\
\text { facility. }\end{array}$ & $\begin{array}{l}\text { \#21. Green } \\
\text { infrastructure should } \\
\text { not be a separate asset } \\
\text { class; it should be } \\
\text { included as part of } \\
\text { existing capital assets. }\end{array}$ & $\begin{array}{l}\text { \#9. Green } \\
\text { infrastructure includes } \\
\text { much more than } \\
\text { stormwater } \\
\text { management facilities. }\end{array}$ \\
\hline $\begin{array}{l}\text { \#20. Green } \\
\text { infrastructure does not } \\
\text { have the appropriate } \\
\text { characteristics or traits } \\
\text { to be treated as a } \\
\text { traditional financial } \\
\text { asset. }\end{array}$ & $\begin{array}{l}\# 10 . \text { Curbside green } \\
\text { infrastructure is like a } \\
\text { series of potted plants } \\
\text { that need constant } \\
\text { maintenance. }\end{array}$ & $\begin{array}{l}\text { \#1. Communication } \\
\text { across institutional silos } \\
\text { is necessary for } \\
\text { successful green } \\
\text { infrastructure } \\
\text { development. }\end{array}$ & $\begin{array}{l}\text { \#7. Natural areas are } \\
\text { an integral part of the } \\
\text { green infrastructure } \\
\text { concept. }\end{array}$ \\
\hline- & $\begin{array}{l}\text { \#11. The public does } \\
\text { not understand the } \\
\text { term 'green } \\
\text { infrastructure.' }\end{array}$ & $\begin{array}{l}\text { \#5. Every vegetated } \\
\text { space in the city is part } \\
\text { of green infrastructure. }\end{array}$ & - \\
\hline
\end{tabular}




\section{Factor 2: Monetization and metrics focus on nature}

Focus in this group is on quantification of nature to both improve and grow green infrastructure; as displayed in Table 4-6, they support both new metrics (\#17) and strongly agree that monetization of green infrastructure is critical to its management (\#14). In fact, they ranked the statement "Monetization of benefits provided by green infrastructure is critical to its accurate and comprehensive management" more strongly than any other factor group at +3 (other factors ranked it at -1 and 0 ). Strong agreement with statement \# 8 , and strong disagreement with \#22 and 20, also show this factor's focus on quantification.

This focus is also reflected in the comments that participants with defining sorts for this factor contributed at the end of the sorting process:

Comment on statement \#14: Money talks. To the public, to funders, to politicians.

Comments on statement \#18: ... if we can not break down the benefits in to a cost analysis then we can not make convincing arguments on why green infrastructure is important.

According to this factor, urban nature is also an important part of green infrastructure (strong agreement with statement \#7), but quantification statements were much more salient in this group than ideas about the definition of green infrastructure as either nature or infrastructure.

Because of the strong quantification and monetization focus, paired with a green infrastructure as network vision of green infrastructure, this group seems to be the most typical of the ecosystem services approach to fitting nature into existing financial structure (as was discussed in Chapter 3). 
Table 4-6: Factor 2 - most strongly agreed with and strongly disagreed with statements

\begin{tabular}{|l|l|l|l|}
\hline Most disagree (-3) & \multicolumn{1}{|c|}{$(\mathbf{- 2 )}$} & \multicolumn{1}{|c|}{$(+2)$} & Most agree (+3) \\
\hline $\begin{array}{l}\text { \#19. Green } \\
\text { infrastructure provides } \\
\text { the same functions in } \\
\text { every city. }\end{array}$ & $\begin{array}{l}\text { \#22. It is problematic to } \\
\text { monetize the benefits } \\
\text { of green infrastructure. }\end{array}$ & $\begin{array}{l}\text { \#8. Including green } \\
\text { infrastructure in } \\
\text { current asset } \\
\text { management processes } \\
\text { will improve } \\
\text { maintenance schedules. }\end{array}$ & $\begin{array}{l}\text { \#7. Natural areas are } \\
\text { an integral part of the } \\
\text { green infrastructure } \\
\text { concept. }\end{array}$ \\
\hline $\begin{array}{l}\text { \#13. Stormwater } \\
\text { management is the } \\
\text { primary service of } \\
\text { green infrastructure. }\end{array}$ & $\begin{array}{l}\text { mostly take care of } \\
\text { themselves; very little } \\
\text { maintenance is needed } \\
\text { for them to provide } \\
\text { services. }\end{array}$ & $\begin{array}{l}\text { \#17. New metrics must } \\
\text { be developed to } \\
\text { evaluate the } \\
\text { performance of green } \\
\text { infrastructure facilities. }\end{array}$ & $\begin{array}{l}\text { \#14. Monetization of } \\
\text { benefits provided by } \\
\text { green infrastructure is } \\
\text { critical to its accurate } \\
\text { and comprehensive } \\
\text { management. }\end{array}$ \\
\hline \multicolumn{1}{|l|}{$\begin{array}{l}\text { m20. Green } \\
\text { infrastructure does not } \\
\text { have the appropriate } \\
\text { characteristics or traits } \\
\text { to be treated as a } \\
\text { traditional financial } \\
\text { asset. }\end{array}$} & $\begin{array}{l}\text { \#9. Green } \\
\text { infrastructure includes } \\
\text { much more than } \\
\text { stormwater } \\
\text { management facilities. }\end{array}$ & \\
\hline
\end{tabular}

Factor 3: GI is specific, built municipal infrastructure

As displayed in Table 4-7, according to this factor, nature is a part of green infrastructure (agreement with statement \#7) but only specific, appropriately maintained nature (disagreement with \#12, \#5, and \#16, and strong agreement with \#2), indicating that this group is strongly focused on 'techno' side facility types that are

Interestingly, green gentrification was met with neutral or no salience responses by most factor groups. Factor 1 and 4 placed it in the +1 category while 2 and 5 ranked it at -1. Both of these categories are quite close to zero indicating the relative lack of salience this idea had to the general work of four of the factor groups. This group, Factor 3, however, ranked the statement “'Green gentrification' must be mitigated in all green infrastructure planning processes" at -3 or most disagree. This is important because it means that it was 
chosen to be only one of two most disagreed with statements in the entire set. This seemed to indicate that this group was not generally a public-facing entity. They viewed green infrastructure as distant from the public and the responsibility of the municipality first and fore-most.

Table 4-7: Factor 3 - most strongly agreed with and strongly disagreed with statements

\begin{tabular}{|c|c|c|c|}
\hline Most disagree (-3) & $(-2)$ & $(+2)$ & Most agree $(+3)$ \\
\hline $\begin{array}{l}\# 5 \text {. Every vegetated } \\
\text { space in the city is part } \\
\text { of green infrastructure. }\end{array}$ & $\begin{array}{l}\# 19 . \text { Green } \\
\text { infrastructure provides } \\
\text { the same functions in } \\
\text { every city. }\end{array}$ & $\begin{array}{l}\text { \#7. Natural areas are an } \\
\text { integral part of the } \\
\text { green infrastructure } \\
\text { concept. }\end{array}$ & $\begin{array}{l}\text { \#1. Communication } \\
\text { across institutional } \\
\text { silos is necessary for } \\
\text { successful green } \\
\text { infrastructure } \\
\text { development. }\end{array}$ \\
\hline $\begin{array}{l}\# 3 . \text { 'Green } \\
\text { gentrification' must be } \\
\text { mitigated in all green } \\
\text { infrastructure planning } \\
\text { processes. }\end{array}$ & $\begin{array}{l}\text { \#16. Natural areas can } \\
\text { mostly take care of } \\
\text { themselves; very little } \\
\text { maintenance is needed } \\
\text { for them to provide } \\
\text { services. }\end{array}$ & $\begin{array}{l}\text { \#8. Including green } \\
\text { infrastructure in } \\
\text { current asset } \\
\text { management processes } \\
\text { will improve } \\
\text { maintenance schedules. }\end{array}$ & $\begin{array}{l}\text { \#2. Maintenance of } \\
\text { green infrastructure } \\
\text { facilities should not be } \\
\text { the responsibility of } \\
\text { community volunteers. }\end{array}$ \\
\hline 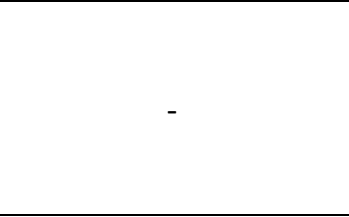 & $\begin{array}{l}\# 12 \text {. Urban agriculture } \\
\text { can be a part of a green } \\
\text { infrastructure plan. }\end{array}$ & $\begin{array}{l}\text { \#4. Green } \\
\text { infrastructure is under- } \\
\text { valued by current asset } \\
\text { management } \\
\text { techniques. }\end{array}$ & 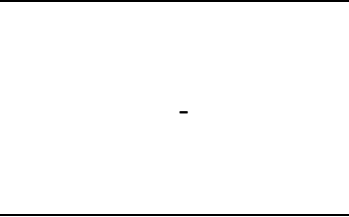 \\
\hline
\end{tabular}

Factor 4: Pro-nature coordination across silos; Broad and open definition for coordination

This group has a broad view of green infrastructure. As displayed in Table 4-8, they engage most strongly with statements regarding the term itself (i.e. statement \#11) and ideas around natural areas (\#7 and \#16). They see that plants have an important function but also that human maintenance of natural areas is important.

Most interestingly, they strongly disagree (-3) with the idea that green infrastructure is too broad to be useful. All of the other factors ranked this statement as having little or 
no salience ( 0 or -1$)$. Comments on these statements help elaborate the coordinating focus of this Factor group:

Comment on statement \#23: It's helpful to have an adaptable definition that can be broad and inclusive of many different things.

Comment on statement \#12: We think urban agriculture can be a part of the GI network and could be an interesting way to bring new partners into GI who are not normally at the table.

This group bucks the trend of the originally proposed stormwater vs network vision of green infrastructure by not associating with either infrastructure distinction strongly. Instead, statement ranking shows a focus on stakeholders (\# ) and communication (\#1). This group was not expected at the outset of this work.

Table 4-8: Factor 4 - most strongly agreed with and strongly disagreed with statements

\begin{tabular}{|c|c|c|c|}
\hline Most disagree $(-3)$ & $(-2)$ & $(+2)$ & Most agree $(+3)$ \\
\hline $\begin{array}{l}\# 23 \text {. Current use of the } \\
\text { term 'green } \\
\text { infrastructure' is too } \\
\text { broad to be useful. }\end{array}$ & $\begin{array}{l}\text { \#19. Green } \\
\text { infrastructure provides } \\
\text { the same functions in } \\
\text { every city. }\end{array}$ & $\begin{array}{l}\text { \#11. The public does } \\
\text { not understand the } \\
\text { term 'green } \\
\text { infrastructure.' }\end{array}$ & $\begin{array}{l}\text { \#1. Communication } \\
\text { across institutional } \\
\text { silos is necessary for } \\
\text { successful green } \\
\text { infrastructure } \\
\text { development. }\end{array}$ \\
\hline $\begin{array}{l}\text { \#6. The term 'green } \\
\text { infrastructure' helps } \\
\text { the public understand } \\
\text { that greenspace is } \\
\text { important and } \\
\text { valuable, like other } \\
\text { urban infrastructures } \\
\text { (e.g. roads, sewer, etc). }\end{array}$ & $\begin{array}{l}\# 15 . \text { The plants in } \\
\text { green infrastructure } \\
\text { facilities don't have a } \\
\text { significant impact on } \\
\text { the functionality of the } \\
\text { facility. }\end{array}$ & $\begin{array}{l}\text { \#2. Maintenance of } \\
\text { green infrastructure } \\
\text { facilities should not be } \\
\text { the responsibility of } \\
\text { community volunteers. }\end{array}$ & $\begin{array}{l}\text { \#9. Green } \\
\text { infrastructure includes } \\
\text { much more than } \\
\text { stormwater } \\
\text { management facilities }\end{array}$ \\
\hline (2) & $\begin{array}{l}\text { \#16. Natural areas can } \\
\text { mostly take care of } \\
\text { themselves; very little } \\
\text { maintenance is needed } \\
\text { for them to provide } \\
\text { services. }\end{array}$ & $\begin{array}{l}\text { \#7. Natural areas are an } \\
\text { integral part of the } \\
\text { green infrastructure } \\
\text { concept. }\end{array}$ & ( \\
\hline
\end{tabular}




\section{Factor 5: Nature not salient; GI is infrastructure}

This group was in favor of including green infrastructure in asset management to improve maintenance (\#8). They think that monetization is critical (\#14) but also that new metrics are needed to evaluate the performance of green infrastructure (\#17). This is consistent with their highly ranked statement that green infrastructure is currently undervalued by asset management techniques (\#4).

This combination of ideas points to a framework/epistemology that sees current practices as useful. They see asset management as a good way forward (all asset management statements ranked highly) but recognize the need for improved metrics for GI performance. This factor appears to be in favor of tweaking the status quo.

This factor group is ambivalent to the statement "Natural areas are an integral part of the GI concept." This is unsurprising as many of them are engineers whose purview does not include the management of natural areas. The lack of salience of this statement in their sorts supports claims throughout this dissertation that engineering knowledge systems do not have ways to think about or engage with natural systems as infrastructures. In contrast to the 0 rating that this factor group gave this statement, Factor 1 and 2 ranked it as +3 or most agree, and Factor $3 \& 4$ ranked it similarly at +2 .

The following comments help to further display the attitude of this group:

Comment on statement \#23: "There are too many definitions right now, and the public does not grasp any of the definitions fully."

Comment on \#17: "The best way to convey the value of green infrastructure to a skeptical audience is with solid performance data, which is currently problematic to develop in a comprehensive manner."

Comment on \#21: "Many people undervalue anything that has 'green' in the name or description. I think green infrastructure should simply be considered 
infrastructure so it's viewed as a beneficial asset rather than a non-essential waste of public dollars."

Comment on \#5: "Al though all green space helps. A lawn or planted area does not provide enough benefit to be called GI."

Table 4-9: Factor 5 - most strongly agreed with and strongly disagreed with statements

\begin{tabular}{|l|l|l|l|}
\hline Most disagree (-3) & \multicolumn{1}{|c|}{$(\mathbf{- 2 )}$} & \multicolumn{1}{|c|}{$(\mathbf{+ 2 )}$} & \multicolumn{1}{|c|}{ Most agree (+3) } \\
\hline $\begin{array}{l}\text { \#19. Green } \\
\text { infrastructure provides } \\
\text { the same functions in } \\
\text { every city. }\end{array}$ & $\begin{array}{l}\text { \#15. The plants in } \\
\text { green infrastructure } \\
\text { facilities don't have a } \\
\text { significant impact on } \\
\text { the functionality of the } \\
\text { facility. }\end{array}$ & $\begin{array}{l}\text { \#4. Green } \\
\text { infrastructure is under- } \\
\text { valued by current asset } \\
\text { management } \\
\text { techniques. }\end{array}$ & $\begin{array}{l}\text { lnfrastructure in } \\
\text { current asset } \\
\text { management processes } \\
\text { will improve } \\
\text { maintenance } \\
\text { schedules. }\end{array}$ \\
\hline $\begin{array}{l}\text { \#5. Every vegetated } \\
\text { space in the city is part } \\
\text { of green infrastructure. }\end{array}$ & $\begin{array}{l}\text { \#10. Curbside green } \\
\text { infrastructure is like a } \\
\text { series of potted plants } \\
\text { that need constant } \\
\text { maintenance. }\end{array}$ & $\begin{array}{l}\text { \#17. New metrics must } \\
\text { be developed to } \\
\text { evaluate the } \\
\text { performance of green } \\
\text { infrastructure facilities. }\end{array}$ & $\begin{array}{l}\text { \#1. Communication } \\
\text { across institutional } \\
\text { silos is necessary for } \\
\text { successful green } \\
\text { infrastructure } \\
\text { development. }\end{array}$ \\
\hline & $\begin{array}{l}\text { \#2. Maintenance of } \\
\text { green infrastructure } \\
\text { facilities should not be } \\
\text { the responsibility of } \\
\text { community volunteers. }\end{array}$ & $\begin{array}{l}\text { benefits provided by } \\
\text { green infrastructure is } \\
\text { critical to its accurate } \\
\text { and comprehensive } \\
\text { management. }\end{array}$ & \\
\hline
\end{tabular}

\section{$\underline{\text { Discussion }}$}

Perhaps unsurprisingly, the caricatures of the out-of-touch command-and-control engineer or the unrealistic tree-hugging ecologist are not apparent in the factors derived from the Q-sorts completed by my participants. (Perhaps this is because my participants were practitioners rather than academics.) While exaggerated characteristics of particular epistemologies is a useful starting point for examination - a strawman if you will - we intuitively know that people are more complex and nuanced than their caricatures. And this was well borne out in the results presented in this chapter. 
First, looking at the entire participant group as a whole, it was incredibly encouraging that the most agreement (ranking either +2 or +3 in all factor arrays) was statement \#1: "Communication across institutional silos is necessary for successful green infrastructure development." As this dissertation at its core is an examination of interdisciplinary, cross-silo work spurred by green infrastructure, this was a personally satisfying response. If there was not genuine excitement about cross-silo work in interviews, there is at least acknowledgement here of its importance, as well as evidence that it is a primary way participants are thinking about their work, relative to the other ideas presented in the Q-set.

Additionally, the most disagreed with statement out of the whole group was statement \#19: "Green infrastructure provides the same functions in every city." This is interesting considering attempts currently in the works to standardize green infrastructure at the national level. While national standardization and green infrastructure functioning differently in every city are not necessarily diametrically opposed futures, they do require quite a bit of care to reconcile. For example, the EPA's emphasis on stormwater and CSO management has focused green infrastructure development on a select few facilities types that are quite technical and focused on the 'techno' end of the eco-techno spectrum. This technology tends to look the same across the country - same plants, same scale, same depth, etc. Each municipality must work - read: spend money - to test these national standards in their own context (environmental, social, and technological context) and adjust standards to perform appropriately in their city. This is not a trivial expense for cities. And unless the dedicated funding is set aside for this kind of testing and adjustment, the general standards 
may very well be installed as is, creating less-than-ideal function and potentially elicit negative responses from residents and experts alike blocking green infrastructure's future potential.

\section{Reflections}

In this section I integrate insights from each of the factor groups with narrative results from chapters 2 and 3, fully utilizing Q-method as a follow-up step in this mixed methods dissertation.

First, the breakdown of factors by city added new insights to the narrative analysis. Participants from Portland loaded most heavily on Factor 1, 2, and 3, while Baltimore loaded on 4 and 5. While in Chapter 2, I found that regulatory context seemed to push differentiation regarding facility types employed, but definition, measurement, and valuation practices appeared to differ by department/bureau rather than city. Ideas about urban nature, for example, seemed to differ primarily between utility departments and planning due to the knowledge claim needs of each. Participants in both BES and DPW expressed the need for more precise definition of green infrastructure and less ambiguity in general due to legal and funding implications. If green infrastructure managed stormwater, it needed to be specific. In contrast, planning departments advocated for an open definition that could allow for greater stakeholder inclusion.

When looking at the Q-sort results, we see a clear distinction between the factor groups by city, indicating that different points of view may be more influenced by city context than was seen in the narrative results. Or that knowledge circulation limitations 
lead to geographically distinct points of view. This suggests that understanding green infrastructure as a singular national phenomena, as much of the literature portrays it, may be increasingly problematic. Continued follow-up with original participants and with participants in other cities is necessary to understand the differentiation uncovered in this Q-sort, including the potential of more traditional survey methods to establish prevalence of the points of view articulated here. But this finding suggests that it is important to examine green infrastructure across cities to better understand its development.

The various definitions of green infrastructure collected in narrative interviews were further refined through the Q-sort process. For example, Factors 1, 2 and 4 ranked statements regarding the inclusion of urban nature highly. This was expected from the narrative results that found overwhelmingly that biological components were an important piece of green infrastructure facilities. However, Factor 5 displayed a nuance regarding this definition. Factor 5 was ambivalent to the inclusion of nature in green infrastructure and instead prioritized built infrastructure concepts and ideas. While every participant mentioned living natural components when defining green infrastructure, this Factor group highlights the lack of prioritization of that concept within a participant's point of view. While they may agree that nature is a part of green infrastructure usually, other concepts regarding its measurement and valuation as infrastructure are more salient and pertinent to decision-making.

One finding from Chapter 2 was reinforced by Q-sort results. This was the narrative finding that definitional ambiguity was useful for some participants whereas it was 
detrimental to others. Factor 4 is a strong point of view reflecting the participants that found the ambiguity of the definition to be useful to

Most participants loaded most heavily on Factor 1 . This grouping was the hardest to categorize due to its inclusion of both network and stormwater views. It seems to represent a group that is integrating across the eco-techno spectrum, recognizing the benefits of urban nature and ecosystems at large, and the connections of this larger system to the modular built green infrastructure facilities on the techno end of the spectrum. A comment from one participant regarding a measurement statement (\# ) lends insight into this point of view:

We can quantify major benefits of both green and grey infrastructure, and this is worthwhile in order to evaluate costs and benefits of services and prioritize projects. However, I think it's unnecessary to spend enormous effort trying to quantify every single benefit provided by both green and grey infrastructure. We don't try to quantify the human health value of providing wastewater collection and treatment - we acknowledge it's part of our societal responsibility and it's part of meeting the Clean Water Act.

For green infrastructure, I think it's OK to have benefits that are recognized (like habitat) that are not fully quantified or monetized. Green infrastructure is invested in by government where it can help solve a problem - stormwater management for quality or quantity; floodplain management; stream stabilization and temperature reduction; etc. Solving those problems is a driver for the work, even if we don't have all of the additional benefits quantified. (Also applies for Statement 22)

\section{$\underline{\text { Conclusion }}$}

In this chapter, I extended the knowledge systems' toolbox to include Q-method. While the results of Q-method are not easily actionable, they are an important exploratory step to better understanding the way that concepts are combined in the field by 
practitioners. This can be used to explicate a knowledge system, and help better understand the points of view that shape the use of some knowledge types over others.

As discussed in the introduction, Q-method is an increasingly popular method used in the study of environmental policy-making (Cotton 2015; Ghoochani et al. 2015; Iribarnegaray et al. 2014; Rastogi et al. 2013; Barry and Proops 1999). Natural resource management conflicts are often stalled out by polarized stakeholder groups; Q-method has been shone to help in cognitive reframing of these conflicts in negotiation processes (Asah et al. 2012; Mazur and Asah 2013). In this chapter, I have added to this discussion by showing the prioritization of different knowledge claims and concepts by those involved in negotiating knowledge system challenges around green infrastructure. By illuminating and acknowledging the various ways of knowing displayed by this Q-sort analysis (including groups focused on quantification, communication, and integration), I highlight different points of leverage within the knowledge system to support green infrastructure development. 


\section{Dissertation Conclusion}

Nature is increasingly known as infrastructure in cities today. In the face of aging human-built infrastructure systems that are deteriorating from lack routine maintenance and new challenges from climate change and changing population densities, municipal governments seek cost-effective solutions to new and old infrastructure problems. Green infrastructure, or the use and mimicry of ecosystem structures and functions to deliver services, is an increasingly popular solution to these problems. Relatively cheaper than many traditional infrastructure systems, green infrastructure can provide a number of social and ecological co-benefits beyond its primary designed service; green infrastructure is often touted as a more socially responsible and ecologically sustainable option due to its multifunctionality.

But, as I have explored throughout this dissertation, making urban nature into infrastructure is difficult. In particular, I have explored the many institutional issues around ontology and epistemology of existing municipal knowledge systems that must be addressed to design, implement, and maintain green infrastructure, such as incompatible data tolerances, classification schemes, and disciplinary norms.

One of the primary knowledge systems changes brought to light through this research, is the shift from 'knowing' urban nature as a luxury or an amenity to 'knowing' urban nature as an essential service provider. I argue here that this is one of the primary conceptual shifts involved in making nature infrastructure and that this shift creates the majority of the knowledge system conflicts and challenges facing green infrastructure presented throughout this dissertation. 
The conceptual shift to nature as service provider creates both opportunities and challenges that I ultimately argue we must acknowledge and reflect on as a community as we continue to design, build, and maintain green infrastructure networks through time (following the insights of the communicative turn in planning (Healey 1997; Innes and Booher 2010; Friedmann 1993)). We must attend to more than the technological uncertainties of this new infrastructural type; we must approach green infrastructure as a socio-political and institutional, as well as a technological, puzzle to be solved (Grabowski et al. 2017). To do this, I have framed green infrastructure as a state simplification, following Scott (1998), highlighting the importance of ecological function rather than product in green infrastructure's development, following Carse (2012).

\section{Historical roots}

The vision of nature as service-provider is not entirely new; however, I argue that its current form differs in important ways from visions in the past. And that it should be critically viewed as an important force shaping urban nature management and quality of life in the city. The historical roots of urban ecosystem services are often traced back to the Progressive Reform era of the early $20^{\text {th }}$ century. As Eisenman (2013) describes, the industrial revolution brought many people to urban areas where they lived densely without appropriate disposal of wastes:

The industrial era yielded significant advancements in human prosperity. However, the physical and institutional infrastructure of cities was not prepared for this unprecedented urban growth, resulting in lamentable living conditions... These conditions inspired Progressive Era social reforms at the turn of the 20th century. (p. 289) 
Progressive reformers were interested in the functions of nature in the city; and particularly in the importance of nature to humans. "The ideology of the public park was predicated on the importance of open, public space to the health and vitality of urban populations." (Eisenman 2013, p. 289). Nature was 'known' as an important part of addressing disease, particularly within the miasma theory of disease at the time.

Progressive era reformers were using a proto-version of ecosystem services, so to speak, to argue for the development of park spaces. They argued that parks improve the physical and mental health of city-dwellers (Eisenman 2013; Rawson 2004). Municipal staff are again using parks and green infrastructure to improve health outcomes in the city. However, current work is attending to an expanded suite of services (e.g. urban heat island mitigation, biodiversity) and also advancing the idea of nature for nature's sake (in some places), as described in Chapters 2 and 3 of this dissertation. Inclusion of these services runs into institutional challenges because methods have not yet been developed to integrate them into business-as-usual in many bureaus, and certainly not city-wide. In contrast, the services of stormwater management, wastewater treatment, and flood mitigation are wellinstitutionalized in current bureau operations (i.e. the norms, protocols, and practices that make up existing knowledge systems); therefore, this set of services is more easily accepted, measured, and managed as the services of green infrastructure. This second set of services also benefits from historical precedent: they are most similar to the services Olmsted (and others of his era) designed for. Therefore, these services have existing institutionalized pathways for current planning to follow, perhaps allowing green infrastructure to focus on these services more easily. 
While health is being promoted as a service of nature, which is similar to historical appeals, the economic implications appear to be different from those of the past. For the most part, the economic argument of the progressives is obscured in environmental historical accounts. Reformers were working in a time of intense growth and increasing budgets for cities. Now we are looking at a time of limited investment in city infrastructure and a time of scarcity on many levels. Both Portland and Baltimore face budget crunches (albeit at different scales and for different reasons) that limit their ability to respond to needed changes. This makes ecosystem services different from the encouragement of health by progressive reformers. Ecosystem services does not make nature into infrastructure inherently (as the views of nature in the past did), it makes nature into infrastructure by valuing it as monetized gain in the market.

For example, current ecosystem services schemes practically skip the step of people altogether. Ecosystem services are meant to support people, but with limited or no monitoring or understanding of the functioning of many of the urban and restored landscapes providing ecosystem services (as they are novel ecosystems (Hobbs, Higgs, and Hall 2013)), it is only assumed that certain functions are happening. Without tracking the interaction of people and these potential ecosystem services, it is unclear who is actually benefiting and in what ways they are benefiting. In the case of wetland credits, for example, land banks are paid for building wetlands, but the services aren't necessarily being created; there is a lack of monitoring and most of the time only restored acreage is tracked. Additionally, wetland banks are often spatially separated from the disturbed site, meaning 
ecosystem service benefit is moved from one human population to another (Robertson et al. 2014; Robertson 2004).

The inclusion of market mentality into the system is, therefore, an important difference between nature as service-provider today vs the era of Olmstead. While the vision of the past was most certainly imbued with the profit-driven development of the industrial city, the way we now talk about, share, and use Olmstead and others as a role model has been sanitized, the economics drivers left undiscussed (as seen in this typical article regarding Olmstead and green infrastructure (Eisenman 2013)). In today's cities, cost-savings and economic efficiency is the number one (stated) reason that green infrastructure is being pursued: it is touted as cheaper and therefore it gets traction.

This makes the knowledge systems of green infrastructure all the more important to analyze, as this dissertation has done. Financial knowledge claims underpin much of the push for municipal development of green infrastructure (as presented in Chapters 2 and 3) and infrastructure development in general (Grabowski et al. 2017; Grabowski et al. in press); it is therefore important to examine the influences of these knowledge claims on the ways that we know (and therefore manage) nature in the city.

\section{Disconnects and Recommendations}

Ultimately, it is important to better understand the knowledge systems underpinning municipal decision-making because these practices influence the solutions that are deemed appropriate to solve pressing urban problems. Potentially useful knowledge claims from alternative knowledge systems may be inadvertently dismissed 
from the decision-making process because the established knowledge system is unable to produce or vet them. As Munoz-Erickson (2014) explains,

...even when new knowledge is created that can support novel solutions, this knowledge may not proceed to be used in the political process because there are other already established and powerful knowledge systems informing the policy process as well (e.g. use of economic indicators in state planning agencies). Moreover, assumptions about what knowledge is more credible in decisionmaking can ultimately affect how well we understand the dynamics of the system under study (e.g. ecosystems). (Munoz-Erickson 2014)

A good example of this phenomenon is engagement with Title 11 in Portland. Title 11 is colloquially referred to as the "tree code." It implements much of the Urban Forest Action Plan within the City of Portland by enforcing standards on street trees and private property trees throughout the city. While an important piece of green infrastructure implementation in Portland (as other researchers have noted (Shandas 2017)), Title 11 was not mentioned in any of the interviews that I conducted with staff in the City of Portland or in any of the self-identified green infrastructure documents I reviewed. Likewise, in all of the various iterations (the original plan from 2007 and all the annual updates that have occurred since 2009) of the Urban Forest Action Plan that compels and guides Title 11, the term "green infrastructure" is used only one: in the 2013 implementation update, green infrastructure is mentioned on page 8 in reference to the Central City 2035 Concept Plan. The original 114-page Urban Forestry Management Plan (which the Action Plan is derived from) only uses the term "green infrastructure" twice: as a section title ("The green infrastructure is as important as the gray infrastructure" (p.3)) that is not elaborated in additional sections, and as a synonym ("the urban forest or 'green infrastructure' requires care and maintenance to maximize the benefits it provides" (p. 73)). In contrast, "tree" is 
mentioned over 1,000 times, "forest" is mentioned over 500 times, and the word "vegetation" is used 123 times (for reference, the term "green infrastructure" is used 736 times in this dissertation and there are 264 references to the term "knowledge systems".) These word counts serve as rough proxy here for the concepts and facilities of most importance or interest to those writing this plan.

As evidenced in this dissertation, vegetation, trees, and forests are all integral parts of the larger green infrastructure concept; but operationally, the integration of these specific facility types in the concept of municipal infrastructure has not yet occurred and is continually faced with institutional challenges, challenges that this dissertation sought to illuminate and explore. For example, I argue that the lack of reference to, or reliance on, the concept of green infrastructure in these tree plans is an example of the disconnects across the eco-techno spectrum. Because of the inability to fit trees into many of the dominant infrastructural knowledge systems of the city (engineering, financial, etc.) they are de facto placed in a separate category. While often recognized as green infrastructure in theory, in practice trees are conceptually separated from the concept of green infrastructure in many of the policies and plans in the City of Portland. This means that staff working on trees, work on trees, and staff working on green infrastructure, work on green infrastructure, leading to a lack of engagement with codes like Title 11 in the set of green-infrastructure-focused interviews I conducted at the City of Portland. This is a knowledge system issue, a point of intervention, that needs to be addressed in future green infrastructure design and planning processes. 
Along these same lines, this dissertation has provided evidence that many different conceptions of green infrastructure are present in both cities and that differing social, ecological, and technological context does not remove competing visions altogether, even if they are marginalized by other needs. Instead, these ideas hang around, sometimes relatively dormant until conditions are favorable to increasing their prominence (an "epistemic seed bank" so to speak). So, while the CSO Program created the appropriate conditions for a green infrastructure as stormwater management vision within City of Portland bureaus, the large network of greenspace vision of green infrastructure was embraced by NGOs like the Intertwine. Likewise, in Maryland, the network vision of green infrastructure emerged from the conservation community regionally and has manifested in NGOs like the Greater Baltimore Wilderness Coalition. City-focused NGOs found it difficult in the past to interact and engage with the City of Baltimore until conditions of the MS4 permit created a mutual interest in green infrastructure. Often differing visions have little to no direct interaction with one another, as both use different terminology and facility types to pursue their visions (as described throughout this dissertation).

While local utility departments need to continue with a stormwater management focus for a variety of legal and practical reasons, larger network conceptions seem to be maintaining themselves in NGOs and other larger-scale government institutions. From experience in Baltimore, I argue that a stronger state-level green infrastructure vision can tie together planning for facilities across the eco-techno spectrum, removing knowledge system challenges from local departments and negotiating these challenges instead through regulatory and policy initiatives further up the hierarchy where funding may be found to 
tackle this issue. At the same time, a wider definition of green infrastructure, relegating green stormwater infrastructure to a specific type of green infrastructure, can allow local knowledges and perspectives to inform and improve infrastructure decision-making, as seen in both the City of Portland and the City of Baltimore.

Lastly, I would not be doing due diligence to the institutional conundrum that is green infrastructure without returning to a discussion maintenance. Much of the theory and theoretical discussion throughout this dissertation is focused on the intangible ontological tensions of green infrastructure that play out in discourse and social arenas. These tensions are made real and solid in the world through the activities of maintenance. Maintenance is where much of the messy work of reconciling human definitions, metrics, and values of urban nature with actual living creatures' lives takes place, in mundane, every-day activities.

My final take-away from this work is that a maintenance regime is where the decisions we have made about how to get the function we want out of urban nature play out materially. Much like the example of scientific forestry, nature does not always act in in the ways we want it to. Just as monoculture crops of economically-pertinent tree species did not grow as well as expected, in biowales some plants whither in a particular location while the same species thrives in an identical facility up the block. Invasive species subsume some parts of a natural area and provide habitat for a rare native bird species, while an immaculately maintained natural area across town remains only a hang-out for crows and other unwanted urban-adapted species. Our maintenance regimes influence performance, sometimes encouraging the services we want, but often hindering them in 
unexpected ways. Maintenance is therefore an important site for future knowledge systems analysis.

In conclusion, at the onset of this work, it appeared that a more definite and precise definition of green infrastructure itself was needed. My focus on definitions in plans and policies across the U.S. was an attempt to find the 'best' definition and work to employ it elsewhere. But this research provides evidence for the useful space created by ambiguity in the term, especially the ways that it allows more stakeholders to be involved and potentially opens possibilities for communicative and collective planning to take place. My final recommendation is then to continue the development of sub-types of green infrastructure that differentiate stormwater specific facility types from broader network visions of green infrastructure. I see great value in the narrowing of facility design into "green stormwater infrastructure", or GSI, and sustainable urban drainage systems (SUDS) so that it can connect more seamlessly with existing practice. But these facilities should always be considered within the broad umbrella of a green infrastructure plan that encompasses all greenspaces within an urban area. In this way, I think that a more productive engagement with whole ecosystems, and with wider social systems, will be possible providing more sustainable and resilient outcomes on the ground.

Ultimately, making urban nature into a service-provider through green infrastructure development is more complicated than first meets the eye. As I have shown throughout this dissertation, there are a number of social, institutional, and ecological challenges that must be negotiated within and between municipal departments; issues of state simplification and standardization expose the politics of mundane technical decision- 
making around infrastructure design, implementation, and maintenance. But continued research into the spaces of socio-technical and enviro-technical co-production in all social arenas (as this dissertation has done in municipal decision-making) can help us better understand the knowledge systems at play in cities and provide an opportunity to more effectively design institutional decision-making processes to facilitate the creation of livable and sustainable city futures. 


\section{Endnotes}

i "Infra- means "below;" so the infrastructure is the "underlying structure" of a country and its economy, the fixed installations that it needs in order to function. These include roads, bridges, dams, the water and sewer systems, railways and subways, airports, and harbors. These are generally government-built and publicly owned. Some people also speak about such things as the intellectual infrastructure or the infrastructure of science research, but the meaning of such notions can be extremely vague." (Merriam-Webster 2017)

ii While definitions of 'scientific' range from highly specific to vague, Hacking's (1999) wide definition serves the purposes of this paper best; he states that science is "... what passes as science, what models itself on the methods of established and successful science, what claims to discover objective truth about the world and its inhabitants, what claims to give explanations, to make falsifiable conjectures, to increase our power to predict, control, and improve" (p. 130).

iii PQMethod was developed by Peter Schmolck. He provides it as a free download at: http://schmolck.org/qmethod/ 


\section{References}

Alberti, Marina, J.M. Marzluff, Gordon Bradley, Clare M. Ryan, Eric Schlenberger, and Craig Zumbrunnen. 2003. "Integrating Humans into Ecology: Opportunities and Challenges for Studying Urban Ecosystems." BioScience 53 (12): 1169-79.

Anderies, John M., Marco A. Janssen, and Elinor Ostrom. 2004. "A Framework to Analyze the Robustness of Social-Ecological Systems from an Institutional Perspective." Ecology and Society 9 (1): 18.

Asah, Stanley T., David N. Bengston, Keith Wendt, and Leif DeVaney. 2012. "Prognostic Framing of Stakeholders' Subjectivities: A Case of All-Terrain Vehicle Management on State Public Lands." Environmental Management 49 (1): 192-206. doi:10.1007/s00267-011-9756-7.

ASCE. 2017. "Infrastructure Report Card: A Comprehensive Assessment of America's Infrastructure."

Baltimore Department of Planning, Office of Sustainability. 2015. "Green Pattern Book: Using Vacant Land to Create Greener Neighborhoods in Baltimore." NRS-INF-3215. Newtown Square, PA: US Department of Agriculture Forest Service.

"Banking on Green: A Look at How Green Infrastructure Can Save Municipalities Money and Provide Economic Benefits Community-Wide." 2012.

Barry, John, and John Proops. 1999. "Seeking Sustainability Discourses with Q Methodology." Ecological Economics 28 (3): 337-345.

Bazeley, Pat. 2008. "Mixed Methods in Management Research." Dictionary of Qualitative Management Research, 133-136.

Benedict, Mark A., and Edward McMahon. 2006. Green Infrastructure: Linking Landscapes and Communities. Washington, DC: Island Press.

Ben-Joseph, Eran. 2005. The Code of the City: Standards and the Hidden Language of Place Making. Urban and Industrial Environments. Cambridge, Mass: MIT Press.

Bocchini, Paolo, Dan M. Frangopol, Thomas Ummenhofer, and Tim Zinke. 2014. "Resilience and Sustainability of Civil Infrastructure: Toward a Unified Approach." Journal of Infrastructure Systems 20 (2): 04014004. doi:10.1061/(ASCE)IS.1943555X.0000177.

Bocking, Stephen. 2004. Nature's Experts: Science, Politics, and the Environment. New Brunswick, N.J: Rutgers University Press.

Booher, David E., and Judith E. Innes. 2010. "Governance for Resilience: CALFED as a Complex Adaptive Network for Resource Management." Ecology and Society 15 (3): 35. 
Bowker, Geoffrey C., Karen Baker, Florence Millerand, and David Ribes. 2009. "Toward Information Infrastructure Studies: Ways of Knowing in a Networked Environment." In International Handbook of Internet Research, edited by Jeremy Hunsinger, Lisbeth Klastrup, and Matthew Allen, 97-117. Dordrecht: Springer Netherlands. http://link.springer.com/10.1007/978-1-4020-9789-8_5.

Bowker, Geoffrey C., and Susan Leigh Star. 1999. Sorting Things out: Classification and Its Consequences. Inside Technology. Cambridge, Mass: MIT Press.

Brown, Steven R. 1980. Political Subjectivity: Applications of Q Methodology in Political Science. New Haven: Yale Univ. Pr.

- - . 1993. "A Primer on Q Methodology." Operant Subjectivity 16 (3/4): 91-138.

Burnham, Morey, Zhao Ma, and Baoqing Zhang. 2016. "Making Sense of Climate Change: Hybrid Epistemologies, Socio-Natural Assemblages and Smallholder Knowledge: Making Sense of Climate Change." Area 48 (1): 18-26. doi:10.1111/area.12150.

Callon, Michel. 1999. "Some Elements of a Sociology of Translation: Domestication of the Scallops and the Fishermen of St. Brieuc Bay." In The Science Studies Reader, edited by Biagioli. New York: Ratledge.

Carlet, Fanny. 2015. "Understanding Attitudes toward Adoption of Green Infrastructure: A Case Study of US Municipal Officials." Environmental Science \& Policy 51 (August): 65-76. doi:10.1016/j.envsci.2015.03.007.

Carmon, Naomi, and Susan S. Fainstein, eds. 2013. Policy, Planning, and People: Promoting Justice in Urban Development. 1st ed. The City in the Twenty-First Century. Philadelphia: University of Pennsylvania Press.

Carse, A. 2012. "Nature as Infrastructure: Making and Managing the Panama Canal Watershed." Social Studies of Science 42 (4): 539-63. doi:10.1177/0306312712440166.

Cartwright, Nancy. 1999. The Dappled World: A Study of the Boundaries of Science. Cambridge, UK : New York, NY: Cambridge University Press.

Cash, David, William Clark, Frank Alcock, Nancy Dickson, Noelle Eckley, David Guston, Jill Jager, and Ronald Mitchell. 2003. "Knowledge Systems for Sustainable Development." Proceedings of the National Academy of Sciences 100 (14): 808691.

Chan, Kai M.A., Terre Satterfield, and Joshua Goldstein. 2012. "Rethinking Ecosystem Services to Better Address and Navigate Cultural Values." Ecological Economics 74 (February): 8-18. doi:10.1016/j.ecolecon.2011.11.011.

"City of Chicago: Green Stormwater Infrastructure Strategy." 2014. Chicago: Department of Water Management. 
"City of Phoenix Code Review to Promote Green Infrastructure - Case Study." 2013. TetraTech.

City of Portland. in preparation. "Green Asset Report." City of Portland.

City of Seattle. 2015. "Green Stormwater Infrastructure in Seattle: Implementation Strategy 2015-2020." Seattle, WA: City of Seattle.

Collins, Scott L, Stephen R Carpenter, Scott M Swinton, Daniel E Orenstein, Daniel L Childers, Ted L Gragson, Nancy B Grimm, et al. 2011. "An Integrated Conceptual Framework for Long-Term Social-ecological Research." Frontiers in Ecology and the Environment 9 (6): 351-57. doi:10.1890/100068.

Cooley, Alexis, and Heejun Chang. 2017. "Precipitation Intensity Trend Detection Using Hourly and Daily Observations in Portland, Oregon." Climate 5 (1): 10. doi:10.3390/cli5010010.

Costanza, Robert. 2011. "Valuing Ecological Systems and Services." F1000 Biology Reports 3 (July). doi:10.3410/B3-14.

Costanza, Robert, Ralph d'Arge, Rudolf S. de Groot, Stephen Farber, Monica Grasso, Bruce Hannon, Karin Limburg, et al. 1997. "The Value of the World's Ecosystem Services and Natural Capital." Nature 387 (May).

Cotton, M. 2015. "Stakeholder Perspectives on Shale Gas Fracking: A Q-Method Study of Environmental Discourses." Environment and Planning A, August. doi:10.1177/0308518X15597134.

Cowan, Gerrard. 2017. "Investors Warm to 'Green Bonds.'” Wall Street Journal, April 10, sec. Markets. https://www.wsj.com/articles/investors-warm-to-green-bonds1491790201.

Cronon, William. 1992. "A Place for Stories: Nature, History, and Narrative." The Journal of American History, 1347-1376.

Davoudi, Simin. 2012. "The Legacy of Positivism and the Emergence of Interpretive Tradition in Spatial Planning." Regional Studies 46 (4): 429-41. doi:10.1080/00343404.2011.618120.

Davoudi, Simin, Keith Shaw, L. Jamila Haider, Allyson E. Quinlan, Garry D. Peterson, Cathy Wilkinson, Hartmut Fünfgeld, Darryn McEvoy, Libby Porter, and Simin Davoudi. 2012. "Resilience: A Bridging Concept or a Dead End? 'Reframing' Resilience: Challenges for Planning Theory and Practice Interacting Traps: Resilience Assessment of a Pasture Management System in Northern Afghanistan Urban Resilience: What Does It Mean in Planning Practice? Resilience as a Useful Concept for Climate Change Adaptation? The Politics of Resilience for Planning: A Cautionary Note: Edited by Simin Davoudi and Libby Porter." Planning Theory \& Practice 13 (2): 299-333. doi:10.1080/14649357.2012.677124. 
De Groot, R. S, M. A Wilson, and R. M.J Boumans. 2002. "A Typology for the Classification, Description and Valuation of Ecosystem Functions, Goods and Services." Ecological Economics 41 (3): 393-408.

Dryzek, John S. 1997. The Politics of the Earth: Environmental Discourses. Oxford ; New York: Oxford University Press.

"Earth Economics: About Us." 2017. Earth Economics. Accessed March 11. http://www.eartheconomics.org/about-us/.

Edwards, Paul N. 2003. "Infrastructure and Modernity: Force, Time, and Social Organization in the History of Sociotechnical Systems." In Modernity and Technology, edited by Thomas J. Misa, Philip. Brey, and Andrew Fennberg, 185225. MIT Press.

Eisenman, Theodore S. 2013. "Frederick Law Olmsted, Green Infrastructure, and the Evolving City." Journal of Planning History 12 (4): 287-311. doi:10.1177/1538513212474227.

Emmanuel, R., and A. Loconsole. 2015. "Green Infrastructure as an Adaptation Approach to Tackling Urban Overheating in the Glasgow Clyde Valley Region, UK." Landscape and Urban Planning 138 (June): 71-86. doi:10.1016/j.landurbplan.2015.02.012.

EPA. 2011. "Urban Waters Small Grants: City of Corvalis." Overviews and Factsheets. US EPA. https://www.epa.gov/urbanwaters/urban-waters-small-grants.

- - . 2015. "What Is Green Infrastructure?" United States Environmental Protection Agency. December. http://www2.epa.gov/green-infrastructure/what-greeninfrastructure.

- - . 2017. "Green Infrastructure in Parks: A Guide to Collaboration, Funding, and Community Engagement." EPA 841-R-16-112. Environmental Protection Agency.

Everett, G., J.E. Lamond, A.T. Morzillo, A.M. Matsler, and F.K.S. Chan. 2015. "Delivering Green Streets: An Exploration of Changing Perceptions and Behaviours over Time around Bioswales in Portland, Oregon." Journal of Flood Risk Management, November, n/a-n/a. doi:10.1111/jfr3.12225.

Fainstein, Susan S. 2010. The Just City. Ithaca: Cornell University Press.

Felson, Alexander J., and Steward T. A. Pickett. 2005. "Designed Experiments: New Approaches to Studying Urban Ecosystems." Frontiers in Ecology and the Environment 3 (10): 549. doi:10.2307/3868611.

Finewood, Michael H. 2016. "Green Infrastructure, Grey Epistemologies, and the Urban Political Ecology of Pittsburgh's Water Governance: Pittsburgh's Water Governance." Antipode 48 (4): 1000-1021. doi:10.1111/anti.12238. 
Fitzgerald, Michael R., and Robert F. Durant. 1980. "Citizen Evaluations and Urban Management: Service Delivery in an Era of Protest." Public Administration Review 40 (6): 585. doi:10.2307/3110311.

Flyvbjerg, Bent. 1998. Rationality and Power: Democracy in Practice. Morality and Society. Chicago: University of Chicago Press.

Forester, John. 1982. "Planning in the Face of Power." Journal of the American Planning Association 48 (1): 67-80. doi:10.1080/01944368208976167.

Friedmann, John. 1993. "Toward a Non-Euclidian Mode of Planning." Journal of the American Planning Association 59 (4): 482-85. doi:10.1080/01944369308975902.

- - . 2011. Insurgencies: Essays in Planning Theory. The RTPI Library Series. Abingdon, Oxon ; New York, NY: Routledge.

Friese, Susanne. 2014. Qualitative Data Analysis with ATLAS.ti. Second edition. Los Angeles: SAGE.

Gandy, Matthew. 2002. Concrete and Clay: Reworking Nature in New York City. Urban and Industrial Environments. Cambridge, Mass: MIT Press.

Ghoochani, Omid M., Azadeh Bakhshi, Matthew Cotton, Azar Hashemi Nejad, and Mansour Ghanian. 2015. "Environmental Values in the Petrochemical Industry: A Q-Method Study in South West Iran." Environmental \& Socio-Economic Studies 3 (4): 1-10.

Gieryn, Thomas F. 1999. Cultural Boundaries of Science: Credibility on the Line. Chicago: University of Chicago Press.

Goldstein, Bruce Evan, ed. 2012. Collaborative Resilience: Moving through Crisis to Opportunity. Cambridge, Mass: MIT Press.

Goodnough, Abby, Monica Davey, and Mitch Smith. 2016. "When the Water Turned Brown." The New York Times, January 23. http://www.nytimes.com/2016/01/24/us/when-the-water-turned-brown.html.

Gottlieb, Robert. 2005. Forcing the Spring: The Transformation of the American Environmental Movement. Rev. and updated ed. Washington, DC: Island Press.

Grabowski, Z. J., A. Denton, M. A. Rozance, S. Kidd, and A. M. Matsler. in press. "Removing Dams, Constructing Science: Co-Production of Un-Dammed Riverscapes by Politics, Finance, Environment, Society and Technology." Water Alternatives Special issue: Dam removal-new environments and new landscapes.

Grabowski, Z. J., A. M. Matsler, C. Thiel, L. McPhillips, R. Hum, A. Bradshaw, T. R. Miller, and C. L. Redman. 2017. "Infrastructures as Socio-Eco-Technical Systems: Five Considerations for Interdisciplinary Dialogue." Journal of Infrastructure Systems 23 (4). 
"Green Infrastructure Report: Baltimore City." 2015. Chesapeake Conservency.

Greenberg, P. 2012. "An Oyster in the Storm." New York Times, October 29. http://www.nytimes.com/2012/10/30/opinion/an-oyster-in-the-storm.html.

Greene, Jennifer, Lehn Benjamin, and Leslie Goodyear. 2001. "The Merits of Mixing Methods in Evaluation." Evaluation 7 (1): 25-44.

Grimm, Nancy, Elizabeth M. Cook, Rebecca L. Hale, and David M. Iwaniec. 2016. "Chapter 14: A Broader Framing of Ecosystem Services in Cities." In The Routledge Handbook of Urbanization and Global Environmental Change, edited by Karen Ching-Yee Seto, William Solecki, and Corrie Griffith, 1 Edition. New York: Routledge, Taylor \& Francis Group.

Gross, Mattias. 2010. Ignorance and Surprise: Science, Society, and Ecological Design. MIT Press.

Grove, J. M., A. R. Troy, J. P. M. O'Neil-Dunne, W. R. Burch, M. L. Cadenasso, and S. T. A. Pickett. 2006. "Characterization of Households and Its Implications for the Vegetation of Urban Ecosystems." Ecosystems 9 (June): 578-97. doi:10.1007/s10021-006-0116-z.

Haas, Peter. 1992. "Epistemic Communities and International Policy Coordination." International Organization 46 (1): 1-35.

Hacking, lan. 1999. "Kind-Making: The Case of Child Abuse." In The Social Construction of What? Harvard University Press.

Hajer, Maarten, and Wytske Versteeg. 2005. "A Decade of Discourse Analysis of Environmental Politics: Achievements, Challenges, Perspectives." Journal of Environmental Policy \& Planning 7 (3): 175-84. doi:10.1080/15239080500339646.

Hartmann, Franz. 1998. "Towards a Social Ecological Politics of Sustainability." In Political Ecology Global and Local. London; New York: Routledge. http://site.ebrary.com/id/10100171.

Healey, Patsy. 1997. Collaborative Planning: Shaping Places in Fragmented Societies. Vancouver: UBC Press.

Hobbs, Richard J., Eric Higgs, and James A. Harris. 2009. "Novel Ecosystems: Implications for Conservation and Restoration." Trends in Ecology \& Evolution 24 (11): 599605. doi:10.1016/j.tree.2009.05.012.

Hobbs, Richard J., Eric S. *1958-* Higgs, and Carol M. Hall, eds. 2013. Novel Ecosystems: Intervening in the New Ecological World Order. This edition first published 2013. Chichester: Wiley-Blackwell.

Howarth, David R. 2000. Discourse. Concepts in the Social Sciences. Buckingham [England] ; Philadelphia, PA: Open University Press. 
Hull, R. Bruce, David P. Robertson, David Richert, Erin Seekamp, Gregory J. Buhyoff, and others. 2002. "Assumptions about Ecological Scale and Nature Knowing Best Hiding in Environmental Decisions." Conservation Ecology 6 (2): 12.

Innes, Judith Eleanor, and David E. Booher. 2010. Planning with Complexity: An Introduction to Collaborative Rationality for Public Policy. Milton Park, Abingdon, Oxon ; New York, NY: Routledge.

Iribarnegaray, M. A., M. F. E. de la Zerda, C. M. Hutton, C. Brannstrom, V. I. Liberal, W. Tejerina, and L. Seghezzo. 2014. "Water-Conservation Policies in Perspective: Insights from a Q-Method Study in Salta, Argentina." Water Policy 16 (5): 897. doi:10.2166/wp.2014.159.

Jasanoff, Sheila, ed. 2004. States of Knowledge: The Co-Production of Science and Social Order. International Library of Sociology. London; New York: Routledge.

Jasanoff, Sheila, and Sang-Hyun Kim. 2013. "Sociotechnical Imaginaries and National Energy Policies." Science as Culture 22 (2): 189-96. doi:10.1080/09505431.2013.786990.

Kabisch, Nadja, and Dagmar Haase. 2014. "Green Justice or Just Green? Provision of Urban Green Spaces in Berlin, Germany." Landscape and Urban Planning 122 (February): 129-39. doi:10.1016/j.landurbplan.2013.11.016.

Karvonen, Andrew. 2011. Politics of Urban Runoff: Nature, Technology, and the Sustainable City. Urban and Industrial Environments. Cambridge, Mass: MIT Press.

Katz, Eric. 1997. Nature as Subject: Human Obligation and Natural Community. Studies in Social, Political, and Legal Philosophy. Lanham: Rowman \& Littlefield.

Kaye, J, P Groffman, N Grimm, L Baker, and R Pouyat. 2006. "A Distinct Urban Biogeochemistry?" Trends in Ecology \& Evolution 21 (April): 192-99. doi:10.1016/j.tree.2005.12.006.

Kimmelman, M. 2012. "Vetoing Business as Usual After the Storm." New York Times, November 19. http://www.nytimes.com/2012/11/20/arts/design/changesneeded-after-hurricane-sandy-include-politics.html?pagewanted=all.

Kingsland, Sharon E. 2005. The Evolution of American Ecology, 1890-2000. Baltimore: Johns Hopkins University Press.

Knorr-Cetina, K. 1999. Epistemic Cultures: How the Sciences Make Knowledge. Cambridge, Mass: Harvard University Press.

Lachmund, Jens. 2004. "Knowing the Urban Wasteland: Ecological Expertise as Local Process." Earthly Politics: Local and Global Environmental Governance, 241-61.

- - - 2013. Greening Berlin: The Co-Production of Science, Politics, and Urban Nature. Inside Technology. Cambridge, Mass: MIT Press. 
LaDuca, Ann, and John Kosco. 2014. "Getting to Green: Paying for Green Infrastructure." EPA 842-R-14-005. EPA.

Lampland, Martha, and Susan Leigh Star, eds. 2009. Standards and Their Stories: How Quantifying, Classifying, and Formalizing Practices Shape Everyday Life. Ithaca: Cornell University Press.

Larkin, Brian. 2013. "The Politics and Poetics of Infrastructure." Annual Review of Anthropology 42 (1): 327-43. doi:10.1146/annurev-anthro-092412-155522.

Latour, Bruno. 1987. Science in Action: How to Follow Scientists and Engineers through Society. Cambridge, Mass.: Harvard University Press.

Lave, Rebecca. 2011. "Circulating Knowledge, Constructing Expertise." In Knowing Nature: Conversations at the Intersection of Political Ecology and Science Studies, edited by Mara Goldman, Paul Nadasdy, and Matt Turner. The University of Chicago Press.

Lave, Rebecca, Matthew W. Wilson, Elizabeth S. Barron, Christine Biermann, Mark A. Carey, Chris S. Duvall, Leigh Johnson, et al. 2014. "Intervention: Critical Physical Geography." The Canadian Geographer / Le Géographe Canadien 58 (1): 1-10. doi:10.1111/cag.12061.

Law, Steve. 2014. "Green Streets: Function or Frill?" Portland Tribune, February 27. http://portlandtribune.com/pt/9-news/212312-70086-green-streets-functionor-frill.

Leighton, Jeff, Kurt Vause, Celine Hyer, Annie Raven, Kevin Campanella, and John J. Galleher. 2016. "Committee Report: Business Practices to Help Utilities Better Manage Assets." Journal of the American Water Works Association 108 (1): 6167.

Lennon, Mick. 2015. "Green Infrastructure and Planning Policy: A Critical Assessment." Local Environment 20 (8): 957-80. doi:10.1080/13549839.2014.880411.

Light, Jennifer S. 2009. The Nature of Cities: Ecological Visions and the American Urban Professions, 1920-1960. Baltimore: Johns Hopkins University Press.

Luck, Gary, Kai M.A. Chan, Uta Eser, Erik Gómez-Baggethun, Bettina Matzdorf, Bryan Norton, and M. B. Potschin. 2012. "Ethical Considerations in On-Ground Applications of the Ecosystem Services Concept." BioScience 62 (12): 1020-29. doi:10.1525/bio.2012.62.12.4.

Lydenberg, Steve, Jean Rogers, and David Wood. 2010. "From Transparency to Performance: Industry-Based Sustainability Reporting on Key Issues." Harvard University: Initiative for Responsible Investment. http://www.sasb.org/wpcontent/uploads/2012/03/IRI_Transparency-to-Performance.pdf. 
Mazur, Kristine E., and Stanley T. Asah. 2013. "Clarifying Standpoints in the Gray Wolf Recovery Conflict: Procuring Management and Policy Forethought." Biological Conservation 167 (November): 79-89. doi:10.1016/j.biocon.2013.07.017.

McGinnis, Michael, and Elinor Ostrom. 2011. "SES Framework: Initial Changes and Continuing Challenges." In Bloomington, IN: Workshop in Political Theory and Policy Analysis, Department of Political Science, and Schoolof Public and Environmental Affairs, Indiana University. http://www.iub.edu/ workshop/publications/materials/W116_McGinnisEO.pdf.

McGraw-Hill Construction. 2013. "Water Infrastructure Asset Management: Adopting Best Practices to Enable Better Investments." Water Infrastructure Asset Management SmartMarket Report. Bedford, MA. http://www.newea.org/wpcontent/uploads/2014/11/McGraw-Hill-Asset-Management-SmartReport20131.pdf.

McIntyre, J.K., J.W. Davis, C. Hinman, K.H. Macneale, B.F. Anulacion, N.L. Scholz, and J.D. Stark. 2015. "Soil Bioretention Protects Juvenile Salmon and Their Prey from the Toxic Impacts of Urban Stormwater Runoff." Chemosphere 132 (August): 213-19. doi:10.1016/j.chemosphere.2014.12.052.

McKeown, Bruce, and Dan B. Thomas. 2013. Q Methodology. Second edition. Quantitative Applications in the Social Sciences 66. Los Angeles: SAGE.

McPhearson, Timon, Steward T. A. Pickett, Nancy B. Grimm, Jari Niemelä, Marina Alberti, Thomas Elmqvist, Christiane Weber, Dagmar Haase, Jürgen Breuste, and Salman Qureshi. 2016. "Advancing Urban Ecology toward a Science of Cities." BioScience 66 (3): 198-212. doi:10.1093/biosci/biw002.

Meadows, Donella. 1999. "Leverage Points: Places to Intervene in a System." Sustainability Institute.

Mell, Ian C. 2013. “Can You Tell a Green Field from a Cold Steel Rail? Examining the 'green' of Green Infrastructure Development." Local Environment 18 (2): 152-66. doi:10.1080/13549839.2012.719019.

Mell, Ian C., John Henneberry, Sigrid Hehl-Lange, and Berna Keskin. 2016. "To Green or Not to Green: Establishing the Economic Value of Green Infrastructure Investments in The Wicker, Sheffield." Urban Forestry \& Urban Greening 18 (August): 257-67. doi:10.1016/j.ufug.2016.06.015.

Melosi, Martin V. 2008. The Sanitary City: Environmental Services in Urban America from Colonial Times to the Present. Abridged ed. History of the Urban Environment. Pittsburgh, Pa: the University of Pittsburgh Press.

Merriam-Webster. 2017. "Definition of INFRASTRUCTURE." https://www.merriamwebster.com/dictionary/infrastructure. 
Millennium Ecosystem Assessment. 2005. "Ecosystems and Human Wellbeing Synthesis." Synthesis.

Miller, Clark A, Tischa Munoz-Erickson, and Chad Monfreda. 2010. "Knowledge Systems Analysis: A Report for the Advancing Conservation in a Social Context Project." \#10-05. CSPO Arizona State University.

Montalto, Franco A., Timothy A. Bartrand, Alexander M. Waldman, Katharine A. Travaline, Charles H. Loomis, Chariss McAfee, Juliet M. Geldi, Gavin J. Riggall, and Laureen M. Boles. 2013. "Decentralised Green Infrastructure: The Importance of Stakeholder Behaviour in Determining Spatial and Temporal Outcomes." Structure and Infrastructure Engineering 9 (12): 1187-1205. doi:10.1080/15732479.2012.671834.

Montalto, Franco, Christopher Behr, Katherine Alfredo, Max Wolf, Matvey Arye, and Mary Walsh. 2007. "Rapid Assessment of the Cost-Effectiveness of Low Impact Development for CSO Control." Landscape and Urban Planning 82 (3): 117-31. doi:10.1016/j.landurbplan.2007.02.004.

Morgan, D. L. 1998. "Practical Strategies for Combining Qualitative and Quantitative Methods: Applications to Health Research." Qualitative Health Research 8 (3): 362-76. doi:10.1177/104973239800800307.

Morgan, David L. 2014. Integrating Qualitative and Quantitative Methods: A Pragmatic Approach. Thousand Oaks, California: SAGE Publications, Inc.

Mukerji, Chandra. 2009. Impossible Engineering: Technology and Territoriality on the Canal Du Midi. Princeton Studies in Cultural Sociology. Princeton, N.J: Princeton University Press.

Munoz-Erickson, Tischa. 2014. "Co-Productiom of Knowledge-Action Systems in Urban Sustainable Governance: The KASA Approach." Environmental Science \& Policy 37: 182-91.

National Ecosystem Services Partnership. 2014. “Federal Resource Management and Ecosystem Services Guidebook." https://nespguidebook.com/.

Nazir, Nurul Nazyddah Mat, Noriah Othman, and Abdul Hadi Nawawi. 2014. "Green Infrastructure and Its Roles in Enhancing Quality of Life." Procedia - Social and Behavioral Sciences 153 (October): 384-94. doi:10.1016/j.sbspro.2014.10.071.

Neff, Mark W. 2011. "What Research Should Be Done and Why? Four Competing Visions among Ecologists." Frontiers in Ecology and the Environment 9 (8): 462-69. doi:10.1890/100035.

Neff, Mark W., and Brendon M.H. Larson. 2014. "Scientists, Managers, and Assisted Colonization: Four Contrasting Perspectives Entangle Science and Policy." Biological Conservation 172 (April): 1-7. doi:10.1016/j.biocon.2014.02.001. 
Nelson, Anne. 2011. History of green infrastruture program in Portland.

Netusil, Noelwah R., Zachary Levin, Vivek Shandas, and Ted Hart. 2014. "Valuing Green Infrastructure in Portland, Oregon." Landscape and Urban Planning 124 (April): 14-21. doi:10.1016/j.landurbplan.2014.01.002.

Norgaard, Richard B. 2010. "Ecosystem Services: From Eye-Opening Metaphor to Complexity Blinder." Ecological Economics 69 (6): 1219-1227.

NRPA. 2010. "Why Parks and Recreation Are Essential Public Services." Ashburn, VA: National Recreation \& Park Association.

- - . 2017. "Green Infrastructure in Parks: Collaboration, Funding, and Community Engagement." Webinar, March 9. https://learning.nrpa.org/webinars.

NYC Environmental Protection. 2010. "NYC Green Infrastructure Plan: Executive Summary."

http://www.nyc.gov/html/dep/pdf/green_infrastructure/NYCGreenInfrastructur ePlan_ExecutiveSummary.pdf.

Ortolano, Leonard. 1984. Environmental Planning and Decision Making. New York: Wiley.

Ozawa, Connie P. 1991. Recasting Science: Consensual Procedures in Public Policy Making. Boulder: Westview Press.

Perrow, Charles. 1999. Normal Accidents Living with High-Risk Technologies. Princeton, N.J.: $\quad$ Princeton University Press. http://www.dawsonera.com/depp/reader/protected/external/AbstractView/S97 81400828494.

Philadelphia Water Department. 2011. "Green City, Clean Waters: The City of Philadelphia's Program for Combined Sewer Overflow Control Program Summary." http://www.phillywatersheds.org/doc/GCCW_AmendedJune2011_LOWRESweb.pdf.

Philadelphia Water Department (PWD). 2011. "Green City, Clean Waters: The City of Philadelphia's Program for Combined Sewer Overflow Control." http://www.phillywatersheds.org/doc/GCCW_AmendedJune2011_LOWRESweb.pdf.

Pickett, S.T.A., M.L. Cadenasso, and J.M. Grove. 2004. "Resilient Cities: Meaning, Models, and Metaphor for Integrating the Ecological, Socio-Economic, and Planning Realms." Landscape and Urban Planning 69 (4): 369-84. doi:10.1016/j.landurbplan.2003.10.035.

Pickett, STA1ã, M. L. Cadenasso, and S. J. Meiners. 2009. "Ever since Clements: From Succession to Vegetation Dynamics and Understanding to Intervention*." Applied Vegetation Science 12 (1): 9-21. 
Pickett, Steward TA, M. L. Cadenasso, J. M. Grove, C. H. Nilon, R. V. Pouyat, W. C. Zipperer, and R. Costanza. 2001. "Urban Ecological Systems: Linking Terrestrial Ecological, Physical, and Socioeconomic Components of Metropolitan Areas." Annual Review of Ecology and Systematics, 127-157.

Pinch, T. 2010. "On Making Infrastructure Visible: Putting the Non-Humans to Rights." Cambridge Journal of Economics 34 (1): 77-89. doi:10.1093/cje/bep044.

Porter, Theodore. 1994. "Making Things Quantitative." Science in Context 7 (3): 389-407.

Porter, Theodore M. 1996. Trust in Numbers: The Pursuit of Objectivity in Science and Public Life. Princeton, N.J.: Princeton University Press.

$\begin{array}{lllll}\text { Portland's } & \text { CSO } & \text { Program } & 1991-2011 .\end{array}$ http://www.portlandonline.com/bes/index.cfm?c=29323\&a=375594.

Pritchard, S. B. 2012. "An Envirotechnical Disaster: Nature, Technology, and Politics at Fukushima." Environmental History 17 (2): 219-43. doi:10.1093/envhis/ems021.

Pritchard, Sara B. 2011. Confluence: The Nature of Technology and the Remaking of the Rhône. Harvard Historical Studies 172. Cambridge, Mass: Harvard University Press.

Ramaswami, Anu, Christopher Weible, Deborah Main, Tanya Heikkila, Saba Siddiki, Andrew Duvall, Andrew Pattison, and Meghan Bernard. 2012. "A Social-EcologicalInfrastructural Systems Framework for Interdisciplinary Study of Sustainable City Systems: An Integrative Curriculum Across Seven Major Disciplines." Journal of Industrial Ecology 16 (6): 801-13. doi:10.1111/j.1530-9290.2012.00566.x.

Rasmussen, Wayne D. 1968. "Advances in American Agriculture: The Mechanical Tomato Harvester as a Case Study." Technology and Culture 9 (4): 531. doi:10.2307/3101894.

Rastogi, Archi, Gordon M. Hickey, Ruchi Badola, and Syed Ainul Hussain. 2013. “Diverging Viewpoints on Tiger Conservation: A Q-Method Study and Survey of Conservation Professionals in India." Biological Conservation 161 (May): 182-92. doi:10.1016/j.biocon.2013.03.013.

Rawson, Michael. 2004. "The Nature of Water: Reform and the Antebellum Crusade for Municipal Water in Boston." Environmental History 9 (3): 411. doi:10.2307/3985767.

Redman, Charles L., and Thaddeus R. Miller. 2015. "The Technosphere and Earth Stewardship." In Earth Stewardship: Linking Ecology and Ethics in Theory and Practice, edited by Ricardo Rozzi, F. Stuart Chapin III, J. Baird Callicott, S.T.A. Pickett, Mary E. Power, Juan J. Armesto, and Roy H. May Jr., 269-79. Cham: Springer International Publishing. http://dx.doi.org/10.1007/978-3-319-121338_17. 
Robbins, Paul, and Rob Krueger. 2000. "Beyond Bias? The Promise and Limits of Q Method in Human Geography." The Professional Geographer 52 (4): 636-48. doi:10.1111/0033-0124.00252.

Robertson, Morgan, Todd K BenDor, Rebecca Lave, Adam Riggsbee, Jb Ruhl, and Martin Doyle. 2014. "Stacking Ecosystem Services." Frontiers in Ecology and the Environment 12 (3): 186-93. doi:10.1890/110292.

Robertson, Morgan M. 2004. "The Neoliberalization of Ecosystem Services: Wetland Mitigation Banking and Problems in Environmental Governance." Geoforum 35 (3): 361-73. doi:10.1016/j.geoforum.2003.06.002.

Romolini, Michele, J. Morgan Grove, Curtis L. Ventriss, Christopher J. Koliba, and Daniel H. Krymkowski. 2016. "Toward an Understanding of Citywide Urban Environmental Governance: An Examination of Stewardship Networks in Baltimore and Seattle." Environmental Management 58 (2): 254-67. doi:10.1007/s00267-016-0704-4.

Rowland, N. J., and J.-H. Passoth. 2014. "Infrastructure and the State in Science and Technology Studies." Social Studies of Science, June. doi:10.1177/0306312714537566.

Royal Society (Great Britain). 2014. Resilience to Extreme Weather.

SASB. 2012. "Mission," September 17. https://www.sasb.org/sasb/vision-mission/.

Schick, Tony. 2017. “Oregon Has The 2nd-Worst Water Quality Permit Backlog In The Country." Oregon Public Broadcasting, March 8. http://www.opb.org/news/article/oregon-has-the-second-worst-water-qualitypermit-backlog-in-the-country/.

Schilling, J., and J. Logan. 2008. "Greening the Rust Belt: A Green Infrastructure Model for Right Sizing America's Shrinking Cities." Journal of the American Planning Association 74 (4): 451.

Schneider, Daniel. 2011. Hybrid Nature: Sewage Treatment and the Contradictions of the Industrial Ecosystem. Urban and Industrial Environments. Cambridge, Mass: MIT Press.

Scott, James C. 1998. Seeing like a State: How Certain Schemes to Improve the Human Condition Have Failed. Yale Agrarian Studies. New Haven: Yale University Press.

Shandas, Vivek. 2017. Personal communciation.

Shapin, Steven, Simon Schaffer, and Thomas Hobbes. 1985. Leviathan and the Air-Pump: Hobbes, Boyle, and the Experimental Life: Including a Translation of Thomas Hobbes, Dialogus Physicus de Natura Aeris by Simon Schaffer. Princeton, N.J.: Princeton University Press. 
Sherman, Ben. 2008. "Cutbacks, Low Morale Cast Haze over DEQ." Oregonian, February 10.

http://www.oregonlive.com/environment/index.ssf/2008/02/cutbacks_low_mor ale_cast_haze.html.

Star, S. L. 1999. "The Ethnography of Infrastructure." American Behavioral Scientist 43 (3): 377-91. doi:10.1177/00027649921955326.

"Stormwater Management Manual (SWMM)." 2015. City of Portland Bureau of Environmental Services. 19. https://www.portlandoregon.gov/bes/64040.

Susskind, Lawrence, and Connie Ozawa. 1984. "Mediated Negotiation in the Public Sector: The Planner as Mediator." Journal of Planning Education and Research.

Tarr, Joel A. 1996. The Search for the Ultimate Sink: Urban Pollution in Historical Perspective. 1st ed. Technology and the Environment. Akron, Ohio: University of Akron Press.

Taylor, Dorceta E. 2009. The Environment and the People in American Cities, 1600-1900s: Disorder, Inequality, and Social Change. Durham: Duke University Press.

TEEB. 2014. "The Economics of Ecosystems \& Biodiversity." http://www.teebweb.org/.

Thorne, C.R., E.C. Lawson, C. Ozawa, S.L. Hamlin, and L.A. Smith. 2015. “Overcoming Uncertainty and Barriers to Adoption of Blue-Green Infrastructure for Urban Flood Risk Management: Uncertainties and Barriers to Adoption of BGI." Journal of Flood Risk Management, December, n/a-n/a. doi:10.1111/jfr3.12218.

Tzoulas, Konstantinos, Kalevi Korpela, Stephen Venn, Vesa Yli-Pelkonen, Aleksandra Kaźmierczak, Jari Niemela, and Philip James. 2007. "Promoting Ecosystem and Human Health in Urban Areas Using Green Infrastructure: A Literature Review." Landscape and Urban Planning $81 \quad$ (3): $167-78$. doi:10.1016/j.landurbplan.2007.02.001.

"UREx Sustainability Research Network." 2015. UREx Sustainability Research Network. https://sustainability.asu.edu/urbanresilience/.

Van Teeffelen, Astrid J. A., Claire C. Vos, Rene Jochem, Johannes M. Baveco, Henk Meeuwsen, and Jelle P. Hilbers. 2015. "Is Green Infrastructure an Effective Climate Adaptation Strategy for Conserving Biodiversity? A Case Study with the Great Crested Newt." Landscape Ecology 30 (5): 937-54. doi:10.1007/s10980-015-01873.

Vanier, D. J., and N. Danylo. 1998. "Municipal Infrastructure Investment Planning: Asset Management." In Innovations in Urban Infrastructure Seminar of the APWA International Public Works Congress, 25-39. Citeseer. 
http://citeseerx.ist.psu.edu/viewdoc/download?doi=10.1.1.10.1568\&rep=rep1\& type $=$ pdf.

Vanier, Dana J. 2000. "Advanced Asset Management: Tools and Techniques." In Innovations in Urban Infrastructure Seminar of the APWA International Public Works Congress, 39-56. http://osp.mans.edu.eg/elbeltagi/Infra\%2013\%20ADVANCED\%20ASSET.pdf.

Vogt, Jess, Richard J. Hauer, and Burnell C. Fischer. 2015. "The Costs of Maintaining and Not Maintaining the Urban Forest: A Review of the Urban Forestry and Arboriculture Literature." Arboriculture \& Urban Forestry 41 (6). http://www.isaarbor.com/quizbank/1443/CostofNotMaintainingTrees.pdf.

Vucetich, John A., Jeremy T. Bruskotter, and Michael Paul Nelson. 2015. "Evaluating Whether Nature's Intrinsic Value Is an Axiom of or Anathema to Conservation: Nature's Intrinsic Value." Conservation Biology 29 (2): 321-32. doi:10.1111/cobi.12464.

Wachsmuth, David. 2012. "Three Ecologies: Urban Metabolism and the Society-Nature Opposition." The Sociological Quarterly 53 (4): 506-523.

Wang, Yafei, Frank Bakker, Rudolf de Groot, and Heinrich Wörtche. 2014. "Effect of Ecosystem Services Provided by Urban Green Infrastructure on Indoor Environment: A Literature Review." Building and Environment 77 (July): 88-100. doi:10.1016/j.buildenv.2014.03.021.

Watts, Simon, and Paul Stenner. 2005. "Doing Q Methodology: Theory, Method and Interpretation." Qualitative Research in Psychology 2 (1): 67-91. doi:10.1191/1478088705qp022oa.

Weber, Barbara, Hans Wilhelm Alfen, and Mirjam Staub-Bisang. 2016. Infrastructure as an Asset Class: Sustainability, Investment Strategies, Project Finance and PPP. Second edition. The Wiley Finance Series. Chichester, West Sussex: John Wiley \& Sons.

Weber, T., and J. Wolf. 2000. "Maryland's Green Infrastructure - Using Landscape Assessment Tools to Identify a Regional Conservation Strategy." Environmental Monitoring and Assessment 63: 265-77.

Weber, Ted, Anne Sloan, and John Wolf. 2006. "Maryland's Green Infrastructure Assessment: Development of a Comprehensive Approach to Land Conservation." Landscape and Urban Planning 77 (1-2): 94-110. doi:10.1016/j.landurbplan.2005.02.002.

Weinstein, Neil. 2008. "Tenth Anniversay Letter from the Executive Director of LID Center," May 1. http://www.lowimpactdevelopment.org/lid\%20articles/LID_Observations_May_ 1_2008.pdf. 
WERF. 2009. "Building a Nationally Recognized Program Through Innovation and Research: Portland, OR Case Study." Case Study. http://www.werf.org/liveablecommunities/studies_port_or.htm.

"Willamette Partnership." 2014. http://willamettepartnership.org/.

Wilson, Matthew W. 2009. "Cyborg Geographies: Towards Hybrid Epistemologies." Gender, Place \& Culture 16 (5): 499-516. doi:10.1080/09663690903148390.

Winner, Langdon. 1986. The Whale and the Reactor: A Search for Limits in an Age of High Technology. Chicago: University of Chicago Press.

Worster, Donald. 1990. "The Ecology of Order and Chaos." Environmental History Review 14 (1/2): 1. doi:10.2307/3984623.

"Wrestore | Watershed REstoration Using Spatio-Temporal Optimization of REsources." 2017. http://wrestore.iupui.edu/.

Wright, Hannah. 2011. "Understanding Green Infrastructure: The Development of a Contested Concept in England." Local Environment 16 (10): 1003-19. doi:10.1080/13549839.2011.631993.

Yin, Robert K. 2014. Case Study Research: Design and Methods. Fifth edition. Los Angeles: SAGE.

Young, Robert, Julie Zanders, Katherine Lieberknecht, and Elizabeth Fassman-Beck. 2014. "A Comprehensive Typology for Mainstreaming Urban Green Infrastructure." Journal of Hydrology 519 (November): 2571-83. doi:10.1016/j.jhydrol.2014.05.048.

Zavestoski, Stephen, and Julian Agyeman, eds. 2015. Incomplete Streets: Processes, Practices and Possibilities. Routledge Equity, Justice and the Sustainable City Series. London; New York: Routledge, Taylor \& Francis Group. 


\section{Appendix A: Interview Guide}

\begin{tabular}{|c|c|c|c|}
\hline Interview Question & $\begin{array}{l}\text { What I want out of } \\
\text { this question }\end{array}$ & Potential Answers & $\begin{array}{l}\text { Theoretical } \\
\text { connections }\end{array}$ \\
\hline \multicolumn{4}{|c|}{$\begin{array}{l}\text { RQ: How do different institutions generate knowledge claims about the definition, performance, and } \\
\text { value of green infrastructure and its built and natural components? How are these contested? What new } \\
\text { knowledge practices are created? }\end{array}$} \\
\hline $\begin{array}{l}\text { I'd like to know a bit } \\
\text { more about your } \\
\text { professional } \\
\text { background. How did } \\
\text { you get involved with } \\
\text { green infrastructure? }\end{array}$ & $\begin{array}{l}\text { Provides information } \\
\text { on formal disciplinary } \\
\text { training of interviewee } \\
\text { Provides information }\end{array}$ & $\begin{array}{l}\text { 1) engineering } \\
\text { background, } \\
\text { environmental science } \\
\text { background, financial } \\
\text { background } \\
\text { A) }\end{array}$ & Disciplinary worldview \\
\hline $\begin{array}{l}\text { What is your working } \\
\text { definition of green } \\
\text { infrastructure? }\end{array}$ & $\begin{array}{l}\text { Provides information } \\
\text { on knowledge claims } \\
\text { about definition, } \\
\text { Provides potential to } \\
\text { reveal sources of } \\
\text { definitions (from grey } \\
\text { or peer-reviewed lit, } \\
\text { consultants, etc) }\end{array}$ & $\begin{array}{l}\text { 1) any sustainable } \\
\text { infrastructure } \rightarrow \\
\text { probably includes non- } \\
\text { living infrastructure like } \\
\text { those that use } \\
\text { renewable energy } \\
\text { 2) infra that mimics } \\
\text { nature } \rightarrow \text { probably } \\
\text { includes non-living } \\
\text { infrastructure like } \\
\text { permeable pavement } \\
\text { 3) infrastructure that } \\
\text { includes nature } \rightarrow \text { only } \\
\text { infra with living stuff in } \\
\text { it } \\
\text { 4)_?? } \rightarrow \text { something } \\
\text { unexpected }\end{array}$ & $\begin{array}{l}\text { Ontological } \\
\text { classification of natural } \\
\text { and man-made } \\
\text { components of } \\
\text { infrastructure; expected } \\
\text { differences between } \\
\text { epistemic communities }\end{array}$ \\
\hline $\begin{array}{l}\text { What services do green } \\
\text { infrastructure facilities } \\
\text { provide? }\end{array}$ & $\begin{array}{l}\text { Describes what } \\
\text { problems the institution } \\
\text { is using green infra to } \\
\text { fix; provides } \\
\text { information on } \\
\text { knowledge claims about } \\
\text { performance }\end{array}$ & $\begin{array}{l}\text { 1) stormwater } \\
\text { management } \\
\text { 2) increased water } \\
\text { quality } \\
\text { 3) urban cooling - } \\
\text { mitigate heat island }\end{array}$ & $\begin{array}{l}\text { Epistemological } \\
\text { conceptions of } \\
\text { performance and } \\
\text { measurement; expected } \\
\text { differences between } \\
\text { epistemic communities }\end{array}$ \\
\hline
\end{tabular}




\begin{tabular}{|c|c|c|c|}
\hline & & $\begin{array}{l}\text { 4) beautification } \\
\text { 5) other??? }\end{array}$ & \\
\hline $\begin{array}{l}\text { (POTENTIAL) Why } \\
\text { use green facilities } \\
\text { rather than grey to } \\
\text { provide those services? }\end{array}$ & $\begin{array}{l}\text { Provides information } \\
\text { regarding the } \\
\text { justification for } \\
\text { switching to green } \\
\text { infrastructure, which } \\
\text { reflects value of GI to } \\
\text { institution }\end{array}$ & $\begin{array}{l}\text { 1) green cheaper than } \\
\text { grey } \\
\text { 2) added benefits } \\
\text { service provided by } \\
\text { green over grey } \\
\text { 3) public pressure to } \\
\text { build green } \\
\text { 4) green infra champion }\end{array}$ & $\begin{array}{l}\text { Credibility } \\
\text { contest/OPPs }\end{array}$ \\
\hline $\begin{array}{l}\text { (POTENTIAL) Who is } \\
\text { responsible for facility } \\
\text { design in your } \\
\text { institution? }\end{array}$ & $\begin{array}{l}\text { Provides information } \\
\text { about who is considered } \\
\text { a credible knowledge } \\
\text { producer; potential } \\
\text { contestations may be } \\
\text { uncovered here; }\end{array}$ & $\begin{array}{l}\text { 1) engineering } \\
\text { department } \\
\text { 2) ?? something } \\
\text { unexpected }\end{array}$ & $\begin{array}{l}\text { Credibility } \\
\text { contest/OPPs }\end{array}$ \\
\hline $\begin{array}{l}\text { (POTENTIAL) Where } \\
\text { did your current design } \\
\text { standards come from? }\end{array}$ & $\begin{array}{l}\text { Provides information } \\
\text { about who is considered } \\
\text { a credible knowledge } \\
\text { producer; potential } \\
\text { contestations may be } \\
\text { uncovered here; }\end{array}$ & $\begin{array}{l}\text { 1) EPA } \\
\text { 2) local consultant } \\
\text { 3) another city's plans }\end{array}$ & $\begin{array}{l}\text { Credibility } \\
\text { contest/OPPs }\end{array}$ \\
\hline $\begin{array}{l}\text { (POTENTIAL) How } \\
\text { are green infrastructure } \\
\text { projects funded in your } \\
\text { institution? How does } \\
\text { this compare with grey } \\
\text { infrastructure? }\end{array}$ & $\begin{array}{l}\text { Provides information } \\
\text { regarding valuation } \\
\text { metrics in use; }\end{array}$ & $\begin{array}{l}\text { 1) fee-based program } \\
\text { 2) general fund } \\
\text { 3) bonds }\end{array}$ & $\begin{array}{l}\text { Credibility } \\
\text { contest/OPPs; } \\
\text { Epistemological } \\
\text { conceptions of } \\
\text { performance and } \\
\text { measurement; expected } \\
\text { differences between } \\
\text { epistemic communities }\end{array}$ \\
\hline
\end{tabular}




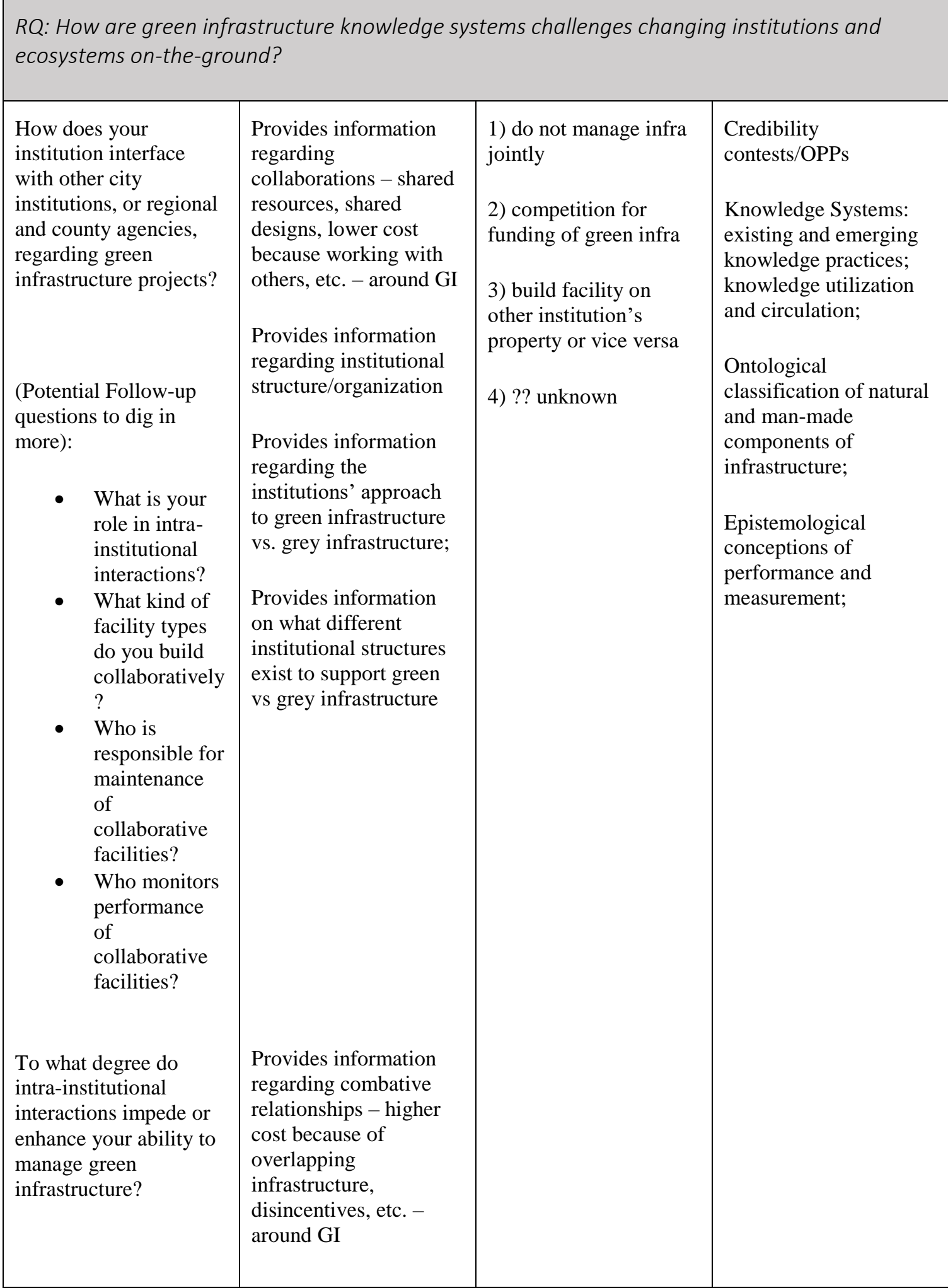




\begin{tabular}{|l|l|l|l|}
\hline \multicolumn{2}{|l|}{ Wrap-up } \\
\hline $\begin{array}{l}\text { Do you think green } \\
\text { infrastructure is the } \\
\text { right way forward for } \\
\text { your city? }\end{array}$ & $\begin{array}{l}\text { Open-ended - what did } \\
\text { I miss? }\end{array}$ & Unknown & $\begin{array}{l}\text { Potentially all } \\
\text { connections; }\end{array}$ \\
\hline $\begin{array}{l}\text { What did I miss? Is } \\
\text { there anything that I } \\
\text { haven't asked you } \\
\text { about green } \\
\text { infrastructure that you } \\
\text { would like to talk } \\
\text { about? }\end{array}$ & $\begin{array}{l}\text { Open-ended - what did } \\
\text { I miss? }\end{array}$ & Unknown & $\begin{array}{l}\text { Potentially all } \\
\text { connections; }\end{array}$ \\
\hline
\end{tabular}




\section{Appendix B: Qualitative Code-Book (final)}

\section{(All codes are listed in alphabetical order; all consolidated sub-codes of primary emergent themes are highlighted in gray)}

DOCUMENT TYPE
\#background: business
\#background: CPA
\#background: ecology
\#background: engineering
\#background: landscape arch
\#background: planner
\#BLT
\#document
\#employer: city
\#employer: nonprofit
\#employer: other (comm member)
\#employer: private comp
\#interview
\#other city
\#PDX

Accountability

ACCOUNTING ACCOUNTING division ACCOUNTING: example

agencies working together aging infra

ASSET MANAGEMENT
AM: allocated \$\$\$
AM: as bridge
AM: Asset Management
AM: asset vs service value
AM: booking green assets
AM: Budgeting
AM: Bureau-specific
AM: capital asset
AM: Capital Asset Policy
AM: city-wide
AM: connected to perf metrics
AM: drivers
AM: example - \% for arts
AM: fixed asset
AM: Green assets
AM: green cost included but only a
part of larger capital project
AM: green many never fit
AM: harder to talk about green assets
AM: inventory
AM: just maintaining it, didn't
purchase a widget
AM: level of service
AM: level of service: not established
AM: momentum for AM
AM: tree not an asset
AM: useful life of facility
AM: want a way to capitalize
another city
Army Corp of Engineers
at the table
Audits

balance with development

basement backup

Biophilia

blackbox: tool

BMP

Bonds

Built

bureau mission

CAFR

CAMG

CB Foundation

\section{CERTIFICATION}

CERT: certification

CERT: regional

Challenge

Champions

\section{CHANGE}

CHANGE:

CHANGE: changing national standards shoudl not be the goal

CHANGE: definition

CHANGE: Ecosystem

CHANGE: Institutional

CHANGE: new code

CHANGE: NO change

CHANGE: potential

CHANGE: takes time to change

CHANGE: update city code

CHANGE: wanted

Chesapeake Bay

city moves slowly

city-NGO

city-wide mandates

Clean and Green Program

Climate Action Plan

code-switching

Collaboration

combined sewer vs separated

\section{COMMUNITY}

COMM: Citizen voice

COMM: community input

COMM: community needs

COMM: community pushing city

COMM: meet after implementation

COMM: neighborhood priorities

COMM: getting used facilities

COMM: working with the comm

\section{COMPARISON}

complaints

\section{Conflict}

CONFLICT: between sewer and GI

\section{CONFLICT: utility conflict}

connecting across E-T spec

connection between PDX \& BLT

Conservation

Construction

Consultants

\section{CONTEXT}

CONTEXT: county vs city -

CONTEXT: diff approaches in diff parts of town

CONTEXT: drier climates/different ecosystems $=$ different needs CONTEXT: important for green, different from pipes in that way CONTEXT: not unique to PDX

contractors

Coordination

coordination not implementation corporate/business community

cross-department work

data sharing

\section{DEFINITION}

DEF: buzzwor

DEF: climate change

DEF: confusing

DEF: defined by who you are

working with

DEF: defining success

DEF: environmentally friendly

DEF: EPA

DEF: even though using nature, not always natural...

DEF: expanding

DEF: GI as a way to reduce burden on ourselves in urban environment DEF: GI vs "greening"

DEF: i wrote our def

DEF: living system

DEF: mimicry

DEF: network / connections of greenspaces

DEF: not agreed upon

DEF: of soil

DEF: other terms

DEF: ref to infra helpful/not helpful

DEF: stormwater

DEF: sustainable

DEF: too general

DEF: two diff defs

DEF: ultimately all green systems

DEF: vegetation

DEF: wider def needed

design storm

deteriorating infra 
Developers

Development

development too slow to retrofit whole city with SWMM

different focus of report through time

discharge/overflow of SW facility

disservice: pests

\section{DRIVER}

DRIVER: feel-good qualities

DRIVER: lack of driver

DRIVER: state regs

DRIVER: water quality

Education

engineered vs natural GI

Engineering

Epistemic

Equity

\section{EXTREME EVENT}

EXTREME EVENT: algal bloom from pollution

EXTREME EVENT: Ellicott City

EXTREME EVENT: Hurricane

Sandy

\section{FACILITY TYPE}

FAC: bioretention

FAC: bioswale

FAC: bumpout

FAC: everything

FAC: flexibility

FAC: green roof

FAC: lined

FAC: natural area

FAC: park

FAC: ponds

FAC: pourous pavement

FAC: private

FAC: proprietary

FAC: public

FAC: rain garden

FAC: remove impervious surface

FAC: retention pond

FAC: riparian areas

FAC: $S W$ reuse

FAC: trees

FAC: unlined

FAC: urban ag

FAC: urban garden

FAC: wetlands

Failure

fear of experiment

FEMA

FINANCE

FINANCE: financial accuracy

FINANCE: financial sustainability

FINANCE: financing tools

first flush

Forest Service

from CSO to separated

\section{Funding}

Funding: diff fac funded differently, even though overlapping

Funding: efficiency

Funding: enterprise fund

Funding: funders need to allow for

building comm support

Funding: gap

Funding: general fund

funding: grantors want city buying

funding: grants

Funding: lack of funding

Funding: only for certain parts of

project

Funding: Source

funding: stealing funding

Funding: transparency

\section{GASB}

green as not a separate thing

Green Network Plan

Green Pattern Book

Greenwashing

grey area of capital budget

groundwater contamination

hard to get $\$ \$$ for O\&M

hard vs soft-scape

haves vs have nots (departments)

HISTORY: early/emerging

implementation of GI

Homelessness

how to work on existing

development

\section{HYBRID}

HYBRID: green pre-treat

HYBRID: grey overflow

Implementation

importance of policy

in lieu fee

in the ROW

Incentives

income stream

incorporating climate change

Industry

influence of CAFR

Inspection

Institutional Structure

Integrated Planning Process (EPA)

interaction between bureaus

interaction between NGOs

interaction with the state

interaction WITHIN bureau

Invasives

inventory increasing

investment in infra

IRS

job titles

Jurisdiction

\section{KNOWLEDGE SYSTEM}

\section{PARAMETER}

KS: "commonly agreed upon"

KS: categories

KS: change

KS: Circulating Knowledge

KS: combining / interaction
KS: compatible

$\mathrm{KS}$ : competing

KS: conflicting knowledge claims

$\mathrm{KS}$ : data feedback into design

KS: data tolerances

$\mathrm{KS}$ : diff services highlighted to diff audiences

KS: discipline perspective/role

KS: disconnect

KS: ecological

$\mathrm{KS}$ : engineering

KS: equations

$\mathrm{KS}$ : expertise

$\mathrm{KS}$ : fitting in existing

KS: hybrid

$\mathrm{KS}$ : incommensurate

KS: in-house

$\mathrm{KS}$ : knowledge from out of state

KS: knowledge needs

KS: knowledge needs differ

KS: knowledge production

KS: lack of understanding

$\mathrm{KS}$ : metrics

KS: model

$\mathrm{KS}$ : new

KS: not well developed

KS: outside orgs

KS: path dependency

$\mathrm{KS}$ : play to strengths

KS: power

KS: pushback

KS: resistance

KS: spatial disconnect

$\mathrm{KS}$ : terminology

KS: translation

KS: inapplicable

$\mathrm{KS}$ : uncertainty

KS: Work-around

lab vs field studies

lack of capacity

land acquisition

Land ownership important

land trust

LAND USE

Landscaping

Lawsuit

LEADERSHIP

LEADERSHIP: community

LEADERSHIP: lack of leadership

LEADERSHIP: Mayor

LEADERSHIP: NGOs

LEED

Legal issues

legit/Cred (neg)

Legit/Cred (pos)

Liability

local level needs to direct GI work

MAINTENANCE

MAINTENANCE data collected

MAINTENANCE: aesthetics

MAINTENANCE: community

model 


MAINTENANCE: connection with
AM
MAINTENANCE: cost
MAINTENANCE: hand off
MAINTENANCE: how often
MAINTENANCE: landscaping
MAINTENANCE: liability
MAINTENANCE: manicured
MAINTENANCE: mowing only
MAINTENANCE: nature takes care
of itself
MAINTENANCE: same across the
country for bioretention
MAINTENANCE: separate city
division dedicated to GI
MAINTENANCE: training
MAINTENANCE: volunteers
MAINTENANCE: watering
MAINTENANCE: who maintains
Masonville Cove

\section{MEASUREMENT}

MEASUREMENT: as-built

MEASUREMENT: bad data

MEASUREMENT: certain facilities

easier to quantify than others

measurement: concern for nutrient

discharge

MEASUREMENT: data availability

MEASUREMENT: data collection

MEASUREMENT: data collection -

photos

MEASUREMENT: data collection -

sewer

MEASUREMENT: data is

important; not just design

MEASUREMENT: monitoring

community outcomes

MEASUREMENT: soils

MEASUREMENT: too many

variables

MEASUREMENT: who monitors?

MEASUREMENT: who owns

monitoring equip

MEAUREMENT: mapping

\section{METRIC}

METRIC: acres treated

METRIC: bureau-specific

METRIC: cost per sq ft of facility

METRIC: ecological health

METRIC: how to measure so many

variables

METRIC: plant mortality

METRIC: vegetative cover

METRICS: good metrics for pipes,

not so much for green asset

METRICS: pipe capacity

Monitoring

MOU

MS4 credits

native plantings

Natural

need to be doing more GI

need to recognize services of green
NETWORK: green space

connectivity

no ask

no pricing advantage

no room for mistakes

not duplicating work

not unique, just new

O\&M budget

O\&M plans

Ontological

Opportunity

other more pressing issues than GI

outcome-based budgeting

Outreach

over-engineered

Oversight

Ownership

ownership: jointly owned

Partnership

\section{PERFORMANCE}

PERF: condition

PERF: metrics

PERF: raising the bar

Permeance

Pipes vs green

Placement of facility

Planning

Plant specs

\section{POLICY}

POLICY: GGI

POLICY: policy sets the direction

POLICY: policy vs AM

Political support

Political will for green

Pressure on nature

Prioritization

Promotional opportunities

Property taxes

Protection

Protection: land / conservation

Protection: people

Public awareness

Public engagement

Public Health

Public perception

Public Support

Public-facing info

Q-sort potential

Quant vs qual benefits

Rating system

\section{REGULATION}

REG: "alternative practices"

REG: City

REG: city is regulated like any other industry

REG: Clean Water Act

REG: compliance w/regs would stop

CB pollution

REG: consent decree

REG: county

REG: credit

REG: CSO
REG: ESA

REG: ESD

REG: Fed

REG: MEP (maximum extent

possible)

REG: MS4

REG: NPDES

REG: permit

REG: prescriptive

REG: Regulatory hammer

REG: Regulatory structure

REG: State

REG: TMDL

REG: trigger SWMM

REG: UIC

REG: WIP

REG: WPCF

Relationship building

Reporting hierarchy

Research done

Research needs

Resiliency

Restoration

Risk

ROLE

Safety

SASB

Scale

Selling it

\section{SERVICE}

SERCVICE: ahead on certain

services but not others

SERVICE

SERVICE: "secondary benefits"

SERVICE: Access to Nature

SERVICE: aesthetic

SERVICE: biodiversity

SERVICE: Carbon Sequestration

SERVICE: clean air

SERVICE: Clean Water

SERVICE: climate resiliency

SERVICE: co-benefits

SERVICE: compatibility of services on a site

SERVICE: conflicting services

SERVICE: crime reduction

SERVICE: disservices

SERVICE: energy savings

SERVICE: flood mitigation

SERVICE: food

SERVICE: Habitat

SERVICE: lower asthma rates

SERVICE: multiple services

Service: Nutrient Cycling

SERVICE: protection of source

water

SERVICE: psychological benefits

Service: Recreation

Service: Sediment capture/reduction

SERVICE: spatial disconnect

SERVICE: traffic calming

Service: UHI mitigation

SERVICE: water quality

SERVICE: water quantity

SERVICE: water recycling 
Sewer discharge

Silo

social justice

SOIL

SOIL: soil leaching

SOIL: soil properties driving design

sources of pollution

spread too thin

STANDARDS

STANDARDS: how strict?

STANDARDS: informal standards

STANDARDS: public vs private

STANDARDS: soil mix

state vs city

Stormwater

stormwater fee

Temporary

Terminology

Testing

time spent on GI projects

Timelines

trade-offs

Transparency

Trash

Trust fund

two different routes green assets

could go

Uncertainty

unintended consequences

Vacant Land

VALUE/Asset Management

VALUE/AM: capital budget

VALUE/AM: capital development

VALUE/AM: capital funds

inflexible

VALUE/AM: capital improvement

project

VALUE/AM: capitalization limit

VALUE/AM: capitalize

VALUE/AM: carbon credits

VALUE/AM: don't need to use

capital funds for this

VALUE

VALUE: benefits vs value...

VALUE: business case

VALUE: CBA

VALUE: cost

VALUE: cost-effective

VALUE: cultural assets

VALUE: depreciation

VALUE: economic loss

VALUE: economic models

VALUE: Ecosystem Services

VALUE: finance

VALUE: for-profit company making valuation tools

VALUE: grey vs green

VALUE: historic cost

VALUE: inflating value

VALUE: let the markets handle it
VALUE: life cycle costing

VALUE: monetization of nature

VALUE: money talks

VALUE: no value on environment

VALUE: paired comparisons method

VALUE: quantification of nature

VALUE: replacement

VALUE: to investors

VALUE: triple/quadruple bottom

line

VALUE: valuation methods

VALUE: value as leverage rather than $\$ \$$

Vetting

Visibility

Volunteers

water qual vs water quant

wise spending

work-force development

WS 263 


\section{Appendix C: Participant Instructions (Q-sort Survey)}

(Sent to participants via email.)

Directions:

1. This is a ranking survey. It takes about $15-20$ mins to complete.

\section{PART 1}

2. You will be presented with a virtual "pile of cards" at the top of the page. Each "card" has a statement regarding green infrastructure. (Statements have been collected from reports and interviews to represent a range of conceptions of green infrastructure in use in municipalities today.)

3. Sort each "card" into the table from "least like how I think" to "most like how I think" in your current professional position. Place statements that have little or no salience to your perspective in the middle column of the table. The arrangement should reflect how you think in your professional capacity, whatever that means to you.

4. You can stop and return to the sort at a later time to finish it. Always use the same link.

\section{PART 2}

5. After all cards have been placed, click the "All Done" button.

6. You will be presented with a page allowing you to elaborate on some of the ranking decisions you made.

**CLICK HERE TO START THE SURVEY: abcdefghijk

Please let me know if you have any issues with the online system, or if you would prefer to respond to Part 2 over the phone instead of online.

Many thanks! I appreciate your time!! 